\title{
Agile development of open educational resources
}

\author{
Maurício Massaru Arimoto
}



Data de Depósito:

Assinatura:

\section{Maurício Massaru Arimoto}

\section{Agile development of open educational resources}

Doctoral dissertation submitted to the Instituto de Ciências Matemáticas e de Computação - ICMC-USP, in partial fulfillment of the requirements for the degree of the Doctorate Program in Computer Science and Computational Mathematics. FINAL VERSION

Concentration Area: Computer Science and Computational Mathematics

Advisor: Prof. Dr. Ellen Francine Barbosa

Co-advisor: Prof. Dr. Leonor Maria Melo Torcato Barroca

\section{USP - São Carlos}

August 2016 
Ficha catalográfica elaborada pela Biblioteca Prof. Achille Bassi e Seção Técnica de Informática, ICMC/USP, com os dados fornecidos pelo(a) autor(a)

Arimoto, Maurício Massaru
Agile development of open educational resources
/ Maurício Massaru Arimoto; orientadora Ellen
Francine Barbosa; coorientadora Leonor Maria Melo
Torcato Barroca. - São Carlos - SP, 2016.
203 f.
Tese (Doutorado - Programa de Pós-Graduação em
Ciências de Computação e Matemática Computacional)
- Instituto de Ciências Matemáticas e de Computação,
Universidade de São Paulo, 2016.
1. Open Educational Resources. 2. Learning Design.
3. Agile Methods. I. Barbosa, Ellen Francine, orient.
II. Barroca, Leonor Maria Melo Torcato, coorient.
III. Título.




\title{
Maurício Massaru Arimoto
}

\section{Desenvolvimento ágil de recursos educacionais abertos}

\author{
Tese apresentada ao Instituto de Ciências \\ Matemáticas e de Computação - ICMC-USP, \\ como parte dos requisitos para obtenção do título \\ de Doutor em Ciências - Ciências de Computação e \\ Matemática Computacional. VERSÃO REVISADA \\ Área de Concentração: Ciências de Computação e \\ Matemática Computacional \\ Orientadora: Prof. Dr. Ellen Francine Barbosa \\ Coorientadora: Prof. Dr. Leonor Maria Melo \\ Torcato Barroca
}



This is dedicated to my beloved parents Tsutomu and Suzana, and to my loving wife Andréia for their endless love and support. They have been a source of inspiration and example, encouraging me to work hard for the things that I believe and aspire to achieve. 

I would like to thank special and wonderful people who have been part of this long and arduous journey - a truly life-changing experience. They directly and indirectly influenced and helped in the development of this P.h.D. work. Without them nothing would be possible.

I am eternally grateful to my father Tsutomu and my mother Suzana for their love, affection and dedication throughout my life. Thank you both for giving me strength to overcome all difficulties and challenges of life. Their teachings underpin my personal and professional growth.

My deeply and sincere thanks to my loving wife Andréia for her unconditional love, companionship and support. She encouraged and supported my academic aspirations and understood my absences towards the achievement of this important project. I am truly thankful for having you in my life.

My heartfelt gratefulness to my parents-in-law, Benjamim (in memoriam) and Neusa for their constant unconditional support and love throughout my life. I greatly appreciate for being part of my life.

My deepest gratitude to my supervisor prof. Ellen Francine Barbosa for her patience, respect, professionalism and commitment; and of course, for the opportunity given to me, which allowed making this P.h.D. Her thoughtful support and guidance throughout the development of this work lead me to the right way.

I am also very grateful to my co-supervisor prof. Leonor Barroca for her respect, professionalism and commitment. Her experience and acquaintance added value to the work. Thank you for the English corrections and helpful suggestions that increased readability and reduced ambiguity of the work we have produced together. I learned from her insight a lot.

Special and warm appreciation to my sisters, brothers, cousins, uncles and nephews for the companionship, relaxing and blissful times we spent together during the weekends and year-end celebrations.

I am thankful for my friends who have been part of my life. I will not mention their names, otherwise I will surely forget some else and I will be unfair.

I also thanks my friends and colleagues from the Software Engineering (LabES) and Computing applied to Education (CaEd) Research Groups for the acquaintanceship, reflection and learning opportunities. 
I am most grateful to the Instituto de Ciências Matemáticas e de Computação of the Universidade de São Paulo (ICMC/USP) whose entire infrastructure and support provided for the development of labour activities made this P.h.D. possible.

My grateful thanks to the professors and others staff of the Doctoral Programme in Computer Science and Computational Mathematics of the ICMC/USP for their professionalism and dedication.

My gratitude to the UK Open University - United Kingdom by the opportunities, infrastructure and support given during internship from November/2013 to April/2014 related to this P.h.D. work.

My sincere appreciation to my colleagues from the Open University - United Kingdom for the welcome and enjoyable stay during my internship carried out there.

I am also very grateful to Fundação de Amparo à Pesquisa do Estado de São Paulo (FAPESP) (grant 2011/06204-1) and Coordenação de Aperfeiçoamento de Pessoal de Nível Superior (CAPES) (grant DS-5834080/D) whose financial support made this P.h.D. possible; and to FAPESP/BEPE (grant 2013/16759-6) for funding the internship abroad. 
"The function of education is to teach one to think intensively and to think critically. Intelligence plus character - that is the goal of true education." (Martin Luther King, Jr.) 



\section{RESUMO}

ARIMOTO, M. M. Agile development of open educational resources. 2016. $203 \mathrm{f}$. Doctoral dissertation (Doctorate Candidate Program in Computer Science and Computational Mathematics) - Instituto de Ciências Matemáticas e de Computação (ICMC/USP), São Carlos - SP.

o longo dos anos, o rápido avanço nas tecnologias computacionais e de comunicação
vem alterando de forma significativa o modo com que a sociedade se comunica e
conduz seus negócios. De forma análoga, mudanças vêm ocorrendo na maneira com que os recursos educacionais são projetados, desenvolvidos e disponibilizados aos aprendizes. Seguindo essa tendência, o desenvolvimento e a adoção de Recursos Educacionais Abertos (REAs) vêm ganhando cada vez mais adeptos em todo o mundo, como uma forma de ampliar o acesso ao conhecimento e melhorar a educação. De fato, a distribuição livre e aberta de recursos educacionais contribui para a disseminação de conhecimento e facilita o acesso à informação, além de promover a democratização do acesso à educação, beneficiando a sociedade como um todo. Embora REAs possam trazer benefícios e impacto sobre a educação, ainda existem muitos desafios para sua ampla produção e adoção. Um dos desafios enfrentados pelos desenvolvedores (incluindo educadores e praticantes) de REAs é produzir materiais de aprendizagem de qualidade, capazes de serem reusados e adaptados a diferentes contextos e situações de aprendizagem. Evidencia-se também a necessidade de mecanismos que propiciem o aumento da produtividade do processo de desenvolvimento e da qualidade dos REAs elaborados. Este trabalho tem como objetivo investigar o desenvolvimento de REAs e estabelecer abordagens flexíveis para apoiar efetivamente o projeto e a criação desses recursos. Nesse contexto, um método ágil para o desenvolvimento e disponibilização de REAs, AM-OER, foi estabelecido. O método é fundamentado em práticas da Engenharia de Software e práticas de projeto de aprendizagem (Learning Design), incorporadas no desenvolvimento de REAs no intuito de melhorar a sua qualidade e facilitar o reúso e adaptação. O objetivo final do método é apoiar o desenvolvimento de REAs de qualidade, capazes de motivar e guiar os aprendizes no processo de construção de conhecimento. Avaliações empíricas preliminares foram conduzidas para validar o AM-OER por meio de sua aplicação no projeto e criação de cursos nos domínios de desenvolvimento de software livre e teste de software. Os resultados obtidos até o momento demonstram que o método é viável e eficaz no projeto e criação de REAs.

Palavras-chave: Recursos Educationais Abertos, Projeto de Aprendizagem, Métodos Ágeis. 



\section{ABSTRACT}

ARIMOTO, M. M. Agile development of open educational resources. 2016. 203 f. Doctoral dissertation (Doctorate Candidate Program in Computer Science and Computational Mathematics) - Instituto de Ciências Matemáticas e de Computação (ICMC/USP), São Carlos - SP.

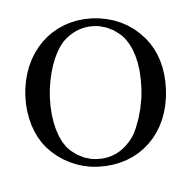
ver the years, the rapid advance of the computer and communication technologies has significantly changed the way in which the society communicates and conducts business. Similarly, changes have occurred in the way in which educational resources are designed, developed and made available to learners. Following this trend, the development and adoption of Open Educational Resources (OERs) has been gaining more supporters across the world, as a means to expand access to knowledge and improve education. Indeed, the free and open distribution of educational resources helps disseminate knowledge, facilitates access to information and promotes the democratisation of access to education, benefiting society as a whole. While OERs can bring benefits to, and impact on education, there are still challenges to their widespread production and adoption. One of the challenges faced by developers (including educators and practitioners) of OERs is to produce quality and relevant learning materials, capable of being reused and adapted in different contexts and learning situations. Also, there is a need for mechanisms that provide higher productivity of the development process and quality of the resulting OERs. This work aims to investigate the development of OERs and establish flexible approaches to effectively support the design and creation of these resources. In this context, an agile method for the development and sharing of OERs, named AM-OER, was established. It is grounded on practices of Software Engineering and on practices of Learning Design. Such practices are embedded in the development of OERs aiming at improving quality and facilitating reuse and adaptation. The ultimate aim of AM-OER is to support the development of quality OERs, able to motivate and guide learners in the process of knowledge construction. Preliminary empirical assessments were conducted to validate AM-OER through its application in the design and creation of courses in the free and open source software development and software testing domain. The results obtained so far have shown that the method is feasible and effective for the design and creation of OERs.

Keywords: Open Educational Resources, Learning Design, Agile Methods. 

Figure 1 - Research phases, methods and purposes. . . . . . . . . . . . . . 32

Figure 2 - The emergence of Open Educational Resources. . . . . . . . . . . . . . 36

Figure 3 - Characterisation of types of OERs. . . . . . . . . . . . . . . 39

Figure $4-$ Key principles behind OERs. . . . . . . . . . . . . . . 40

Figure 5 - Open licensing timeline. . . . . . . . . . . . . . . . 45

Figure 6 - Course on Computer Algorithms in System Engineering . . . . . . . . . . 49

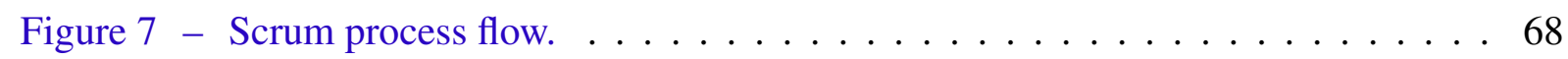

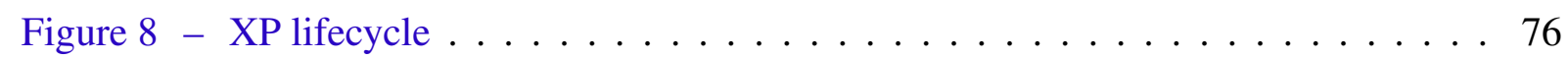

Figure $9-$ Distribution of the primary studies by type of publication. . . . . . . . 87

Figure 10 - Distribution of the primary studies by year of publication. . . . . . . . 87

Figure 11 - Distribution of the primary studies through approach type and focus . . . . 88

Figure 12 - Distribution of the primary studies by research approach. . . . . . . . . . 89

Figure 13 - Distribution of primary studies through type and research approach. . . . . . 90

Figure 14 - Distribution of the primary studies by approach proposed/used. . . . . . . . 9 91

Figure 15 - Distribution of primary studies through approach proposed/used and focus. . 92

Figure 16 - Distribution of the primary studies by development purpose. . . . . . . . . 93

Figure 17 - Distribution of the primary studies through approach type and purpose. . . . 93

Figure 18 - Sample population: familiarity with the development of OERs. . . . . . . . 97

Figure 19 - Average score of the assessed items. . . . . . . . . . . . . . . . 102

Figure 20 - Beneficial factors for the development and dissemination of OERs. . . . . . 102

Figure 21 - AM-OER development flow. . . . . . . . . . . . . . . . . . . . . . . . . . 109

Figure 22 - Modules and releases of Software Engineering course. . . . . . . . . . . . 111

Figure 23 - Dividing releases in sprints. . . . . . . . . . . . . . . 111

Figure 24 - Learning Design approach to support the design and creation of OERs. . . . 112

Figure 25 - AM-OER timeline. . . . . . . . . . . . . . . . . . . . 114

Figure 26 - The AM-OER life cycle for OERs. . . . . . . . . . . . . . . . . . 117

Figure 27 - Kickoff: main steps. . . . . . . . . . . . . . . . . . . . . . . . 119

Figure 28 - Development: main steps. . . . . . . . . . . . . . . . . 125

Figure 29 - Learning Outcomes View: Mapping learning activities with learning outcomes, content, tools and assessment activities. . . . . . . . . . . . . . 126

Figure 30 - Learning Tasks View: Mapping learning activity into individual and atomic tasks. . . . . . . . . . . . . . . . . . . . . . . 131

Figure 31 - Sharing: main steps. . . . . . . . . . . . . . . . 135 
Figure 32 - OER on FLOSS: Overall structure . . . . . . . . . . . . . . . . . . 150

Figure 33 - OER on FLOSS: Learning structure overview (in portuguese) . . . . . . . . . 151

Figure 34 - OER on FLOSS: Learning structure refinement (in portuguese). . . . . . . . 152

Figure 35 - OER on FLOSS: what is FLOSS? (in portuguese) . . . . . . . . . . . . . 153

Figure 36 - OER on FLOSS: Licensing options (in portuguese). . . . . . . . . . . . . 153

Figure 37 - OER on FLOSS: Business model. . . . . . . . . . . . . . . . . . 154

Figure 38 - Experimental study configuration. . . . . . . . . . . . . . . . . . 159

Figure 39 - Participants: Experience on pedagogical design and creation of OERs . . . 160

Figure 40 - Participants: Experience on agile development and software testing. . . . . . 161

Figure 41 - Results obtained by each method. . . . . . . . . . . . . . . . . . . 163

Figure 42 - Quality of the results of each method. . . . . . . . . . . . . . 166

Figure 43 - Qualitative analysis. . . . . . . . . . . . . . . . . . . . 167

Figure 44 - OER on software testing: Overall structure. . . . . . . . . . . . . . . . . . 169

Figure 45 - OER on software testing: Learning structure overview. . . . . . . . . . . . 170

Figure 46 - OER on software testing: Learning structure refinement. . . . . . . . . . . 171

Figure 47 - OER on software testing: Assessment activity. . . . . . . . . . . . 171 
Table 1 - Creative Commons licenses. . . . . . . . . . . . . . . . . 47

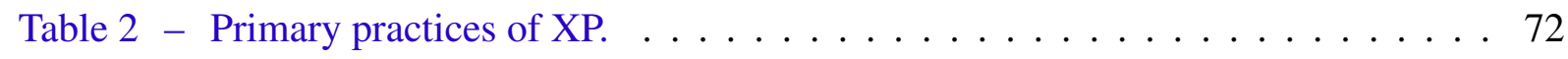

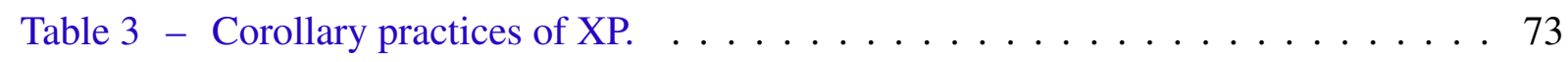

Table 4 - Fundamental principles of XP. . . . . . . . . . . . . 74

Table 5 - General characteristics of Scrum and XP . . . . . . . . . . 78

Table 6 - Correlation between practices . . . . . . . . . . . . . . . 79

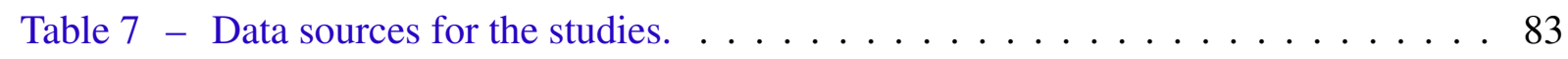

Table 8 - General search string. . . . . . . . . . . . . . . . 84

Table 9 - Summary of the included and excluded primary studies of each data source. $\quad 85$

Table 10 - Summary of the selected primary studies. . . . . . . . . . . . 86

Table 11 - Development of OERs: usage of a process. . . . . . . . . . . . . . 98

Table 12 - Development of OERs: methods/approach used. . . . . . . . . . . . . . 98

Table 13 - Development of OERs: type and purpose. . . . . . . . . . . . . . . . 99

Table 14 - Development of OERs: domain and teaching/learning context. . . . . . . . . 99

Table 15 - Development of OERs: Involvement of users versus played role. . . . . . . . 100

Table 16 - Development of OERs: assessment process. . . . . . . . . . . . . . . . 100

Table 17 - Barriers to the development of OERs: Lack of recognition and incentive. . . . 101

Table 18 - Kickoff: summary of the steps. . . . . . . . . . . . . . . . 118

Table 19 - Development: summary of the steps. . . . . . . . . . . . . . . . . 124

Table 20 - Creative Commons licenses: Compatibility between licenses. . . . . . . . . . 133

Table 21 - Sharing phase: summary of the steps. . . . . . . . . . . . . . 135

Table 22 - Bloom's taxonomy of the cognitive domain. . . . . . . . . . . . . . . 138

Table 23 - Text-based contents supporting tools. . . . . . . . . . . . . . . . 142

Table 24 - Image supporting tools. . . . . . . . . . . . . . . . . . . . 143

Table 25 - Audio/video supporting tools. . . . . . . . . . . . . . . . . . . . 144

Table 26 - Experimental study: Summary of objectives. . . . . . . . . . . . . . . . 157

Table 27 - Results obtained by each method. . . . . . . . . . . . . . . . . . . 164 



\section{LIST OF ABBREVIATIONS AND ACRONYMS}

AM-OER . Agile Method for the development of OERs

AS ...... Average Score

ASD ..... Adaptive Software Development

BDD ..... Behaviour-Driven Development

BIOE .... . Banco Internacional de Objetos Educacionais

BSD ..... Berkeley Software Distribution

BY ....... Attribution

BY-NC ... Attribution Non-Commercial

BY-NC-ND Attribution Non-Commercial No Derivatives

BY-NC-SA Attribution Non-Commercial Share Alike

BY-ND ... Attribution No Derivatives

BY-SA ... Attribution Share Alike

CCSL .... Centro de Competência em Software Livre

EC ...... Exclusion Criteria

FDD ..... Feature Driven Development

FDL ..... GNU Free Documentation License

FLOSS ... Free/Libre and Open Source Software

GIMP .... GNU Image Manipulation Program

GPL ..... GNU General Public License

GQM ..... Goal/Question/Metric

IC ....... Inclusion Criteria

ICTs ..... Information and Communication Technologies

IP ...... Intellectual Property

ISD ..... Instructional System Design

JISC .... Joint Information Systems Committee UK

JIT ...... Just-In-Time

Kdenlive .. KDE Non-Linear Video Editor

LAMS ... Learning Activities Management Systems

LD ....... Lean Development

LDSE ... Learning Design Support Environment

LGPL ... GNU Library or Lesser General Public Licence 
LOM .... Learning Object Metadata

LOs ...... Learning Objects

LPPL .... LaTeX Project Public License

LRMI .... Learning Resource Metadata Initiative

MDD ..... Model-Driven Development

MERLOT . Multimedia Educational Resource for Learning and Online Teaching

MIT ..... Massachusetts Institute of Technology

MPL ..... Mozilla Public License

NAP-SoL . Núcleo de Apoio à Pesquisa em Software Livre

OECD .... Organisation for Economic Co-operation and Development

OERs .... Open Educational Resources

OO ....... Oriented-Object

OULDI ... Open Learning Design Initiative

Q1 ...... First Quartile or Lower Quartile

Q2 ...... Second Quartile or Median Quartile

Q3 ....... Third Quartile or Upper Quartile

RIVED ... Rede Interativa de Educação

RQ ...... Research Questions

SP-DEM . Standard Process for Developing Educational Modules

SVG .... Scalable Vector Graphics

TDD ..... Test-Driven Development

UNESCO . United Nations Educational, Scientific and Cultural Organisation

WA ..... Weighted Average

XP ...... eXtreme Programming 
INTRODUCTION . . . . . . . . . . . . . . . . . . 25

1.1 Motivation and Justification for the Research . . . . . . . . . 26

1.2 Objectives and Research Questions . . . . . . . . . . . . . 30

$1.3 \quad$ Research Design ....................... 31

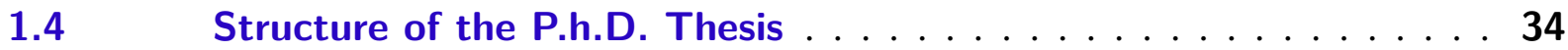

2 FUNDAMENTALS OF OPEN EDUCATIONAL RESOURCES . . . . 35

$2.1 \quad$ History of Open Educational Resources . . . . . . . . . . . 36

$2.2 \quad$ Characterising Open Educational Resources . . . . . . . . . . . 37

2.2.1 Types of Open Educational Resources . . . . . . . . . . . . . . . . 39

2.2.2 Key Principles of Open Educational Resources . . . . . . . . . . . . . 40

$2.3 \quad$ Potential Behind Open Educational Resources . . . . . . . . . . . 42

$2.4 \quad$ Open Licensing for Open Educational Resources . . . . . . . . . . . . 44

2.4.1 Open Content License/Open Publication License. . . . . . . . . . . . 44

2.4.2 GNU Free Documentation License . . . . . . . . . . . . . . . . 45

2.4.3 Creative Commons Licenses. . . . . . . . . . . . . . . . . . 46

$2.5 \quad$ Open Educational Resources Sharing Initiatives Worldwide . . . . 48

2.5.1 MIT OpenCourseWare ................... 48

2.5.2 UK OpenLearn . . . . . . . . . . . . . . . . . 49

2.5.3 Open Learning Initiative . . . . . . . . . . . . . . . . 50

2.5.4 ConneXions ..................... 50

$2.6 \quad$ Open Educational Resources Sharing Initiatives in Brazil . . . . . . 51

2.6.1 Rede Interativa de Educação - RIVED . . . . . . . . . . . . 51

2.6.2 Banco Internacional de Objetos Educacionais - BIOE . . . . . . . 52

2.6.3 Acesso Aberto and Brasiliana USP . . . . . . . . . . . . . 52

2.6.4 UNICAMP OpenCourseWare . . . . . . . . . . . . . 53

2.7 Development of Open Educational Resources: Pedagogical Issues . 53

2.7.1 Open University Learning Design Initiative . . . . . . . . . . . . . . 54

$2.8 \quad$ Concluding Remarks . . . . . . . . . . . . . . . . 57

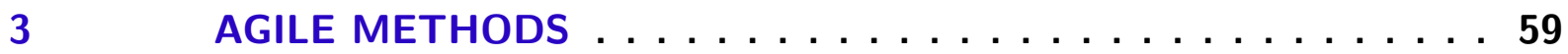

$3.1 \quad$ The Emergence of Agile Methods . . . . . . . . . . . . 59

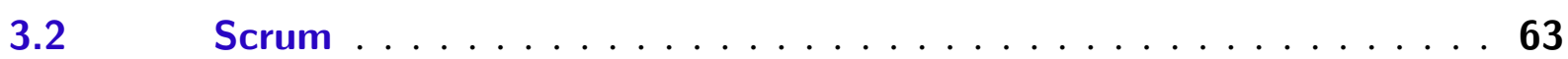


3.2.1 Scrum Theory . . . . . . . . . . . . . . . . .63 63

3.2.2 Scrum Framework . . . . . . . . . . . . . . . . . . 64

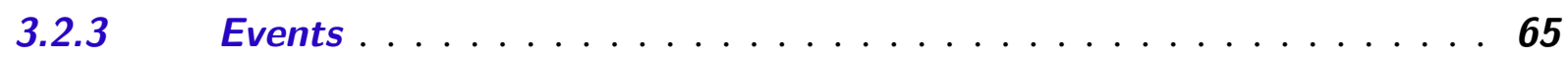

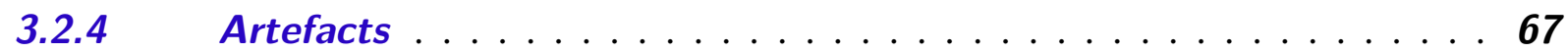

3.2.5 Scrum Life Cycle . . . . . . . . . . . . . . . . . . . . 68

3.3 eXtreme Programming . . . . . . . . . . . . . . . . 69

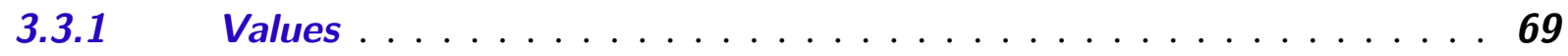

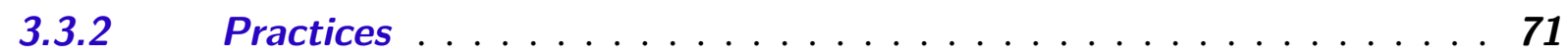

3.3.3 Principles . . . . . . . . . . . . . . . . . . 73

3.3.4 Roles. . . . . . . . . . . . . . . . . . . . . . 74

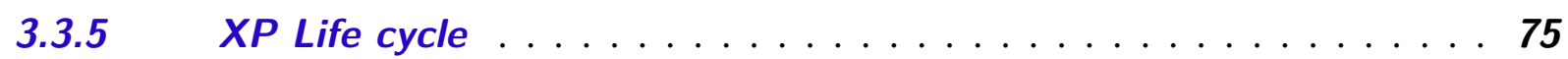

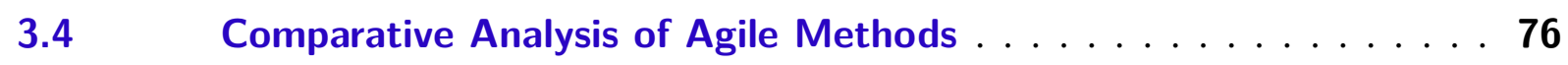

$3.5 \quad$ Concluding Remarks . . . . . . . . . . . . . . . . . . . . . . 79

4 DEVELOPMENT OF OPEN EDUCATIONAL RESOURCES . . . . 81

4.1 Approaches for the Development of OERs: A Systematic Mapping . 82

4.1.1 Objectives and Research Questions . . . . . . . . . . . . . . 82

4.1.2 Data Sources and Search Strategies . . . . . . . . . . . . . 83

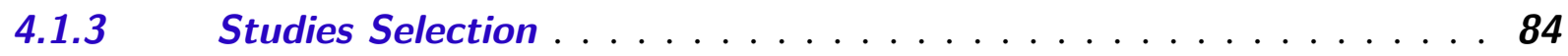

4.1.4 Data Analysis and Results . . . . . . . . . . . . . . 85

4.1.5 Threats to Validity . . . . . . . . . . . . . . . . . . . . . 93

4.1.6 Summary of the Results . . . . . . . . . . . . . . . . . . . 94

4.2 Development of OERs in Brazil: A Survey Research . . . . . . . . . 95

4.2.1 Objectives and Research Questions . . . . . . . . . . . . . 96

4.2.2 Sample Population . . . . . . . . . . . . . . . . . . . . 96

4.2.3 Data Analysis and Results . . . . . . . . . . . . . . . 97

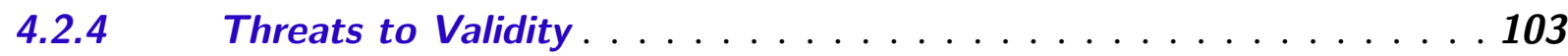

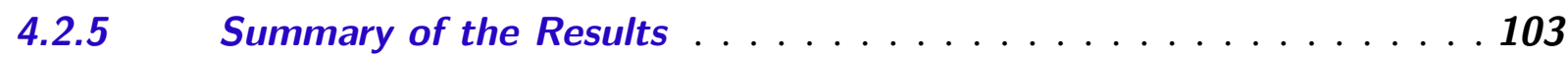

$4.3 \quad$ Concluding Remarks . . . . . . . . . . . . . . . . . . . . . . . . . . 104

5 AM-OER: AN AGILE METHOD FOR THE DEVELOPMENT OF OPEN EDUCATIONAL RESOURCES . . . . . . . . . . . 107

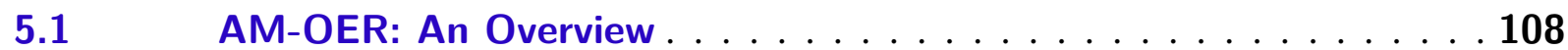

$5.2 \quad$ Characteristics and Practices . . . . . . . . . . . . . 109

5.2.1 Short-term and Continuous Planning . . . . . . . . . . . 110

5.2.2 Dynamic and Incremental Design . . . . . . . . . . . . . 112

5.2.3 Iterative and Incremental Development . . . . . . . . . . . . . . 113

5.2.4 Collaborative Approach . . . . . . . . . . . . . . . . . . . 114

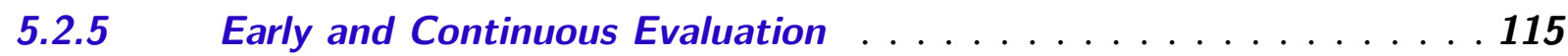

$5.3 \quad$ Roles . . . . . . . . . . . . . . . . . . . . . . 115 
5.4.1.1 Identify Learning Needs . . . . . . . . . . . . . . . . . . . 118

5.4.1.2 Establish Learning Contents . . . . . . . . . . . . . . . . . . . . . . . 120

5.4.1.3 Define Learning Assessments . . . . . . . . . . . . . . . . . . . . 121

5.4.1.4 Establish Means of Communication and Collaboration . . . . . . . . . . . 121

5.4.2 Development . . . . . . . . . . . . . . . . . 122

5.4.2.1 Prioritise and Select OER Modules . . . . . . . . . . . . . . . . . 123

5.4.2.2 Design the Learning Structure . . . . . . . . . . . . . . . . . . . . . 124

5.4.2.3 Define Metadata . . . . . . . . . . . . . . . . . . . 126

5.4.2.4 Search for Learning Contents . . . . . . . . . . . . . . . . . . . . . 128

5.4.2.5 Evaluate and Adapt Learning Contents . . . . . . . . . . . . . . . . . 129

5.4.2.6 Create OER Modules from Scratch . . . . . . . . . . . . . . . . . . . 130

5.4.2.7 Establish Licensing Policies . . . . . . . . . . . . . . . . . . . . . 132

5.4.2.8 Evaluate OER Modules . . . . . . . . . . . . . . . . . 132

5.4.2.9 Evaluate Sprint Execution . . . . . . . . . . . . . . . . . . . . . 134

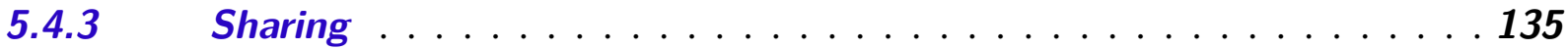

5.4.3.1 Deliver to a Target Audience . . . . . . . . . . . . . . . . 135

5.4.3.2 Make Available in Easily Accessible Locations . . . . . . . . . . . . . . . . . 136

5.4.3.3 Gather Feedback and Review . . . . . . . . . . . . . . . . . 136

$5.5 \quad$ Supporting Tools . . . . . . . . . . . . . . . . . 137

5.5.1 Learning Objectives Statement Mechanisms . . . . . . . . . . . . . 137

5.5.2 Learning Design Tools . . . . . . . . . . . . . . . . . . . . . 139

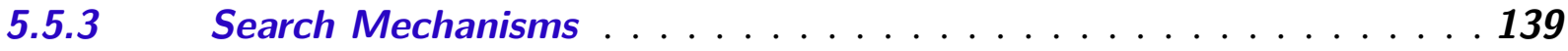

5.5.4 Content Editing Tools . . . . . . . . . . . . . . . 141

5.5.4.1 Text-based Contents . . . . . . . . . . . . . . . . . . . . 141

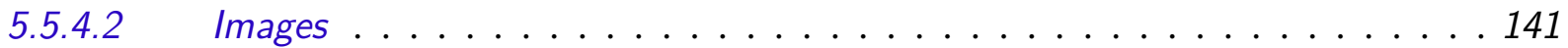

5.5.4.3 Audios and Videos . . . . . . . . . . . . . . . . . . 142

5.5.4.4 Statistical Data . . . . . . . . . . . . . . . . . . . . . . 144

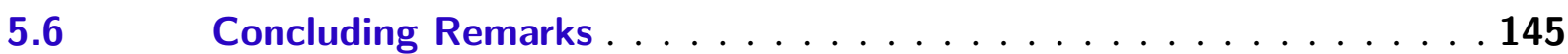

6 APPLYING AM-OER IN THE SOFTWARE ENGINEERING DOMAIN147

6.1 An OER on FlOSS: A Case Study . . . . . . . . . . . . . 147

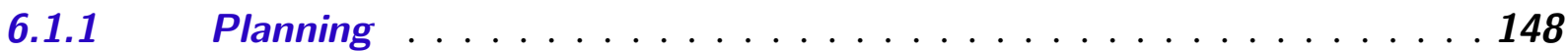

6.1.2 General Overview of the OER on FLOSS . . . . . . . . . . . . . 149

6.1.3 Summary of the Results . . . . . . . . . . . . . 155

6.2 An OER on Software Testing: An Experiment . . . . . . . . . 156

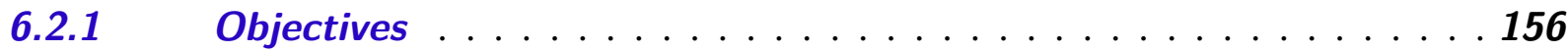

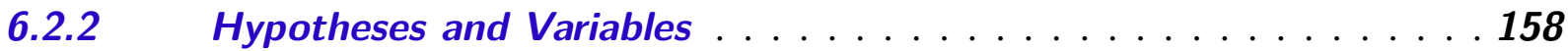

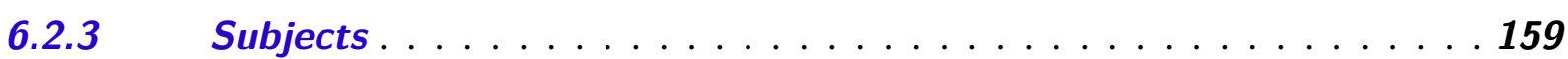


6.2.4 Experiment Design . . . . . . . . . . . . . . . . . . . 161

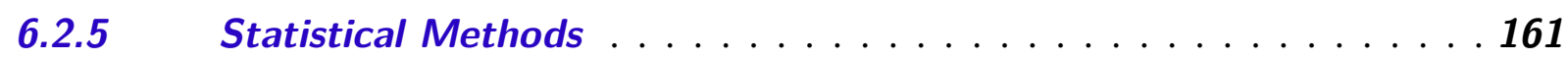

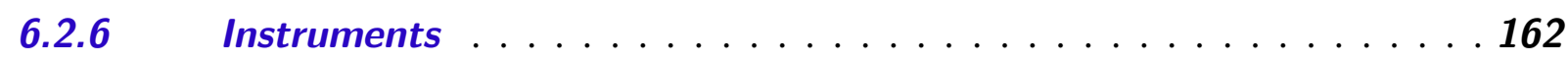

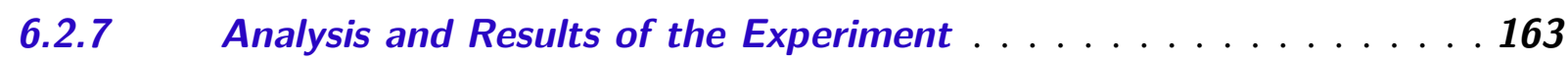

6.2.8 General Overview of the OER on Software Testing . . . . . . . 167

6.2.9 Threats to Validity. . . . . . . . . . . . . . . . . . 172

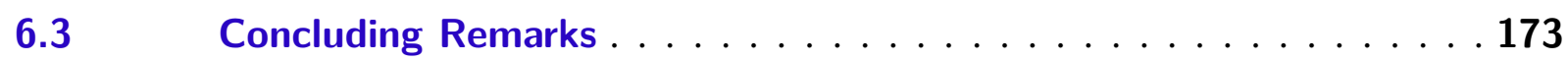

7 CONCLUSIONS AND FURTHER WORK $\ldots \ldots \ldots \ldots \ldots$

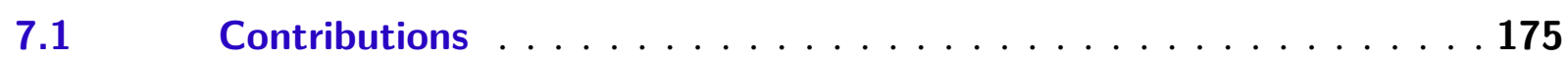

$7.2 \quad$ Limitations and Further Work $\ldots \ldots \ldots \ldots \ldots \ldots \ldots$

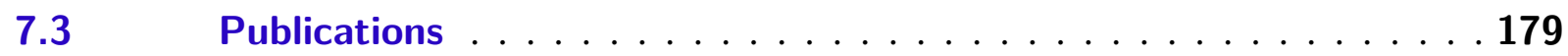

BIBLIOGRAPHY $\ldots \ldots \ldots \ldots \ldots \ldots \ldots \ldots \ldots \ldots \ldots \ldots \ldots \ldots \ldots$

APPENDIX A SURVEY ON THE DEVELOPMENT OF OERS IN

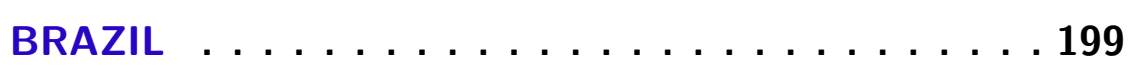

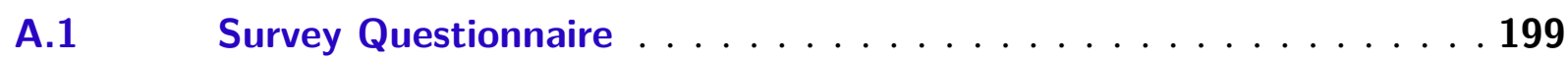



provided by the use of Information and Communication Technologies (ICTs), particularly Web 2.0, have promoted new ways of construction and access to knowledge, changing the landscape of education (ARIMOTO; BARBOSA, 2012b; ARIMOTO; BARBOSA, 2012a).

Issues related to teaching and learning processes, together with the increase in demand for training and personnel qualification, have driven the related researches to education in different areas of knowledge. Particularly, there is a need to rethink the way in which educational resources are designed, developed and made available for learners in order to effectively support teaching and learning, whether in the classroom, in a blended or distance mode.

Open Educational Resources (OERs) (UNESCO, 2002) have emerged as important elements of education in the contemporary society, transcending the constraints imposed by traditional education. They have provided effective mechanisms for open and flexible education, expanding access to knowledge with reduced costs and enhancing cooperation and collaboration. Furthermore, they promote and support innovative practices in teaching and learning, bringing significant impact on education.

OERs can be characterised as learning materials provided freely and openly for educators and learners/self-learners to be (re)used with the purpose of teaching, learning and research (Organisation for Economic Co-operation and Development, 2007). They are usually provided through an open license, in the same way of the Free/Libre and Open Source Software (FLOSS) (WHEELER, 2003; FELLER et al., 2005). They can range from lecture notes/presentations, images and audios/videos to course materials, full courses and textbooks, as well as any software or other tools, materials or techniques used to support the construction and access to knowledge.

The OERs movement originated from developments in open and distance learning, and in the wider context of a culture of open knowledge, open source, free sharing and peer 
collaboration (WILEY, 2006). The movement starts from the idea that knowledge is a public good and that technology, and the Internet in particular, provide a great opportunity for everyone to share and reuse this knowledge (William and Flora Hewlett Foundation, 2010), benefiting the whole society and promoting the global education.

OERs can play an important role in the transition to an educational system in which innovation, customisation, high quality, cost reduction and efficiency go together (EVERTSE, 2011). However, one of the current challenges is to take the advantage of the mechanisms provided by OERs to expand the creation and training of human resources and the intellectual level of the wider population (GIMENES; BARROCA; FELTRIM, 2012).

The adoption of open contents such as OERs is gradually moving forward in Brazilian Universities. An example is a joint effort from the Institute of Mathematics and Computer Sciences (ICMC) and the Institute of Mathematics and Statistics (IME) at University of São Paulo (USP), who maintain the FLOSS Competence Center - CCSL (Centro de Competência em Software Livre $)^{1}$, an initiative that combines activities for undergraduate and graduate teaching, research, development and dissemination of FLOSS and open contents. We also highlight, at ICMC, the Research Support Centre on FLOSS and open contents - NAP-Sol (Núcleo de Apoio à Pesquisa em Software Livre $)^{2}$. Both initiatives have acting in different areas of knowledge, especially in Computing, through scientific and technological production related to FLOSS and open contents.

Despite the advantages and benefits that OERs together with FLOSS can aggregate to education, research focused on the development and adoption of these resources in Computing teaching and in several other areas of knowledge, especially in the Brazilian context, are still incipient.

This P.h.D research focuses on the development of OERs. In this context, the idea is to investigate the application of agile methods to support the development of OERs. Agile methods have gained prominence in software development to address problems of long delivery times, and of software that did not fulfil its requirements or solved what was required (ARIMOTO; BARROCA; BARBOSA, 2015). Besides that, we aim to investigate Learning Design practices for the pedagogical design of OERs. Learning Design has emerged as an alternative to support educators in the definition of a more effective pedagogical design of learning materials, and to make the design more explicit and sharable (DIMITRIADIS et al., 2009; CONOLE, 2010).

\subsection{Motivation and Justification for the Research}

The education in the twenty-first century society, in which the computer and communication technologies are important allies, relates us to the need of a more open and

ccsl.icmc.usp.br [last accessed on 02-2016]

2 napsol.icmc.usp.br [last accessed on 02-2016] 
flexible learning, which can expand the possibilities of construction, access and sharing of knowledge.

However, in the current educational setting remains a strong dependence on the usage of "proprietary" software and "closed" educational contents. Proprietary and closed formats have several restrictions on their use, whether technical and legal issues or price barriers. As a result, both the evolution of software and educational contents cannot occur regularly, making them outdated and probably inadequate to more dynamic educational settings, capable of motivating the student in discovering and consolidating new knowledge. Also, versions of proprietary software and closed contents are eventually discontinued and become obsolete. Issues like these inhibit creativity and innovation in education.

Open contents and tools, particularly OERs, have potential to enhance the education at a global level. As they are usually available in digital formats with little or no cost, the user only needs to have Internet access to take advantage of them, regardless of his/her available time or geographical location.

From the point of view of the open philosophy, a user whether he/she is an educator, student or any other individual, holds certain rights and freedoms to (re)use, adapt, revise and (re)distribute the educational content in order to benefit others.

Therefore, important issues on the adoption of OERs are related to the possibility of "sharing" and subsequent "(re) creation" of related materials. New works can be produced more quickly from the derivation of third-part materials. One can also reuse existing materials, adjusting and adapting them to meet particular contexts or specific needs and educational goals. By allowing virtually anyone to have access to quality education and use and adapt materials previously reserved only for students at universities, OERs have the potential to jump start careers and economic development in communities that lag behind (William and Flora Hewlett Foundation, 2013), helping to reduce socioeconomic inequality.

Another issue to be highlighted in the OERs context is the possibility of increasing the efficiency and quality of learning materials available on the Web. These materials can be reused and constantly reviewed by different users, keeping them up to date. We also highlight the "cost factor" of OERs, minimising dependence on proprietary material such as commercial books (and therefore), reducing the production costs of the required materials. Finally, initiatives to OERs are also responsible for providing opportunities for entrepreneurship and innovation in educational institutions, whether public or private.

Although the development and adoption of OERs have gained support and encouragement from several institutions and researchers across the globe, the full potential of OERs has not been reached yet (OCHOA; DUVAL, 2009; EHLERS; CONOLE, 2010; CONOLE, 2013). One of the challenges faced by developers and practitioners of OERs has been how to produce quality and relevant materials that can be reused and adapted in different context and learning situations. 
In addition, educators have difficulty in understanding the implicit design behind OERs and how to reuse and adapt them to their own teaching context (DIMITRIADIS et al., 2009).

The design and quality of available OERs have been hindering their (re)use. Also, there are some issues that need more attention (CONOLE, 2013; DIMITRIADIS et al., 2009; LOCKYER et al., 2008; Open Educational Quality Initiative, 2011; Organisation for Economic Co-operation and Development, 2007). Issues related to the contextualisation of OERs (AMIEL; OREY; WEST, 2011; BUTCHER, 2015), including cultural and language issues, have also been neglected during the development of OERs, hindering the potential for the reuse of OERs and their adoption. Researchers report the difficulty to reuse and adapt third-part OERs (AMIEL; OREY; WEST, 2011; Open Educational Quality Initiative, 2011; RICHTER; EHLERS, 2010). Sometimes this occurs due to the diversity of languages and culture which is not considered during the design and creation of OERs. For instance, in the case of Brazil, educators have difficulty to find learning materials in Portuguese and to adapt them to the local context (AMIEL; SANTOS, 2013). Such issues should be taken into consideration during the development process in order to deliver flexible OERs to be reused and adapted more broadly by others.

Instructional Design emerged as an approach for designing learning instructions in a systematic way. It is defined as a systematic application of scientific principles about "how people learn" to develop instruction (MOLENDA, 2003; CONOLE, 2010; CONOLE, 2013). The term "instructional" means anything that is done purposely to help and facilitate learning (MOLENDA, 2003; REIGELUTH, 1983; REIGELUTH; CARR-CHELLMAN, 2009).

With the advent of the Web 2.0, new approaches for designing learning materials have been proposed. Learning Design has emerged within this context, bringing a broader perspective to teaching and learning. It consists of a set of activities supporting the understanding, description and sharing of pedagogical design practices (BEETHAM; SHARPE, 2007; CONOLE, 2013; DIMITRIADIS et al., 2009).

Learning Design has been developed as a means of helping teachers make informed choices in terms of creating pedagogically effective learning interventions that make effective use of technologies (CONOLE, 2013; KOPER, 2006). Research on Learning Design has increased in the last few years primarily due to the gap between the potential and actual use of technology to support teaching and learning (HERRINGTON; REEVES; OLIVER, 2005; BEETHAM; SHARPE, 2007).

In the context of OERs, studies have suggested the need for systematic and, at the same time, flexible approaches to support their design, creation and sharing (PETRIDES et al., 2008; SCLATER, 2009; CONOLE et al., 2009; Open Educational Quality Initiative, 2011; ARIMOTO; BARBOSA, 2012a; ARIMOTO; BARROCA; BARBOSA, 2014; ARIMOTO; BARROCA; BARBOSA, 2016). Furthermore, in most initiatives involving the provision of OERs, the production activities are considered the most costly, highlighting the need for an effective production process for a sustainable provision of OERs (SCHUWER et al., 2010). 
However, initiatives to foster the design and creation of quality OERs with reduced time and costs are still incipient. There is no evidence in the literature of approaches to effectively support the development of OERs. In Brazil, particularly, this scenario seems more problematic (ROSSINI, 2010; SANTOS, 2013). We observed a lack of approaches specifically focused on designing, creating and delivering OERs (ARIMOTO; BARBOSA, 2012a; ARIMOTO; BARROCA; BARBOSA, 2014; ARIMOTO; BARROCA; BARBOSA, 2015; ARIMOTO; BARROCA; BARBOSA, 2016).

Another important characteristic associated with the development and delivery of OERs refers to the dynamic and evolutionary aspect of knowledge, from which the contents should be continuously evolved in consequence of previous learning experiences. Furthermore, the production of an OER may involve collaborative aspects in which developers, locally or remotely distributed, interact and cooperate to its construction (BARBOSA; MALDONADO, 2011; ARIMOTO; BARBOSA, 2012a).

The collaboration and involvement of users (including educators and learners) is also appealing in the context of the development of OERs (DOWNES, 2007; BUTCHER, 2015; BLACKALL; JELLEY, 2013; PAWLOWSKI, 2011; ARIMOTO; BARROCA; BARBOSA, 2014). Generally, collaborative aspects in the development of OERs, together with the flexibility to accommodate changes and modifications, have not been fully explored during the development of OERs. Many OERs are created individually, without the involvement of learners and the collaboration between educators and learners. These issues have contributed to the lack of motivation in developing and adopting OERs. In addition, such issues are viewed as a means to increase the adoption and impact of OERs (Cape Town Open Education Declaration, 2007; BUTCHER, 2015).

Agile methods (BECK; FOWLER, 2000; BECK; ANDRES, 2004; COCKBURN, 2004; HIGHSMITH; COCKBURN, 2001; SCHWABER; BEEDLE, 2002; SUTHERLAND et al., 2007) fit into this perspective, promoting simplicity and flexibility to deliver products and services that are relevant and add value to the market in due time. One of the characteristics of agile methods is that they are "people-centred", encouraging and prioritising effective collaboration and involvement of users in the development to deliver software more quickly and efficiently (ARIMOTO, 2009).

The agile development is characterised by rapid and continuous deliveries of "working software", allowing customer to use and test the system and provide rapid feedback. These deliverable are prioritised by the customer, taking into consideration their value/importance to the business (ARIMOTO et al., 2009; ARIMOTO; BARBOSA, 2012b; ARIMOTO; BARBOSA, 2012a).

The concerns and characteristics of agile methods resonate with the needs identified in the development of OERs, as previously mentioned. These methods constitute an interesting 
development alternative, providing flexible and suitable approaches for elaboration of products in constant evolution, such as OERs (ARIMOTO; BARBOSA, 2012a).

In this work we propose an Agile Method for the development of OERs (AM-OER) based on practices from agile methods (AMBLER, 2001; AMBLER, 2002; BECK; FOWLER, 2000; BECK; ANDRES, 2004; SCHWABER; BEEDLE, 2002) and on practices of Learning Design that originate in the Open Learning Design Initiative (OULDI) project (CROSS et al., 2012; CONOLE, 2013), proposed at the UK Open University. The AM-OER method considers not only Learning Design as a dynamic process but also allows for the design to evolve incrementally, and be modified and enhanced as needed. The idea is to facilitate the reuse and adaptation of OERs and to contribute to their quality by embedding pedagogical design practices. Empirical studies have been performed to assess the applicability and effectiveness of our proposal by applying it in the design and creation of OERs within the Software Engineering domain.

\subsection{Objectives and Research Questions}

The main goal of this P.h.D. research is to investigate the development of OERs and propose flexible and suitable approach for their development and sharing. Particularly, we intend to investigate how agile methods together with Learning Design practices can effectively support the development process of OERs. Our main objective is to establish an agile method with embedded pedagogical design practices for designing and creating effective OERs.

This P.h.D research is guided by the following overall research question: How can agile methods in combination with Learning Design practices support the development process of Open Educational Resources? Based on this research question, the main objectives of this P.h.D. research are described as follows:

- Study on the development of OERs: we aim to define a big picture on the development of OERs. The primary idea is to characterise how OERs have been developed, including the mechanisms/approaches proposed and used to support the development of learning materials, especially OERs. In the Brazilian context, in particular, we intend to characterise the main problems and barriers that hinder the development and widespread adoption of OERs.

- Study on Learning Design approach for OERs: we aim to study pedagogical design issues of learning materials, focusing on Learning Design approach. Particularly, we intend to investigate the Learning Design approach proposed within the OULDI project. The idea is to identify useful practices of Learning Design to supporting the design of OERs.

- Study and establishment of an agile method for OERs: we aim to investigate and establish a flexible method for the development and delivery of OERs based on agile methods. We intend to combine Learning Design practices within the proposed method, 
including essential practices and activities for designing and creating effective OERs. The idea is to embed pedagogical design practices from Learning Design into the OERs development process in order to improve the quality of OERs and facilitate further reuse and adaptation. The initial proposal of the method should be refined and evolved incrementally, by incorporating new features, changes and improvements until obtaining a consistent version of the method.

- Plan and conduct empirical assessment studies: Firstly, we intend to study empirical research strategies/methods suitable to the research conducted in this P.h.D thesis. After that, we aim to establish, plan and conduct preliminary empirical assessment studies to validate the proposed method for OERs. In this case, research methods based on observation and experimentation should be used, particularly case study and experiment. The proposed method should be applied in the development of OERs within the software engineering domain, including courses on FLOSS development and on software testing.

\subsection{Research Design}

In this P.h.D. research we adopt mixed method research, particularly case study research, survey-based research and controlled experiment/experiment. These research methods are appropriate to answer the type of research question we intend to answer, as described in the previous section.

The mixed research methods apply both qualitative and quantitative methods/techniques for collecting and analysing the empirical data from the studies conducted in this P.h.D. research. Qualitative methods involve collecting data or material derived from observations or interviews that are analysed through non-statistical methods whilst quantitative methods involve collecting numerical data that are analysed through statistical methods (LETHBRIDGE; SIM; SINGER, 2005; HARDY; BRYMAN, 2009).

Regarding the characteristics and types of research, we combine exploratory and explanatory research. Exploratory research aims at "finding out what is happening, seeking new insights, and generating ideas and hypotheses for new research" whilst explanatory research aims at "seeking an explanation for a situation or a problem, mostly but not necessarily, in the form of a causal relationship" (ROBSON, 2011).

In Figure 1 we summarise the research phases, the research methods used and their purposes. Phase \#1 is a result of two studies. The first study was a deep investigation on the literature to determine the concepts, definitions, and characteristics related to OERs. Based on the literature, we proposed a definition of OERs emphasising their intrinsic characteristics and the need of using open licencing for sharing OERs. We classified OERs in four main types according to the characteristic and purpose of each one. We also described the open licensing options for educational purpose. The study also helped to explore the potential of adopting OERs 
and strategies to increase their impact on education, and to identify initiatives for sharing and disseminating OERs worldwide.

The second study involved a deep and systematic evidence-based research, particularly a systematic review in order to identify existing mechanisms/approaches applied to the development of learning materials. We collected and gathered the evidence found, characterising the approaches/mechanisms proposed and used for the development of these materials. The results of this study were published and presented in the International Conference on Computer in Education (ICCE/2012) (ARIMOTO; BARBOSA, 2012b).

Figure 1 - Research phases, methods and purposes.

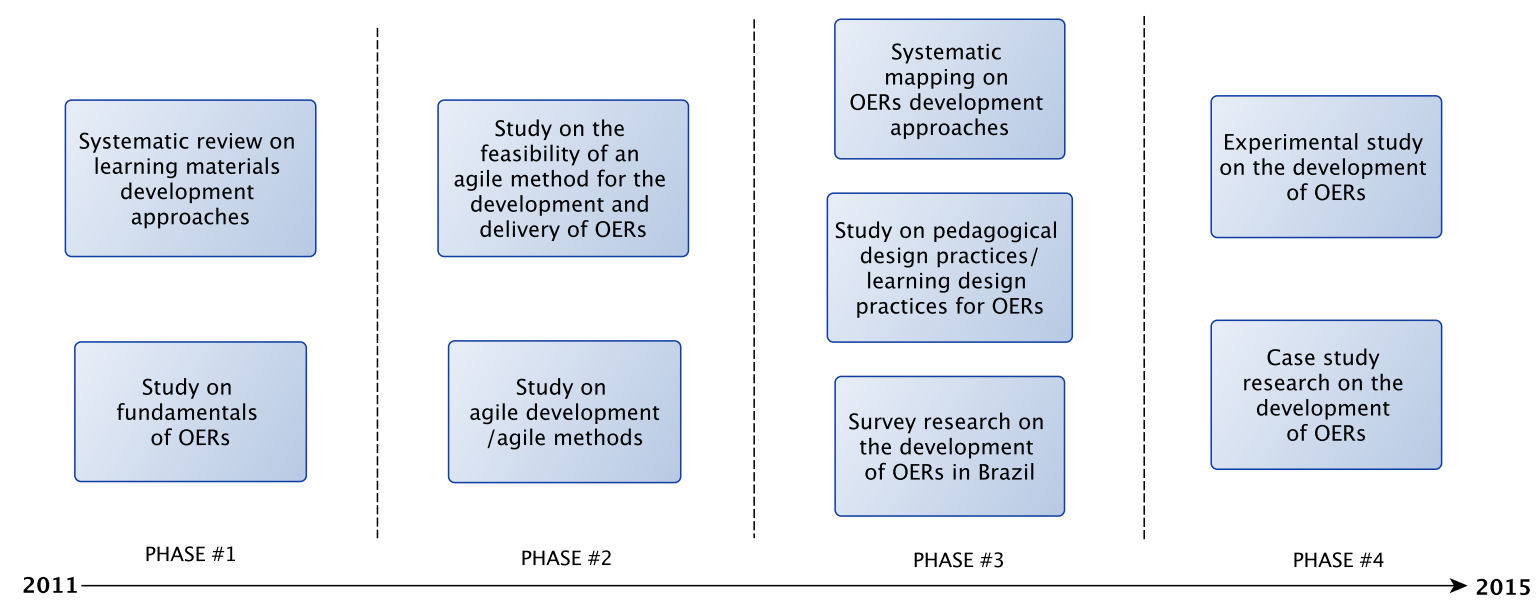

Source: Elaborated by the author.

Phase \#2 comprises two different studies on agile methods. Firstly, we conducted a literature review on the principles, values and practices of software agile development, focusing on the well-known and widely used agile methods Scrum and eXtreme Programming (XP). We characterised the main characteristics of agile methods and summarised the similarities and differences between them. From this, a very preliminary set of practices that could be useful for the development of OERs was proposed. The practices were defined from characteristics identified on OERs and the comparison from agile methods characteristics, particularly Scrum and XP. The results of this study were published and presented in the II International Symposium on OER: Issues for globalisation and localisation of the Congresso Brasileiro de Informática na Educação (CBIE/2012) (ARIMOTO; BARBOSA, 2012a).

Secondly, we conducted a feasibility study toward the proposal of a preliminary version of an agile method for the development and delivery of OERs based on agile methods Scrum and XP. We illustrated our idea by applying the proposed method in the development of a short course in the Software Engineering domain. The results of this study were published and presented in the IEEE Frontiers in Education Conference (FIE/2013) (ARIMOTO; BARBOSA, 2013). 
Phase \#3 is a result of three type of studies. The first study, a survey-based research, involved the investigation of OERs in the Brazilian context. We characterised how OERs have been developed and determined the obstacles, problems and challenges that difficult the development and adoption of OERs in Brazil. The results of this study were gathered and published in the Revista Novas Tecnologias na Educação (RENOTE/2014) (ARIMOTO; BARROCA; BARBOSA, 2014).

The second study consisted of an investigation on pedagogical design practices for the design and creation of OERs. We have focused on Learning Design practices, particularly within the context of OULDI project from UK Open University. Then, we incorporated practices of Learning Design of OULDI into the first preliminary version of the method for OERs, which is based on agile practices from Scrum and XP. The results of this study were published and presented in the IEEE Frontiers in Education Conference (FIE/2015) (ARIMOTO; BARROCA; BARBOSA, 2015).

The third study, an evidence-based research, consisted of a systematic mapping involving the search for mechanisms/approaches for the development of learning materials, focusing on OERs and on the application of agile methods in the development of these materials. This systematic mapping was an adaptation and updating of the systematic review previously conducted. We were concerned in obtaining an overview (a map) of the development of OERs, identifying the approaches proposed/used for OERs. Systematic mapping is more suitable in this kind of research. The results of this study were gathered in a paper and submitted to the International Journal of Distance Education Technologies (IJDET).

Phase \#4 is a combination of two type of studies: case study research, and experimental-based research. The case study involved the application of the proposed method in the design and creation of a full course on FLOSS development. We were concerned in providing an initial assessment of the feasibility and applicability of the proposed method in the OERs development context. The results of this study were gathered in a paper and submitted to the Congresso Brasileiro de Informática na Educação, XXVII Simpósio Brasileiro de Informática na Educação (CIBE-SBIE/2016). The experimental study involved the application of the proposed method in the development of a course on software testing within a controlled environment. We were concerned to conduct a preliminary assessment on the effectiveness, efficiency, and quality of the results produced by the method. Issues related to the appropriateness, ease of use and satisfaction were also investigated. The findings answer our global research question. The results of the experimental study was gathered in a paper and accepted for publication in the Informatics in Education International Journal (ARIMOTO; BARROCA; BARBOSA, 2016). 


\subsection{Structure of the P.h.D. Thesis}

The remainder of this P.h.D. thesis is organised as follows. In Chapter 2 we present a background on the fundamentals of OERs. Particularly, we characterised OERs based on the investigation of main definitions, classification of OERs, and principles that underpin the OER's philosophy. We identified characteristics related to OERs that differentiate them from other materials. We discussed about open licensing issues in the educational context, being essential for sharing and disseminating OERs. The pedagogical design of OERs was another essential issue addressed in this chapter, helping to increase the quality and the potential for reusing and adapting OERs. We focused on the Learning Design approach for designing and describing pedagogically learning materials.

In Chapter 3 we present a background on the agile methods, highlighting the values and principles that underpin their philosophy. We focused on the agile methods Scrum and XP. We discussed on the main characteristics and practices of the target agile methods, briefly comparing them and summarising their similarities and differences in order to help in the establishment of AM-OER.

In Chapter 4 we present an investigation on the development of OERs. Firstly, we conducted a systematic mapping to characterise the mechanisms/approaches proposed and used for the development of learning materials. We focus on approaches for the development of OERs and that follow agile methods. Finally, we conducted a quantitative survey-based research to provide a big picture on the development of OERs in Brazil. We identified the barriers related to the development of OERs and the gaps that hinder the widespread adoption of OERs in the Brazilian setting.

In Chapter 5 we present our proposal for designing and creating OERs with embedded pedagogical design practices. It consists of an Agile Method for the development of Open Educational Resources (AM-OER), grounded on agile practices and on Learning Design practices. We introduce the characteristics and practices of AM-OER, and describe the phases and steps to be undertaken for the effective development and sharing of OERs.

In Chapter 6 we present two assessment studies to validate AM-OER. The first assessment consisted of an exploratory study based on observation, a case study involving the application of AM-OER in the development of an OER on FLOSS. The second assessment consisted of an explanatory study based on experimentation, an experiment involving the application of AM-OER in the development of an OER on software testing. Data from two studies are collected and analysed using both qualitative and quantitative methods.

In Chapter 7 we summarise the work conducted in this P.h.D. research. We outline the main contributions of each study and its limitations. We also highlight the current state of the work, providing some directions for future work. 


\section{FUNDAMENTALS OF OPEN EDUCATIONAL RESOURCES}

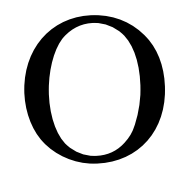
pen Educational Resources (OERs) have emerged as an important element of education. They open new perspectives for teaching and learning in the contemporary society, which is characterised by the intensive use of technologies and by the increasing adoption of collaborative learning approaches centred on the learners. This chapter covers the background on OERs, underpinning the research conducted in this P.h.D. thesis and providing the theoretical basis to understand the subject. In Section 2.1 we introduce the history of the OERs movement, highlighting the key events that helped to spread the OERs culture and philosophy. In Section 2.2 we discuss the concepts, definitions and terminologies related to OERs. A summary of the different types of OERs is presented. Based on the literature, we defined and characterised OERs into four main types: complete modules, components, interactive media and supporting mechanisms. We also introduce the key principles behind the characterisation of OERs. In Section 2.3 we highlight the transformative potential and impact of OERs on global education. In Section 2.4 we discuss the licensing policies applied to the educational context. We describe the main licensing initiatives of learning materials and focus on Creative Commons licenses, the most commonly and widely used nowadays. In Section 2.5 we describe some popular initiatives for sharing OERs worldwide. In Section 2.6 we describe some initiatives for sharing OERs in the Brazilian scenario. In Section 2.7 we discuss the pedagogical design of OERs. We summarise issues of pedagogical design, including an introduction on Learning Design and on OULDI project that is inserted in this context. Concluding remarks are given in Section 2.8. 


\subsection{History of Open Educational Resources}

Open Educational Resources (OERs) have been gaining importance for promoting life-long and personalised learning, helping to break demographic, economic, and geographic educational boundaries (YUAN; NEILL; KRAAN, 2008).

The emergence of the OERs movement is related to the comprehensive context of open and distance learning that transcends social and geographical barriers, helping to promote the idea of broad access and participation of all citizens in education. Developments in this context were motivated mainly by the removal of the constraints imposed by traditional learning and by the need for free knowledge sharing.

The main events that contributed to the emergence of OERs over the years are summarised in Figure 2. In the late 90s, the development and use of Learning Objects (LOs), even though an elementary and primary way, represented an important step forward in the context of learning supported by technology and towards the emergence of OERs. Learning objects, term coined by Wayne Hodgins in 1994, performed their role in the trajectory of OERs as they popularised the idea that digital learning materials can be designed and produced to be reused easily numerous times and in a variety of pedagogical situations (WILEY, 2006).

Figure 2 - The emergence of Open Educational Resources.

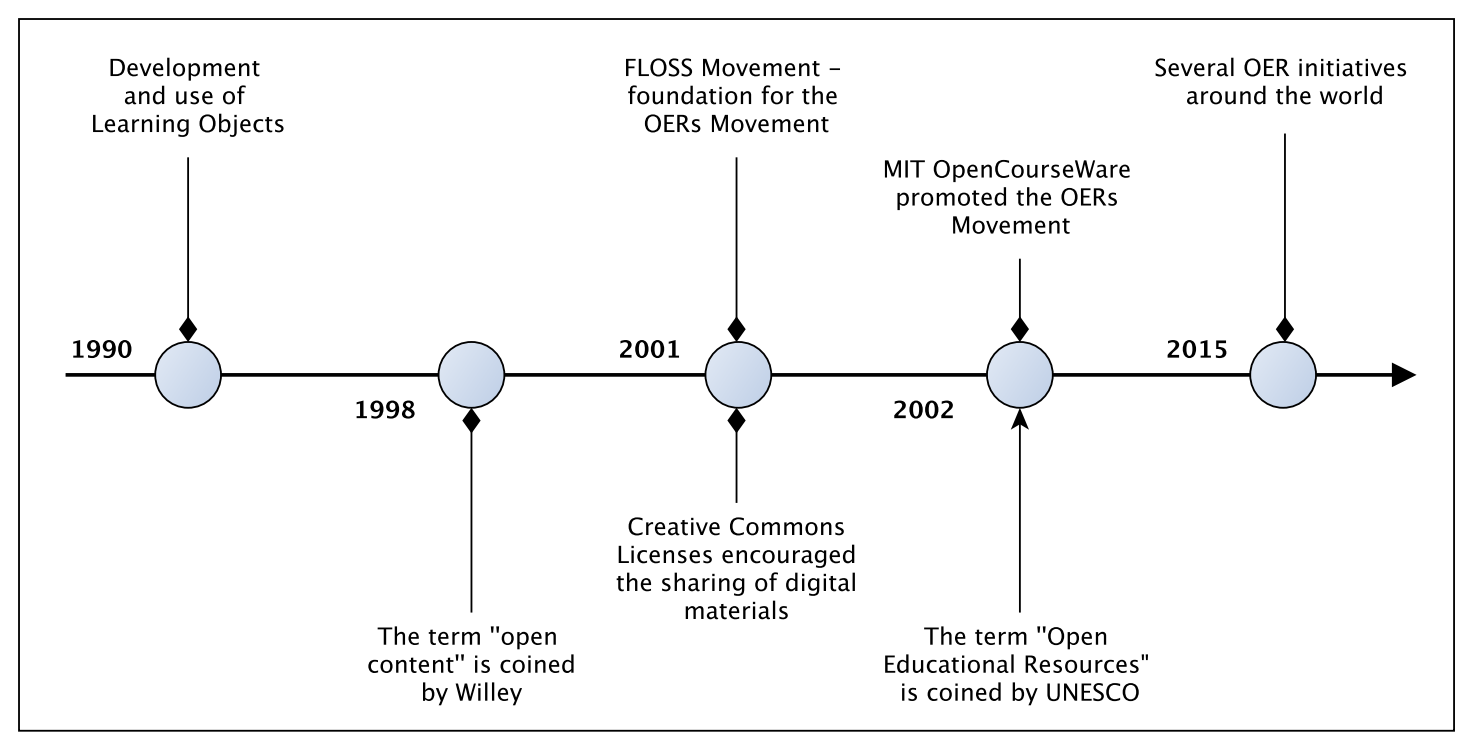

Source: Elaborated by the author.

The history of the OERs movement also relates us to the history of the Free/Libre and Open Source Software (FLOSS) (WHEELER, 2003; FELLER et al., 2005) movement, which gained notoriety in recent years as a viable alternative to software development. Initiatives such as Apache, Linux, Mozilla, among others contributed to the dissemination of the FLOSS movement, encouraging research on open contents and providing foundation for the development of the OERs movement. 
In 1998, Wiley (1998) coined the term "open content" by analogy with open source from Software Engineering. It helped popularise the idea that the principles of the open source software could be applied to the development of learning materials as well.

In 2001, the release of the Creative Commons Licenses ${ }^{1}$ by Larry Lessig from the Stanford University was important to encourage the creation and provision of digital materials in the way of OERs. Creative Commons Licenses follow the principles of the FLOSS Licenses, and provide an easy and flexible way to make available materials as OERs, benefiting both author/content provider and user of the materials.

In 2002, the release of the MIT OpenCourseWare (Massachusetts Institute Technology, 2002), created by Massachusetts Institute of Technology, was a kickoff for the OERs movement to take off and gain support worldwide. The MIT OpenCourseWare is still now a successful initiative to publish digital materials for free and open public access.

Also in 2002, the term "Open Educational Resources" was introduced during the forum conducted by the United Nations Educational, Scientific and Cultural Organisation (UNESCO), aimed at promoting the development of universal educational resources accessible for all people.

Currently, OERs have been consolidated in the global scenario, being used by academic institutions and governmental and non-governmental organisations worldwide as strategy to improve education, enabling new ways of access and dissemination of knowledge.

\subsection{Characterising Open Educational Resources}

The concept of OERs has several interpretations, ranging from more restrictive to broader definitions. However, many of them are based on the definition used by the William and Flora Hewlett Foundation ${ }^{2}$, one of the major promoters of the OERs movement. It refers to OERs as teaching, learning and research materials which reside in the public domain or have been released under an intellectual property license allowing their free use or re-purposing by others (William and Flora Hewlett Foundation, 2010).

According to the Commonwealth of Learning ${ }^{3}$, the concept of OERs describes essentially "any educational material that is openly available for use by educators and students, without an accompanying need to pay royalties or licence fees" (BUTCHER, 2015).

The Organisation for Economic Co-operation and Development (OECD) ${ }^{4}$ refers to OERs as digital materials provided freely and openly for educators, learners/self-learners to (re)use with the purpose of teaching, learning and research (Organisation for Economic Co-operation and Development, 2007).

\footnotetext{
creativecommons.org [last accessed on 01-2016]

hewlett.org [last accessed on 01-2016]

col.org [last accessed on 01-2016]

oecd.org [last accessed on 01-2016]
} 
In a broader sense, UNESCO $^{5}$ (UNESCO, 2002) refers to OERs as teaching, learning and research materials available digitally or otherwise, being in the public domain or licensed in an open way in order to be used or adapted by others with little or no restriction.

For the purpose of our research we define OERs as "educational/learning materials for teaching, learning and research which are freely and openly available through an open license, allowing their (re)use, modification, adaptation, and distribution in a flexible way with little or no restriction". The definition clearly states the need for open license for OER, a key factor that differentiates an OER from other kinds of educational resources.

There is no universally accepted definition for OERs. However, Geser (2012) suggests three fundamental attributes when referring to OERs:

- Access to open content must be offered for free, either by educational institutions, content providers, educators, students, or other users;

- Content must be licensed in a generous way in order to be reused in educational activities and free of restrictions which would prevent them from being modified, combined and remixed; and,

- The systems and tools used must have the source code available, prioritising the use of open source software.

As previously said, the term Open Educational Resources emerged during an event organised by UNESCO in 2002 focused on the discussion about the impact of the OpenCourseWare for higher education (Organisation for Economic Co-operation and Development, 2007). Since then, the free and open access to digital scientific content has been gaining support and several projects involving the provision of OERs have been consolidated in the global scenario. Successful examples include: (1) MIT OpenCourseWare ${ }^{6}$ (Massachusetts Institute of Technology); (2) OpenCourseWare Consortium ${ }^{7}$ (Community involving over 250 universities and associated organisations worldwide); (3) OpenLearn ${ }^{8}$ (UK Open University); (4) Connexions $^{9}$ (Rice University); and (5) Open Learning Initiative ${ }^{10}$ (Carnegie Mellon University).

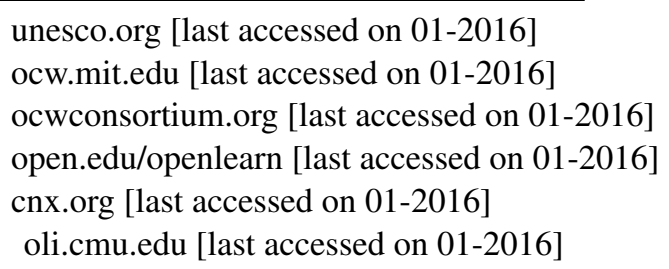




\subsubsection{Types of Open Educational Resources}

According to the definition of OERs, a wide variety of resources can be considered as OERs, ranging from courses in a curriculum level to any tools to support the creation and the free access to knowledge. Hylén (2006) classifies OERs as:

- Learning materials: include educational materials used for learning such as educational modules, learning objects, full courses, supporting materials, lecture notes, audios/videos, images, textbooks, among others.

- Software: include software, techniques and systems to support the creation and provision of educational materials such as media format converters, content creation tools, learning/environment systems, learning platforms and repositories, among others.

- Standards: include standards of implementation and licensing of open materials, design principles and best practices of implementation, among others.

Following the definition adopted in this research (Section 2.2), we characterise OERs in four main types: complete modules, components, interactive media, and supporting mechanisms. A conceptual map representing them is shown in Figure 3.

Figure 3 - Characterisation of types of OERs.

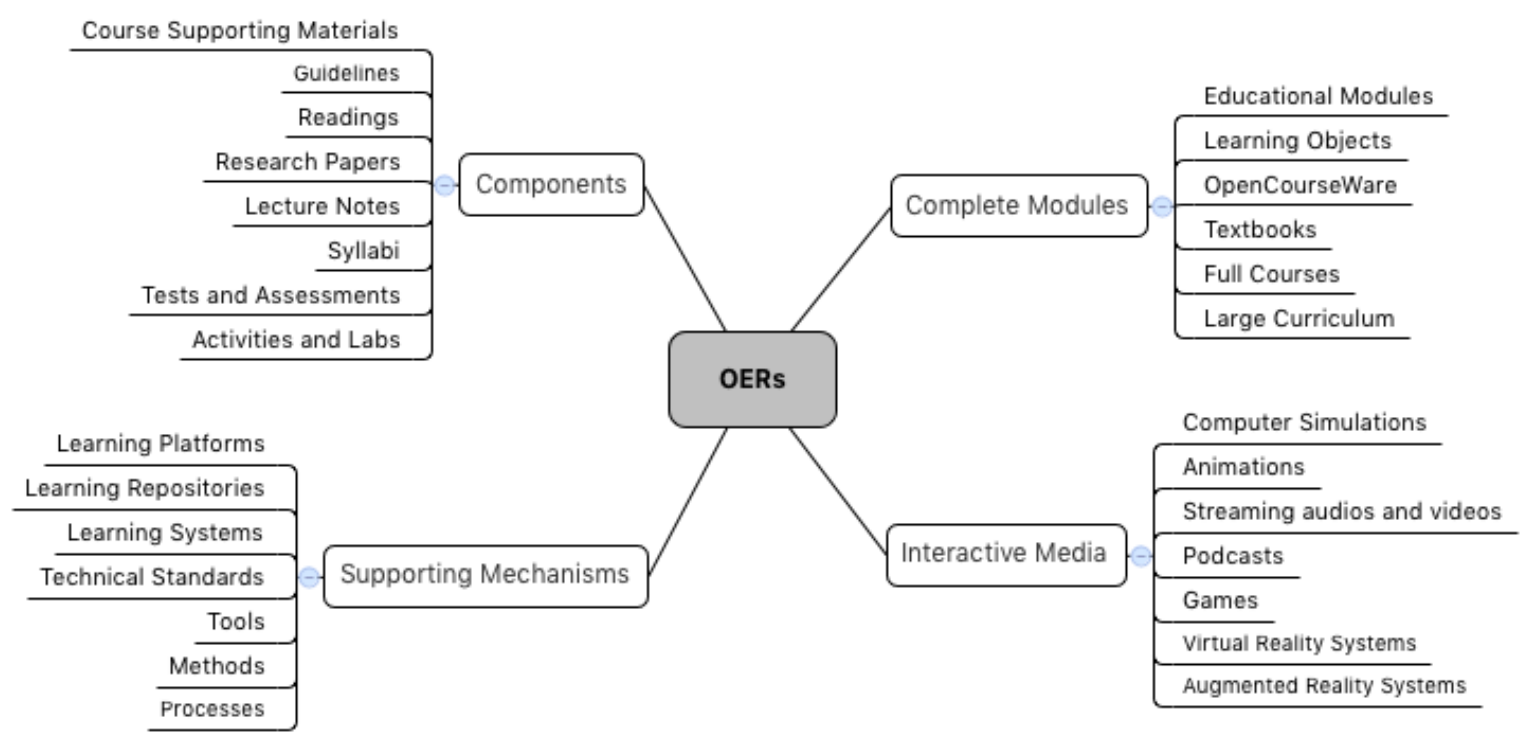

Source: Elaborated by the author.

Complete Modules represent a more complete and standardised structure of learning materials. Typical examples of complete modules include educational modules ${ }^{11}$, learning

11 Educational Modules are characterised as concise study units composed mainly of theoretical contents integrated with practices and assessment activities, being available to learners through technological and computational resources (BARBOSA; MALDONADO, 2011). 
objects $^{12}$, OpenCourseWare ${ }^{13}$ materials, open textbooks and full courses or a complete curriculum.

Components represent small blocks of educational contents and activities. Typical examples of components include course supporting materials, guidelines, readings, research papers, course lecture notes/presentations, syllabi, and tests and assessments activities.

Interactive Media represent digital and interactive components within a module. Examples of interactive media include computer simulations and animations, audios and videos, podcasts, or even a complete module as a game, a virtual reality system or an augmented reality system, among others.

Supporting Mechanisms represent mechanisms that support the teaching and learning process, and the construction and delivery of learning materials freely and openly, including any open platforms, repositories, learning systems or environments and technical standards. It also includes any open source software, tools, methods and processes.

\subsubsection{Key Principles of Open Educational Resources}

In Figure 4 we summarise the key principles and characteristics behind OERs and their dependency relationship. One of the principles that underpins the OERs philosophy is the "openness". Geser (2012) stresses the openness as the core principle of OERs in the Web 2.0 digital environment. He argues that in the future "OERs will more likely be found in these social environments and contexts of learning than in typical courses that are supported by the Virtual Learning Environments of schools and universities".

Figure 4 - Key principles behind OERs.

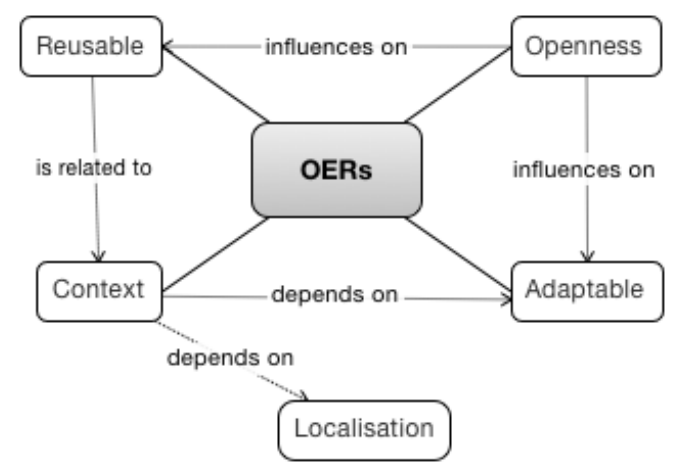

Source: Elaborated by the author.

Openness is intrinsically related to the free and open availability of OERs, with the possibility to (re)use them with few or no restriction. There should be no technical restrictions 
preventing access to the OERs, including interoperability issues, no price barriers requiring any licensing tax or payment, and no several legal permission barriers imposing restrictions of use for the end-user (HYLÉN, 2006). Therefore, the openness can be viewed from different perspectives. We characterise it into three main strands:

1. Legal: refers to the ability to reuse and adapt an OER without having the need to ask for permissions, or without violating the rights of authorship and intellectual property. This implies the explicit use of open licenses.

2. Technical: refers to open source software, open standards and formats in which the OER is built so that it is more easily reused and adapted. The use of open licenses should also contemplate the use of open technologies.

3. Social: refers to the social and economic benefits and ethical aspects related to the freedom to use, contribute and share the OER. This implies to provide education accessible for all.

Openness in OERs means users have permission through a license, performing four main actions (4R) (WILEY, 2010):

- Reuse: the right to use the content in its unaltered/verbatim form (e.g., make a backup copy of the content).

- Review: the right to adapt, adjust, modify, or alter the content itself (e.g., translate the content into another language).

- Remix: the right to combine the original or revised content with other content to create something new (e.g., incorporate the content into a mashup).

- Redistribute: the right to share copies of the original content, your revisions, or your remixes with others (e.g., give a copy of the content to a colleague).

We can state that the "degree" and the "perspective" of openness depends on three fundamental aspects: (1) the type of license of the OERs; (2) the file and media formats; and (3) the tools and standards used in the construction and provision of OERs.

The degree of openness affects the reusable capability behind OERs. Reusable means OERs can be (re)used in different contexts of learning, allowing them to be recombined and modified by other users, and adapted to meet particular needs.

To be effectively reused, OERs should meet the different users needs, including not only the appropriateness of the content to the learning objectives but also appropriateness to the context in which the users are inserted. Thus, context in OERs is important for their reusability. 
The reuse of OERs in different contexts of learning is intrinsically related to their adaptation and localisation capabilities (AMIEL; OREY; WEST, 2011). However, the problem is to identify "how" and at "what time" this process should occur (WILEY, 2007).

Adaptation may involve a simple change of file or media format, or the translation of OERs into other languages, or even more complex issues such as the adaptation of OERs for different cultures. Consequently, the availability of OERs in different languages tends to facilitate their localisation. In addition, the proper description of OERs through metadata also makes them easier to be found by search mechanisms.

As previously mentioned, one of the factors that affect the (re)use of OERs and contribute to wider adoption of these resources refers to the use of open licensing. OERs licensing options are briefly discussed in Section 2.4.

\subsection{Potential Behind Open Educational Resources}

The creation and adoption of OERs can bring forward many benefits and impact on education such as (JOYCE, 2006; BARANIUK; BURRUS, 2008; MASTERMAN; WILD, 2011; Open Educational Quality Initiative, 2011; ROLFE, 2012; HILTON; WILEY, 2012; HYLÉN et al., 2012):

- Enhance student's learning, encouraging and engaging them for lifelong learning;

- Enhance teacher's skills from developing OERs and adopting different pedagogical approaches, especially learner-centred pedagogy;

- Minimise dependence on commercial textbooks, and consequently cutting costs to produce such materials;

- Improve collaboration among colleagues within institutions, reducing barriers for translating OERs into other languages, improving access for users with special needs, and keeping OERs up-to-date by avoiding lengthy and costly publishing processes;

- Enable open and flexible learning, providing learning opportunities tailored and appropriate to individual needs;

- Increase efficiency and quality of the learning materials, allowing rapid update of the content and the increase of its life cycle;

- Improve cost efficiency (but this depends on educational strategies and policies for the production and delivery of OERs);

- Increase the teachers's productivity (but this depends on the type and granularity of OERs, and on the pedagogical intent behind their use); and, 
- Innovations in pedagogical and institutional practices, although there is still much to be explored.

Besides that, Hylén et al. (2012) highlight other benefits associated to OERs such as: (1) allow educators/teachers to reuse, modify, adapt and combine different and a large variety of learning materials in new ways; (2) improve of intra and inter-institutional cooperation and collaboration; (3) contribute for active and individual/independent learning; (4) make teaching activities more visible to colleagues and to the general public; (5) provide ability to attract and motivate students; and (6) enable teaching activities capable of being referenced by others.

We can infer that the effective adoption of OERs sets a new scenario in which the traditional teacher-centred learning environment opens the way for a more flexible and focused on collaborative and participative learning environment. In this new "educational paradigm", there are still many challenges to overcome. There is a need for a collective engagement involving government, institutions, educators and learners to cooperate and promote the creation and dissemination of OERs (ARIMOTO; BARBOSA, 2013; BARBOSA; ARIMOTO, 2013).

From the point of view of government and institutions, we emphasise the need for:

- Policy incentives and professional recognition for the production of OERs, because they are activities that require time and effort;

- Connectivity strategies, especially in places and institutions with limitations on access to Internet; and,

- Approaches to effectively support the design, creation and delivery of OERs.

Educators in general need to understand the importance of producing and sharing these materials, and rethink pedagogical approaches, enabling a more effective participation and collaboration of learners and instigating their critical thinking. They should also make use of the several learning materials available primarily on the Internet, encouraging their reuse and redistribution to benefit others.

On the other hand, learners play a key role in this process, closely linked to the understanding that learning occurs from the active participation in the construction of knowledge. Learners must be willing to interact with each other and act more effectively and with autonomy, ceasing to be just "information consumers" and going to play the role of "collaborators" in the promotion and production of knowledge. Cultural change allied to new government and institutional policies are essential not only for the creation and use of OERs, but especially for broad access to knowledge, therefore, for the democratisation of education. 


\subsection{Open Licensing for Open Educational Resources}

To preserve the authorship and intellectual property rights, the distribution of any material that characterise an OER occurs through an open license. The licenses applied to learning materials are usually based on licenses applied to FLOSS.

From the perspective of FLOSS, a license comprehends a document in which the holders of the software rights grant permissions for the use of their work. These "permitted uses" allow developers, among other possibilities, to adapt the software for specific needs, as to use it as foundation for the construction of more complex software systems (KON; SABINO, 2009; KON et al., 2011). Currently, there are various FLOSS licenses such as: Berkeley Software Distribution (BSD) license ${ }^{14}$, Massachusetts Institute of Technology License (MIT) ${ }^{15}$ Apache License ${ }^{16}$, GNU General Public License (GPL)/GNU Library or Lesser General Public Licence (LGPL), GNU Free Documentation License (FDL) ${ }^{17}$ and Mozilla Public License (MPL) (MPL) ${ }^{18}$.

In Figure 5 we show a timeline summarising the development and evolution of licenses within the educational scope. The first initiative of license emerged in mid-1998, when David Wiley proposed the term "open content" to refer to all contents available to their users in an open way, creating the Open Content License ${ }^{19}$, and later the Open Publication License ${ }^{20}$ for publishing theses contents (WILEY, 1998). The idea was to encourage debate and provision of open educational contents by the institutions of higher education. Over the years, these licenses were replaced by licenses such as Creative Commons Licenses (Creative Commons, 2013a).

\subsubsection{Open Content License/Open Publication License}

The Open Content License was developed by Willey in July 1988 in order to meet the academic needs, so that people could share their work. It was one of the first attempts to translate the terms of the FLOSS licenses for the context of non-software materials. However, it contemplates a larger variety of content, and the term "content" is not well-defined, allowing the license to be applied to any medium (LIANG, 2004).

The Open Content License follows the premise of the GNU GPL and is based on three degrees of freedom: (1) the user has the right to make copies of the content; (2) the user has the right to distribute the content; and (3) the user has the right to make changes in the content. It is not compatible with any other license as it requires derivative works be licensed under the same terms of the license.

The Open Publication License was developed by Willey in June 1999, replacing the Open Content License. It allows licensed works to be repurposed and redistributed in part or

\footnotetext{
opensource.org/licenses/BSD [last accessed on 01-2016]

15 opensource.org/licenses/MIT [last accessed on 01-2016]

16 apache.org/licenses [last accessed on 01-2016]

17 gnu.org/licenses [last accessed on 01-2016]

18 mozilla.org/MPL [last accessed on 01-2016]

19 opencontent.org [last accessed on 01-2016]

20 opencontent.org/openpub [last accessed on 01-2016]
} 
in their entirety in physical or electronic means, but the terms of the license must be included and the license or part of it must be present in the repurpose. In any means of publication, the original authors and publishers must be referenced.

Figure 5 - Open licensing timeline.

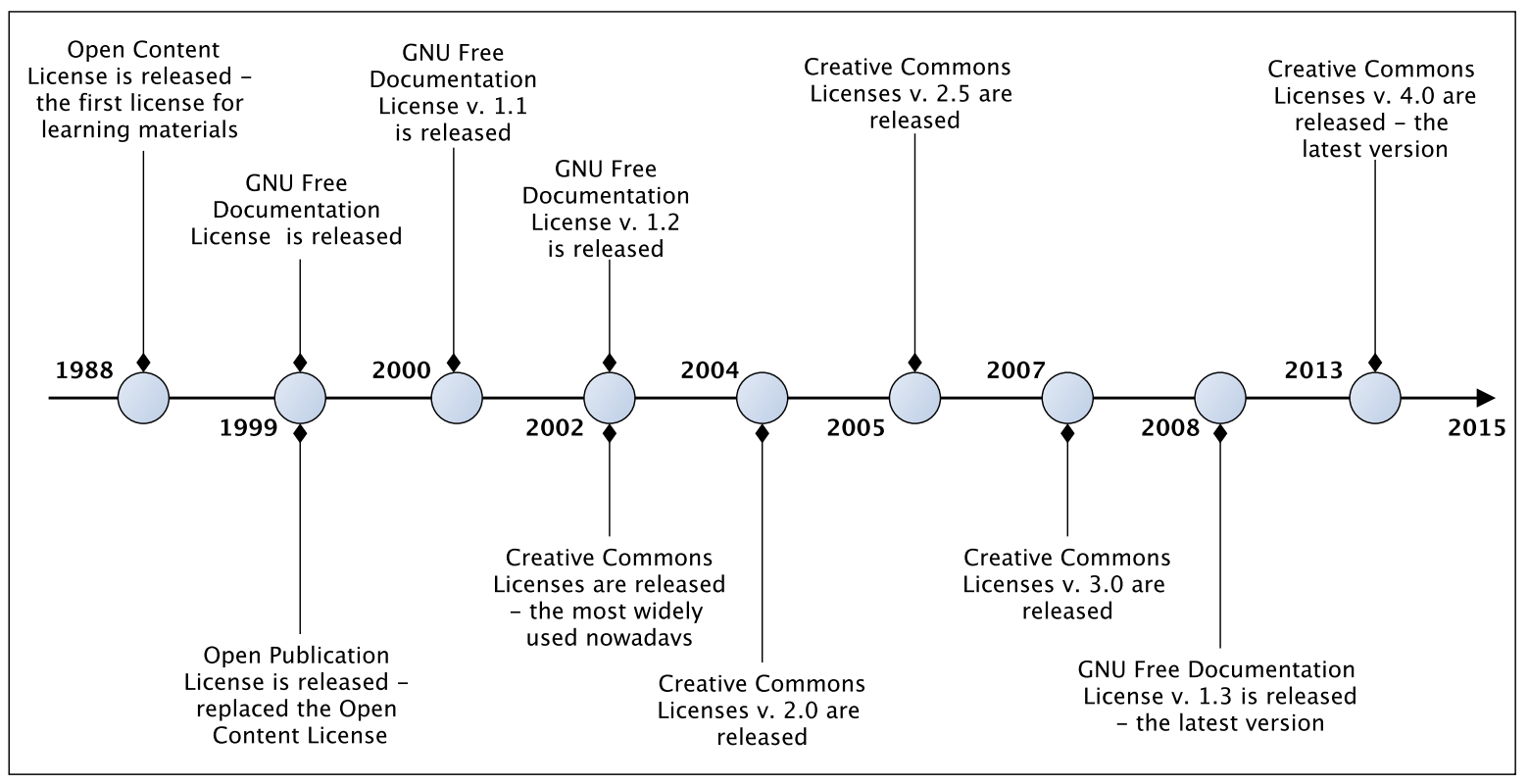

Source: Elaborated by the author.

Liang (2004) argues that one of the problems of the Open Publication License is the possibility of imposing type of restrictions that affect its philosophy, turning it into a non-open license. This is possible through the Section VI - Licenses Options ${ }^{21}$, in which a licensor can add new clauses that presuppose the possibility of major changes without proper permission from the licensor.

In addition, the Open Publication License should not be considered a "free-documentation" license because it is not in accordance with the "copyleft" model (Free Software Foundation, 2012), unless the rights holder does not exert any of the options licenses specified in Section VI. Copyleft specifies that anyone who distributes a resource, with or without modifications, must pass along the freedom to copy and modify the resource again (Free Software Foundation, 2012).

\subsubsection{GNU Free Documentation License}

The GNU Free Documentation License (GNU FDL) was developed from 1999 by the Free Software Foundation (Free Software Foundation, 2012) for free documentation, as a complement to the GNU GPL. It emerged to assist software developers writing manuals and documenting their work under the the copyleft model (HOFMAN; WEST, 2008). It can

21 opencontent.org [last accessed on 01-2016] 
also be used with other documents and materials; thereby, it may cause confusion and is not recommended for non-technical work (LIANG, 2004).

Similar to the GNU GPL, the GNU FDL allows users to make copy, redistribute, and modify a work; also requires copies and derivative works be shared under the same terms of the license.

The first revised version of the GNU FDL (FDL v.1.1) appeared in March 2000 (as shown in Figure 5), and the second one in November 2002 (FDL v.1.2), whilst the current version of the GNU FDL appeared in November 2008.

\subsubsection{Creative Commons Licenses}

Creative Commons Licenses (Creative Commons, 2013a) are one of the major initiatives in the educational field and also the most used nowadays, having great acceptance by content providers. Such licenses were launched in December 2002, by the Creative Commons, a nonprofit organisation concerned to the sharing of creative works through free legal tools (Creative Commons, 2013b). The Creative Commons Licenses follow the precepts of the FLOSS licenses, and are based on the principle that it is necessary to create and make available a large amount of information and content to ensure the creativity on a sustained basis (LIANG, 2004), having fewer restrictions than the traditional "all rights reserved". The latest version of the Creative Commons Licenses (referred to as "4.0 international licenses") was lunched in December 2013 with significant improvement to ensure that the licenses operate well internationally 22.

Creative Commons provides a suite of six licenses which differ in certain aspects, but have a set of basic rights (baseline rights). The baseline rights guarantee to the licensor rights of authorship and obtaining credits for its work. On the other hand, the baseline rights ensure to user rights to use and distribute, as well as allow changes since the full work is maintained (HOFMAN; WEST, 2008).

The suite of Creative Commons Licenses is described as follows (Creative Commons, 2013a):

1. Attribution Non-Commercial No Derivatives (BY-NC-ND): this license allows the use and distribution of the work only for non-commercial purposes, but the authorship credits for the original creation must be maintained. The work can not be modified in any way.

2. Attribution Non-Commercial Share Alike (BY-NC-SA): this license allows the use, adaptation, remix and redistribution of the work only for non-commercial purposes, but the authorship credits for the original creation must be maintained. Derivative works must be licensed under the terms of this license.

3. Attribution Non-Commercial (BY-NC): this license allows the use, adaptation, remix and redistribution of the work only for non-commercial purposes, but the authorship credits 
for the original creation must be maintained. Derivative works do not need to be licensed under the terms of this license.

4. Attribution No Derivatives (BY-ND): this license allows the use and redistribution of the work, but the authorship credits for the original creation must be maintained. The work must be redistributed without modifications and in fully.

5. Attribution Share Alike (BY-SA): this license allows the use, adaptation, remix and redistribution for commercial and non-commercial purposes, but the authorship credits for the original creation must be maintained. Derivative works must be licensed under the terms of this license. This type of license is often compared to FLOSS licenses.

6. Attribution (BY): this license allows the use, adaptation, remix and redistribution of the work, but the authorship credits for the original creation must be maintained. This type of license is similar to BSD and MIT licenses.

In Table 1 we summarise the permissions and restrictions of each Creative Commons license. Whilst the BY license is the less restrictive, the BY-NC-ND license is the most restrictive, neither allowing commercial use and distribution of the work nor remix and adaptation.

Table 1 - Creative Commons licenses.

\begin{tabular}{|c|c|c|c|c|c|c|c|}
\hline License & Use & Adapt & Remix & Redistribute & Commercial & $\begin{array}{l}\text { Non- } \\
\text { Commercial }\end{array}$ & $\begin{array}{l}\text { Share } \\
\text { Alike }\end{array}$ \\
\hline (c) (i) \&) $(9$ & $\checkmark$ & $x$ & $x$ & $\checkmark$ & $x$ & $\checkmark$ & $x$ \\
\hline (c) (i) () (2) & $\checkmark$ & $\checkmark$ & $\checkmark$ & $\checkmark$ & $x$ & $\checkmark$ & $\checkmark$ \\
\hline (c) (i) (\$) & $\checkmark$ & $\checkmark$ & $\checkmark$ & $\checkmark$ & $x$ & $\checkmark$ & $x$ \\
\hline (c) (i) $\Theta$ & $\checkmark$ & $x$ & $x$ & $\checkmark$ & $\checkmark$ & $\checkmark$ & $x$ \\
\hline (c) (i) (2) & $\checkmark$ & $\checkmark$ & $\checkmark$ & $\checkmark$ & $\checkmark$ & $\checkmark$ & $\checkmark$ \\
\hline (c) & $\checkmark$ & $\checkmark$ & $\checkmark$ & $\checkmark$ & $\checkmark$ & $\checkmark$ & $x$ \\
\hline
\end{tabular}

Source: Elaborated by the author.

In synthesis, the aforementioned licenses determine a series of freedoms overlapping copyright laws, also allowing freedoms that surpass the traditional fair use in such manner which users do not need to hire a solicitor to use the works under these licenses because they provide a plausible set of copyright law (LESSIG, 2005). 


\subsection{Open Educational Resources Sharing Initiatives Worldwide}

Many initiatives involving the development and sharing of OERs are derived from regular proprietary courses materials used on classroom teaching. Examples of these are institution-based initiatives such as OpenCourseWare programmes shared by several universities. Also, many OERs are created individually by educators reusing educational materials available on the Internet and suiting them to their particular needs. Following, we briefly describe some of the most renowned OERs sharing initiatives.

\subsubsection{MIT OpenCourseWare}

One of the most widespread initiatives which has contributed to the creation and dissemination of OERs is the MIT OpenCourseWare, launched by Massachusetts Institute of Technology (MIT) in 2002, and supported by the William and Flora Hewlett Foundation and the Andrew W. Mellon Foundation (Massachusetts Institute Technology, 2002). The OpenCourseWare initiative aims to provide courses and digital materials used by the institution in the undergraduate and graduate levels, freely and openly access for researchers and students within the institutions and others.

OpenCourseWare is inserted into the OERs movement (CASWELL et al., 2008), allowing distance education support equal access to education. OpenCourseWare is a free and open publication of digital materials organised as courses (OpenCourseWare Consortium, 2012). These courses may include lecture notes, videos, reviews, reading, or any other materials used for courses at universities and organisations around the world. Courses are made available to users under the license Attribution Non-Commercial Share Alike - BY-NC-SA (Creative Commons License) (Creative Commons, 2013a).

In Figure 6 we show a homepage of a course provided by the MIT OpenCourseWare called "Computer Algorithms in Systems Engineering". This course is offered at the undergraduate level and is organised into: (1) syllabus including course meeting times, course description, prerequisites, among others; (2) calendar with topics of the course and key dates; (3) recommended readings; (4) lecture notes; (5) assignments; (6) exams; and (7) support tools for the course. Users can also download all the materials available in the course.

Since 2005, the MIT OpenCourseWare together with other institutions of higher education and organisations, became part of the OpenCourseWare Consortium (CARSON; FORWARD, 2010; OpenCourseWare Consortium, 2012). The idea was to extend the reach and impact of open courses materials in global education to promote the creation of new materials and encourage the creation of sustainable models to publish these materials. Currently, the OpenCourseWare Consortium comprises a community of collaborators and consultants with more than 250 universities and associated organisations worldwide such as UK Open 
University $^{23}$, UC Berkeley ${ }^{24}$, Connexions ${ }^{25}$ and Multimedia Educational Resource for Learning and Online Teaching (MERLOT) ${ }^{26}$, among others.

\subsubsection{UK OpenLearn}

The UK Open University proposed an OER initiative named OpenLearn in mid-2006 supported by the William and Flora Foundation. The OpenLearn initiative aims to provide free university content at the undergraduate and graduate levels (MCANDREW et al., 2008).

The UK Open University is one of the precursors in the distance learning modality, founded in 1969, in order to facilitate access to education, especially those who did not have the opportunity to join a course in traditional higher education (MCANDREW et al., 2008; GIMENES; BARROCA; FELTRIM, 2012). The university provides a large catalogue of educational material in different formats. Through the OpenLearn platform, some of these materials are freely available on the Internet under the license Attribution Non-Commercial Share Alike - BY-NC-SA (Creative Commons License).

Figure 6 - Course on Computer Algorithms in System Engineering

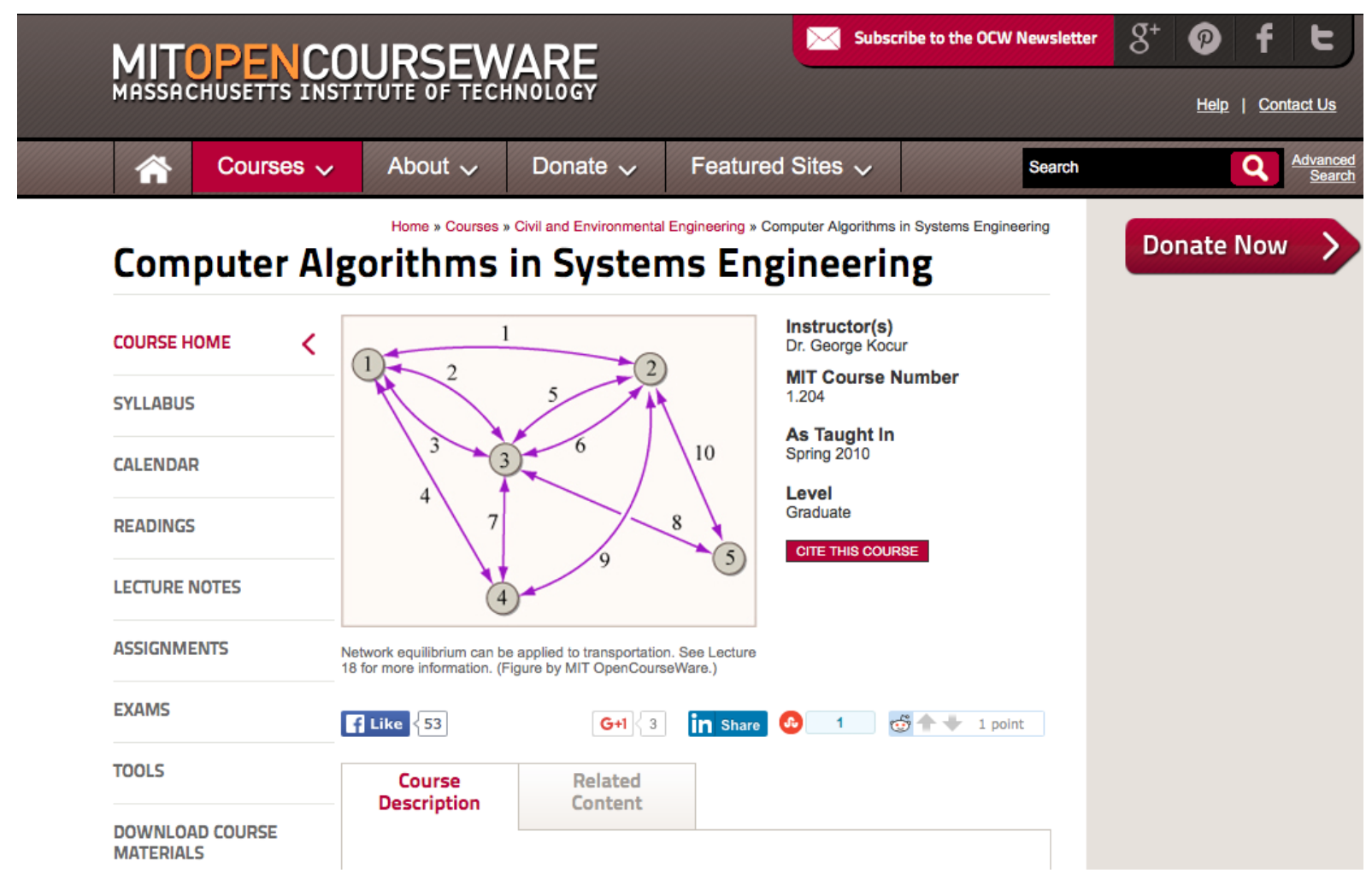

Source: Massachusetts Institute Technology (2002).

open.ac.uk [last accessed on 02-2016]

berkeley.edu [last accessed on 02-2016]

cnx.org [last accessed on 02-2016]

merlot.org [last accessed on 02-2016] 
The OpenLearn platform includes two main components to help in learning and reuse of materials available: (1) the LearningSpace, a learning environment, and (2) the LabSpace, a monitoring environment of the educators/teachers. By accessing the LearningSpace ${ }^{27}$ students $^{2}$ have free access to various materials used in the Open UK University. In the LabSpace ${ }^{28}$ students can download, edit and publish new versions of the materials to share with others.

\subsubsection{Open Learning Initiative}

The Open Learning Initiative, released in 2002, was created by the Carnegie Mellon University (STRADER; THILLE, 2012) and supported by the William and Flora Foundation. It consists of a learning platform composed by intelligent tutoring systems, virtual labs, simulations and frequent opportunity of appraisal and feedback to produce dynamic and flexible courses. These courses are under the license Attribution Non-Commercial Share Alike - BY-NC-SA (Creative Commons License).

The Open Learning Initiative differs in some aspects from most of learning platforms or the OpenCourseWare initiatives (THILLE, 2010; STRADER; THILLE, 2012), especially as regards the delivery of learning materials in parallel with the use of technology to collect, in real time, the level of data interaction on how students are learning. These data are used to drive cycles of positive feedback to students, teachers, course designers, institutions and researchers in learning science (a combination of disciplines including cognitive psychology, computer science, human-computer interaction and machine learning).

Students receive feedback on corrections, suggestions and tips, adapted according to the current context and the individual's performance, allowing the review and refinement of the material. The platform provides support in specific context during problem-solving, unlikely the traditional approach of computer-based learning, in which the feedback refers to the final student answers. Teachers receive feedback keeping them in line with various aspects of student learning such as knowledge, essential competencies and future goals. The designers of courses benefit from the usage data and student learning. These are frequently analysed to assess the impact of usage patterns of students learning outcomes, also allowing the proper refinement of the material. Finally, the institutions and researchers of learning science receive feedback that contribute to the generation of new knowledge about human learning, allowing this knowledge be translated into new learning materials (THILLE, 2010; VLĂDOIU, 2011).

\subsubsection{ConneXions}

ConneXions platform, created in 1999 by the Rice University, is a dynamic ecosystem of education consisting of a repository of learning materials organised into modules, and an optimised management system for the delivery of these materials. The ConneXions platform

27 openlearn.open.ac.uk [last accessed on 01-2016]

28 labspace.open.ac.uk [last accessed on 01-2016] 
provides open source tools to support the creation, maintenance, and organisation of the learning materials (BURRUS, 2010; GIMENES; BARROCA; FELTRIM, 2012).

According to (BURRUS et al., 2004), the information is usually transmitted linearly, but learning occurs, in general, through "connexions" between new concepts and things already known. In the ConneXions platform, the content is modular to facilitate the updating and adaptation of the content. The modules can compose a collection of modules structured into textbooks, courses, as well as entire curricula. ConneXions adopts the less restrictive license of the initiatives presented here. The materials can be used and reused freely and openly by others by the license Attribution - BY (Creative Common License).

ConneXions platform also provides an open source tool named Rhaptos (Rhaptos Software, 2013) to assist in providing any kind of learning materials, from traditional textbooks to materials based on interactive multimedia games.

In 2009, the ConneXions Consortium was created to allow the participation of institutions interested in the development and expansion of the platform. Currently, the international consortium is composed by more than 20 members from different countries, including public and private institutions and governmental entities and organisations.

\subsection{Open Educational Resources Sharing Initiatives in Brazil}

In the Brazilian scenario, initiatives for the creation and provision of OERs are still limited. Most initiatives were not created with a specific focus on OERs, or with the purpose of being available through open licenses as Creative Commons or similar (SANTOS, 2013). Examples of these initiatives are summarised next.

\subsubsection{Rede Interativa de Educação - RIVED}

Rede Interativa de Educação (RIVED) (Interactive Education Network) ${ }^{29}$ consists of a program focused on the production and delivery of LOs. The program arose from an agreement between Brazil and United States in 1997 on the development of technology for educational purposes. The participation of Brazil began in early 1999 through a partnership between Department of Secondary Education and Technology and Department of Distance Education.

Initially, the production of LOs was restricted to areas of Biology, Chemistry, Physics and Mathematics for Secondary Education. From the expansion of the program in 2004 to universities, the creation of LOs was also planned for others areas of knowledge and for elementary education and professional learning.

$29 \quad$ rived.mec.gov.br [last accessed on 02-2016] 
The LOs available on RIVED are not associated with any specific open license, although there is an express permission for their free use.

\subsubsection{Banco Internacional de Objetos Educacionais - BIOE}

Banco Internacional de Objetos Educacionais (BIOE) (International Database of Educational Objects) ${ }^{30}$ consists of a web portal for maintenance and sharing of digital learning materials created by the Ministry of Education of Brazil in 2008, with the cooperation of the Ministério da Ciência, Tecnologia e Inovação (Brazilian Ministry of Science, Technology and Innovation $)^{31}$, the Latin-American Network of Educational Portals ${ }^{32}$, the Organization of Ibero-American Countries ${ }^{33}$, among others.

The BIOE web portal was designed to maintain digital learning materials in different formats and languages. In this sense, many teachers can access the materials in their native language and adapt to their needs with some restrictions (SANTOS, 2013). These materials are available for public access, allowing their reuse, redistribution and translation to other languages only for educational purposes. The users must indicate the original authorship. The Ministério da Ciência, Tecnologia e Inovação (Brazilian Ministry of Science, Technology and Innovation) detains most of authorship rights under the available materials. However, there are also materials available without any information about the authorship rights and license of use.

\subsubsection{Acesso Aberto and Brasiliana USP}

Acesso Aberto (Open Access) ${ }^{34}$ and Brasiliana $U S P^{35}$ are both initiatives from the University of São Paulo (USP). Acesso Aberto (Open Access) is a repository/website that provides open access to technical-scientific, artistic and didactic production in higher education. The aim is to encourage the open sharing of works across and outside the university in order to increase their visibility. The materials provided by the Acesso Aberto repository follow the license Attribution Non-Commercial - BY-NC (Creative Commons License).

Brasiliana is a digital library that holds a historical bibliographic and documentary archive covering Brazilian issues. It provides to students, researchers and general public an expressive set of textbooks and manuscripts, with around 17,000 titles or 40,000 volumes. The aim is to promote the dissemination of Brazilian issues studies through specific programs and projects. The whole archive is in the public domain, but the commercial use is not allowed.

30 objetoseducacionais2.mec.gov.br [last accessed on 02-2016]

31 mct.gov.br [last accessed on 02-2016]

32 ambiente.educacao.ba.gov.br [last accessed on 02-2016]

33 direitos humanos.usp.br [last accessed on 02-2016]

34 acessoaberto.usp.br [last accessed on 02-2016]

35 brasiliana.usp.br [last accessed on 02-2016] 


\subsubsection{UNICAMP OpenCourseWare}

UNICAMP OpenCourseWare ${ }^{36}$ consists of a web portal launched in 2011 by the State University of Campinas (UNICAMP) inspired in the OpenCourseWare Consortium. Such web portal aims to maintain some learning materials in a digital format, particularly, PDF format.

The digital materials published in the website for free and public access are derived from the learning materials used by the institution in higher education. The learning materials available are licensed through the licenses adopted by OpenCourseWare initiatives, i.e., Attribution Non-Commercial Share Alike - BY-NC-SA (Creative Commons License).

Other public and private initiatives to publish learning materials can be found such as Portal Domínio Público (Public Domain Portal) ${ }^{37}$, Portal do Professor (Teacher Portal) ${ }^{38}$, Projeto Folhas ${ }^{39}$, Rede Interativa Virtual de Educação - Bibvirt-LabVirt (Interactive Network Virtual of Education) $)^{40}$, Fundação Getúlio Vargas (Getúlio Vargas Foundaton) ${ }^{41}$, LUME Digital Repository - Federal University of Rio Grande do Sul ${ }^{42}$, among others.

\subsection{Development of Open Educational Resources: Pedagogical Issues}

One of the difficulties faced by educators and practitioners is to understand the implicit design behind OERs to know how to reuse them in the teaching contexts (DIMITRIADIS et al., 2009). Making the design more explicit helps to capture the key aspects of the design, as well as to demonstrate the learning goals, activities and outcomes associated with the learning material, therefore supporting both teachers and learners (LOCKYER et al., 2008).

Learning Design has emerged over the last decade, primarily in Europe and Australia (KOPER, 2006), aiming at helping in the definition and creation of a more effective pedagogical design of learning materials (DIMITRIADIS et al., 2009; CONOLE, 2010; CONOLE, 2013) such as OERs.

Learning Design is closely aligned to Instructional Design but with a different focus. Instructional Design focuses on designing the instructions to meet learning needs for a specific audience and setting (REIGELUTH, 1983; CONOLE, 2010). Learning Design, in turn, takes a much broader perspective and regards design as a dynamic process, which is ongoing and inclusive, considering all stakeholders involved in the teaching and learning (CONOLE, 2010).

Instructional Design has a long trajectory as an approach for designing learning instructions in a systematic way. "It is the process of deciding which methods of instruction

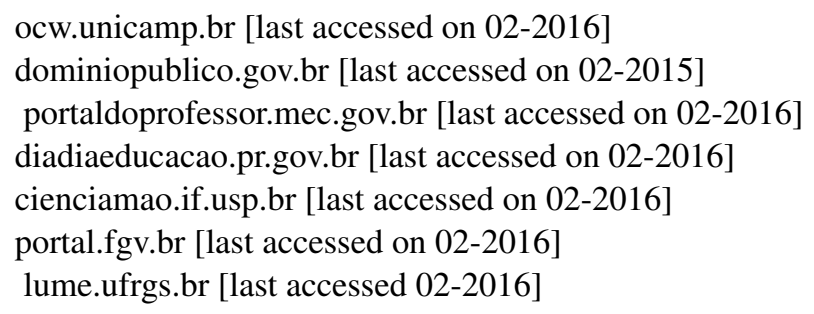


are best for bringing about desired changes in student knowledge and skills for a specific course content and specific student population" (CONOLE, 2010). It consists of a systematic application of scientific principles about "how people learn" to develop instruction (CONOLE, 2010; MOLENDA, 2003). The term "instructional" means anything that is done purposely to help and facilitate learning (REIGELUTH; CARR-CHELLMAN, 2009).

Learning Design can be seen as a set of activities to assist in understating and describing pedagogical design practices. The key points of Learning Design are (CROSS; CONOLE, 2009):

- To make the structures of intended teaching and learning visible and explicit to facilitate their understanding; and

- To serve as a description or template to be reused by others according to their own context.

"Designing for learning" (BEETHAM; SHARPE, 2007) is another term used as a meaning for Learning Design. The authors define it as the process which educators and practitioners use to create a plan or structure for learning situations. The term "educational design" (GOODYEAR; YANG, 2008) is also used in this context, being defined as a set of activities or practices to support the learning representation in particular cases or circumstances.

Learning Design can be used at different levels of granularity. It can be used to represent a learning activity, the sequencing and linking of activities and contents, a course or even a whole curriculum (CONOLE, 2013).

There are some benefits when adopting a Learning Design approach (CONOLE, 2013): (1) the design of materials provides a "common vocabulary and understanding of learning activities"; (2) the design can be reused in the same way as occurs with the contents; (3) the design can guide educators through the process of creating learning interventions; (4) the design can help learners in complex activities by guiding them through the activity sequence, among others.

In this P.h.D. thesis we adopt the term "Learning Design", the most well-known and widely used by the community.

\subsubsection{Open University Learning Design Initiative}

The Open University Learning Design Initiative (OULDI) project proposed by the UK Open University was initiated in 2007 to derive a more "practice-focused approach for Learning Design" (CROSS et al., 2012). The OULDI was funded by Joint Information Systems Committee UK (JISC) ${ }^{43}$, a public body that supports and champions the use of digital technologies in education and research across the UK.

OULDI project comprises a method, tools and a notation to represent Learning Design, including (BRASHER et al., 2012; CONOLE, 2013):

- Different types of design representations to help guide design decision-making process;

43 jisc.ac.uk [last accessed on 02-2016] 
- Digital tools to help visualise and represent designs; and,

- Mechanisms to encourage the sharing and discussion of learning teaching ideas, including face-to-face events such as workshops and the use of digital tools to foster communication and sharing.

Design representations in the OULDI consider five levels (CONOLE et al., 2009; BRASHER et al., 2012): Macro-level, Meso-level, Pedagogical Profile, Course Dimension and Micro-level. The Macro-level (the course map view) provides an overview of main components of the course and enable educators and practitioners to think about the design of a course using four dimensions: (1) content and experience, including information on the course materials and activities; (2) guide and support, including information on the course structure and timetable; (3) communication and collaboration, including dialogic elements of the course; and (4) reflection and demonstration, including assessment activities of the course. These dimensions synthesise the learning activities of students throughout the course.

Meso-level (the learning outcomes view) provides a notational vision based on Bigg's works on Constructive Alignment (BIGGS, 1999), showing how learning activities and assessment tasks are linked with intended learning outcomes of the course.

Pedagogy Profile articulates types of activities in which learners participate during the course or sequence of learning events. Types of activities are categorised as assimilative, information handling, communication, productive, experimental, adaptive and evaluation. They were derived from a learning activity taxonomy (CONOLE, 2008).

Course Dimensions provides more information on the nature of the course and how it is supported. It can be seen as a refinement of the Macro-level (course map view).

Micro-level (the tasks swimlane view) describes the levels of learning activities, mapping tasks that the learners undertake to the learning materials and resources/tools they use during the activities in the course.

As highlighted by Avraamidou e Economou (2012), the levels of the OULDI aforementioned ( 1 up to 5) cannot be seen as separate parts. Learning Design often requires refinement and improvement. This implies that the design process should allow moving back and forwards through the levels according to the needs. Although the OULDI approach intends to make the design more explicit, it does not specify the steps and guidelines for a Learning Design process.

There are other initiatives using Learning Design. Learning Activities Management Systems (LAMS) (DALZIEL, 2009; DALZIEL, 2011) is a platform that offers automated support for Learning Design. This platform is used to design learning activity sequences, describing the whole teaching process including learning contents, learning activities, and assessment. The Learning Design Support Environment (LDSE) (LAURILLARD et al., 2011) and the CADMOS learning design tool (KATSAMANI; RETALIS, 2013) are other initiatives in this direction. They 
have in common more self-contained and complex environments than the OULDI, which difficult the use of these platforms and tools.

The demand for the development of learning materials as OERs within the expected cost and schedule, together with the lack of time (SCHUWER et al., 2010) to produce these materials also highlight the need for more agility in the development process.

In the context of Learning Design, there is a lack of initiatives that explore the use of agile methods; this is not the case with Instructional Design. Bahl (2012) proposed an approach for Instructional Design based on a ADDIE (Analysis, Development, Design, Implementation, Evaluation) model $^{44}$ (STRICKLAND, 2006) and Scrum. The approach proposed by Bahl defines a linear and iterative cycle distributed into five phases:

1. Initiation and planning: planning of the overall project, including project definition, pedagogical needs, objectives, stakeholder's identification and high level budget and timelines.

2. High level analysis: understanding of functionalities needs to prepare a high level project plan.

3. Iterative design \& development: implementation of functionalities by iterative cycles. At the end of each cycle, functionalities are reviewed by experts.

4. Feature integration: integration of functionalities implemented throughout the cycles. New revisions should be conducted.

5. Solution roll out: preparation of the solution implemented for its use, culminating with the closure of the project.

Willeke (2011) discusses the use of Scrum and Instructional Design in an online educational course at Ohio Christian University ${ }^{45}$ with the following quantitative improvements:

- Satisfaction: the team provided positive feedback on the process based on Scrum, contributing for developing a better quality course.

- Time saving: the time invested in weeks reduced over $30 \%$, and the time for total development dropped $40 \%$.

- Internal communication: the interaction and communication within the team involved in the process increased, allowing problems to be solved quicker.

Despite the success in the creation of online course, Willeke (2011) mentions the needs of a cultural change for the adoption of an agile approach in the educational environment.

\footnotetext{
$44 \quad$ ADDIE is generic model for Instructional Design used for the development of instructional materials and training (MORRISON et al., 2010).

45 ohiochristian.edu [accessed 02-2016]
} 
Both initiatives aforementioned fall short of the application of some agile practices such as the active participation of users (e.g., educators and learners), throughout the development.

\subsection{Concluding Remarks}

In this chapter we presented the essential background for this $\mathrm{PhD}$ research. We introduced OERs going through the motivation behind the "birth" of OERs movement up to the current scenario. Particularly, we found different definitions, resources and characteristics related to OERs. Within this context, we discussed important issues related to open licensing that facilitate sharing and preserve the authorship and intellectual property rights on learning materials.

Regarding the OER initiatives worldwide, very little is known about the development activities and the producers and users involved. The production process is, in most cases, unknown as well (HYLÉN, 2006; Organisation for Economic Co-operation and Development, 2007; SCHUWER et al., 2010). In the Brazilian scenario this problem is even more evident. Besides the several problems in relation to the licensing policies of the educational materials (ROSSINI, 2010; SANTOS, 2013), and the lack of institutional and governmental policies to encourage the production and sharing of OERs, most of the existing initiatives do not provide information about how educational materials are designed and developed.

The chapter offers a contribution regarding the concept and definition of OERs, helping to get a better understanding on the subject. We identified essential characteristics that need to be considered during the development and sharing of OERs in order to increase their adoption and impact on education.

In the next chapter we discuss about the agile software development. We describe two agile methods: Scrum and eXtreme Programming (XP). The aim is to investigate the main characteristics and practices of both agile methods, helping to identify how they can be adapted to the context of OERs development. 



\section{AGILE METHODS}

I plan-driven software development, analysts and software developers can only move to the design and implementation phases after an exhaustive elicitation and specification of the software requirements (BARESI; NITTO; GHEZZI, 2006). Several researchers and experienced software developers have sought alternatives which could support a more flexible development process, focusing on cost and product quality and consequently in the project efficiency. Agile methods have emerged in this context as an alternative to plan-driven development methods, proposing flexible approaches that suit to the constant changes in software projects and business environment. Whilst agile methods are focused on people and prioritise a fast delivery of the system and an effective collaboration of those involved, plan-driven methods are focused on processes and prioritise a more formal and detailed documentation (HIGHSMITH; COCKBURN, 2001; LYCETT et al., 2003).

In this chapter we discuss on the agile methods for software development, focusing on the values and principles that underpin the agile philosophy. We also aim to identify the main characteristics, similarities and differences between agile methods, particularly Scrum and XP. The chapter is organised as follows. In Section 3.1 we highlight issues that guided the emergence of agile methods and contributed to their popularisation. In Section 3.2 we focus on Scrum, its philosophy and practices for software and non-software projects. In Section 3.3 we describe the XP method, its values, principles and practices for software development. In Section 3.4 we summarise a comparative analysis of the agile methods considered in this chapter. Concluding remarks are presented in Section 3.5.

\subsection{The Emergence of Agile Methods}

Plan-driven development methods are based on "waterfall" model wherein the work starts from a complete and detailed definition and documentation of the software requirements, followed by a complete software architecture and design (LINDVALL et al., 2002). An 
operational version of the software is visible and delivered to the customer only at the end of the development project, when the software is deployed in the production environment.

The waterfall model (ROYCE, 1970), the most well-known plan-driven method, is characterised as a linear-sequential model in which the software development occurs linearly through a sequence of phases (requirement, design, coding, testing and deployment/maintenance). Each phase must be completed before another starts, and the result of the previous phase is used as the basis for executing the next phase.

The ability to respond to changes throughout the development process often determines the success or failure of a software product (WILLIAMS; COCKBURN, 2003). A main criticism of plan-driven development methods is the lack of facilities to adapt to changes in software requirements and to the new demands from users (ABRAHAMSSON; SALO, 2004).

Over the years, other development methods were proposed, such as the incremental (PRESSMAN, 2011) and the spiral methods (BOEHM, 1988), with the idea of promoting the iterative and incremental development. Agile methods emerged in this context, as a reaction to the consequences of the plan-driven development methods and to the increasing changes in the business environment (ABRAHAMSSON et al., 2002; HIGHSMITH; COCKBURN, 2001; HIGHSMITH, 2002; PAULK, 2002; LARMAN, 2003; COHEN; LINDVALL; COSTA, 2004; DYBAं; JØRGENSEN, 2008). They follow the iterative and incremental characteristic, wherein the software gradually growing in repetitive iterations, encompassing more elements to each iteration (TELES, 2004).

In software development there are a lot of details that need to be considered. Usually, at the moment when the customer specifies the system only some aspects of the software are known. Many other aspects become clear only when the customer has the opportunity to use the system. Therefore, these details cannot be specified at the beginning of the project as they are not yet known about (BECK; ANDRES, 2004).

Agile methods are based on the premise that the customer learns throughout the development (TELES, 2004). The customer understands the technical difficulties, visualises new perspectives of features, and requests changes in the system to meet some particular needs. This apprenticeship arises from feedback that the system provides to the customer whilst it is being developed.

The popularisation of agile methods started from 2001 with the Agile Manifesto for Software Development (Agile Manifesto, 2001), when a group of researchers and experienced developers gathered in order to improve the performance of the projects and the quality of the software products. The manifesto was also important to establish the differences compared to plan-driven development methods (BECK; ANDRES, 2004). Essential values and principles of an agile approach were specified, with the values defined as follows:

1. Individuals and interactions are more important than process and tools.

2. Working software is more important than comprehensive documentation. 
3. Customer collaboration is more important than contract negotiation.

4. Adapt to change is more important than follow a plan.

Although the items on the right (italicised text) are important for software development, agile methods value more the items highlighted on the left (bolded text).

The set of principles established in the Agile Manifesto complement the values, helping to spread the philosophy of the agile development. Twelve principles were established:

1. The highest priority is the customer satisfaction, through rapid and continuous delivery of valuable software.

2. Changes in requirements are welcome, regardless the stage of development. Agile processes are flexible to changes in order to provide competitive advantages to the customer.

3. Working software is often delivered, in weeks or even months, preferably at shorter intervals.

4. Business people and developers must work together throughout the project.

5. Projects need to be build by motivated individuals. Environment and necessary support as well as confidence in the work of the individuals are fundamental.

6. The most efficiency and effective way to transmit information within and outside the development team is through face-to-face communication.

7. Working software is the main measure of progress.

8. Agile processes promote the development in sustainable pace. The sponsors, developers and users should be able to maintain a constant pace.

9. Ongoing concern to technical excellence and good design enhances agility.

10. The art of maximising the amount of unnecessary work (simplicity) is fundamental.

11. The best requirements, architectures and designs emerge from self-organising team.

12. At regular intervals, the team reflects on how to become more effective, refining and improving their behaviour accordingly.

Among the main agile methods we can highlight: Scrum (SCHWABER; BEEDLE, 2002; SCHWABER; SUTHERLAND, 2010); eXtreme Programming (XP) (BECK; FOWLER, 2000; BECK; ANDRES, 2004); Adaptive Software Development (ASD) (HIGHSMITH, 2002); Feature Driven Development (FDD) (PALMER; FELSING, 2002); Crystal Family 
(COCKBURN, 2004; COCKBURN, 2006); and Lean Development (LD) (LARMAN; VODDE, 2010; POPPENDIECK; POPPENDIECK, 2003; POPPENDIECK; POPPENDIECK, 2006; POPPENDIECK; POPPENDIECK, 2009).

Over the past decade, the adoption of agile methods by organisations worldwide has increased. The software industry has adopted agile methods in order to improve productivity and competitiveness. Empirical findings on the applicability and effectiveness of agile methods can be found in the literature. According to the CHAOS report from the Standish Group (2011), projects using agile methods are three times more successful than plan-driven development methods, besides having a much lower percentage of time and cost overruns. The CHAOS report database considered projects conducted from 2002 through 2010.

An exploratory study was conducted on the usage and perception of agile methods within the Microsoft Corporation (BEETHAM; SHARPE, 2007). The authors applied a survey with employees directly involved with the software development, including analysts, designers, developers and managers. Approximately 500 people participated in the survey. At Microsoft, the adoption of agile methods was still in the beginning; many projects adopted agile for less than two years. One-third of the respondents use agile methods; Scrum is the most popular, used by $65 \%$ of the respondents. The main benefits reported include: (1) improved communication and coordination; (2) quick releases; (3) flexibility, quicker response to changes, (4) more reasonable process; and (5) increased software product quality. On the other hand, the concern of the respondents was whether agile methods scale to larger projects.

Melo et al. (2012) investigated the adoption and adaptation of agile methods in the Brazilian companies. The research involved 466 participants who answered an online questionnaire. The results indicate that most of the respondents use Scrum $(51,1 \%)$ followed by a "mix" between Scrum and XP (Scrum/XP Hybrid). Most Brazilian companies (60.7\%) adopt agile methods in more than half of their projects. The main benefits reported were: (1) increased team productivity (76\%); (2) increased software product quality (75\%); improvement of the team confidence (75\%); and (3) simplification of the development process (75\%). Considering the project velocity, $67 \%$ of the respondents indicated that agile projects finish faster than traditional development methods. In relation to the main causes of failure on the adoption of agile methods respondents indicated: (1) the lack of experience with agile methods (16.3\%); (2) the company philosophy/culture goes against the agile philosophy (12.4\%); and (3) the external pressure to follow traditional development cycle $(10.4 \%)$.

A research within the SAP AG was conducted in order to perceive the impact of agile engineering practices from the developer and the product owner perspective (SCHMIDT; VENKATESHA; HEYMANN, 2014). The SAP AG is a large global organisation operating in more than 130 countries. Since 2008 the SAP AG introduced a training program on agile practices. Over the last three years, the company has trained about 4,000 of its developers. The results from SAP AG indicate that agile practices effectively contributed to the quality of the software product and to the efficiency of the development team. 
The worldwide survey conducted by the VersionOne (2015) indicates that agile methods are more and more adopted by people and scaled through their organisations. $94 \%$ of all organisations surveyed are adopting agile methods practices. Among the agile methods used, Scrum predominates (56\%), followed by Scrum/XP Hybrid (10\%). The results bring evidences that agile practices work. The main improvements from implementing agile practices include: (1) ability to manage changing priorities (87\%); (2) increased team productivity (84\%); (3) improved project visibility (82\%); (4) increased team morale/motivation (79\%); (5) better delivery predictability (79\%); and (6) enhanced software quality (78\%). On the other hand, the main reasons for failures in agile projects include: (1) the lack of experience with agile methods (44\%); (2) the organisation philosophy or culture at odds with core agile values (42\%); and (4) the lack of support for cultural transition (36\%).

Other works on agile methods could also be found in the literature related to: general issues on the adoption of agile methods (BOEHM, 2002; NERUR; MAHAPATRA; MANGALARAJ, 2005; MANGALARAJ; MAHAPATRA; NERUR, 2009), benefits and limitations (DYBÅ; JØRGENSEN, 2008), issues of agility (LEE; XIA, 2010), dynamic of agile teams (MOE; DINGSØYR; DYBÅ, 2009), agile in distributed settings (BAHETI; GEEHRTNGER; STOTTS, 2002; RAMESH et al., 2006), impact of agile practices (WILLIAMS et al., 2000; PIKKARAINEN et al., 2008), among others.

The research aforementioned indicate that Scrum and XP are the most well-known and widely used by companies. We describe both agile methods following.

\subsection{Scrum}

Scrum (COHN, 2009; KNIBERG, 2008; SCHWABER; BEEDLE, 2002; SCHWABER, 2004; SCHWABER; BEEDLE, 2007; SUTHERLAND, 2005) is an agile method for the planning and management of software (and non-software) projects. It provides a set of practices to support the work of teams in environments whose characteristics are frequently changing requirements.

Unlikely traditional methods, Scrum allows team members to select the amount of work they are "able to do and the better way to do it", thereby providing a more pleasant and productive work environment (SUTHERLAND et al., 2007).

Scrum was designed to adapt to the new demands that arise during the development process. It allows teams to prioritise customers needs and to adapt the work product according to their needs at short and regular intervals. It prioritises work based on business value, improving the usefulness of which is delivered to the customers and increasing their gains more quickly (SUTHERLAND et al., 2007).

\subsubsection{Scrum Theory}

Scrum is founded on empirical process control theory (SCHWABER, 1995). In the perspective of the empiricism, the knowledge comes from the experience based on what is 
known. Scrum uses an iterative and incremental approach to optimise predictability and control risks. Three basic aspects underpin the empirical process (SCHWABER; SUTHERLAND, 2010; SCHWABER; SUTHERLAND, 2011):

1. Transparency: all artefacts and events associated with the development that can impact the outcomes need to be visible and easily understood by all those involved in the process.

2. Inspection: the project progress in Scrum and its artefacts need to be frequently checked (as long as they do not comprise the work progress) to detect any undesirable variance in the process.

3. Adaptation: the variations identified in the process that deviate from the acceptable limits and may affect the acceptance of the resulting product need to be adjusted quickly.

\subsubsection{Scrum Framework}

Scrum can be seen as a framework for dealing with complex adaptive problems, helping to deliver products in a productive and creative manner. The framework consists of Scrum teams, along with their roles, events and artefacts. These elements meet a specific purpose and are crucial for the successful and the usage of Scrum (SCHWABER; SUTHERLAND, 2011; SUTHERLAND et al., 2007).

\section{Roles}

In a Scrum project there may be several teams involved, however, each team should preferably have five to nine members. Scrum teams are self-organising, i.e., they themselves need to define how best to perform their work. Scrum teams are also cross-functional, i.e., they need to have all skills and knowledge to perform the work. A Scrum team includes the following roles (SCHWABER; SUTHERLAND, 2011; SUTHERLAND et al., 2007):

- Product Owner: represents the customer of the product and accounts for: (1) defining the characteristics of the product; (2) establishing the data of release, as well its content; (3) maximising the return on investment; (4) prioritising features according to business value; (5) adjusting features and priority of every sprint; and (6) accepting or rejecting work results.

- Development Team: represents the professionals who will deliver a product increment at the end of each sprint. The team has multidisciplinary characteristic, self-organised and self-manageable and accounts for: (1) selecting features prioritised by the product owner to be implemented during the sprint, with total autonomy to decide "what implement" to accomplish the objectives of the sprint; (2) estimating features of product backlog and ensuring the effort required to obtain realistic estimatives; (3) self-organising and 
managing their own work tasks; and (4) demonstrating work results for the product owner at the end of the sprint.

- ScrumMaster: represents the manager of the Scrum project. However, he/she works differently to the traditional way, acting as facilitator leader of the team, besides working closely with the product owner. The ScrumMaster accounts for: (1) ensuring a functional and productive team; (2) allowing mutual cooperation among all roles and functions; (3) removing obstacles of the project; (4) protecting the team from external interference; and (5) making sure that the Scrum process is followed by all team members.

\subsubsection{Events}

A fundamental concept in Scrum refers to the Sprint - a closed period of time (time-box) of a month or even less in which the whole work is developed. In this period, a potential increment of the product is created and released to be experienced by users.

Scrum provides facilities for the inspection and adaptation of the process through four events: (1) sprint planning, (2) daily Scrum, (3) sprint review and (4) sprint retrospective.

\section{Sprint Planning}

The sprint planning comprises a meeting to review and decide on what will be implemented within a sprint and how the work will be performed by the team.

In general, a sprint planning meeting is divided into two parts. In the first part, the focus is to achieve an agreement on the sprint goal in terms of business value, including work items that will be implemented within the sprint. Initially, the product owner shows to the team the product backlog with the items sorted according to his/her priority, explaining what should be done in each work item. The team estimates the effort required to implement the work items and agree with the product owner about what will be delivered at the end of the sprint, considering the order of priority established by the product owner. The goal established for the sprint should be something that generates value to the product owner. The goal helps the team keep focused on what is most important to the increment of the product.

In the second part of the sprint planning meeting, the focus is to achieve an agreement about how the work will be conducted within the sprint in order to maintain a commitment to the sprint goal. The team needs to decide how to implement the planned items, generating an increment of the product at the end of the sprint. In this context, the team divides the work items of the product backlog into individual tasks. Then, each team member selects the amount of work that each one undertakes to develop and deliver at the end of the sprint, and estimates the time (in hours) required to finish it. At the end of the meeting, there is a detailed plan on what will be implemented in the current sprint of the project. 


\section{Daily Scrum}

During each sprint, the team conducts a daily meeting to obtain an overview of the project, discover new dependencies, address individual needs of the team members and adjust the work plan in real time to the needs of day-to-day (SCHWABER; SUTHERLAND, 2011; SUTHERLAND et al., 2007).

Daily Scrum is a useful mechanism to disseminate knowledge and information regarding the status of the project, allowing continuous monitoring of the project progress. In summary, the goal is to obtain information on the work carried out on the day before, identify key constraints and prioritise the work to be undertaken on the day beginning. The team members are asked to answer three elementary questions:

- What was carried out on the day before meeting?

- What will be held today? and,

- Is there any impediment/obstacle to perform the work?

Ideally, daily meetings should be held in the morning allowing the establishment of work priorities for the day ahead. Meetings should be short (15 minutes on average), with the participation of all team members. Eventually, other people may attend the meeting, but only as spectators.

\section{Sprint Review}

A sprint review meeting is conducted at the end of each sprint to demonstrate the work done during on each one. The meeting is organised by the ScrumMaster, not exceeding more than four hours. The development team is responsible for demonstrating the product or set of implemented features for the product owner and other stakeholders (customers and users), if applicable. The product owner verifies whether features are in accordance with what has been planned and suggests changes whenever necessary. Any suggested changes in the product backlog are discussed between product owner and development team.

\section{Sprint Retrospective}

The sprint retrospective is carried out immediately after the sprint review. It is an opportunity for the team to: (1) discuss what is working and what is not working well in the project; and (2) achieve an agreement about the changes needed for the next sprint.

The sprint retrospective is one of the most important practices for the success of projects using Scrum (SUTHERLAND et al., 2007), acting as a continuous improvement cycle in which the team collects the lessons learned to improve next sprint. 


\subsubsection{Artefacts}

An artefact in Scrum represents a work product that is useful in providing transparency and opportunities for inspection and adaptation. Essentially, there are three artefacts in Scrum (SCHWABER; SUTHERLAND, 2011): product backlog, sprint backlog and increment.

\section{Product Backlog}

The product backlog contains a list of required features for the product with their respective priorities established by the product owner. Items in the product backlog are prioritised by the product owner at the beginning of each sprint. Each item should have an associated business value in order to enable the measurement of the project return and the implementation priorities for the work items.

The product backlog is constantly updated, as the development progresses and/or new emerging needs are identified by the product owner. Therefore, for each iteration, new features can be part of the product backlog, being necessary re-prioritisation.

\section{Sprint Backlog}

The sprint backlog contains a list of tasks that should be undertaken during the next sprint of the project. As previously mentioned, this list of tasks is defined in the sprint planning meeting from the product backlog prioritised by the product owner.

Whilst executing the sprint, the ScrumMaster keeps the sprint backlog up-to-date, indicating the tasks that have been completed and the time that the team needs to fulfil the tasks not yet finalised. The ScrumMaster maintains a daily estimate of work that remains to be done during the sprint as a sprint burndown chart. Highsmith (2009) argues that the sprint burndown chart is one of the main mechanisms to track a project in Scrum, showing the daily progress of the team (in hours) according to the sum of tasks listed in the sprint backlog.

Additionally to the sprint burndown chart, the team uses a taskboard to ensure the visibility of a project in Scrum for the whole team. A typically taskboard contains: (1) the items of work of the product backlog; (2) the tasks associated to items of work to do; (3) the tasks in progress; and (4) the tasks done.

\section{Increment}

An increment refers to all items in the product backlog completed during the execution of a sprint (including previous sprints). At the end of each sprint, a new increment needs to be fulfilled; such increment must meet the definition of "done" established by the team, being in conditions of use by the customer (SCHWABER; SUTHERLAND, 2011). In short, such definition presupposes that a potentially releasable increment for the production environment needs to be delivered at the end of each sprint. 


\subsubsection{Scrum Life Cycle}

The Scrum life cycle process is structured into three main phases (ABRAHAMSSON et al., 2002; SCHWABER; BEEDLE, 2002):

1. Pre-Game: the product features are identified and described, becoming part of the product backlog. These features are prioritised and allocated to be implemented in the next sprint. Resources are planned and the product architecture is established.

2. Game: the product is developed through several sprints. Features are developed or modified in iterative cycles, aiming at producing new increments periodically.

3. Post-Game: the Scrum meetings are conducted to analyse the project progress and demonstrate the product to the customer, aiming at preparing it for the production environment.

In Figure 7 we illustrate a simplified representation of the Scrum process flow. In short, a Scrum project is divided into cycles called sprints (or iterations). Each sprint ranges from one to four weeks and is preceded by a sprint planning meeting. During the planning meeting, the product owner prioritises the work items which compose the product backlog, whilst the development team selects and estimates the tasks that each member is able to implement within the sprint. These tasks comprise the sprint backlog of the product. Every day the team performs quick meetings (daily Scrum meetings) to track the project progress. At the end of the sprint, the team conduct a meeting (sprint review) to demonstrate the implemented features. Next, the team performs the sprint retrospective. At the end of each sprint, an increment with added value needs to be delivered to the customer. The process repeats until the product backlog is fully met.

Figure 7 - Scrum process flow.

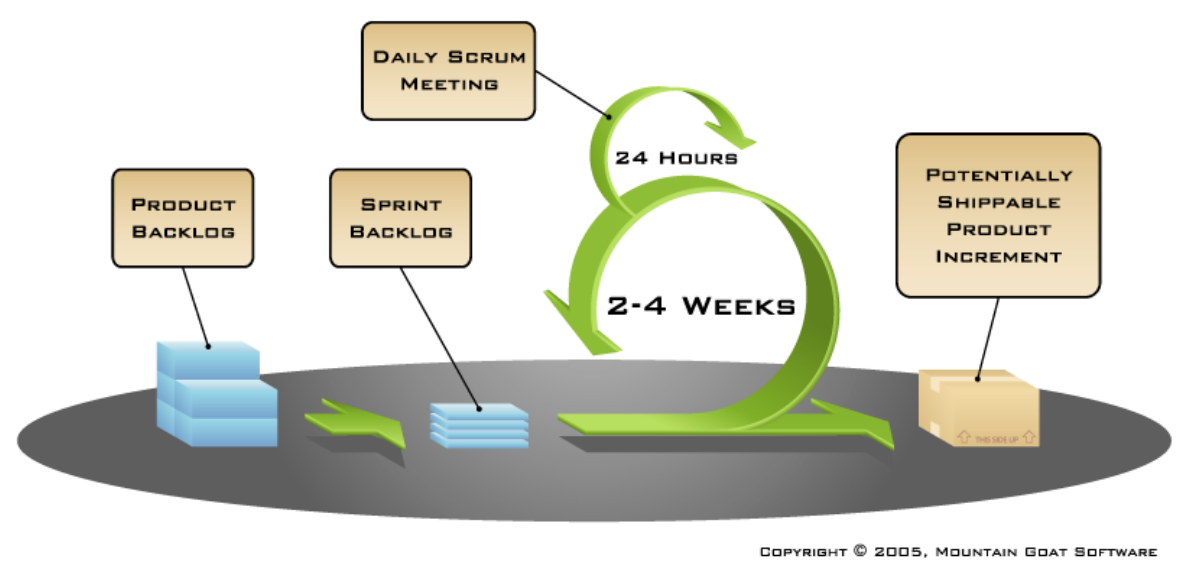

Source: Mountain Goat Software (2005).

Currently, Scrum has been successfully used and adapted to a wide variety of projects worldwide with different sizes and complexities (SUTHERLAND et al., 2007; CRISTAL; WILDT; PRIKLADNICKI, 2008; SALO; ABRAHAMSSON, 2008; PAASIVAARA; 
DURASIEWICZ; LASSENIUS, ; AKHTAR; AHSAN; SADIQ, 2010; LAVAZZA et al., 2010; SCHMIDT; VENKATESHA; HEYMANN, 2014).

\section{3 eXtreme Programming}

eXtreme Programming (XP) (BECK; FOWLER, 2000; BECK; ANDRES, 2004; LINDSTROM; JEFFRIES, 2005) is an agile method for the software development focused on projects whose requirements are vague and/or that changes often. Some characteristics that define XP are outlined as follows (BECK; ANDRES, 2004):

- It is a lightweight method in which the team must perform only what is needed to add value to the customer/business;

- It is focused on the software development projects;

- It works for teams of any size, although it is more suitable for smaller teams; and,

- It adapts to vague or changing requirements.

$\mathrm{XP}$ is based on a set of values and best practices that are mutually supportive in the software development. Essentially, XP includes the following (BECK; ANDRES, 2004):

- A philosophy for the software development based on five values: communication, feedback, simplicity, courage and respect;

- A set of best practices expressing the values of XP and supporting the software development;

- A set of principles serving as a "bridge" between values and practices. These principles act as intellectual practices, by turning values into practices; and,

- An assiduous community worldwide sharing the same values and practices.

\subsubsection{Values}

The philosophy adopted by XP is based on a set of values that guide the software development, helping to apply its principles and practices.

\section{Communication}

$\mathrm{XP}$ assumes that many problems of the software development projects occur due to communication difficulties (LARMAN, 2003). Communication is one of the values of the Agile Manifesto (Agile Manifesto, 2001).

Traditionally, communication in software development takes place through documents. On the other hand, agile development prioritise face-to-face communication over other kinds 
of communication. In XP, communication is present throughout the development process. For instance, in order to have feedback in software development, communication is essential, whether between the development team or between the team and the customer.

\section{Simplicity}

The concept of simplicity consists in proposing a simple solution to address more emerging problems and avoid losing time with generic solutions concerned to secondary problems. Furthermore, adding unnecessary complexity and functionality tends to make the implementation more prone to errors, requiring extra effort with testing and refactoring activities.

However, maintaining the simplicity of a software is not a trivial task. There are four rules to ensure the software simplicity, according to the order of priority (BECK; FOWLER, 2000): (1) software (source code and test suite) should express everything that the developer wants to communicate; (2) software must not contain duplicate code; (3) software should have the smallest set of classes as possible; and (4) software should have the smallest set of method as possible.

\section{Feedback}

The agile philosophy emphasises obtaining feedback throughout the software development. In XP, feedback comes in different levels. For instance, the customer provides feedback to the development team when he/she learns something new about the software, whilst he/she better understands about the features or the way in which features have been implemented. From this learning, the customer can have new ideas on what should be developed, how and when it should be developed. Analogously, the development team provides feedback to the customer providing estimatives, identifying technical risks, suggesting design alternatives, among others. This reflects the team apprenticeship on what needs to be done (TELES, 2004).

Furthermore, the development team designs unit testing to verify the logic of the software and get immediate and concrete feedback, showing whether the code written by the team performs the required functions.

\section{Courage}

According to Teles (2004), XP follows several premises contrary to those used in the traditional methods for software development. A team using XP needs to have courage (confidence) to: (1) develop software incrementally; (2) maintain the emphasis on simplicity throughout the development; (3) allow the customer to prioritise the features to be developed; (4) encourage the pair programming; (5) invest time in refactoring; (6) invest time in automated testing; (7) estimate the stories with the customer's presence; (8) share code will all team members; (9) integrate features of the software several times a day; (10) adopt a sustainable pace 
of work; (11) abdicate of documentation that serves as a defence; and (12) propose the adoption of a new process.

\section{Respect}

Respect serves as the foundation for all other XP values. For example, if there is no respect in the workplace among team members, the communication will be faulty and there will be no feedback. The excellence in the software development is related to the people involved in the process. In this context, respect among team members is essential. If team members do not care about their colleagues or project results, XP will not work (BECK; ANDRES, 2004).

\subsubsection{Practices}

The practices in XP are divided into 13 primary practices and 11 corollary practices. Primary practices introduce immediate benefits and are essential when adopting XP. The 13 primary practices of XP (BECK; FOWLER, 2000; BECK; ANDRES, 2004) are summarised in Table 2. In XP, software features are described as stories in simple paper cards, containing only their central idea. Cohn (2004) suggests a fairly simple format for describing stories, highlighting the business value associated with each one: as a $<$ user $/$ role $>$ I would like $<$ feature $>$ so that $<$ business value $>$.

XP prioritises sustainable pacelenergised work, implying that the development team should have a realistic working day. Extra working hours are only permitted in extreme situations. Through an intense pace of work, particularly in the software development, the team's performance decreases and the work efficiency is impaired, directly affecting the quality of the resulting product.

Two primary practices of XP are crucial to ensure the quality of the system: Pair Programming and Test-Driven Development (TDD) (BECK, 2003). In a XP project, a pair of developers work together implementing the same feature of the software, promoting the collective and collaborative development. Code is constantly reviewed as it is created, preventing mistakes go undetected; such mistakes can be detected early in the project. Also, the developers may have different ideas for solving the same problem. It is still possible exploit the complementary knowledge of the developers to propose a better solution for a given problem. By adopting TDD, developers create tests even before coding the software features. Such tests help developers understand the desired functioning of the software, and can be used throughout the development to validate it.

Corollary practices are more specific and difficult to apply, requiring knowledge and experience with the primary practices. Collectively applied, they should increase the efficiency on the software development (BECK; FOWLER, 2000; BECK; ANDRES, 2004).

The 11 corollary practices are summarised in Table 3. For instance, XP works with incremental deployment of the system. Particularly, when a new system replaces a legacy system, 
the exchange should take place gradually, minimising risk, effort and cost. The code of the system must be accessible (collective code ownership); any developer can make changes he/she deems relevant without requiring prior authorisation of another member. However, it is extremely important that the responsible for the changes executes the necessary tests.

Table 2 - Primary practices of XP.

\begin{tabular}{|c|c|}
\hline Practices & Description \\
\hline $\begin{array}{l}\text { Pair } \\
\text { Programming }\end{array}$ & $\begin{array}{l}\text { Two developers working on the same problem, side by side on a computer, allowing the } \\
\text { code be constantly reviewed, and reducing the number of mistakes. Developers working } \\
\text { together can also make the system implementation simpler and effective }\end{array}$ \\
\hline $\begin{array}{l}\text { Continuous } \\
\text { Integration }\end{array}$ & $\begin{array}{l}\text { Releases of the software are integrated and tested several times a day, whenever a task is } \\
\text { completed during the development }\end{array}$ \\
\hline Energised work & $\begin{array}{l}\text { The pace of work of each team member should no hinder his/her personal life. The number } \\
\text { of hours for the development of a XP project needs to be realistically planned }\end{array}$ \\
\hline $\begin{array}{l}\text { Test-Driven } \\
\text { Development } \\
\text { (TDD) }\end{array}$ & $\begin{array}{l}\text { Software is continually assessed during the development through several testing activities } \\
\text { XP team practice TDD, a preventive technique in which the test is written before coding } \\
\text { each feature. As well as the pair programming, TDD is a useful technique to validate the } \\
\text { software correctness }\end{array}$ \\
\hline Stories & $\begin{array}{l}\text { The desired features for the software are briefly described on small paper cards called user } \\
\text { stories. Each story contains an estimative together with its priority of implementation }\end{array}$ \\
\hline Whole Team & $\begin{array}{l}\text { The team should be multidisciplinary, bring together all skills required to the project success } \\
\text { Members work cooperatively, interacting and contributing to the effective development of } \\
\text { the project }\end{array}$ \\
\hline Sit Together & $\begin{array}{l}\text { The workspace needs to be wide enough to accommodate all team members, fostering } \\
\text { interaction and collaboration among them }\end{array}$ \\
\hline $\begin{array}{l}\text { Informative } \\
\text { Workspace }\end{array}$ & $\begin{array}{l}\text { The workspace needs to reflect the project progress (including stories cards, white } \\
\text { boards, graphics, etc.), giving visibility to relevant information, and supporting team in } \\
\text { decision-making }\end{array}$ \\
\hline Weekly Cycle & $\begin{array}{l}\text { The team needs to plan the work undertaken throughout the week. It should reflect on the } \\
\text { progress of work, planning and prioritising the stories of the week and "breaking down" the } \\
\text { stories into tasks to be implemented }\end{array}$ \\
\hline Quarterly Cycle & $\begin{array}{l}\text { The team needs to plan the releases quarterly. A plausible set of stories are selected, } \\
\text { becoming the primary focus of the quarter }\end{array}$ \\
\hline Slack & $\begin{array}{l}\text { Estimatives are only predictions for conducting the work. Then, all scheduled tasks will be } \\
\text { not completed in time. This principle presupposes a clearance boundary in project planning, } \\
\text { avoiding possible conflicts and pressures on the team }\end{array}$ \\
\hline $\begin{array}{l}\text { Incremental } \\
\text { Design }\end{array}$ & $\begin{array}{l}\text { The development flow is iterative and incremental. The goal is to design a solution as } \\
\text { simple as possible to easily adapt to changes, without demanding much effort. Unnecessary } \\
\text { complexity is removed as soon as it is discovered }\end{array}$ \\
\hline $\begin{array}{l}\text { Ten-minute } \\
\text { Build }\end{array}$ & $\begin{array}{l}\text { The executable build needs to be carried out quickly, checking the code consistency and the } \\
\text { how software works in a similar environment to the production, and promoting cycles of } \\
\text { frequent feedback }\end{array}$ \\
\hline
\end{tabular}

Source: Elaborated by the author. 


\subsubsection{Principles}

The XP values have a high level of abstraction so that principles were introduced, making them more concrete and applicable in the software development.

An overview of the principles of XP is shown in Table 4. For instance, the principle of improvement must underpin the software development. Throughout the development cycle, the opportunities of identified improvements must be implemented in order to prepare the software more quickly towards the production environment, fulfilling the real needs of the customers.

Table 3 - Corollary practices of XP.

\begin{tabular}{|c|c|}
\hline Practices & Description \\
\hline Daily Deployment & $\begin{array}{l}\text { New versions of the system go into production every night in order to increase the } \\
\text { overall development }\end{array}$ \\
\hline $\begin{array}{l}\text { Incremental } \\
\text { Deployment }\end{array}$ & $\begin{array}{l}\text { Deployment of features of the system should take place gradually, minimising risk, } \\
\text { effort and cost }\end{array}$ \\
\hline Team Continuity & $\begin{array}{l}\text { Teams should be maintained throughout the development whenever possible, ensuring } \\
\text { the synergy between members }\end{array}$ \\
\hline Shrinking Team & $\begin{array}{l}\text { When the team improves its workflow, any member can be allocated to another team, } \\
\text { helping to disseminate knowledge and experience across the company }\end{array}$ \\
\hline $\begin{array}{l}\text { Root Cause } \\
\text { Analysis }\end{array}$ & $\begin{array}{l}\text { Every defect found throughout the development is fixed as well as the origin of its } \\
\text { cause, increasing the overall quality of the system }\end{array}$ \\
\hline Code and Tests & $\begin{array}{l}\text { Cover the artefacts that really must be permanently maintained. XP prevents obsolete } \\
\text { and unnecessary documentation }\end{array}$ \\
\hline Single Code Base & $\begin{array}{l}\text { Assumes only one code repository, preferably without ramifications (branches), } \\
\text { facilitating future maintenance }\end{array}$ \\
\hline $\begin{array}{l}\text { Negotiated Scope } \\
\text { Contract }\end{array}$ & $\begin{array}{l}\text { Contracts must establish time, cost and quality, but the scope keeps variable, being } \\
\text { defined according to the project's progress }\end{array}$ \\
\hline $\begin{array}{l}\text { Collective Code } \\
\text { Ownership }\end{array}$ & $\begin{array}{l}\text { The code is collective, i.e., it belongs to every member of the team. Any developer can } \\
\text { fix bugs, add functionality or improve any part of the system }\end{array}$ \\
\hline Pay-per-Use & Customer will pay by the usage of the system \\
\hline $\begin{array}{l}\text { Real Customer } \\
\text { Involvement }\end{array}$ & $\begin{array}{l}\text { The customer actively participate in the project and clarify any doubts that arise during } \\
\text { development }\end{array}$ \\
\hline
\end{tabular}

Source: Elaborated by the author.

Reflection is another essential principle of XP. The software development activity involves reflection and learning. At each development cycle the team must make a critical analysis of the project's progress. Learning takes place through previous experiences, including possible mistakes and problems faced by the team. 
Table 4 - Fundamental principles of XP.

\begin{tabular}{|c|c|}
\hline Principles & Description \\
\hline Humanity & Individual needs should be respected and harmonised with the business and team needs \\
\hline Improvement & improvement on the software should be a constant activity during its development \\
\hline Reflection & $\begin{array}{l}\text { Team members should rethink about the ongoing work and whether they are in the } \\
\text { right track, evaluating decisions they taken and therefore, seeing opportunities for } \\
\text { improvements }\end{array}$ \\
\hline Economy & $\begin{array}{l}\text { There should be an ongoing concern about maximising the software value and customer } \\
\text { satisfaction }\end{array}$ \\
\hline Diversity & $\begin{array}{l}\text { The team should bring together knowledge, skills and personalities to ensure that the } \\
\text { problems are viewed by different perspectives, enabling to identity different solutions } \\
\text { and choosing a solution that best fits in a particular context }\end{array}$ \\
\hline Self-similarity & $\begin{array}{l}\text { Composing a solution to a problem should be replicated in other similar situations and } \\
\text { issues; for instance, using design patterns (GAMMA et al., 1994) }\end{array}$ \\
\hline Flow & $\begin{array}{l}\text { Software development should follow a continuous flow by regularly delivery of software } \\
\text { releases }\end{array}$ \\
\hline Baby paces & $\begin{array}{l}\text { Complement to the flow principle; indicate, for instance, that the whole implementation } \\
\text { and/or change of a feature be conducted gradually, providing greater safety }\end{array}$ \\
\hline $\begin{array}{l}\text { Acceptance of } \\
\text { Responsibility }\end{array}$ & $\begin{array}{l}\text { Each team member who proposes to carry out a working should accept responsibility } \\
\text { without any imposition }\end{array}$ \\
\hline Opportunity & $\begin{array}{l}\text { The problems faced by the team should not be an obstacle to the project's success, but } \\
\text { rather as opportunities for change, increasing knowledge and improvements }\end{array}$ \\
\hline Mutual Benefit & All activities and tasks performed should bring benefits to all involved in the project \\
\hline Redundancy & $\begin{array}{l}\text { Critical problems should be solved in distinctive ways. If a solution eventually fails, there } \\
\text { will be another solution to be implemented }\end{array}$ \\
\hline Failure & $\begin{array}{l}\text { Complementary to the principle of redundancy, working as opportunities for learning and } \\
\text { improvement }\end{array}$ \\
\hline Quality & $\begin{array}{l}\text { Quality should not be "negotiable". Actually, the team gives priority for excellence in the } \\
\text { software development }\end{array}$ \\
\hline
\end{tabular}

Source: Elaborated by the author.

\subsubsection{Roles}

A XP team should be composed of people from different technical and business skills. A summary of the main roles played by the XP team is shown following:

- Project Manager: responsible for reporting overall project progress to the customer, including problems and obstacles which may affect the progress of the project. He/she has a macro vision of the project and of the values and practices of XP. This role is essential to maintain the good relationship between the development team and the customer.

- Tester: responsible for testing and ensuring the quality of the system being developed. $\mathrm{He} / \mathrm{she}$ assists the customer in drafting the acceptance testing. This role is essential to detect errors as early as possible throughout the project. 
- Developer: responsible for analysing, designing and coding the system. There is no hierarchical division among analysts, designers and developers. A developer can take on different roles at different stages of the project.

- Technical Writer: responsible for helping the development team to keep up-to-date the software documentation. Developers can prioritise the development of the software without spending time with documentation.

- Customer/User: responsible for helping to write and select stories and to make decisions about the business domain during development. Users are involved from the beginning of the project in order to obtain feedback as early as possible and prioritise the implementation of features that add immediate value to the organisation.

\subsubsection{XP Life cycle}

The XP process life cycle (Figure 8) is divided into six phases (BECK; FOWLER, 2000; BECK; ANDRES, 2004; AMBLER, 2002; LINDSTROM; JEFFRIES, 2005), as summarised next:

1. Exploration: understanding of the real scope of the system in an enough level of detail to estimate it. The customer writes the user stories, each containing a desired feature for the first release. Customer and developers staff agree on the date on which a small set of most relevant stories will be implemented.

2. Planning: definition of the priorities of the stories with the customer and estimative of the effort and development time for each story.

3. Iterations to Release: execution of several iterations to complete the first release. Each iteration lasts approximately from two to four weeks. Later, the features are added according to the priorities defined in the previous phase.

4. Productionizing: validation of the system through extensive testing and verification activities in order to prepare it for the production environment.

5. Maintenance: after the end of the first release, new versions of the system are created, adding new features and/or improvements.

6. Death: all stories have been implemented and fulfil the customer needs. The system documentation is created and no change in the architecture, design or code could be performed.

In summary, a project in XP is divided into releases and iterations (two-weeks average). At the beginning of each release and each iteration, a meeting (planning game) is performed in 
which the customer evaluates the features to be developed, and prioritises those features that will be incorporated into the next release or iteration. The features are developed in pairs by developers (pair programming). The team gets together daily (stand up meeting) to evaluate the work done in the day before and to prioritise the work to be done in the day ahead. The development is driven by testing (test-driven development), i.e., developers create tests for each feature even before implementing them. At the end of the iteration, the customer validates the implemented features; and at the end of release, the system is released in the production environment.

Figure 8 - XP lifecycle

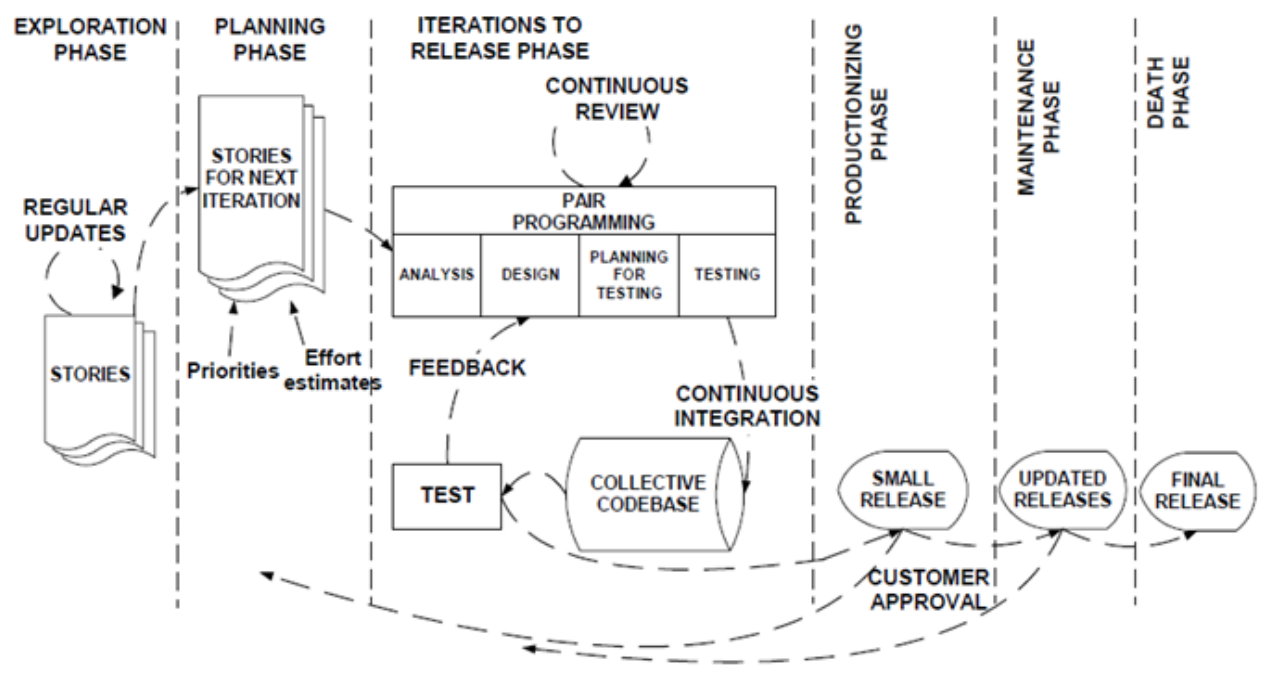

Source: Abrahamsson et al. (2002).

Currently, XP has been successfully implemented both in academic environment (SCHNEIDER; JOHNSTON, 2003; GOLDMAN et al., 2004; FREIRE; GATTO; KON, 2005; FREIRE; KON; GOLDMAN, 2007) and software industry (LAYMAN; WILLIAMS; CUNNINGHAM, 2004; SALO; ABRAHAMSSON, 2008; SCHMIDT; VENKATESHA; HEYMANN, 2014).

\subsection{Comparative Analysis of Agile Methods}

The agile methods described in this chapter have several characteristics in common. Among the common characteristics shared by them we highlight:

- Iterative development: development occurs in small cycles, also called iterations or sprints varying according to the method chosen and team skills. The goal is to produce and integrate parts of the software constantly throughout the development.

- Incremental Development: development occurs incrementally through repetitive cycles, adding new features or evolving the features already implemented. 
- People-oriented: the focus is more on people rather than on processes, as in traditional development methods. Agile methods recognise people as the "primary drivers of project success, coupled with an intense focus on effectiveness and maneuverability" (COCKBURN, 2004).

- Empirical process: agile development process is empirical, i.e., it considers the complexity of the software, the risks associated to the uncertainty of the project and the changes that can occur throughout the development process.

- Flexibility/Adaptability: due to the iterative and incremental nature of the agile methods, the development becomes flexible to accommodate changes in requirements and software design. Changes are welcome in any part of the software development process.

- Collaboration: developers, customers and users are involved throughout the software development process. The customer provides quick feedback and facilitates communication among stakeholders. Thus, problems and difficulties concerning to the development of the product can be solved more quickly.

- Testing: testing activities are conducted at the beginning of the project and extended throughout the development process. Tests are performed at two levels of granularity. Developers perform unit testing throughout the development process, whilst the customer specifies the acceptance testing in order to check whether the specified requirements were met. Usually, tests are designed in a automated manner, being able to be executed easily and frequently by the team. Such characteristic helps in identifying problems early in the process, reducing the overall cost of the software.

- Planning: the focus is on the continuous and short-term planning in each development cycle. The long-term planning is done superficially, since the degree of uncertainty is much higher when trying to "predict the future".

- Estimative: estimative are made with transparency and communication. Instead of treating the estimative as facts, it is considered that there is an uncertainty in relation to the estimated value for each increment of the software.

In Table 5 we summarise the general characteristics of Scrum and XP. Notice that Scrum and XP have different but complementary approaches. Whilst the focus of the Scrum is on the planning and project management, XP focuses on the software development practices.

Scrum and XP prioritise short development cycles (sprint/iteration). Sprints in Scrum typically range from two to four weeks or months whilst iterations in XP can be even shorter, ranging from one to two weeks of duration. In Scrum, planned sprints remain unchanged until their conclusion. On the other hand, XP is more flexible to change, allowing team members to exchange unstarted features by other features with similar size. 
Table 5 - General characteristics of Scrum and XP

\begin{tabular}{llllll}
\hline \multirow{2}{*}{ Method } & Focus & \multicolumn{2}{c}{ Iteration/Sprint } & \multicolumn{2}{c}{ Team } \\
\cline { 3 - 5 } Scrum & Duration & Time & Ideal Size (people) & Characteristic \\
\hline XP & $\begin{array}{l}\text { Planning/project } \\
\text { management }\end{array}$ & 2 to 4 weeks & Time-box & $<=10$ & $\begin{array}{l}\text { Self-organising and } \\
\text { self-manageable }\end{array}$ \\
& $\begin{array}{l}\text { Software } \\
\text { development } \\
\text { practices }\end{array}$ & 1 to 2 weeks & Time-box & $<=20$ & $\begin{array}{l}\text { Self-organising and } \\
\text { self-manageable }\end{array}$ \\
\hline
\end{tabular}

Source: Elaborated by the author.

Both agile methods focus on self-organising and self-manageable team, i.e., the team members take their responsibilities on the development activities and determine the best way to do their work. Although such agile methods are more suitable for small and co-located teams, several researches have shown that they can be scaled for projects involving large and distributed teams (BOLAND; FITZGERALD, 2004; LINDVALL; MUTHIG; DAGNINO A. WALLIN, 2004; VERSIONONE, 2015).

In Table 6 we illustrate the correlation between the main practices observed in Scrum and XP. For instance, in XP, the current versions of the code are integrated every day in order to reduce integration errors (incompatibility), and to identify implementation errors as fast as possible. In the case of Scrum, the integration occurs only at the end of each sprint (iteration). In $\mathrm{XP}$, developers create tests for each feature before implementing them (using TDD). In Scrum, tests occur in parallel with the implementation within the sprint.

Scrum and XP work on the prioritisation of features. Customer prioritise the features usually based on business value. The highest-priority features should be implemented firstly. Both agile methods encourage the active participation of users throughout the project. In the same way, sprint/iteration planning, release planning, sprint/iteration evaluation, release evaluation, and daily meetings are practised, promoting the communication and collaboration among all those engaged in the process.

Regarding the intrinsic characteristics of each method, we emphasise the pair programming practice of XP wherein features of a system are created in pairs of developers. This development practice contributes to the spread of knowledge among team members, besides serving as a process of code review.

Metaphor is another intrinsic practice of XP in which the functioning of the system as a whole is described in a simplified manner through of a common language. The purpose is to guide the development and facilitate communication with the customer.

In contrast to XP, Scrum does not prescribe any engineering practice including TDD, unit testing, integration testing, simple design, refactoring, coding standard, collective code ownership, continuous integration, pair programming and automated builds. In fact, Scrum is focused on planning and project management (as previously shown in Table 2). Hence, it is more "generic" and can be used in both software and non-software projects. 
Table 6 - Correlation between practices

\begin{tabular}{|c|c|c|}
\hline Practices & $\mathrm{XP}$ & Scrum \\
\hline Sprint/iteration planning & $\checkmark$ & $\checkmark$ \\
\hline Release planning & $\checkmark$ & $\checkmark$ \\
\hline Stories & $\checkmark$ & $\checkmark$ \\
\hline Prioritised features/product backlog & $\checkmark$ & $\checkmark$ \\
\hline Metaphors & $\checkmark$ & $x$ \\
\hline Daily meetings & $\checkmark$ & $\checkmark$ \\
\hline Iteration evaluation & $\checkmark$ & $\checkmark$ \\
\hline Release evaluation & $\checkmark$ & $\checkmark$ \\
\hline Retrospective & $x$ & $\checkmark$ \\
\hline TDD & $\checkmark$ & $x$ \\
\hline Unit testing & $\checkmark$ & $x$ \\
\hline Integration testing & $\checkmark$ & $x$ \\
\hline Acceptance criteria/testing & $\checkmark$ & $\checkmark$ \\
\hline Simple design & $\checkmark$ & $x$ \\
\hline Refactoring & $\checkmark$ & $x$ \\
\hline Coding standard & $\checkmark$ & $x$ \\
\hline Collective code ownership & $\checkmark$ & $x$ \\
\hline Continuous integration & $\checkmark$ & $x$ \\
\hline Small releases & $\checkmark$ & $\checkmark$ \\
\hline Sustainable pace & $\checkmark$ & $x$ \\
\hline Pair programming & $\checkmark$ & $x$ \\
\hline Automated/ten-minutes builds & $\checkmark$ & $x$ \\
\hline Active participation of users & $\checkmark$ & $\checkmark$ \\
\hline Sit together & $\checkmark$ & $\checkmark$ \\
\hline Cross-functional/whole team & $\checkmark$ & $\checkmark$ \\
\hline Informative Workspace & $\checkmark$ & $\checkmark$ \\
\hline
\end{tabular}

Source: Elaborated by the author.

The characteristics and practices of the agile methods described in this chapter serve as foundation for the establishment of the agile method proposed in the Chapter 5, within the context of the development of OERs.

\subsection{Concluding Remarks}

In this chapter we discussed about the fundamentals of agile methods for software development. We described the values and principles behind agile methods philosophy. Studies on the adoption and adaptation of agile methods by organisations were summarised. We described in detail Scrum and XP, since they are the most well-known and widely adopted ones. We also identified and discussed the common characteristics, similarities and main differences between them.

The study conducted provides subsidies for the establishment of an agile method for the development of OERs, proposed in this thesis. In short, we noticed that agile methods, particularly Scrum and XP, have some characteristics that can be suitable for OERs. For instance, in the context of agile development, versions of system are delivered in short and regular 
intervals, constantly evolving to meet new needs of customers/users. Similarly, learning materials (including OERs) are constantly evolving in response to the dynamic characteristic associated with knowledge, and to the results of learning experiences of users/learners.

In the next chapter we discuss practical issues about the development of OERs. We describe two empirical studies to investigate the development of OERs in the international and national scope. The aim is to map the mechanisms proposed and used to support the development of OERs, and to provide a big picture on the development of OERs in Brazilian context. 


\section{DEVELOPMENT OF OPEN EDUCATIONAL RESOURCES}

\section{$\mathrm{T}$} he adoption of OERs has increased in recent years within schools and universities worldwide. However, in spite of several initiatives related to OERs, the development and sharing of OERs remains limited (PETRIDES et al., 2008; SCLATER, 2009; SANTOS, 2013; ARIMOTO; BARROCA; BARBOSA, 2015).

Similarly to the software development, the production of OERs requires the use of appropriate mechanisms to ensure the productivity of the development process and the quality of the resulting materials (ARIMOTO; BARBOSA, 2012b). This chapter covers the background on the development of OERs in order to obtain an overview of the development process of learning materials, particularly OERs, and better understand how these materials have been produced worldwide.

In Section 4.1 we discuss the planning and conduction of a systematic mapping research to investigate the mechanisms/approaches that have been proposed and used to support the development of learning materials. Additionally, we are interested in identifying the application of agile methods in the development of OERs. The purpose is to characterise the approaches applied in the development of learning materials, identifying gaps and needs associated to the development of OERs. In Section 4.2 we discuss the planning and conduction of a quantitative survey research to investigate how OERs have been developed in Brazil. The purpose is to characterise the development of OERs in Brazilian context, identifying the main problems and barriers, as well as the factors that may contribute to enhance the development and adoption of OERs in Brazil. Concluding remarks are given in Section 4.3. 


\subsection{Approaches for the Development of OERs: A Systematic Mapping}

This study provides an overview on the development of learning materials. We aim to identify which mechanisms/approaches have been applied in the development of learning materials, especially OERs. The study follows an evidence-based paradigm, particularly a systematic mapping. We chose the systematic mapping as research method/approach because it is useful when the objective is to obtain an overview of a research area (a map), identifying the number and type of research undertaken and the results available in this area (PETERSEN et al., 2008).

Historically, evidence-based paradigm has been successfully used in clinical medicine, being expanded to other disciplines, such as psychiatry, nursing and education. More recently, it has raised the interest of software engineering community, aimed to provide knowledge about "when", "how" and " in which context" technologies, methods, processes and tools are more suitable for software engineering practices (KITCHENHAM, 2004; KITCHENHAM, 2007).

A mapping study provides "a systematic and objective procedure for identifying the nature and extent of the empirical study data that is available to answer a particular research question" (BUDGEN et al., 2008). The research question is more general/broader than specific, as in a systematic review approach. The aim is to map the study within a research area instead of providing detailed information about a research question or interest phenomenon (PETERSEN et al., 2008).

Unlikely traditional literature reviews, usually carried out in an AD-HOC way, a systematic mapping is formally planned, having well-defined stages to minimise bias and produce research with scientific significance. On the other hand, by adopting rigorous strategies it requires more effort and time to be conducted.

It is important to notice that this systematic mapping research is a reexecution/updating of a study previously conducted in Arimoto e Barbosa (2012b).

\subsubsection{Objectives and Research Questions}

The overall aim of this study is to characterise the mechanisms/approaches for the development of OERs. We intend to investigate and analyse approaches used to support the development process of learning materials, focusing on OERs. In particular, we are interested in investigating the proposition and usage of agile methods for the development of OERs.

In order to address these objectives, we defined the following Research Questions (RQ):

- RQ1. Which approaches have been proposed and used for the development of learning materials to date?

- RQ2. Which of these approaches are specifically related to agile methods? 
- RQ3. Which of these approaches are specifically applied for the development of OERs?

The research questions were grounded in different perspectives, having the following scope and specificities: (1) intervention: the development of learning materials; (2) population: studies covering the development of learning materials; and (3) results: approaches supporting the development of learning materials, focusing on OERs.

\subsubsection{Data Sources and Search Strategies}

The data sources were selected taking into account their importance and relevance, the search query accessible through the web, the number of indexed researches, and the reliability of the results. In Table 7 we present the selected data sources. It includes electronic and manual data sources, i.e., conference proceedings, journals and reference search engine (Google Scholar). The languages for the studies under investigation were English and Portuguese.

Table 7 - Data sources for the studies.

\begin{tabular}{ll}
\hline Digital Library & $\begin{array}{l}\text { Manual (Conference Proceedings, Journal and Reference } \\
\text { Search Engine) }\end{array}$ \\
\hline - ACM Digital Library & - Congresso Brasileiro de Informática na Educação (CBIE) \\
- IEEE Xplore Digital Library & - Revista Brasileira de Informática na Educação (RBIE) \\
- Scopus & - Google Scholar \\
- Web of Knowledge (Web of Science) & \\
- Compendex & \\
\hline
\end{tabular}

Source: Elaborated by the author.

We established a set of common terms and synonyms related to the topic under investigation and divided the terms into two categories: (1) approaches: including methods, methodologies and processes; and (2) educational resources: including open educational resources, learning objects, educational modules, learning materials and learning contents.

In Table 8 we present a general search string generated from the combination of the terms and synonyms defined for the study using Boolean operators (AND/OR). When necessary, the search string was refined and modified to suit the needs of each data source. Specific keywords such as "agile" and "education" were used in some data sources. This procedure aimed at assessing the relevance of the terms used and the retrieved studies through the search.

All searches were limited per year, ranging from 2001 to part of 2015. The restriction from 2001 was due to the fact that OERs and agile methods started appearing in such period. In certain data sources, such as Scopus and Web of Knowledge, searches were also limited by area, i.e., Computer Science, Engineering, Education and Educational Research. 
Table 8 - General search string.

$$
\begin{aligned}
& \text { ((“approach" OR "method" OR "methodology" OR "process") AND } \\
& \text { ("oer" OR "open educational resource" OR "learning object" OR } \\
& \text { “educational module" OR "learning material" OR learning content")) }
\end{aligned}
$$

Source: Elaborated by the author.

\subsubsection{Studies Selection}

To obtain coherent and consistent results for the research we defined some inclusion and exclusion criteria for the retrieved studies. Inclusion Criteria (IC) included:

- IC1. Studies describing approaches for the development of learning materials;

- IC2. Studies focusing on the proposition and/or usage of approaches for the development of OERs;

- IC3. Studies focusing on the proposition and/or usage of agile approaches for the development of OERs; and,

- IC4. Studies published in English or Portuguese language (and that meet the IC1, IC2, and IC3 criteria).

The Exclusion Criteria (EC) were defined as follows:

- EC1. Studies describing approaches applied in other areas;

- EC2. Studies focusing on proposition and/or usage of agile approaches in other contexts;

- EC3. Studies focusing on open contents outside the educational context; and,

- EC4. Studies not fully available for download or reading.

The studies selection was performed in two phases. Firstly, the studies retrieved by the data sources were filtered through a preliminary selection based on reading their title, keywords and abstracts. Duplicate studies, found in more than one data source, were excluded. Secondly, the potentially relevant studies were read fully by two reviewers. Disagreement in relation to the inclusion or exclusion of a particular study was discussed face-to-face between reviewers. When conflicting opinions persisted, the study was submitted to another reviewer. As the studies were selected, relevant information about them was gathered and documented for further analysis. 


\subsubsection{Data Analysis and Results}

The systematic mapping was conducted from June 2015 to August 2015. The search conducted on the selected data sources retrieved 1364 studies. In Table 9 we summarise the number of studies selected in each data source, both in the preliminary and final selection phases. In the preliminary selection, we identified 122 potentially relevant studies. After a complete reading of the pre-selected studies, we identified 28 relevant primary studies to the research objectives. We found a significant number of duplicate studies. This occurs because some data sources, such as Compendex and Scopus, index other data sources, including IEEE Xplore Digital Library and ACM Digital Library.

Table 9 - Summary of the included and excluded primary studies of each data source.

\begin{tabular}{lccccc}
\hline \multirow{2}{*}{ Data Sources } & Results & \multicolumn{2}{c}{ Preliminary Selection } & \multicolumn{2}{c}{ Final Selection } \\
\cline { 3 - 6 } & & Included & Excluded & Included & Excluded \\
\hline ACM Digital Library & 393 & 15 & 378 & 2 & 13 \\
IEEE Xplore Digital Library & 262 & 28 & 233 & 7 & 21 \\
Scopus & 234 & 21 & 213 & 3 & 18 \\
Web of Knowledge (Web of Science) & 109 & 12 & 97 & 3 & 9 \\
Compendex & 343 & 23 & 320 & 3 & 20 \\
CBIE and RBIE & 6 & 6 & & 5 & 1 \\
Google Scholar & 17 & 17 & & 5 & 12 \\
Total & 1364 & 122 & 1240 & 28 & 94 \\
\hline
\end{tabular}

Source: Research data.

All selected primary studies are summarised in Table 10. Most of the primary studies were selected according to the IC1 and IC4 inclusion criteria.

In Figure 9 we show the distribution of the primary studies according to the type of publication. We obtained primary studies published in Journals/Periodicals, Conferences, Symposiums, Workshops and Books. Most of them were published in Conferences (12 primary studies), followed by Journals/Periodicals (7 primary studies) and Symposiums (6 primary studies).

In Figure 10 we show the distribution of the primary studies according to the year of publication - from 2001 to 2015 . We observed an increase in the number of studies concerning the development of learning materials, showing the community's interest in this research area. The results highlight the importance of conducting and keeping up to date empirical research in this area.

Following we map and summarise some evidences in order to answer the research questions of this systematic mapping. 
Table 10 - Summary of the selected primary studies.

\begin{tabular}{|c|c|c|c|}
\hline ID & Study Title & Reference & $\begin{array}{l}\text { Inclusion } \\
\text { Criteria }\end{array}$ \\
\hline PS1 & $\begin{array}{l}\text { Towards the establishment of supporting mechanisms for modelling and } \\
\text { generating educational content }\end{array}$ & $\begin{array}{l}\text { (BORGES; } \\
\text { MALDONADO; } \\
\text { BARBOSA, 2011) }\end{array}$ & IC1,IC4 \\
\hline PS2 & $\begin{array}{l}\text { Enforcing reuse and customization in the development of learning objects: a } \\
\text { product line approach }\end{array}$ & (LABIB et al., 2015) & IC1,IC4 \\
\hline PS3 & Establishing a mutation testing educational module based on IMA-CID & $\begin{array}{l}\text { (BARBOSA; } \\
\text { MALDONADO, 2006) }\end{array}$ & IC1,IC4 \\
\hline PS4 & $\begin{array}{l}\text { Specialization and instantiation aspects of a standard process for developing } \\
\text { educational modules }\end{array}$ & $\begin{array}{l}\text { (BARBOSA; } \\
\text { MALDONADO, 2008) }\end{array}$ & IC1,IC4 \\
\hline PS5 & $\begin{array}{l}\text { Rapid prototyping of learning objects for agricultural and biological } \\
\text { engineering education }\end{array}$ & $\begin{array}{l}\text { (SEPULVEDA et al., } \\
\text { 2006) }\end{array}$ & IC1,IC4 \\
\hline PS6 & $\begin{array}{l}\text { Towards the establishment of an agile method for OERs development and } \\
\text { delivery }\end{array}$ & $\begin{array}{l}\text { (ARIMOTO; } \\
\text { BARBOSA, 2013) }\end{array}$ & $\begin{array}{l}\text { IC } 1, \text { IC } 2, \\
\text { IC } 3, \text { IC } 4\end{array}$ \\
\hline PS7 & $\begin{array}{l}\text { An experience on applying learning mechanisms for teaching inspection and } \\
\text { software testing }\end{array}$ & $\begin{array}{l}\text { (BARBOSA; SOUZA; } \\
\text { MALDONADO, 2008) }\end{array}$ & IC1,IC4 \\
\hline PS8 & A methodology for design collaborative learning objects & $\begin{array}{l}\text { (FUENTES; ARTEAGA; } \\
\text { RODRIGUEZ, 2008) }\end{array}$ & IC1,IC4 \\
\hline PS9 & $\begin{array}{l}\text { Employing object-oriented design principles in the design of learning objects } \\
\text { in a software engineering course }\end{array}$ & $\begin{array}{l}\text { (MOHAN; BUCAREY; } \\
\text { DANIEL, 2006) }\end{array}$ & IC1,IC4 \\
\hline PS10 & A framework for learning objects reusability within learning activities & $\begin{array}{l}\text { (SAMPSON; } \\
\text { PAPANIKOU, 2009) }\end{array}$ & IC1,IC4 \\
\hline PS11 & A model-driven development of learning objects & $\begin{array}{l}\text { (SILVA; BARBOSA; } \\
\text { MALDONADO, 2011) }\end{array}$ & IC1,IC4 \\
\hline PS12 & $\begin{array}{l}\text { Modelling process for the development of learning content for tertiary } \\
\text { education }\end{array}$ & (WU; DOULAI, 2010) & IC1,IC4 \\
\hline PS13 & Metodologia para construção de objetos de aprendizagem interativos & $\begin{array}{l}\text { (KEMCZINSKI et al., } \\
\text { 2012) }\end{array}$ & IC1,IC4 \\
\hline PS14 & Metodologia intera para o desenvolvimento de objetos de aprendizagem & $\begin{array}{l}\text { (BRAGA; PIMENTEL; } \\
\text { DOTTA, 2013) }\end{array}$ & IC1,IC4 \\
\hline PS15 & $\begin{array}{l}\text { Modelo de desenvolvimento de objetos de aprendizagem baseado em } \\
\text { metodologias ágeis e scaffoldings }\end{array}$ & (LAPOLLI et al., 2010) & $\begin{array}{l}\text { IC } 1, \mathrm{IC} 2 \\
\mathrm{IC} 4\end{array}$ \\
\hline PS16 & Ciclo de vida de objetos de aprendizagem baseado no padrão SCORM & $\begin{array}{l}\text { (OLIVEIRA; NELSON; } \\
\text { ISHITANI, 2007) }\end{array}$ & IC1,IC4 \\
\hline PS17 & $\begin{array}{l}\text { Elaboração de objetos de aprendizagem para o LAPREN: processo de } \\
\text { desenvolvimento e sistema de produção }\end{array}$ & (MORAES et al., 2011) & IC1,IC4 \\
\hline PS18 & $\begin{array}{l}\text { Um aprimoramento do modelo de processo de criação de objetos de } \\
\text { aprendizagem do projeto RIVED }\end{array}$ & (AMARAL et al., 2006) & IC1,IC4 \\
\hline PS19 & $\begin{array}{l}\text { New design approach to repurposing open educational resources for } \\
\text { collaborative learning using mediating artefacts }\end{array}$ & $\begin{array}{l}\text { (DIMITRIADIS et al., } \\
\text { 2009) }\end{array}$ & $\begin{array}{l}\text { IC1,IC3, } \\
\text { IC4 }\end{array}$ \\
\hline PS20 & $\begin{array}{l}\text { Uma experiência para definição de storyboard em metodologia de } \\
\text { desenvolvimento colaborativo de objetos de aprendizagem }\end{array}$ & $\begin{array}{l}\text { (OLIVEIRA; AMARAL; } \\
\text { BARTHOLO, 2010) }\end{array}$ & IC1,IC4 \\
\hline PS21 & OER's production cycle with social authorship and semantic tools & $\begin{array}{l}\text { (PATRICIA; } \quad \text { ROCIO; } \\
\text { ELIZABETH, 2010) }\end{array}$ & $\begin{array}{l}\text { IC } 1, \mathrm{IC} 3 \\
\mathrm{IC} 4\end{array}$ \\
\hline PS22 & Proposta de um processo para produção de objetos de aprendizagem & $\begin{array}{l}\text { (PESSOA; BENITTI, } \\
\text { 2008) }\end{array}$ & IC1,IC4 \\
\hline PS23 & $\begin{array}{l}\text { Towards the establishment of a standard process for developing educational } \\
\text { modules }\end{array}$ & $\begin{array}{l}\text { (BARBOSA; } \\
\text { MALDONADO, 2006) }\end{array}$ & IC1,IC4 \\
\hline PS24 & An agile method for developing learning objects & (BOYLE et al., 2006) & $\begin{array}{l}\text { IC } 1, \mathrm{IC} 2, \\
\mathrm{IC} 4\end{array}$ \\
\hline PS25 & Didactic designing of learning objects & $\begin{array}{l}\text { (VAKHTINA; } \\
\text { PALKOVÁ, 2015) }\end{array}$ & IC1,IC4 \\
\hline PS26 & $\begin{array}{l}\text { Layered learning design: towards an integration of learning design and } \\
\text { learning object perspectives }\end{array}$ & (BOYLE, 2010) & IC1,IC4 \\
\hline PS27 & Semantic web technologies for e-learning: models and implementation & $\begin{array}{l}\text { (DAGIENE; } \\
\text { GUDONIENE; } \\
\text { BURBAITE, 2015) }\end{array}$ & IC1,IC4 \\
\hline PS28 & A case study: developing learning objects with an explicit learning design & (WATSON, 2010) & IC1,IC4 \\
\hline
\end{tabular}

Source: Research data. 
Figure 9 - Distribution of the primary studies by type of publication.

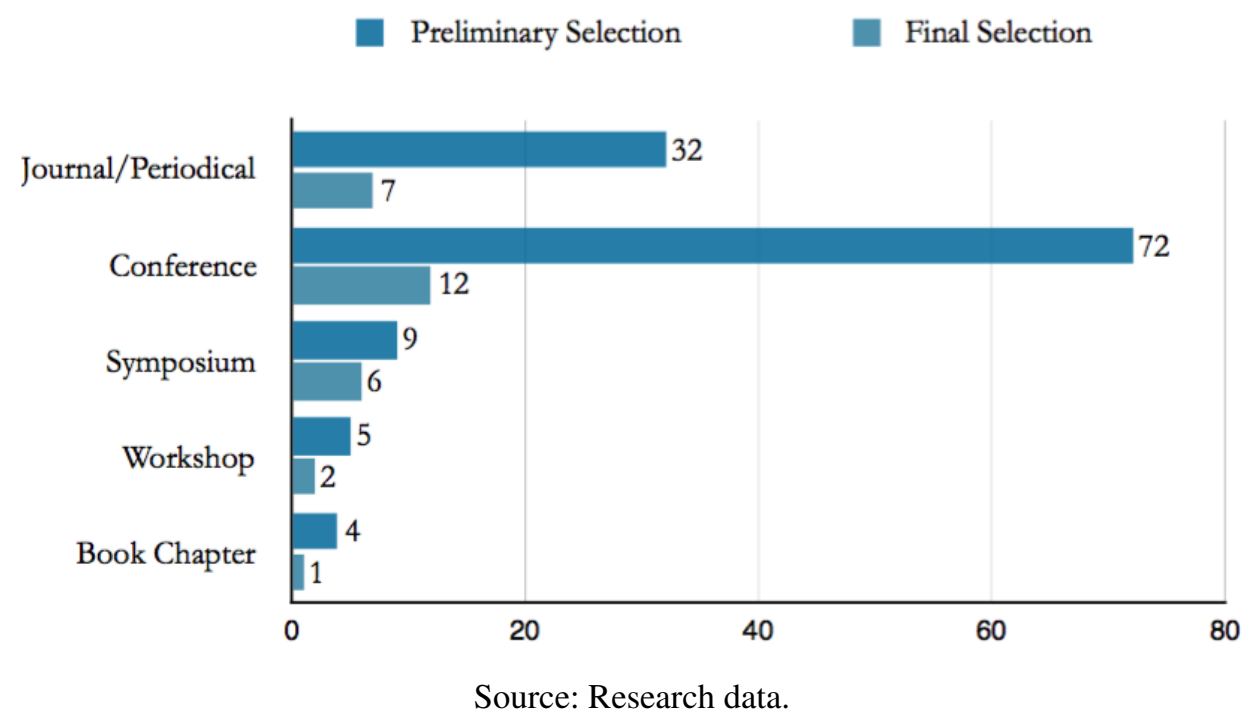

Figure 10 - Distribution of the primary studies by year of publication.

Preliminary Selection

Final Selection

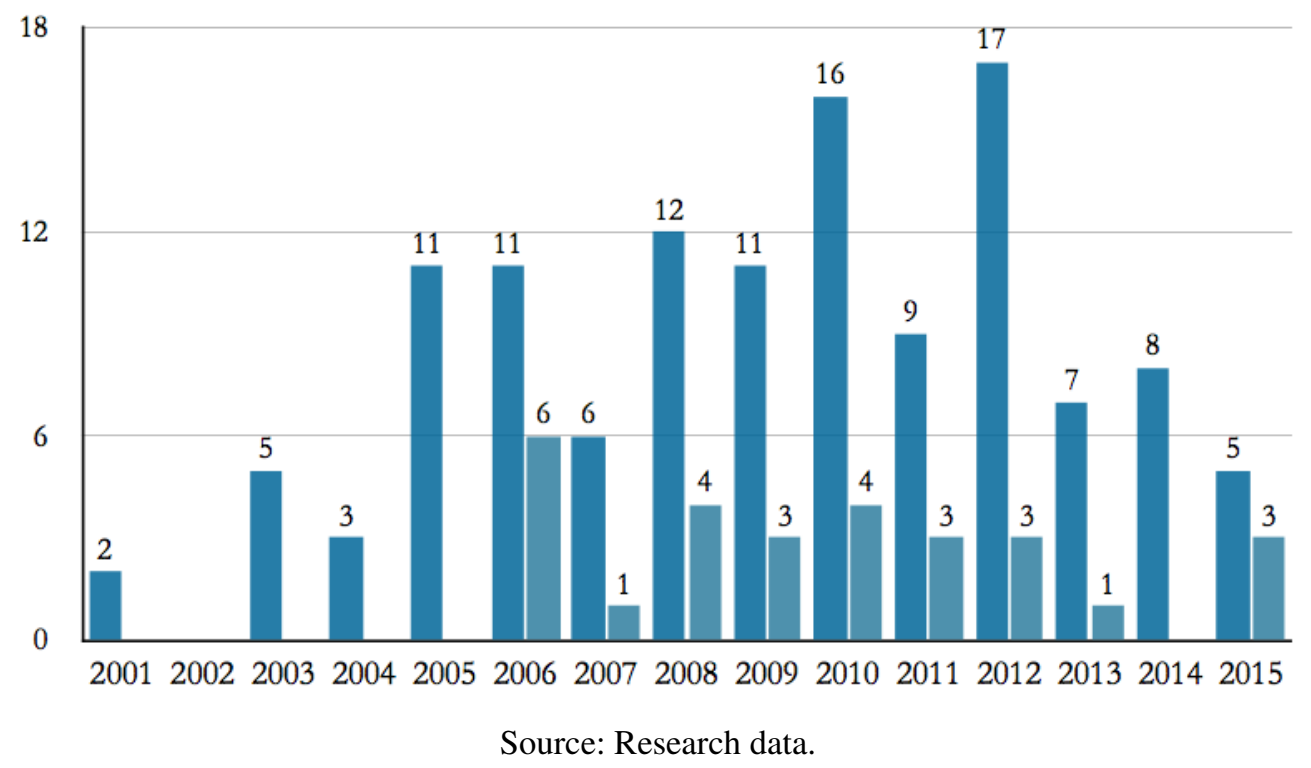

\section{RQ1. Which approaches have been proposed and used for the development of learning materials to date?}

RQ1 aimed at investigating and providing a general overview of the mechanisms/approaches being applied in the development of learning materials to date. As summarised in Table 10, the systematic mapping resulted in 28 primary studies. To map the approaches proposed and/or used for the development of learning materials we created a classification scheme according to the "type" of approach described in the primary studies. 
By analysing the studies through skimming and scanning their contents, we classified the approaches as: (1) method/methodology; (2) process; (3) life cycle; (4) model; and (5) framework. Although similar, these terms have subtle differences among them. For instance, a method is a set of systematic activities and procedures for achieving an objective, and a methodology is a body of methods. Similarly, a process is an organised set of activities and procedures generating a specific result, and a life cycle prescribes a set of structured phases for achieving this result. On the other hand, a framework is a set of abstract solutions for specific and related problems, whilst a model is a conceptual representation of solutions for these problems (ARIMOTO; CAMARGO; CAGNIN, 2007; ARIMOTO; CAMARGO; CAGNIN, 2008).

We also classified the primary studies taking into consideration the level of coverage (focus) of each approach described in the primary studies. By skimming and scanning the studies we categorised the approaches into four different focus: (1) modelling and content generation; (2) design; (3) reuse and customisation; and (4) whole process.

In Figure 11 we present the classification of the studies according to the types of approach and their focus. The results show that model is related to $36 \%$ of the studies (i.e., 10 studies), followed by $29 \%$ of method/methodology ( 8 studies), $25 \%$ of process ( 7 studies), $7 \%$ of life cycle ( 2 studies), and $4 \%$ of framework (only 1 study) (Figure 11a). In relation to the focus of each approach, almost half of them (46\%) focus on the development process as whole (i.e., 13 studies), 32\% focus on the design ( 9 studies), $14 \%$ focus on the modelling and content generation (4 studies), whilst $7 \%$ focus on the reuse and customisation ( 2 studies) (Figure 11b).

Figure 11 - Distribution of the primary studies through approach type and focus

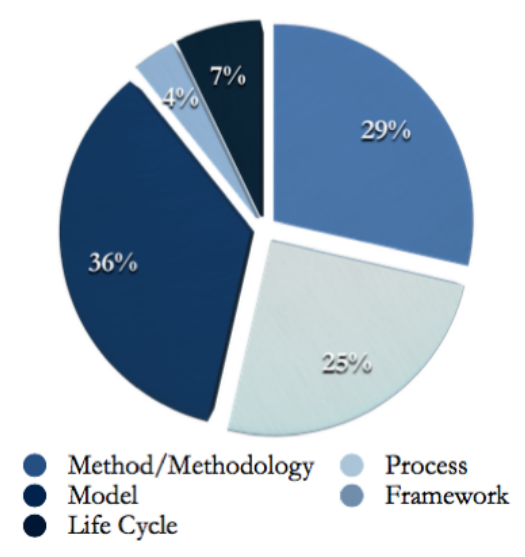

(a) Approach type

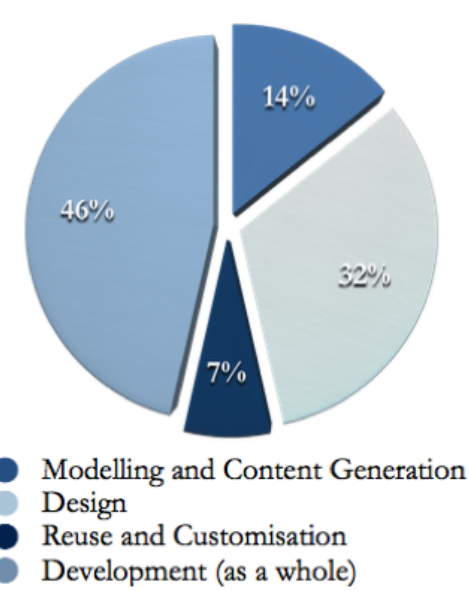

(b) Approach focus

Source: Research data.

In order to identify the research approach used by each primary study we adopted the classification scheme proposed by Wieringa et al. (2006) in the context of requirement engineering. Petersen et al. (2008) argue that the research facet that reflects the research approach 
used by a study is "general and independent from a specific focus area". This classification scheme is composed by six research approach facets:

1. Evaluation Research: the study implements the techniques in practice and assesses them. It involves the solution implementation and its consequence regarding the benefits and drawbacks.

2. Validation Research: the study investigates novel techniques - they are not implemented in practice. Such techniques include experiments conducted in controlled environment without external interference.

3. Solution Proposal: the study proposes a solution to a problem. It is a novel solution or substantial improvement of an existing technique without a full-blown validation. A small example or strong argument is used to assess the feasibility and applicability of the solution.

4. Philosophical Paper: the study sketches a new way of looking at existing things, structuring the area of research through a conceptual framework.

5. Experience Paper: the study demonstrates the author's personal experience regarding what something has been done in practice.

6. Opinion Paper: the study reports the author's opinion regarding specific techniques or things, including their strengths, and weaknesses, and how they should be used or implemented.

In Figure 12 we present the distribution of the primary studies according to classification scheme previously described. More than half of the primary studies (57\%) use solution proposal as research approach (i.e, 16 studies), whilst $25 \%$ of them use experience paper ( 7 studies). In relation to the remaining primary studies, $7 \%$ use validation research as research approach (2 studies), whilst 3.6\% use evaluation research (1 study), 3.6\% use philosophical paper (1 study), and $3.6 \%$ use opinion paper (1 study).

Figure 12 - Distribution of the primary studies by research approach.

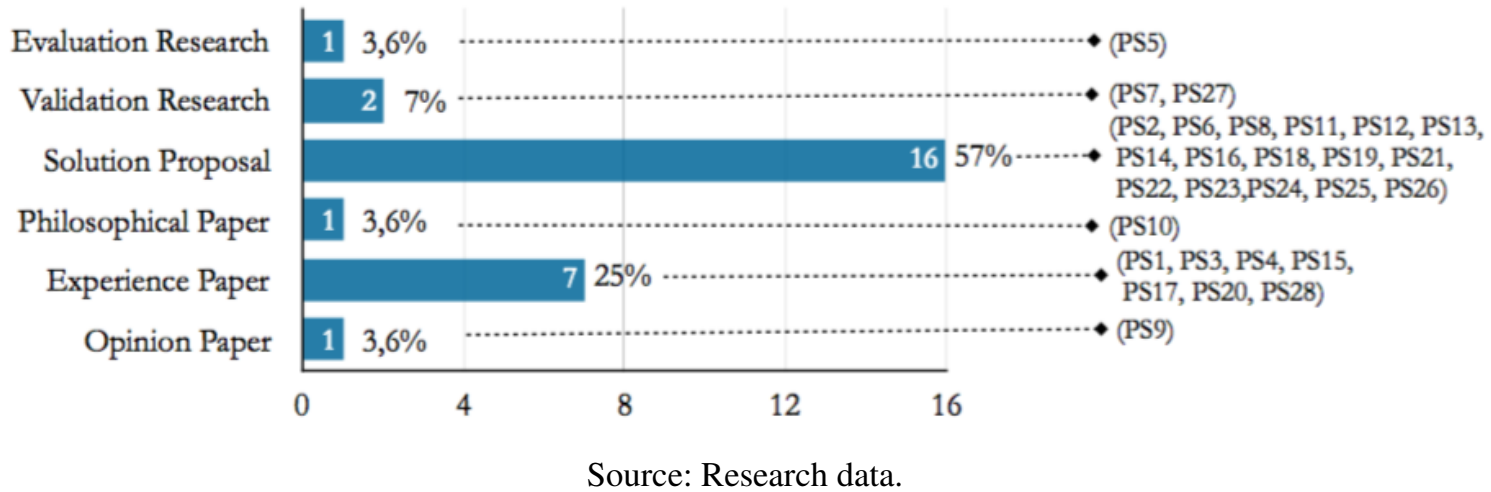


Finally, we mapped the types of approaches described in the primary studies (axis $x$ ) with the research approach (axis $y$ ) adopted by them to obtain a better understanding on the studies. Most of the methods/methodologies are related to validation research (6 studies), processes are related to solution proposal (4 studies) and experience paper ( 2 studies), life cycles are related to solution proposal (2 studies), framework is related to philosophical paper (1 study), whilst models are related to solution proposal (4 studies) and experience paper (4 studies) (Figure 13).

Figure 13 - Distribution of primary studies through type and research approach.

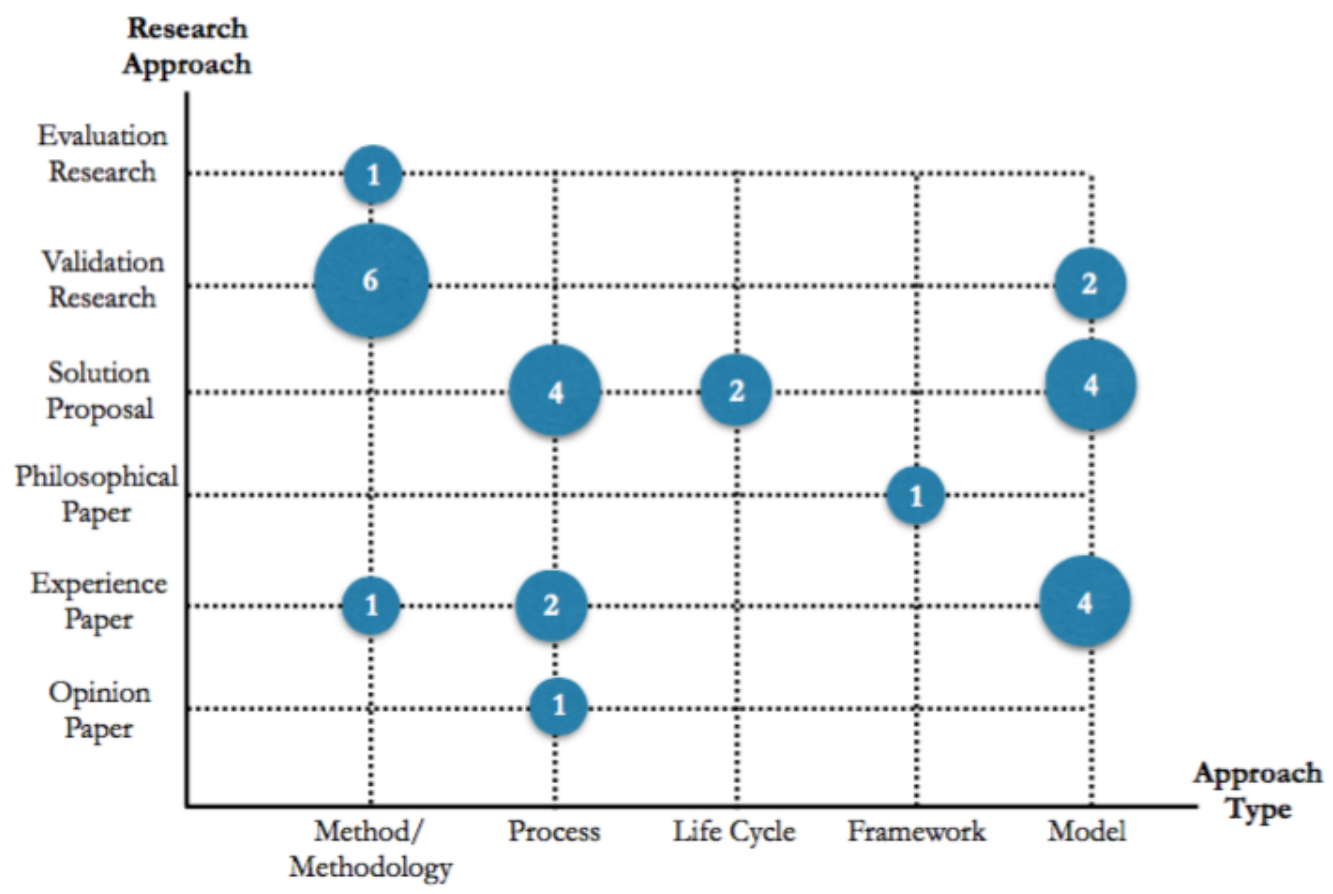

Source: Research data.

\section{RQ2. Which of these approaches are specifically related to agile methods?}

RQ2 aimed at investigating and identifying the primary studies describing approaches specifically related to the application of agile methods in the context of learning materials, focusing on OERs development. In order to map the approaches and identify which are specifically related to agile methods, we created a classification scheme taking into account the "foundation" of the approaches described in the primary studies. By skimming and scanning the study contents we found approaches based on: (1) standard process, (2) product lines, (3) rapid prototyping, (4) agile methods, (5) design patterns and oriented-object (OO) design , (6) model-driven development (MDD), (7) traditional methods, (8) instructional design (ISD), (9) learning design, and (10) semantic design.

In Figure 14 we show the distribution of the primary studies following the classification previously mentioned. Analysing the studies we identified only three approaches (11\%) 
addressing this research question (i.e., PS6, PS15, PS24). The first approach related to agile methods (PS15) was proposed by Boyle et al. (2006) in mid-2006. The authors defined an agile method focusing on LOs aiming at providing a robust and flexible structure that contributes to the development of these kind of materials.

The second approach related to agile methods (PS24) was proposed by Lapolli et al. (2010) in mid-2010. The authors proposed a model focusing on the instructional design of LOs grounded in agile methods, specifically behaviour-driven development (BDD) practice, and interaction design through scaffolding's interface (AUSUBEL, 2003).

Figure 14 - Distribution of the primary studies by approach proposed/used.

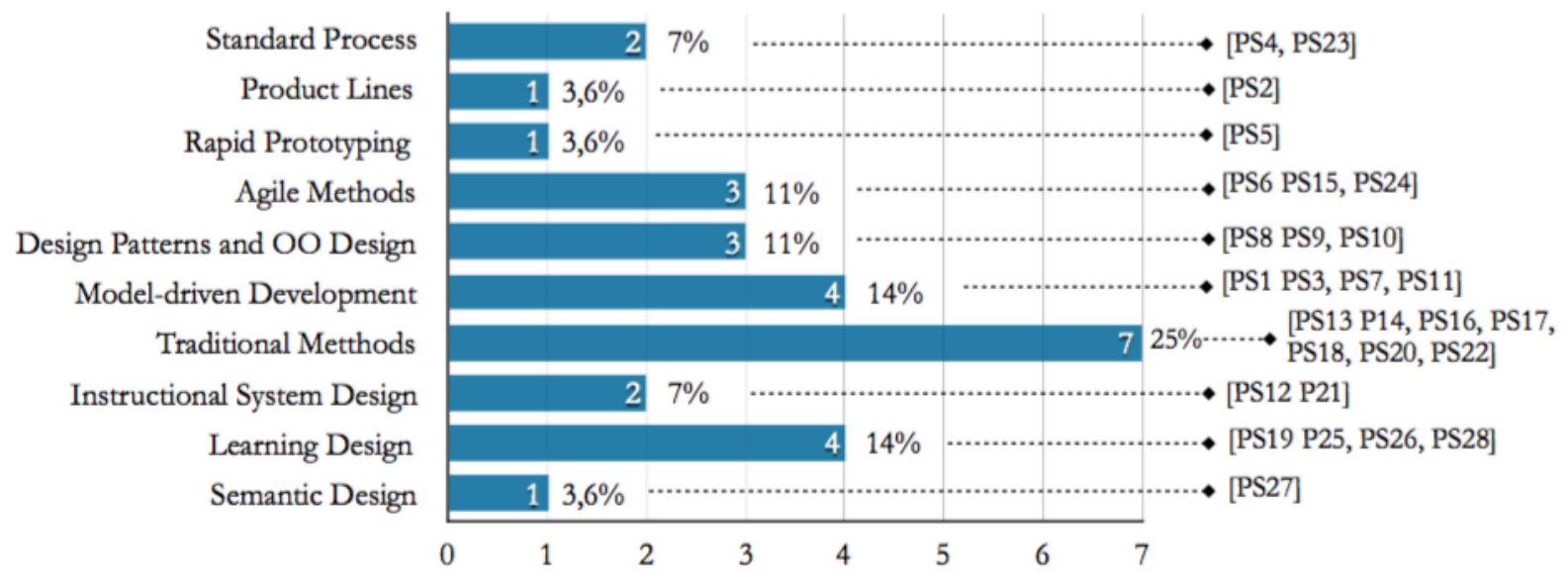

Source: Research data.

The third approach related to agile methods (PS6) (ARIMOTO; BARBOSA, 2013) is an attempt to minimise the lack of agile methods specifically applied to the context of OERs development. The authors proposed a preliminary version of an agile method to support the development and delivery of quality OERs, particularly based on practices of Scrum and XP.

In relation to other approaches, many of them are based on traditional methods/plan-driven used derived from software development (25\%) such as sequential model/cascade. We also found approaches based on other well-known technologies focused on software development, including design patterns and object-oriented $(\mathrm{OO})$ design principles (11\%), standard processes (7\%), such as ISO/IEC 12207 Standard (International Organization for Standardization, 2008), product lines engineering principles and tools (4\%), and rapid prototyping principles and practices $(4 \%)$.

Specific approaches focused on the design and development of learning materials were also identified, including Learning Design practices (14\%), and instructional system design (ISD) such as ADDIE model (STRICKLAND, 2006) (7\%).

In Figure 15 we map the approaches proposed/used (axis $x$ ) with their level of coverage or focus (axis $y$ ). The results show that half of the approaches described in the primary studies are focused on the development process (as a whole), whilst the other half focus on specific 
parts/phases of the development process. Considering the approaches related to application of agile methods, we observe that two approaches are focused on the whole development process, while one approach is focused on the design phase.

\section{RQ3. Which of these approaches are specifically applied for the development of OERs?}

RQ3 aimed at investigating and identifying the primary studies that propose/use approaches specifically focused on the development of OERs. For this, we classified the approaches described in the primary studies according to the development purpose of each one, including: (1) educational modules; (2) learning objects; and (3) open educational resources (OERs).

Figure 15 - Distribution of primary studies through approach proposed/used and focus.

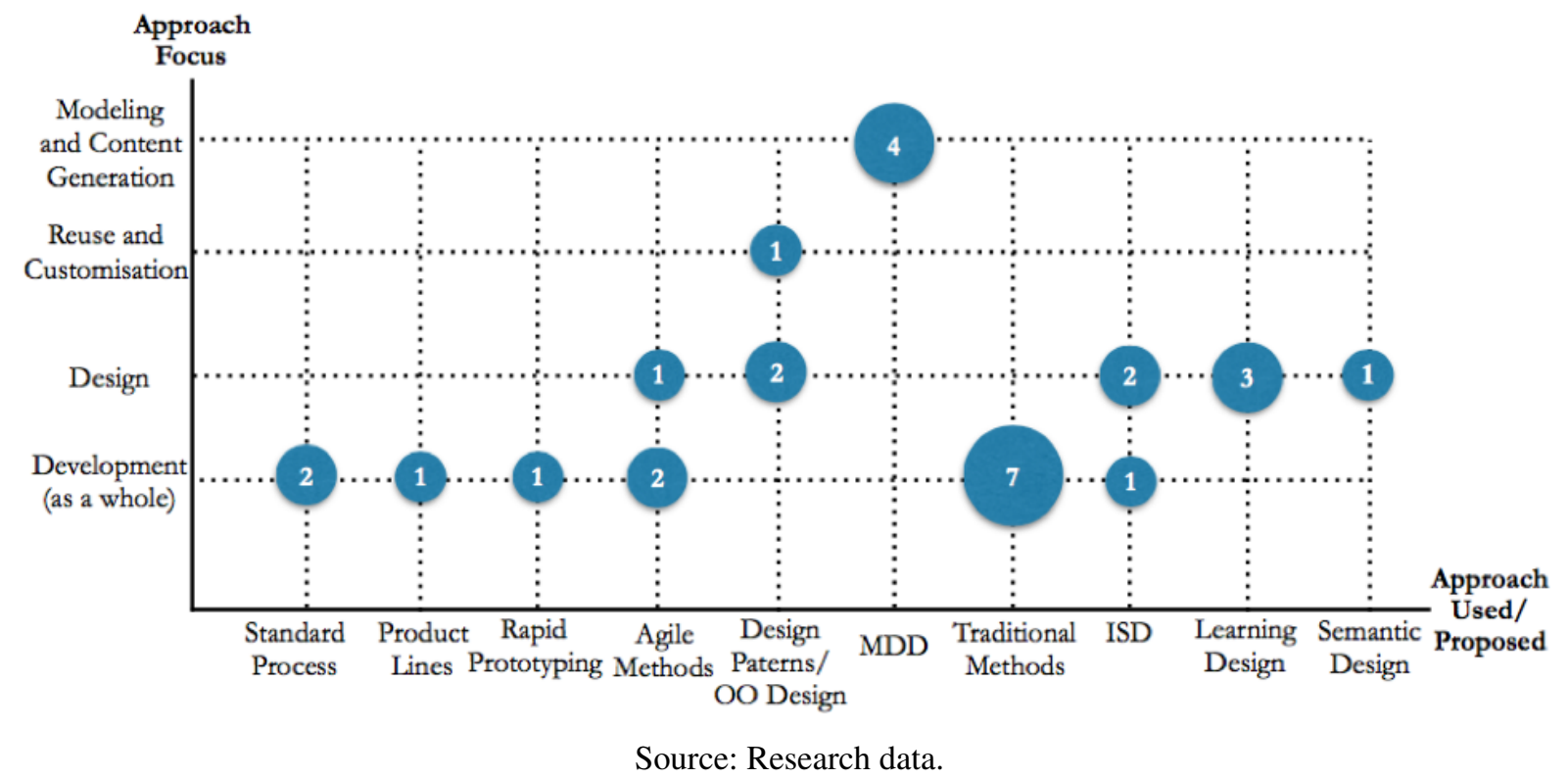

In Figure 16 we present the distribution of the primary studies according to the classification scheme aforementioned. The results show that only few approaches found are focused on the development of OERs, representing $11 \%$ of approaches (i.e., 3 studies). On the other hand, most of the approaches are focused on the development of LOs $(68 \%-19$ approaches), followed by approaches focused on the development of educational modules ( $21 \%$ -6 approaches).

Finally, in Figure 17 we map the type of approaches described in the primary studies (axis $x$ ) with the purpose of each one (axis $y$ ). The first initiative specifically for the OERs development was proposed in mid-2009 (DIMITRIADIS et al., 2009). It consists of a process that focuses on the design and repurposing OERs based on learning design approach. The second initiative related to OERs development was proposed in mind-2010 by Patricia, Rocio e Elizabeth (2010). It consists of a life cycle for the development of OERs with a set of 
well-defined phases based on ADDIE model. It also includes activities to incorporate social networking and semantic technologies. Another initiative related to OERs development was proposed in mid-2013 (ARIMOTO; BARBOSA, 2013), consisting of an agile method for the development and delivery of OERs, as previously mentioned.

Figure 16 - Distribution of the primary studies by development purpose.

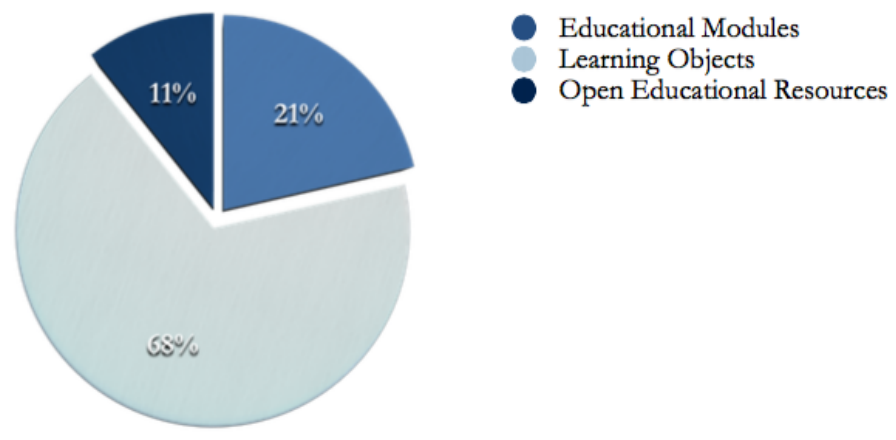

Source: Research data.

Figure 17 - Distribution of the primary studies through approach type and purpose.

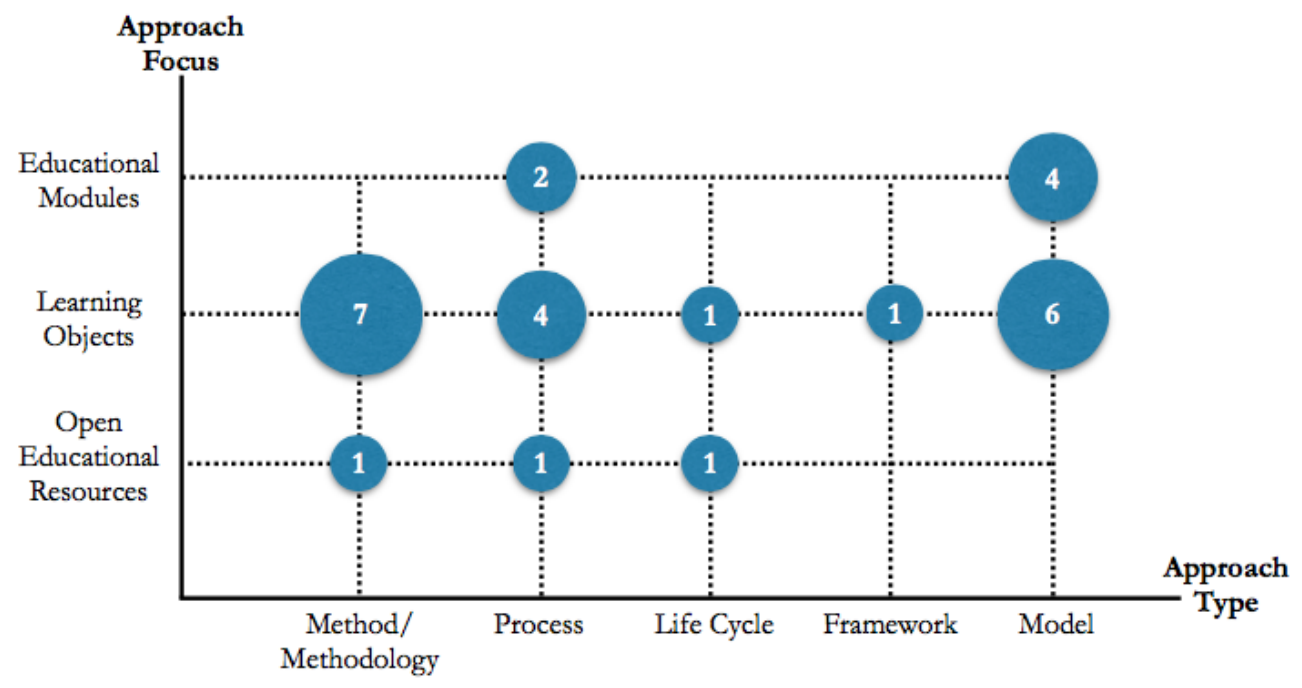

Source: Research data.

\subsubsection{Threats to Validity}

The main threats to validity related to this systematic mapping are summarised next:

- Search strategies: when using automated searches, potentially relevant studies cannot be retrieved by the data sources. Recent studies cannot be indexed by search engines as well. The same can occur with studies published in Portuguese language. We have tried to use significant terms and keywords associated to the subject under investigation. The general search string was tested and refined several times before executing the systematic 
mapping. We also used manual searches including reference search, journal and conference proceedings of the research area.

- Sample representativeness: the quantity of selected primary studies is still small and may not be representative of the population. However, we have tried to conduct a comprehensive and exhaustive search for primary studies in order to obtain the maximum relevant studies and achieve consistent and coherent results for the research.

- Studies Selection: when searching for potentially relevant studies, hundreds of results can be retrieved by the data sources. Then, the first selection filter for the studies found takes place through skimming and scanning their title, keywords and abstracts. Some studies can be excluded if they have a poor abstract but a rich content. We have tried to minimise this risk by using peer-review, and considering the whole content. Sometimes conflicting opinions on a particular study may reject it even though the study is relevant to the research. In this case, we considered the opinion of another reviewer in order to solve any doubt or divergent opinion on rejecting or accepting a study.

\subsubsection{Summary of the Results}

From the systematic mapping conducted, we were able to identify different approaches applied to the development of learning materials. Some of them have been proposed to address specific needs including modelling and content generation, design or reuse and customisation of learning; whilst others are more generic, focusing on the whole development process of learning materials.

Among the approaches focusing on the whole process, most of them are based on traditional methods derived from software development. For instance, two studies (PS4 and PS23) describe a Standard Process for Developing Educational Modules (SP-DEM) based on the ISO/IEC 12207. Similarly, other studies (PS13, PS14, PS16, PS17, PS18, and PS20), describe life cycles and methodologies for developing LOs based on sequential model/cascade from software development. These approaches are plan-driven and have characteristics in common, with little flexibility and lack of involvement of users (especially educators and learners) throughout the development. Due to their strictly sequential characteristics, the development process becomes little flexible and adaptable to changes. In general, the team can only advance to the next stage after finishing the previous one.

Regarding the research approach of the primary studies, we identified that most of them uses solution proposal as research approach, wherein the authors propose a solution or a considerable improvement for a particular problem, followed by a small example of implementing the proposal to verify its feasibility and applicability (i.e., as described in the PS11, PS16, and PS23 studies). 
We found some initiatives that intend to make the development process of learning materials more collaborative and flexible. In this context, Boyle et al. (2006) proposed an agile method for learning materials covering the main phases of a development process, whilst Lapolli et al. (2010) proposed a model based on agile practices focusing on the content and instructional design. These approaches are specifically focused on the development of LOs, and may not be suitable for the development of OERs. Particularly, they do not address specific issues related to the development of OERs, such as the need for clear definition of licensing policies for the associated contents (e.g., permissions for using, reusing, remixing, and sharing). Also, they do not consider the involvement and effective participation of the users throughout the development process.

Although the approaches for developing learning materials found through the systematic mapping have characteristics in common, each one denotes different aspects, which can be tailored to a particular educational context and inappropriate to others.

Another finding is related to the little attention given specifically to the development of OERs. We identified only three studies proposing approaches for OERs. The first approach (presented in the PS19 study) is based on learning design approach and focuses on the design process aiming at facilitating the repurpose of OERs. The second (presented in the PS21 study) covers the whole process, proposing a life cycle with predefined phases for the development of OERs. However, the life cycle is based on the ADDIE model that follows the traditional methods for software development. Therefore, it has the same shortcomings of the approaches previously mentioned. The third approach (presented in the PS6 study) covers the whole process and is based on agile methods in order to make the development of OERs flexible and easier. This approach is a preliminary version of an agile method for OERs proposed by the authors of this P.h.D. research.

We claim that the systematic mapping performed has highlighted the gaps and identified trends for research and development. In particular, we highlight the need for a systematic and flexible approach for the development and delivery of OERs, which is the main aim of this P.h.D. work.

\subsection{Development of OERs in Brazil: A Survey Research}

The second study aims to determine how OERs have been developed in Brazil and identify the main barriers to the development and dissemination of OERs across the country. In this study we use a research method based on the observation - a quantitative survey to collect, manipulate and analyse empirical data (PFLEEGER; KITCHENHAM, 2003). We chose the survey as a research method/approach because it is useful when the objective is to collect information of a population of individuals (in our case, developers and practitioners of OERs in Brazil) and understand them, for instance, describing, comparing, and explaining their knowledge, attitudes and behaviours. 
Pfleeger e Kitchenham (2001) define survey as the "collection of standardised information from a specific population, or some sample from one", commonly associated with the use of questionnaires or interviews for data collection (EASTERBROOK et al., 2007).

According to Pinsonneault e Kraemer (1993) a survey research is more suitable and indicated when it is not possible or desirable to control the independent and dependent variables, and the phenomena of interest need to be studied in its natural setting.

In software engineering, surveys usually investigate a set of data to determine trends or relationships, or to determine how a population reacts to a particular method, tool or technique (SJØBERG; DYBA; JØRGENSEN, 2007).

\subsubsection{Objectives and Research Questions}

Our objective is to investigate "how" OERs have been developed in the Brazilian context. We also intend to highlight the key issues and difficulties associated with the development of these materials. The ultimate aim is to characterise the Brazilian current scenario regarding the development of OERs. The study is guided by five general research questions (RQ):

1. RQ1. Do you follow any process to develop Open Educational Resources?

2. RQ2. Is there any involvement of users during the development of Open Educational Resources?

3. RQ3. How do you evaluate Open Educational Resources?

4. RQ4. What are the problems and difficulties for the development of Open Educational Resources?

5. RQ5. What are the factors that can contribute to the increase and the improvement in the development and distribution of Open Educational Resources in Brazil?

We proposed additional questions to extend the scope of the research and increase the significance of the survey. We obtained information to complement the analysis and measurement of the results, including: (1) the experience of the participants in the development of OERs; (2) the methods/approaches used to develop OERs; (3) the type and purpose of the OERs produced; (4) the areas/domains of knowledge of the OERs, (5) the teaching/learning context of the OERs; and (6) the role played by users (educators and learners) during the development of OERs.

\subsubsection{Sample Population}

The sample population was composed by subjects involved with the development of OERs, either individually or as part of some educational institution, research centre or other type of organisation. 
The survey included an online questionnaire with 16 structured questions (Appendix A) submitted to three different discussion lists:

1. SBC-ListaIE (<sbc-ie-1@ sbc.org.br>);

2. SBC-lista (<sbc-1@ sbc.org.br $>)$; and,

3. REA Brasil (<rea-lista@googlegroups.com>).

The survey questionnaire was applied from March 2014 to May 2014. At the end, answers of 40 participants were collected. No reward was offered to individuals who participated in the survey.

In Figure 18 we summarise the sample of the population according to the familiarity of the participants regarding the development of OERs. A significant number of participants had experience ( $15 \%$ - very high and $28 \%$ - high) whilst nearly half of them had median experience $(45 \%)$. The remainder had low (10\%) and very low (7\%) experience.

Figure 18 - Sample population: familiarity with the development of OERs.

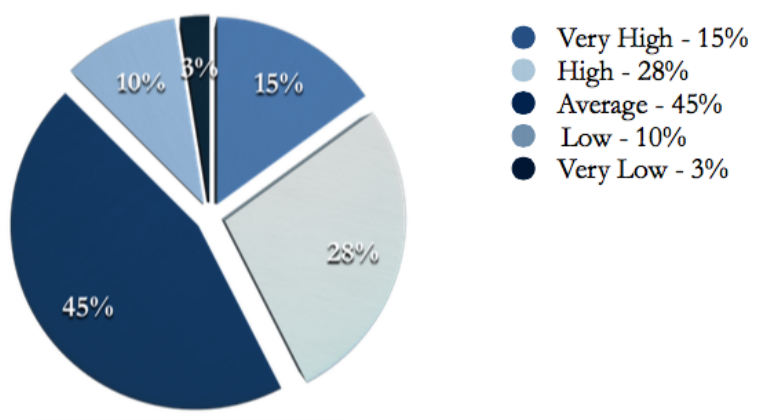

Source: Research data.

\subsubsection{Data Analysis and Results}

Following, we gathered and summarised the results in order to answer the research questions investigated in this survey.

\section{RQ1. Do you follow any process to develop Open Educational Resources?}

RQ1 aimed at identifying whether participants follow or not a process during the development of OERs. In Table 11 we summarise the results for this research question. Most of the participants follow a process, either in a complete $(60 \%)$ or partial $(32 \%)$ way (Table 11a). The same applies to the more experienced participants, i.e, participants with "high" and "very high" experience. We observed that $71 \%$ of them use a process throughout the development, whilst $23 \%$ adapts a process in some parts of the development (Table 11b). 
In Table 12 we present the methods and/or approaches pointed out by the participants for the development of OERs. Specific methods for learning materials such as RIVED (AMARAL et al., 2006), ADDIE (STRICKLAND, 2006) and SOPHIA (PESSOA; BENITTI, 2008) are used by $38 \%$ of participants. Traditional methods/approaches from software development, such as sequential model/cascade or plan-driven, are used by $20 \%$ of them. The results are similar considering the more experienced participants (experts), wherein most of them (47\%) use specific methods for learning materials (Table 12). Other approaches such as "game design" (PERUCIA et al., 2007) and a "mix" of good practices from different approaches were also mentioned by the participants $(27,5 \%$ for general participants and $6 \%$ for experts).

Table 11 - Development of OERs: usage of a process.

\begin{tabular}{lcc}
\hline Answer & \multicolumn{2}{c}{ Frequency } \\
\hline Yes & 24 & $60 \%$ \\
Partially & 13 & $32 \%$ \\
No & 1 & $3 \%$ \\
Unable to answer & 2 & $5 \%$ \\
Total & 40 & $100 \%$ \\
\hline
\end{tabular}

\begin{tabular}{lccc}
\hline \multirow{2}{*}{ Experience } & \multicolumn{3}{c}{ Usage of process } \\
\cline { 2 - 4 } & Yes & Partially & No \\
\hline High/Very High & $71 \%$ & $23 \%$ & $6 \%$ \\
\hline
\end{tabular}

(b) Experienced participants

(a) General participants

Source: Research data.

Table 12 - Development of OERs: methods/approach used.

\begin{tabular}{ll|c|c|c}
\hline Method/Approach & & General & & Expert \\
\hline Specific to learning materials & 15 & $37.5 \%$ & 8 & $47 \%$ \\
Traditional methods for software development & 8 & $20 \%$ & 3 & $17.5 \%$ \\
Agile methods/practices & 2 & $5 \%$ & 2 & $11 \%$ \\
Learning design practices & 4 & $10 \%$ & 3 & $17.5 \%$ \\
Others & 11 & $27.5 \%$ & 1 & $6 \%$ \\
\hline
\end{tabular}

Source: Research data.

Additionally, we intended to identify the type and purpose of the OERs developed by developers, educators and practitioners (Table 13). We identified different types of OERs including audios/videos (20\%), lessons/lecture notes (19\%), textbooks (13\%), images (12\%), research papers (11\%), test and assessments (11\%) and games (11\%) (Table 13a). Participants also mentioned environments and virtual reality systems and other environments and educational software. Among the types of OERs developed, most of them (55\%) are used only as supporting material, whilst a significant part (30\%) is used as the main course material (Table 13b). In general, such OERs are developed from "scratch" by $38 \%$ of participants, whilst $36 \%$ reuse and adapt existing OER materials, and $25 \%$ reuse and adapt non-OER materials.

We also asked the participants about the domains/areas of knowledge and the teaching/learning context of OERs (Table 14). The results show OERs developed for different 
areas of knowledge, especially for Education (21\%), Computer Science (13\%), Mathematics and Statistics (12\%), Chemistry (9\%), Physics (9\%), and Languages (9\%) (Table 14a). Other areas of knowledge found include Management/Administration, Law, Human Rights, Sociology and Engineering. In relation to the teaching/learning context we found Middle School (25\%), Higher Education (24\%), Elementary School (22\%), and Vocational Training (18\%). Other teaching context includes Informal Teaching (7\%) (Table 14b).

Table 13 - Development of OERs: type and purpose.

\begin{tabular}{lcc}
\hline Type & \multicolumn{2}{c}{ Frequency } \\
\hline Texbooks & 17 & $13 \%$ \\
Research papers & 14 & $11 \%$ \\
Lessons/lecture notes & 25 & $19 \%$ \\
Test and assessments & 14 & $11 \%$ \\
Audios/videos & 27 & $20 \%$ \\
Games & 15 & $11 \%$ \\
Images & 16 & $12 \%$ \\
Others & 5 & $14 \%$ \\
\hline
\end{tabular}

\begin{tabular}{|c|c|c|}
\hline Purpose & Fre & uency \\
\hline $\begin{array}{l}\text { Supporting material (additional } \\
\text { material to a course) }\end{array}$ & 22 & $55 \%$ \\
\hline Main material of the course & 12 & $30 \%$ \\
\hline Only to share & 2 & $5 \%$ \\
\hline Others & 4 & $10 \%$ \\
\hline
\end{tabular}

(b) OERs purpose

(a) OERs type

Source: Research data.

Table 14 - Development of OERs: domain and teaching/learning context.

\begin{tabular}{lcc}
\hline Domain/Area & \multicolumn{2}{c}{ Frequency } \\
\hline Computer Science & 17 & $13 \%$ \\
Mathematics and Statistics & 16 & $12 \%$ \\
Chemistry & 12 & $9 \%$ \\
Physics & 12 & $9 \%$ \\
Biology & 9 & $7 \%$ \\
Education & 28 & $21 \%$ \\
Languages & 12 & $9 \%$ \\
Geography & 6 & $5 \%$ \\
History & 6 & $5 \%$ \\
Other & 14 & $11 \%$ \\
\hline
\end{tabular}

\begin{tabular}{lcc}
\hline Focus & \multicolumn{2}{c}{ Frequency } \\
\hline Pre-school & 4 & $4 \%$ \\
Elementary School & 20 & $22 \%$ \\
Middle School & 22 & $25 \%$ \\
Vocational Training & 16 & $18 \%$ \\
Higher Education & 21 & $24 \%$ \\
Others & 6 & $7 \%$ \\
\hline
\end{tabular}

(b) Teaching/learning context

(a) Knowledge area

Source: Research data.

\section{RQ2. Is there any involvement of users during the development of Open Educational Resources?}

RQ2 aimed at identifying whether there is or not the involvement of users (especially educators and learners) during the development of OERs. The results indicate that users are involved in most OERs development initiatives: $45 \%$ are partially involved and $37 \%$ are involved throughout the whole process. 
We were also interested in identify the role played by the users in the development of OERs. We identified that $50 \%$ of them participate as collaborator, whilst $39 \%$ actively participate during the whole development. In Table 15 we correlate the involvement of users and the role played by each one. Considering only the answers in which there is the involvement of users (partial or full), we found that most users (58\%) acts as collaborator whilst $42 \%$ actively participate in the process (Table 15b).

\section{RQ3. How Open Educational Resources are evaluated?}

RQ3 aimed at identifying how developers and practitioners assess the OERs they develop. In Table 16 we summarise the results for this research question. The individual assessment is more common (40\%) followed by external assessment (external reviewers to the team or institution) (27\%), and peer review (peer of specialists in the field) (27\%) (Table 16a).

Table 15 - Development of OERs: Involvement of users versus played role.

\begin{tabular}{lcc}
\hline Level of Involvement & \multicolumn{2}{c}{ Frequency } \\
\hline Throughout the development & 15 & $38 \%$ \\
Partial & 18 & $45 \%$ \\
Unable to answer & 2 & $5 \%$ \\
Others & 5 & $13 \%$ \\
Total & 40 & $100 \%$ \\
\hline
\end{tabular}

(a) User's involvement

\begin{tabular}{lcc}
\hline Role & \multicolumn{2}{c}{ Frequency } \\
\hline Active participation & 14 & $42 \%$ \\
Only as collaborator & 19 & $58 \%$ \\
Total & 33 & $100 \%$ \\
\hline
\end{tabular}

(b) User's role

Source: Research data.

Table 16 - Development of OERs: assessment process.

\begin{tabular}{lcc}
\hline Method & \multicolumn{2}{c}{ Frequency } \\
\hline Peer review & 15 & $27 \%$ \\
Individual Assessment & 22 & $40 \%$ \\
External Assessment & 15 & $27 \%$ \\
Unable to answer & 3 & $5 \%$ \\
\hline
\end{tabular}

(a) Assessment method

\begin{tabular}{lcc}
\hline Criteria & Frequency \\
\hline Didactic-pedagogical & 35 & $40 \%$ \\
Technical & 26 & $30 \%$ \\
Legal & 22 & $25 \%$ \\
Unable to answer & 4 & $5 \%$ \\
\hline
\end{tabular}

(b) Assessment criteria

Source: Research data.

In order to identify the assessment criteria used by participants, we classified them into three categories (Table 16b): (1) didactic-pedagogical, such as accuracy and relevance of the content, and pedagogical design of content and activities; (2) technical, such as accessibility, usability, discoverability and localisation capabilities; and (3) legal, such as intellectual property and rights and licenses for OERs reuse. The first one is used by nearly half (40\%), the second by $30 \%$, and the third by $25 \%$ of the participants. 


\section{RQ4. What are the problems and difficulties for the development of Open Educational Resources?}

RQ4 aimed at identifying the main obstacles related to the development of OERs. We proposed a set of items representing common problems and difficulties faced by educators, developers and practitioners of OERs to answer this research question (Figure 19). This set of items was proposed based on previous work on the subject (RICHTER; EHLERS, 2010; Open Educational Quality Initiative, 2011; MCKERLICH; IVES; MCGREAL, 2013). Each item was classified in relation to its level of relevance, ranging from "very important" to "irrelevant". In order to quantitatively analyse the answers, each scale received a numeric value representing its level of relevance, ranging from 4 (very important) to 1 (irrelevant). In Table 17 we summarise the results for "the lack of recognition and incentive", for instance. The table is given by:

- $x_{i}$ representing the values associated to each answer, i.e., 4 (very important), 3 (important), 2 (less important), 1 (irrelevant);

- $f_{i}$ representing the observed frequency of each answer; and,

- $f_{x}$ representing the result of $f_{i} * x_{i}$.

Table 17 - Barriers to the development of OERs: Lack of recognition and incentive.

\begin{tabular}{lccc}
\hline The lack of recognition and incentive & $x i$ & $f i$ & $f x$ \\
\hline Very important & 4 & 31 & 124 \\
Important & 3 & 7 & 21 \\
Slightly important & 2 & 2 & 4 \\
Irrelevant & 1 & - & - \\
Total & & 40 & 149 \\
\hline
\end{tabular}

Source: Research data.

In Figure 19 we show the Average Score (AS) of all assessed items. The AS is calculated based on the work presented in Oliveira (2005), as follows:

- $\mathrm{AS}=\mathrm{WA} /\left(f_{i}\right)$, where Weighted Average $(\mathrm{WA})=\sum(f i * x i)$

The higher is the result of AS, the higher is the importance level of the item for participants. According to Figure 19, all items obtained a high score, especially the lack of public and institutional policies $(A S=3.86)$, the lack of recognition and incentive $(A S=3.72)$ and the lack of methods and approaches to support the development of OERs $(A S=3.75)$. Therefore, they were considered as "significant" from the perspective of problems, difficulties and barriers for the development of OERs. 
Figure 19 - Average score of the assessed items.

Cultural and language issues (reuse/adaptation)
Lack of quality and relevance of the available materials
Lack of public and institutional policies

Lack of methods and approaches to support the development

Lack of acquaintance

Lack of time

Lack of recognition and incentive

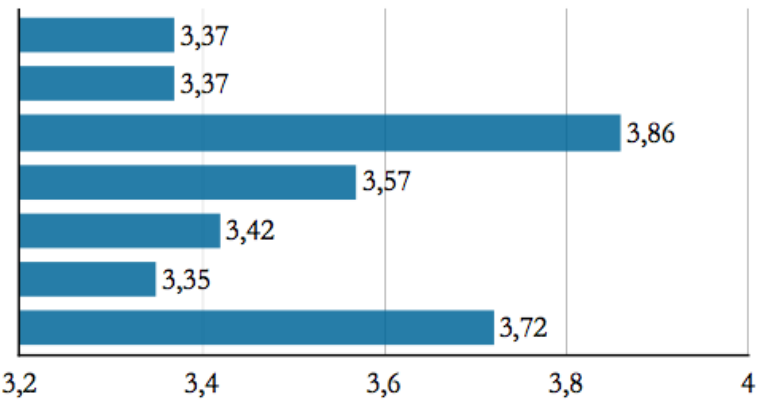

Source: Research data.

\section{RQ5. What are the factors that can contribute to the increase and the improvement in the development and distribution of Open Educational Resources in Brazil?}

RQ5 aimed at identifying the main factors that may contribute to increase the adoption of OERs in the Brazilian context, and improve the development and distribution of these materials.

We created a categorisation scheme composed of a set of factors based on participant answers. In Figure 20 we present the factors coupled with the frequency indicated by participants. The results indicate as the most relevant factors: (1) public and institutional policies for using, producing and sharing OERs (16\%); (2) research and investment in OERs (16\%); (3) aware of the importance/benefits of using, creating and sharing OERs (12\%); (4) proposal of methods, approaches and techniques for the development of OERs (11\%); (5) acquaintance, awareness and usage of open licenses to share OERs (11\%); (6) more effective disclosure of OERs (11\%); (7) recognition and financial support for the development of OERs (11\%); and (8) acquaintance and capacity building on OERs (9\%).

Figure 20 - Beneficial factors for the development and dissemination of OERs.

Public and institutional policies for using, producing and sharing OERs Recognition and financial support for the development of OERs More effective disclosure of OERs

Proposal of methods, approaches and techniques for the development of OERs Aware of the importance/benefits of using, creating and sharing OERs Acquaintance, awareness and usage of open licenses Acquaintance and capacity building on OERs

Research and investment in OERs Adequate availability (accessible location and open repositories)

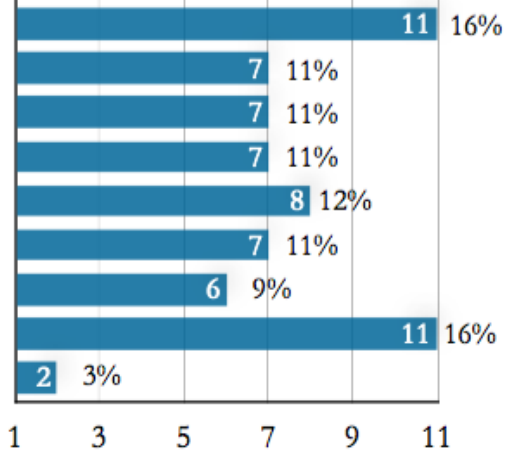

Source: Research data. 


\subsubsection{Threats to Validity}

As the main threats to validity related to this survey, we highlight the following:

- Understanding of the questions: participants may not understand well the survey questionnaire or may interpret the survey equivocally. This may affect the survey outcomes. We have tried to mitigate this risk by proposing clear and objective questions following a logic and structured sequence. The survey questionnaire was assessed by two specialists in the area. We also conducted a pilot study to assess the clarity and objectivity of each question before submit it to participants.

- Familiarity with the subject: participants may not have adequate knowledge on the subject under investigation. We have tried to minimise this effect by submitting the survey questionnaire to list of discussions specifically related to the subject. We gave some advice that only people directly involved with the development of OERs could reply to the survey questionnaire. We also proposed questions to identify the level of participant's familiarity with the subject, helping to properly gather the data and analysis the results of the survey.

- Sample representativeness: the survey questionnaire was submitted to three different list of discussions. We cannot claim that the sample is representative of the population, since it was not possible to determine the exact number of participants who received the questionnaire.

\subsubsection{Summary of the Results}

This survey showed similar results to previous work (PETRIDES et al., 2008; SCLATER, 2009; CONOLE et al., 2009; Open Educational Quality Initiative, 2011; ARIMOTO; BARBOSA, 2012a), pointing toward the need for methods, approaches and techniques that effectively support the process of design, creation and delivery of OERs, particularly in the Brazilian setting. Specific methods for the development of learning materials have been used to develop OERs, followed by traditional methods used in software development. In general, both approaches have the same philosophy (PESSOA; BENITTI, 2008), establishing prescriptive processes whose characteristics are the linear/sequential development and little flexible to changes, which may not be suitable for the development of OERs (ARIMOTO; BARBOSA, 2012b; ARIMOTO; BARBOSA, 2012a).

The need for collaboration and effective involvement of users in the development of OERs are recurring concerns (DOWNES, 2007; PAWLOWSKI, 2011; BUTCHER, 2015; BLACKALL; JELLEY, 2013; ARIMOTO; BARROCA; BARBOSA, 2014), and, therefore, may increase the adoption and impact of OERs (Cape Town Open Education Declaration, 2007; BUTCHER, 2015). The same applies to the Brazilian scenario regarding the OERs development, where the level of involvement and participation of users is still limited; in most cases, users are partially 
involved and their participation is restricted to a collaborator considering the development process.

Issues related to the need for more engagement of users in the development and sharing of OERs were evidenced by this survey, including the lack of: (1) awareness (especially educators and learners) on the importance to use, produce and share OERs; (2) awareness on the benefits that OERs may aggregate to education; and (3) knowledge, awareness on the use of open licenses to share OERs. Accordingly, users, developers, practitioners and educational institutions need to encourage the (re)use, development and free and open distribution of OERs, expanding the possibilities of adoption and dissemination of these materials in Brazil.

The results also indicate that there are still many challenges to be overcome, mainly demanding joint efforts among government, educational institutions, organisations, researchers, educators, learners and others who are engaged with education. Many issues identified as critical for the development and dissemination of OERs in Brazil converge with the problems, difficulties and barriers faced by educators, developers and practitioners of OERs. These issues range from "the lack of public and institutional policies" to encourage the production of OERs to "the lack of methods, approaches and techniques" suitable for the development of these materials.

We can infer that issues related to the lack of public and institutional policies, and recognition and incentives for producing OERs are still challenges to be overcome worldwide. In the Brazilian scenario, these concerns are more significant, and need more attention from the competent authorities. Government, institutions and organisations have the responsibility to provide mechanisms for encouraging research, development and adoption of OERs. In addition, it is necessary to grant professional recognition to this kind of intellectual production, since it is an activity that consumes too much time and effort from professionals.

The survey has defined a big picture on the development of OERs in the Brazilian context, evidencing barriers and gaps, as well as factors that can help to promote the production, use and effective sharing of such materials. The idea is to contribute to deepening the discussions and improvement of the development process, and therefore contributing to the wide dissemination and adoption of OERs in Brazil. This survey was published and presented in Arimoto, Barroca e Barbosa (2014).

\subsection{Concluding Remarks}

This chapter presented a general picture on the development of learning materials (especially OERs) both in the international and in the Brazilian scenarios. We focused on issues related to the development process, including the approaches and mechanisms applied to support the development of OERs. We also focused on the identification of the main barriers and gaps that hinder the development and widespread adoption of OERs Brazil.

The main contributions of this chapter are twofold. The first contribution is an evidence-based research, consisting of a systematic mapping that provides an overview of 
the approaches that have been proposed and used for the development of learning materials, especially OERs. The second contribution is a quantitative survey research that provides an overview on how OERs have been developed in Brazil. It was possible to identify the main problems, difficulties and barriers faced by developers and practitioners of OERs, and also to highlight key factors that may contribute to spread OERs culture in Brazil. Both studies highlight the gaps and trends for research and development in the area, and also provide a guide to help researchers in planning and developing future research.

In the next chapter we describe our proposal to minimise the gap regarding the lack of systematic and at the same time flexible approach to support the development of OERs. It consists of an agile method named AM-OER that incorporates learning design practices for developing and delivering quality and reliable OERs. 

CHAPTER

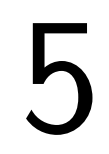

\section{AM-OER: AN AGILE METHOD FOR THE DEVELOPMENT OF OPEN EDUCATIONAL RESOURCES} ost OER initiatives found in the literature neither explicitly show the production process used to develop their materials, nor provide more comprehensive information about how these materials are developed (Organisation for Economic Co-operation and Development, 2007; SCHUWER et al., 2010; ARIMOTO; BARROCA; BARBOSA, 2014). In the Brazilian context, we observed that many initiatives for the development of learning materials are plan-driven (ARIMOTO; BARBOSA, 2012a; PESSOA; BENITTI, 2008; ARIMOTO; BARROCA; BARBOSA, 2014), following prescriptive processes whose characteristics are linear/sequential development and little flexible to changes, which may not be adequate for the development of OERs (ARIMOTO; BARBOSA, 2012b; ARIMOTO; BARBOSA, 2013).

In this chapter we discuss the establishment of a method based on practices from other disciplines, namely the practice of agile methods in software development. The method, called AM-OER - Agile Method for the Development of Open Educational Resources aims to effectively support the development of quality OERs through a flexible approach that prioritises the communication and collaboration of those involved in the construction of such materials. The chapter is organised as follows. In Section 5.1 we summarise the rationale underpinning our proposal, followed by an overview of its functioning. In Section 5.2 we describe the main characteristics and practices of the AM-OER, and how they can be useful for the development of OERs. In Section 5.3 we introduce the main roles performed by a team using the AM-OER. In Section 5.4 we describe in detail the phases of the AM-OER, including the steps needed to develop an OER. In Section 5.5 we provide a useful guide of mechanisms and tools to supporting the whole development process of OERs. Concluding remarks are given in Section 5.6. 


\subsection{AM-OER: An Overview}

The main goal of this P.h.D. research is to investigate the development of OERs and propose a flexible and suitable approach for the production of such materials. In this context, we established the AM-OER, an agile method that embeds pedagogical design practices to support designing and creating effective OERs.

AM-OER is based on Scrum (SCHWABER; BEEDLE, 2002; SCHWABER; SUTHERLAND, 2010) and on XP (BECK; FOWLER, 2000; BECK; ANDRES, 2004). Such agile methods were chosen because they are well-known, widely used, and have complementary characteristics. Furthermore, they focus on collaborative and flexible aspects of planning and software development and improvement of quality and productivity, which are concerns regarding the development of OERs.

An analysis of agile methods was conducted to identify the main characteristics, similarities and differences between them. Based on such analysis, a preliminary set of development practices was sketched out to the context of OERs (ARIMOTO; BARBOSA, 2012a). A very preliminary version of the intended method for OERs was sketched out (ARIMOTO; BARBOSA, 2013). Both served as the foundation for the agile method for OERs proposed in this work.

Additionally, an investigation on Learning Design was conducted. A Learning Design approach aims to assist in defining and establishing more effective learning materials (DIMITRIADIS et al., 2009; CONOLE, 2010; CONOLE, 2013) such as OERs. Therefore, Learning Design practices were adapted and incorporated into AM-OER (ARIMOTO; BARROCA; BARBOSA, 2015) from the Learning Design approach proposed by the UK Open University, within the OULDI project (CROSS et al., 2012; CONOLE, 2013).

AM-OER was developed incrementally, also following the precepts of the agile approaches. While AM-OER was being validated, other aspects that were not addressed in previous versions were incorporated, as well changes and improvements. This cycle repeated until obtaining a more consistent version of the AM-OER.

In Figure 21 we illustrate the AM-OER development flow together with its general characteristics and practices (discussed in Section 5.2). In short, an OER development project starts from the learning needs and/or problems identified by the educators. From this, a high-level initial architecture with the main components/elements needed to the OER are sketched. Team gets together to plan the OER releases (small deliveries of OER) and the sprints (predefined period of time) needed to develop them. Then, they define which parts (modules) of OER will be designed and created firstly, in the current sprint. Modules are developed iteratively and incrementally by short sprints, with a sprint lasting from days to few weeks. During a sprint, team members communicate and constantly interact with each other to discuss the development activities, monitor their progress, and to identify the main obstacles that hinder the progress of work. At the end of the sprint, the team gets together to evaluate the produced release and the progress of the sprint as a whole, identifying changes, improvements and needs for new 
components/elements. Small releases of the OER approved by the educators are delivered in a relatively short period of time to be used by learners, obtaining important feedback about their learning experiences on the OER. The process is repeated until all planned releases are developed and a final version of the OER is delivered (final and updated release).

Figure 21 - AM-OER development flow.

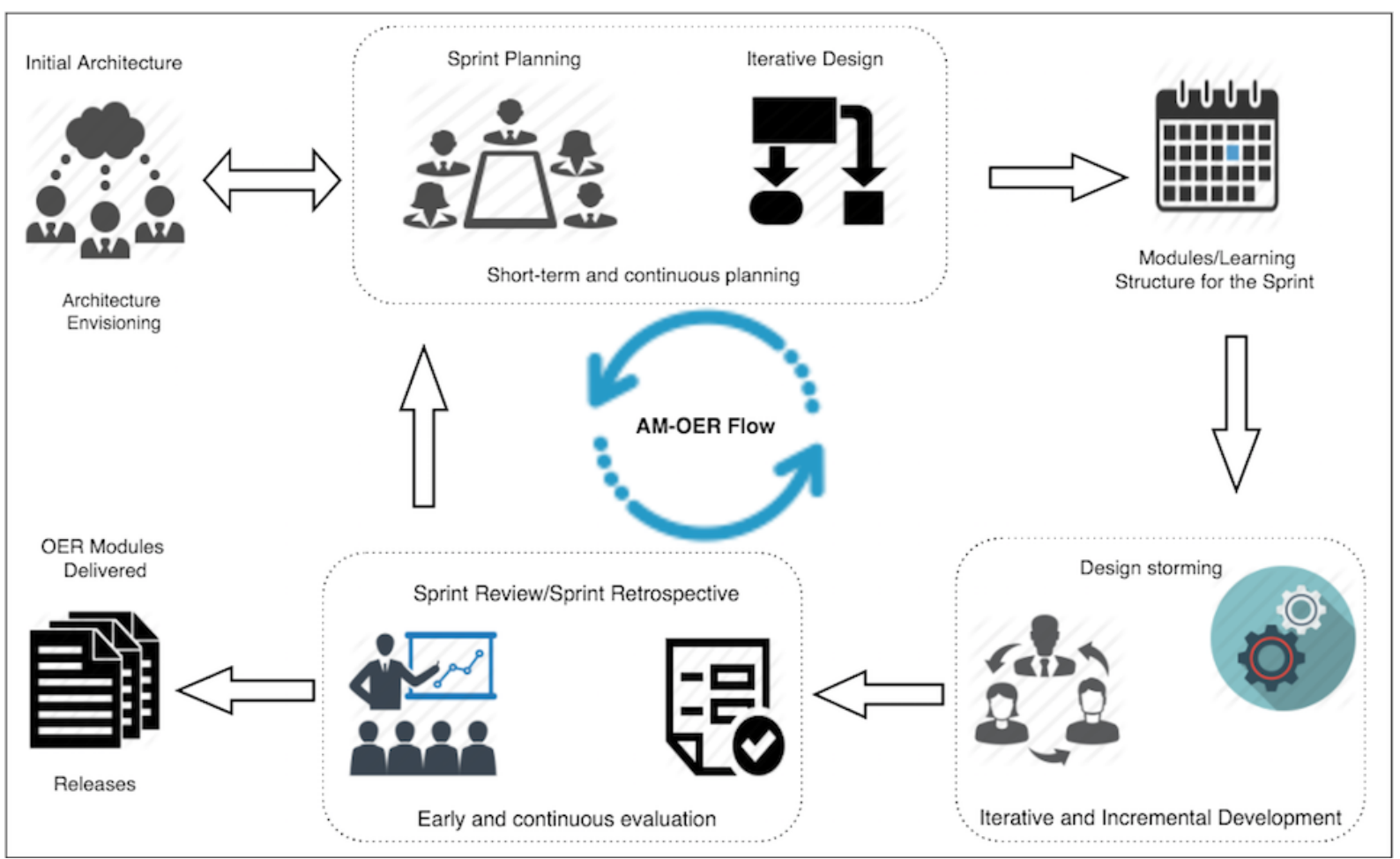

Source: Elaborated by the author.

AM-OER can be applied in the development of any type of OER. However, the simplest kinds of OERs or isolated components, as lecture notes and similar learning materials, do not necessarily need a method to develop them. In this sense, our focus is on the production of more complete and structured OERs. This includes curriculum, full and small courses, educational modules, learning objects, textbooks, games, among others.

Next, we describe the AM-OER method in detail, focusing on its main characteristics and related practices, roles and phases.

\subsection{Characteristics and Practices}

AM-OER has a set of characteristics and practices derived from Software Engineering (BECK; ANDRES, 2004; AMBLER, 2001; SCHWABER, 1995) and Learning Design (KOPER, 2006). Collectively implemented, they effectively assist and guide the process of OERs development. Such characteristics and practices are intended to: 
- Enable the design and creation of OERs iteratively and with regular deliveries of OERs for use by learners;

- Promote the creation of OERs with embedded pedagogical design practices to contribute to improving the quality and facilitate the reuse and adaptation;

- Promote an adaptive approach with flexible ways to accommodate changes;

- Enable rapid feedback from educators ${ }^{1}$ and learners; and,

- Promote the collaborative development and increase the interaction and communication within the team.

The characteristics and associated practices that support and guide the development of OERs are summarised next.

\subsubsection{Short-term and Continuous Planning}

The planning for the development of OERs focuses on short-term and continuous planning in each development cycle. Initially, the team gets together to plan and agree about the releases to be delivered in a short period of time, usually ranging from a week (or more) to months, depending on the complexity and size of OERs.

Agile methods adopt the practice of Small Releases (BECK; FOWLER, 2000), initially composed by a small set of the more important features from the customer point of view. In terms of OERs, a release corresponds to modules ${ }^{2}$ or a small set of modules considered "ready" to be used by learners. A release is composed by learning contents, roles, learning activities, assessments and tools needed to meet the learning objectives of the OER.

In Figure 22 we present an example of a structure of an OER for Software Engineering course composed by six modules (i.e., Requirement Engineering, Development Process, Software Testing, Configuration Management, Quality Management, Quality Assurance and Maintenance). Each of this modules can represent a release. For instance, the dashed line box represents a release for Software Testing, including even smaller releases such as Structural Testing, Functional Testing and Error-based, followed by a set of smaller modules (or topics) such as Control Flow Testing, Data Flow Testing and Branch Testing.

The team plans the sprint(s) needed to create and deliver the releases. Each release can be divided into one or more sprints (Figure 23). Sprints are short, ranging from days to few weeks. In Figure 23, the first release (R1) has only one sprint (I1), whereas others (R1, R2, Rn) are composed by three or more sprints.

Similarly to the Sprint Planning practice from Scrum, the team gets together to discuss and decide on what will be developed and delivered at the end of the current sprint, and on the

1 By using the term"educators" we also include practitioners, teachers, lectures and tutors.

2 Modules correspond to parts or units that will compose a more complex structure, for instance, a course. 
way in which the work will be conducted. In the example of Figure 22, a release could represent the entire module of Software Testing or parts of modules, such as Functional Testing, or smaller modules such as Control Flow Testing.

Figure 22 - Modules and releases of Software Engineering course.

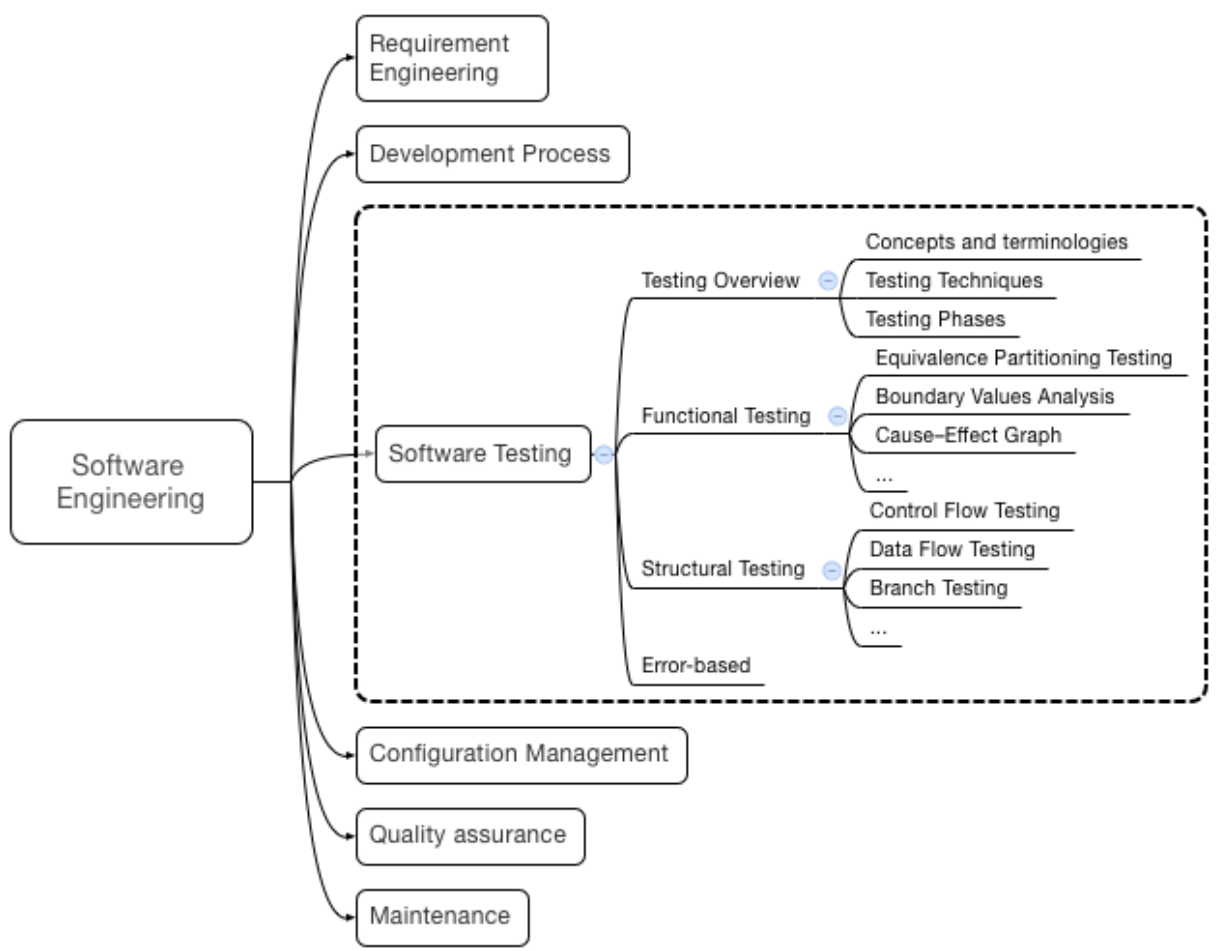

Source: Elaborated by the author.

Figure 23 - Dividing releases in sprints.

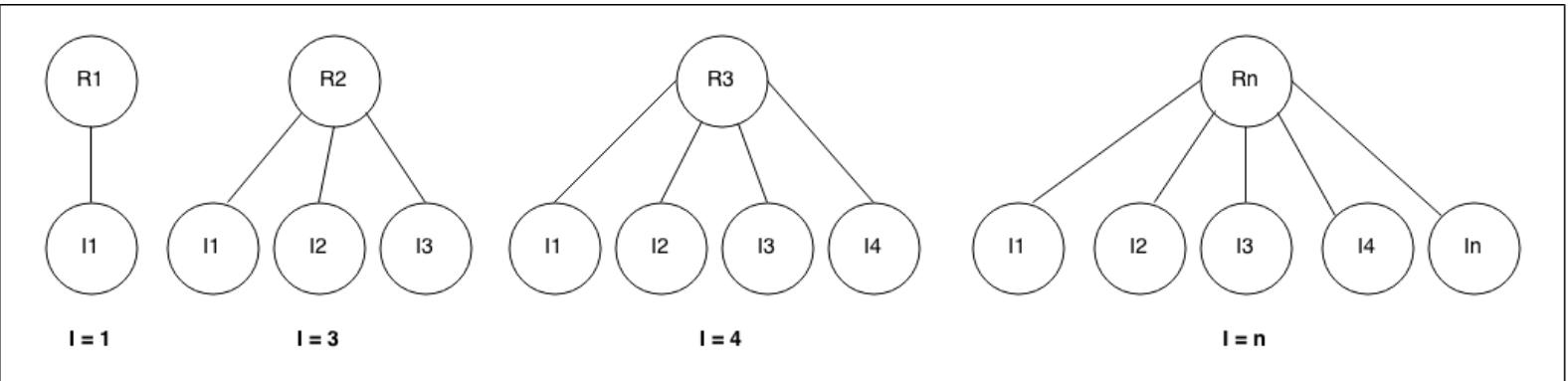

Source: Elaborated by the author.

Since the tasks are established, each member of the development team selects the amount of work that each one can develop and deliver at the end of the sprint.

The development team can estimate the time (for instance, in hours) needed to finish the work. At the end, it is possible to obtain a detailed plan of what will be developed within the sprint. 


\subsubsection{Dynamic and Incremental Design}

The design process of OERs is dynamic and involves the whole team, especially educators. The design is performed incrementally, allowing modifications and improvements can be carried out in any part of process.

In Figure 24 we present a Learning Design approach for OERs that was incorporated into the AM-OER. It combines specific agile design practices, derived from software development (AMBLER, 2001), with Learning Design practices, derived from OULDI (BRASHER et al., 2012).

Figure 24 - Learning Design approach to support the design and creation of OERs.

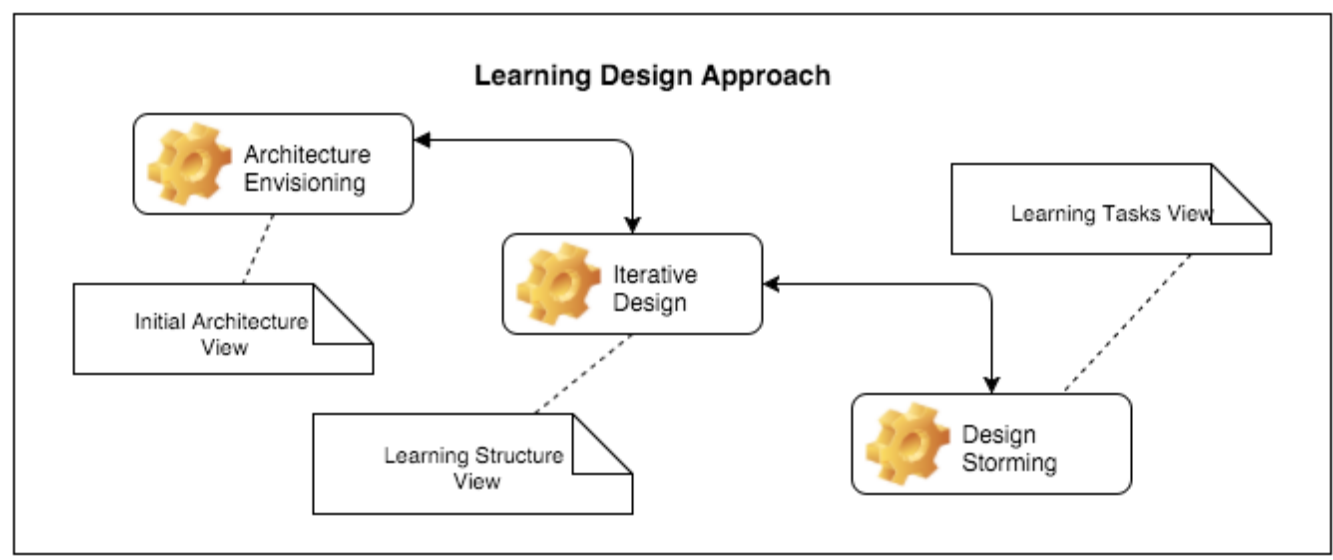

Source: Elaborated by the author.

Architecture Envisioning is a practice adopted in agile development at the beginning of a project to sketch an initial software architecture and requirements. The aim is to identify and think through critical issues related to software under development (AMBLER, 2001). In the context of OERs development, the Architecture Envisioning is adopted early in the project to obtain an overall structure of the intended OER. Learning Design practices (CONOLE, 2013) are used in combination with the Architecture Envisioning to help educators to think about and define the key components/elements within the learning context of OER, including: (1) main learning contents needed; (2) context and domain of application; (3) learning assessment activities; and (4) learners/educators dialogic and collaboration issues. As a result, an Initial Architecture View is sketched in high-level, based on the Course Map View of OULDI (BRASHER et al., 2012).

Iterative Modelling/Design is a practice adopted in agile development at the beginning of an iteration or sprint for modelling software functionalities, identifying team's strategy for that iteration or sprint (AMBLER, 2001). In the context of OERs development, the Iterative Design is carried out throughout the whole process to sketch iteratively and incrementally the learning structure of the intended OER. It produces sketch of the OERs modules in each cycle of development/sprint. Learning Design practices are used in combination with the Iterative Modelling to describe and map the main components of the intended learning structure of the 
OER, including the learning activities and their connections to the intended learning outcomes, the contents, the tools and assessments. A Learning Structure View is sketched based on the Learning Outcomes View of OULDI (BRASHER et al., 2012).

Model/Design Storming is a practice used in agile development to model software functionalities on a Just-In-Time (JIT) basis to reflect on specific aspects of team's solution (AMBLER, 2001). In the context of OERs development, the Design Storming is used for specific aspects related to the flow of activities and the strategies for the development of OER. Learning Design practices are used in combination with the Design Storming to describe and map how learners will interact with their individual activities and tasks, specific contents or resources/tools, and assessments. It triggers refining and decomposition of activities from the Learning Structure View into simpler individual activities and tasks, helping educators to reflect upon an aspect of design solutions. As a result, a Learning Task View is sketched based on the Learning Swimlane View of OULDI (BRASHER et al., 2012).

Similarly to the Simple Design practice from XP, the design involves design just enough for the current sprint, prioritising the most relevant aspects to be addressed by the OERs under development. OERs are designed to facilitate the understanding about how contents, activities, roles and tools associated to the OERs should be connected and interact with each other to contribute to a more effective learning.

OERs are designed iteratively to adapt to changes throughout the process without requiring much effort of the team. In every sprint or release, the design of OERs modules is defined, created and evaluated by users (educators and learners). After, the design can be refined, improved and associated to new learning contents. The central idea is to allow the OERs design to be modified, repurposed and evolved according to the needs that emerge during the development process.

\subsubsection{Iterative and Incremental Development}

The development of OERs occurs incrementally by short repetitive sprints. The iterative and incremental development characteristic provides a more flexible approach, in which responses to changes can be made faster during the process to minimise their cost and impact.

Releases are delivered periodically throughout the process and can be used by a target audience. The aim is to ensure that learners have the opportunity to use and evaluate them, providing feedback on the OER being developed.

In Figure 25 we show a timeline representing the development of OER using the AM-OER method. The kickoff, also characterised as sprint \#0 (initial phase), consists in identifying what are the learning needs/problems and defining an initial architecture with the main components of OER, required to start its development. From this, small modules of OER are designed and created by one or more sprints. In each sprint, all remaining phases of the AM-OER are carried out. At the end of all sprints scheduled for a release, one version of the OER can already be available for users. 
Figure 25 - AM-OER timeline.

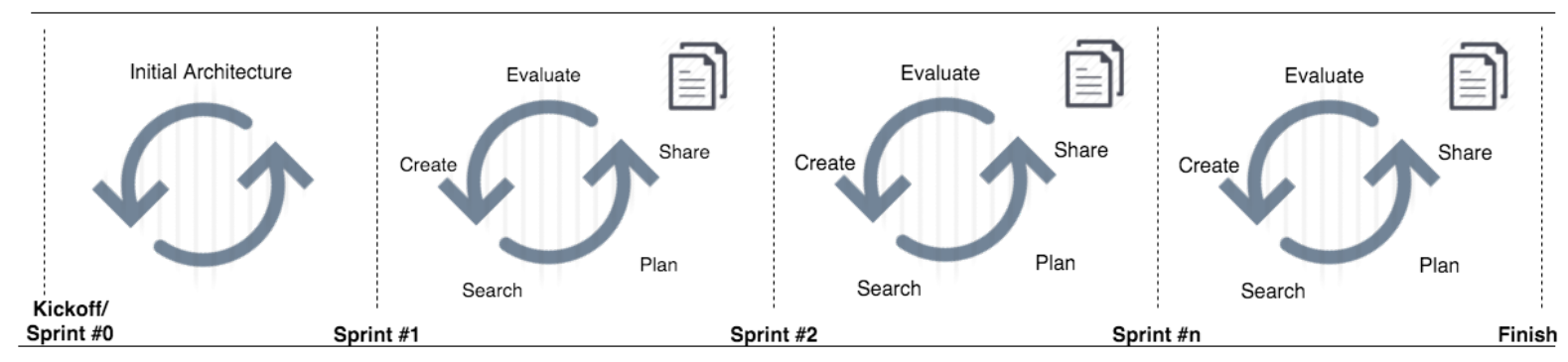

Source: Elaborated by the author.

New learning contents and enhancement requests are produced by the team as development progresses in the process. By using the concept of Refactoring from XP, the team can review and improve the OERs development through small changes without changing the intended learning outcomes. This practice should be performed whenever an opportunity for change and/or improvement is identified throughout the development.

Following the Continuous Integration practice from XP, modules of OER are integrated and validated throughout the process by the team. At the end of all sprints planned for OER development, a stable and robust release to be used and shared with others is delivered.

\subsubsection{Collaborative Approach}

All those involved in the OER development should interact and cooperate constantly throughout the development. This helps to solve problems related to the specification, design and implementation more quickly, reducing time and effort and enabling development of OERs in an effective way.

As in agile development (BECK; FOWLER, 2000; SCHWABER, 1995), the Active Participation of Users (educators and learners) is encouraged throughout the process, either in person or via collaborative technologies (Web 2.0 tools such as wikis, microblogging, social networking and instant messaging systems). They assist in the identification and establishment of the aims of OER, together with the learning objectives, learning activities and pathways, contents tools and assessments.

During the OERs development, several activities are carried out in groups through brainstorming and workshop sessions (such as initial architecture envisioning, sprint planning, iterative design, design storming, sprint review, and sprint retrospective), either face-to-face or by synchronous communications (text mode or videoconference). Collaborative development is promoted, increasing the interaction and communication amongst those involved in the development. 


\subsubsection{Early and Continuous Evaluation}

Evaluation is carried out early and continuously throughout the development process. During the Sprint Review (similar to Scrum (SCHWABER, 1995)), immediately after the end of the sprint, the development team introduces the work done, demonstrating the OER modules developed in the current sprint. Educators (and possibly learners) have the opportunity to check whether the modules created are in agreement with those previously planned before the sprint start. It is possible to identify new perspectives for the OER, possibility of modifications and/or inclusion of new learning contents and needs for improvements in relatively short period of time, minimising the cost of change.

Periodically, releases of OERs are made available to be used by the target audience. Learners have the opportunity to use the releases and evaluate them regarding their effectiveness in learning.

Furthermore, during the Sprint Retrospective (similar to Scrum (SCHWABER, 1995)) the team members have the opportunity to think about how the OER development is progressing. They can identify and analyse the problems and mistakes occurred during the process. The lessons learned help them to decide what can be done to improve the performance of the next sprints.

\subsection{Roles}

The AM-OER team should have multidisciplinary characteristics and bring together the knowledge and skills needed for agile and effective development of OERs. AM-OER considers four key category of roles: (1) User; (2) Intellectual Property (IP) Expert; (3) Coach; and (4) Development Team.

The User collaborates with the development team, pointing out the problems, needs and key characteristics for the OER. He/she also assists in the understanding of the work to be done. Such role can be represented by users potentially affected by the OER, having associated roles:

- Educator: detains enough knowledge regarding the domain in which the OER is inserted. $\mathrm{He} / \mathrm{she}$ provides support for the determination of relevant parts and components of the OER. He/she also supervises and monitors the OER development, helping identify and record problems and improvements. Plays a fundamental role as a creator and consumer of OER, designing learning activities, writing text documents and assessment materials, and validating the OER produced.

- Learner: uses the OER throughout the development process and evaluates whether the learning objectives are being met. He/she is encouraged to get involved from the beginning of the OER project in order to obtain feedback early and guide its development. He/she can also acts as creator of learning contents and activities. 
The IP expert is responsible for identifying and establishing which persons and institutions have intellectual property rights on the OER. He/she plays an important role especially when the OER is derived from third-part materials, maintaining clearly defined the intellectual property rights.

The Coach detains global knowledge about the development process and associated activities and tasks required. He/she works closely with users and development team, serving as a communication channel between the parties. Acts not as a controller but as a facilitator, being responsible for managing the progress of the project, solving/minimising the conflicts, problems and obstacles faced by the team. He/she is also responsible for planning and arranging of meetings that take place throughout the development.

The Development Team designs and creates the learning materials and activities associated with the OER, including the content editing, sequence of learning activities and integration of multimedia components. It can have the following associated roles:

- Designer: responsible for the learning design activities. He/she models the learning materials and their relationship with learning activities, tools, roles involved in the learning scenario, and the intended learning outcomes.

- Media creator: responsible for the overall media files. He/she selects and creates the appropriate media to the context of OER, ensuring their accuracy, consistence and organisation. Media files include all educational contents needed to the OER, such as textbooks, lessons plans, lecture notes, images, audio-visual files, among others.

- Reviewer: responsible for the overall evaluation of the OER. He/she implements and executes the validation and verification activities throughout the development process to ensure the quality of OER. He/she also collects learners information as they use and interact with the OER under development.

We emphasise that different roles can be taken by one same person. Depending on the size and complexity of the OER, it is possible that not all of the roles aforementioned will be necessary.

\subsection{Phases}

The life cycle proposed to support the agile development of OERs follows the iterative and incremental characteristic of agile methods for software development. Sprints are shorter to promote visibility for the OER under development, i.e., an opportunity for educators to perceive how the development of OER is progressing during the cycle. The aim is to provide the educators with mechanisms for monitoring the OERs development. Besides that, a small release of the OER is incrementally delivered in relatively short period of time to be used by learners, 
obtaining important feedback about their learning experience, which can be used to improve and incorporate new components/elements to the OER.

The AM-OER life cycle for OERs is flexible, allowing the team to make changes, if necessary, during the OERs development. The life cycle is divided into three phases (Figure 26) : (1) Kickoff; (2) Development; and (3) Sharing.

Figure 26 - The AM-OER life cycle for OERs.

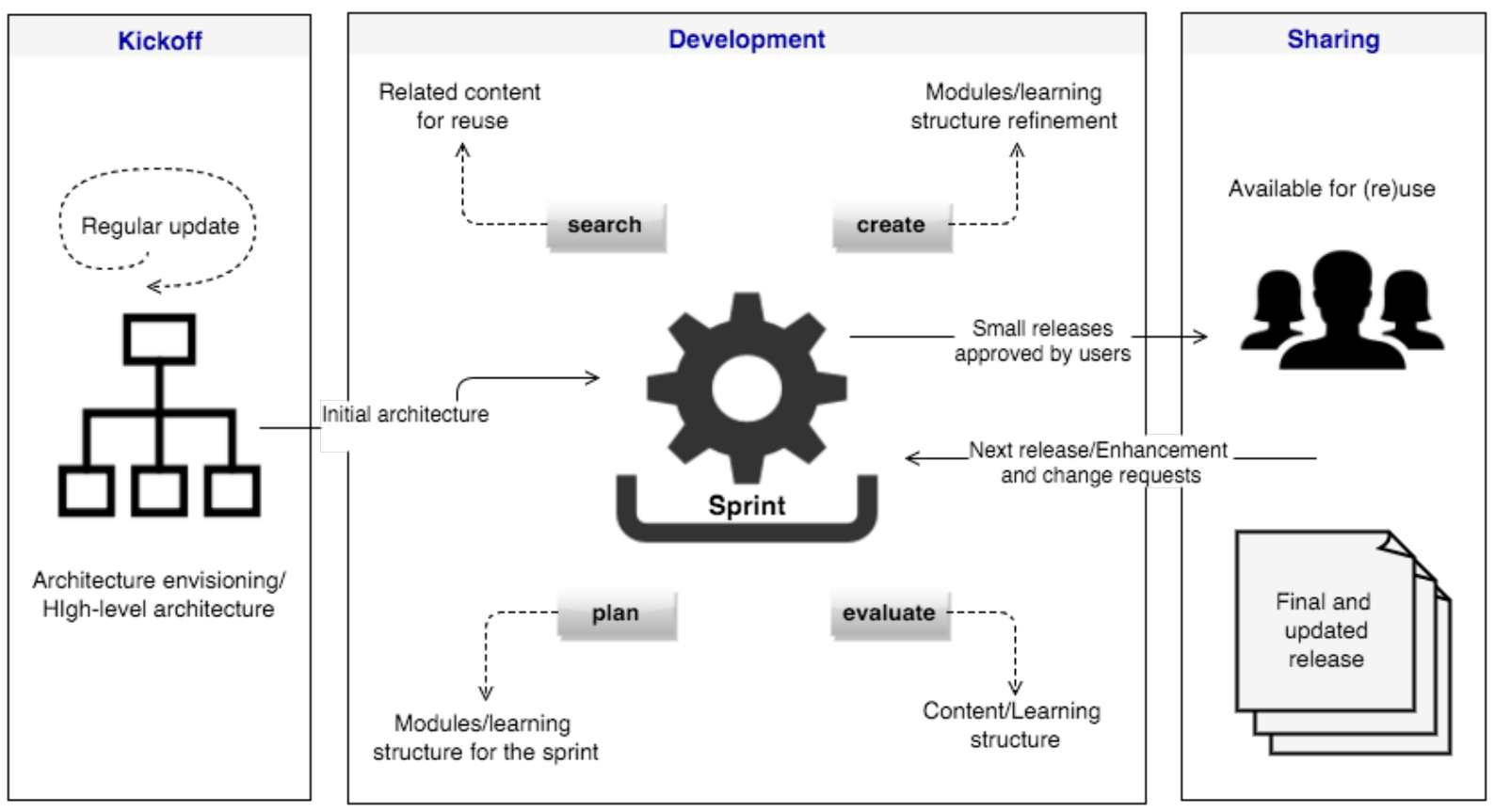

Source: Elaborated by the author.

\subsubsection{Kickoff}

At the beginning of the OER project (sprint \#0), users (educators and learners) come together with the development team through a brainstorming session, organised by the coach, to identify and think about critical issues and the main components/elements of the intended learning. Educators and potential learners identify the learning needs or problems that need to be addressed by the new OER and introduce them to the development team.

The overall structure of the desired OER is discussed and the main components/elements needed. The main components/elements of the OER are sketched, but without too much detail (just barely good enough), following the concept of Architecture Envisioning (AMBLER, 2001), as the design should be constantly evolved throughout the sprints. Practices of Learning Design are used together to identify and map the main components of the desired OER. These include OER activities in terms of learning experiences, how the learner will interact with educators and colleagues, the required support to the learner and the mechanisms for learning assessment. An Initial Architecture View is created based on the Course Map View of OULDI (BRASHER et al., 2012). The Initial Architecture View is used as input for the next phase. 
In Figure 27 we illustrate the main steps conducted in this phase: (1) identify learning needs; (2) establish learning contents; (3) define learning assessments; and (4) establish means of communication and collaboration. In the figure, these steps are shown sequentially, however, they can be performed in parallel and jointly. Such steps are summarised in Table 18, including the participants, the input and/or supporting documents, and the outcomes and/or artefacts. The steps are described next.

Table 18 - Kickoff: summary of the steps.

\begin{tabular}{llll}
\hline Steps & Participants & $\begin{array}{l}\text { Input/Support } \\
\text { Documents }\end{array}$ & Outcomes \\
\hline $\begin{array}{l}\text { Identify Learning } \\
\text { Needs }\end{array}$ & $\begin{array}{l}\text { Educators/Learners/ } \\
\text { Development Team }\end{array}$ & General Goals/ Learning \\
$\begin{array}{l}\text { Establish Learning } \\
\text { Contents }\end{array}$ & $\begin{array}{l}\text { Educators/ } \\
\text { Development Team }\end{array}$ & $\begin{array}{l}\text { General } \\
\text { Learning Objectives }\end{array}$ & $\begin{array}{l}\text { Objectives } \\
\text { (Initial Architecture View) }\end{array}$ \\
$\begin{array}{l}\text { Establish Learning } \\
\text { Assessments }\end{array}$ & $\begin{array}{l}\text { Educators/Development } \\
\text { Team }\end{array}$ & $\begin{array}{l}\text { General } \\
\text { Learning Objectives }\end{array}$ & $\begin{array}{l}\text { Assessment activities (Initial } \\
\text { Architecture View) }\end{array}$ \\
$\begin{array}{l}\text { Establish Means of } \\
\text { Communication and } \\
\text { Collaboration }\end{array}$ & $\begin{array}{l}\text { Educators/Development } \\
\text { Team }\end{array}$ & & $\begin{array}{l}\text { Means of Communication } \\
\text { and Collaboration established }\end{array}$ \\
\hline
\end{tabular}

Source: Research data.

\subsubsection{Identify Learning Needs}

This step comprises the identification and gathering of the learning needs to be addressed by the development of OER, such as general goals, specific learning objectives, context and domain in which the OER will be applied.

Boyle et al. (2006) argue that a common deficiency of many learning materials is the inadequate analysis of the learner's needs. Then, the starting point is to focus on the needs and problems that learners face. In this case, the educator plays a crucial role as a source of information, since he/she has expertise on the student's background and on the knowledge domain.

To help in identifying the learning needs and/or learning problems, the following issues should be taken into consideration:

- What are the main needs and/or motivations for developing a new OER?

- What are the problems that need to be addressed by the new OER to meet the learning needs?

- Who is the target audience (for instance, informal learning, primary and secondary school, undergraduate and graduate)?

- What is the learning context and application domain of the new OER? 
Figure 27 - Kickoff: main steps.

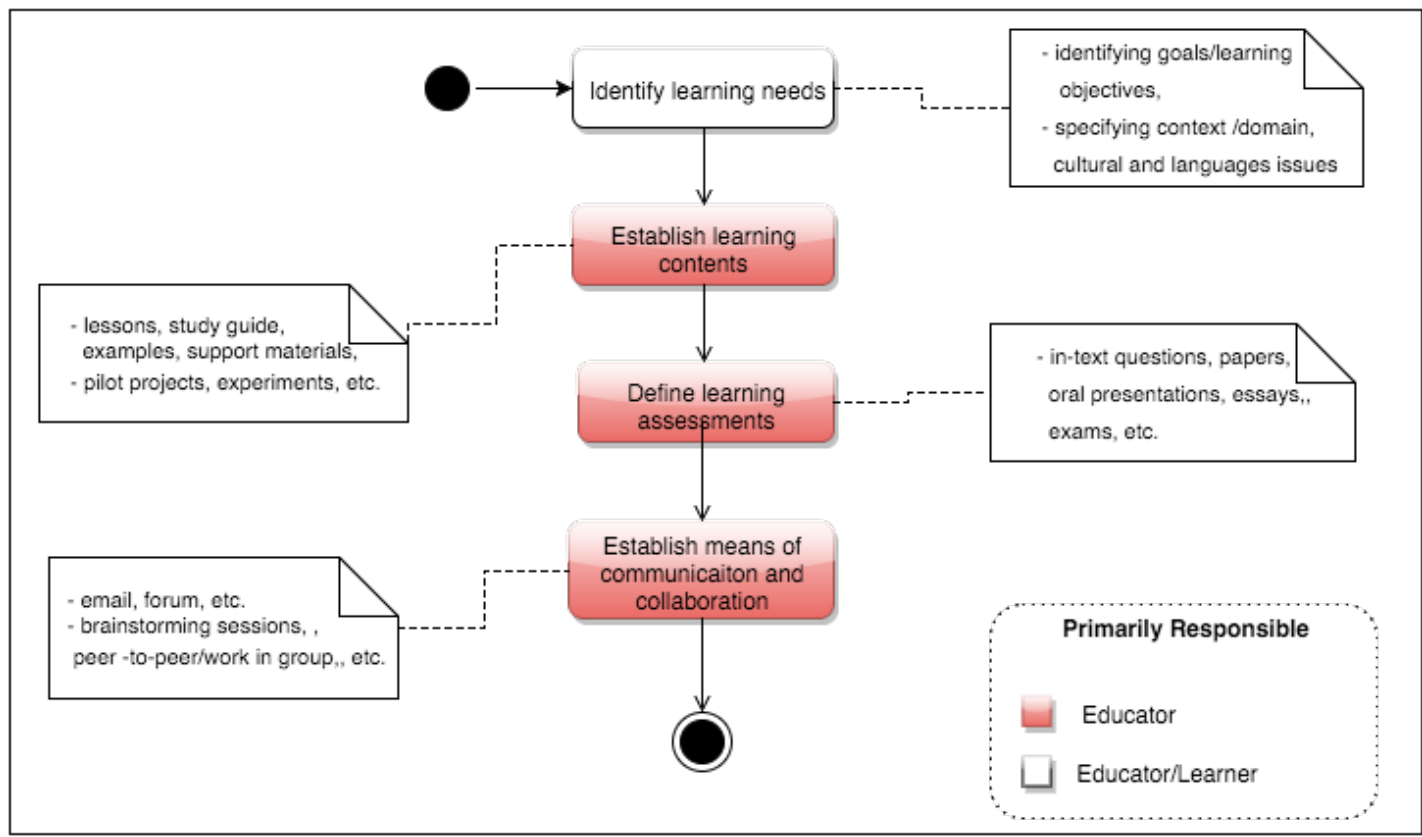

Source: Elaborated by the author.

Educators start by establishing the general goals/aims of the intended OER, indicating what they intend to cover/present in the OER under development (HARTEL; FOEGEDING, 2004; KENNEDY; HYLAND; RYAN, 2007). For instance, the general goals of an OER could be the following:

- To explain the fundamentals of functional (black-box) testing technique.

- To provide students a general introduction to testing in concurrent programs.

After sketched the general goals of the intended OER, educators begin to draft the associated learning objectives. They consist of specific statements of teaching/learning intention, indicating one of the specific subjects that the educators intend to present in an OER (KENNEDY; HYLAND; RYAN, 2007).

A learning objective should be measurable and clearly specify the knowledge and skills that learners will acquire or will be able to put into practice at the end of a class or course. DeVries (2013) highlights that many OERs do not have basic elements of Learning Design such as learning objectives. This makes it hard to assess the OER in terms of its overall purpose and intended learning outcomes, and of the pedagogical alignment of learning materials, activities and assessments. He also argues that learning objectives are essential elements for reuse, help identifying if an OER has the level of coverage and depth appropriate to be used in a different context or learning situation.

Examples of learning objectives statement may be the following:

- Students would understand the main ideas behind testing of concurrent programs. 
- Students will be able to plan and implement test cases in concurrent programs using mutation testing.

A useful mechanism to help defining effective and measurable learning objectives is the Bloom's taxonomy (BLOOM et al., 1956; HUITT, 2011). This taxonomy intends to organise the acquisition of cognitive skills/learning into levels (i.e., Knowledge, Comprehension, Application, Analysis, Synthesis, and Evaluation), facilitating the identification and measurement of the learning objectives (MOREIRA, 1999). Bloom's taxonomy is discussed in Section 5.5 Supporting Tools.

Furthermore, educators specify the context or domain in which the OER will initially intended to be applied. For instance, whether the OER will be a key part of a complete course in the curriculum level, or it will be a complementary part of a course, or a short course of a specialisation, among others. The context of OER should also address cultural and languages issues (AMIEL; OREY; WEST, 2011; AMIEL; SANTOS, 2013). For instance, learning materials in English are very common worldwide, but cultural context of learning usually differs from one country to another. Then, these issues should be considered during the design and creation of an OER.

\subsubsection{Establish Learning Contents}

The learning contents to be developed and integrated in the OER should be established in a high level, without going into details on the type of content or media (for instance, whether will be an open textbook, a research paper, a podcast or a video) to be used. Pre-requirements or expertise needed to use the OER are also specified, including a calendar with information about the duration related to its usage in a course or training.

Educators/domain experts should identify the primary contents of the OER according to the intended learning needs. There is no need to identify all contents a priori; further contents can be added or changed throughout the development. In order to identify contents, the following issues should be taken into consideration:

- How will OER modules/course be delivered to learners (e.g., face-to-face, online or hybrid)?

- How will learners be supported (e.g., face-to-face, online or hybrid)?

- How will subjects, topics or concepts be introduced to learners?

- What kind of activities learners will need to perform?

Typical examples of learning contents may include the following: lessons, lab activities, study guides/guidelines, readings, examples, supporting materials, case studies, pilot projects, systems development, survey researches, ethnographies, action researches, systematic reviews, systematic mapping, experiments/controlled experiments, among others. 
Educators should also define the pre-requirements and prior experience or specific expertise/knowledge needed to use the OER within a class/course. For instance, when a student is attending a practical course in object-oriented development, it is desirable that he/she holds basic knowledge and skills (pre-requirements) about programming.

Additionally, educators should specify the estimated time (duration) for the usage of OER in a particular course or training. For instance, a class, presentation or short course on Software Engineering may have an estimated time of few hours. On the other hand, a full course or training on Software Engineering may have an estimated time of weeks, months or even years.

\subsubsection{Define Learning Assessments}

Educators/domain experts should define the learning assessment activities, i.e., the way in which learners will be evaluated within a teaching and learning process. Learning assessment includes any activity which contribute to assess whether a learner has assimilated the contents discussed during a class/course.

Learning assessment activities can be categorised as diagnostic, formative and summative (BLOOM; HASTINGS; MADAUS, 1983). Diagnostic assessment or pre-assessment is used at the beginning of a class/course to determine the learner's level of knowledge and expertise on a particular topic, identify the learner's learning style or preferences, and determine how well he/she can perform certain skills linked to a particular subject. Formative assessment is used throughout a class/course to determine the learner's knowledge and skills as he/she progresses through a class/course, as well as to instruct and guide learning. Summative assessment is used at the end of a learning process (semester/at end of the class/course), focusing on the learning outputs to determine knowledge and skills the learners have acquired.

Educators should define learning assessment activities take into account the following questions:

- How will assessment activities be (e.g., online, paper based or both)?

- Which assessment strategy will be used (diagnostic, formative, summative or which combination of them)?

Typical examples of learning assessments activities may include: in-text questions, self-assessment questions, brief in-class assessments, oral or written presentations, blogs, e-portfolios, experiment replication, team projects, reports, papers, essays, thesis, written or oral exams, among others.

\subsubsection{Establish Means of Communication and Collaboration}

Educators need to think about the dialogic and collaboration aspects related to the usage of the OER. They need to establish the way in which learners are expected to communicate and collaborate with educators and colleagues when using the OER within a class/course. 
In order to help in establishing the mechanisms of communication and collaboration, the following questions should be take into consideration:

- How will learners communicate and collaborate with their colleagues (e.g., online, face-to-face, both)?

- How learners will communicate and collaborate with educators (e.g., online, face-to-face, both)?

- How learners will perform their activities (e.g., individually, peer-to-peer work, work in a group)?

Typical examples of means of communication and collaboration include the following:

- Synchronous tools: interaction occurs in real time (online), such as instant messaging system, chat, and videoconference.

- Asynchronous tools: interaction can be performed in different periods of time (independent of time), such as social networking, forum, mailing list, blog, microblogging, and electronic email.

- Face-to-face tools: interaction can take place through workshops, brainstorming sessions, dialogical activities, discussions/debates, peer-to-peer works, work in groups, and seminars.

At the end of this phase, the whole team needs to agree about the general goals, the learning objectives and the Initial Architecture View of the desired OER. As previously described, the steps Establish Learning Contents, Define Learning Assessments and Establish Means of Communication and Collaboration are responsible for identifying and mapping the main components of the new OER, resulting in the creation of the Initial Architecture View. After that, the new OER is approved and can be developed in the next phase.

\subsubsection{Development}

The development phase comprises the whole effort to plan, design, create and evaluate the OER within a sprint. At the beginning of the sprint (\#sprint 1) the whole team, especially development team and users (including educators, domain experts and learners, if appropriate), come together during the Sprint Planning to define the OER modules to be developed in the current sprint, including the design of associated learning structure.

The OER is designed in an iterative way, following the concept of Iterative Modelling/Design, wherein the design of OER is created "just enough for now, since we can always come back later" (AMBLER, 2001). By incorporating practices of Learning Design (BRASHER et al., 2012), a light-weight design for learning activities, content/tools, assessment/ 
learning outcomes and their relationship are sketched out, enabling the team to think about and define the development strategies for each sprint.

The team members should check for related learning contents to be reused to compose the new OER. Levery (2012) argues that it may be easier or more efficient to reuse and adapt existing learning contents than creating new ones. According to Gurell and Wiley's life cycle (GURELL; WILEY, 2008), the development of an OER usually starts from the search for suitable learning contents which could be reused and adapted to meet the intended objectives or to satisfy some required needs.

The learning structure of the OER should be refined and related contents are adapted or created through short sprints previously established by the team during the Sprint Planning. At the end of the sprint, the OER modules are evaluated and approved by the users (especially educators and learners), and can be used in a class or course.

In Figure 28) we illustrate the steps conducted in this phase: (1) prioritise and select OER modules, (2) design the learning structure, (3) define metadata, (4) search learning contents (including evaluate and adapt learning contents, when found), (5) create OER module (from scratch), when related contents were not found), (6) establish licensing policies, (7) evaluate OER modules, and (8) evaluate sprint execution. Such steps are summarised in Table 19, including the main participants, the input and/or support documents, and the outcomes and/or artefacts. The steps are described in detail next.

\subsubsection{Prioritise and Select OER Modules}

Before starting the development cycle (sprint \#1), the whole team comes together through a workshop session to conduct the Sprint Planning under the supervision and mediation of Coach. Small modules of OER should be prioritised and selected to be developed during the current sprint based on the Initial Architecture View.

Firstly, the team should establish a plan for a release to be delivered to a target audience, as discussed in Section 5.2. This occurs before starting the sprint (sprint \#1). Depending on the size of project, an OER can have one or more releases and each release can need one or more short sprints.

Educators should prioritise the small modules of the OER and introduce to designers and media creators, indicating what should be done with each one. They focus on the most relevant aspects to be addressed by the OER. Secondary aspects or less important should be discussed later.

When necessary, the OER can be explained as simple "stories" in terms of their learning objectives, only describing the key idea to facilitate their understanding. We consider learning objectives as requirements, use cases or user stories in the software development.

The development team, especially the media creators together with designers, should think about the strategy they will use to create the OER module in the current sprint. They 
select the modules to be created taking into account the priority of the OER modules established previously by the educators.

Table 19 - Development: summary of the steps.

\begin{tabular}{|c|c|c|c|}
\hline Steps & Participants & $\begin{array}{l}\text { Input/Support } \\
\text { Documents }\end{array}$ & Outcomes \\
\hline $\begin{array}{l}\text { Prioritise and Select } \\
\text { OER Modules }\end{array}$ & Whole Team & Initial Architecture View & $\begin{array}{l}\text { OER modules } \\
\text { prioritised and selected }\end{array}$ \\
\hline $\begin{array}{l}\text { Design the Learning } \\
\text { Structure }\end{array}$ & Whole Team & $\begin{array}{l}\text { General Goals/Learning } \\
\text { Objectives/Initial } \\
\text { Architecture View }\end{array}$ & $\begin{array}{l}\text { Learning Outcomes } \\
\text { View }\end{array}$ \\
\hline Define Metadata & $\begin{array}{l}\text { Educators/Development } \\
\text { Team }\end{array}$ & Initial Architecture View & Primary Metadata \\
\hline $\begin{array}{l}\text { Search Learning } \\
\text { Contents }\end{array}$ & $\begin{array}{l}\text { Educators/Development } \\
\text { Team }\end{array}$ & $\begin{array}{l}\text { General Goals/Learning } \\
\text { Objectives/Initial } \\
\text { Architecture View }\end{array}$ & $\begin{array}{l}\text { Related Learning } \\
\text { Contents }\end{array}$ \\
\hline $\begin{array}{l}\text { Evaluate and Adapt } \\
\text { Learning Contents }\end{array}$ & Whole team & Related Learning Contents & $\begin{array}{l}\text { Related Learning } \\
\text { Contents approved }\end{array}$ \\
\hline $\begin{array}{l}\text { Create OER modules } \\
\text { (from scratch) }\end{array}$ & $\begin{array}{l}\text { Development } \\
\text { Team/Educators }\end{array}$ & $\begin{array}{l}\text { General Goals/Learning } \\
\text { Objectives/Initial } \\
\text { Architecture View }\end{array}$ & OER modules created \\
\hline $\begin{array}{l}\text { Establish Licensing } \\
\text { Policies }\end{array}$ & $\begin{array}{l}\text { Educators/IP } \\
\text { Expert/Development } \\
\text { Team }\end{array}$ & OER modules created & Licensing chosen \\
\hline Evaluate OER modules & Whole team & OER modules created & OER modules approved \\
\hline $\begin{array}{l}\text { Evaluate } \\
\text { Execution }\end{array}$ & Coach/Development Team & & Lessons Learned \\
\hline
\end{tabular}

Source: Research data.

The development team can make estimatives of the OER to be created. Estimatives are required when it is necessary to predict the effort to create or re-purpose a module, or to predict the duration of the OER project as a whole. Then, the development team comes into agreement with the users about what will be delivered at the end of the current sprint.

The process repeats until all sprints planned are finished and the OER is approved by users. Thus, it is possible to obtain a detailed planning accepted and approved by the team for each sprint; a continuous planning where the generated artefacts can be updated throughout the development process.

\subsubsection{Design the Learning Structure}

A learning structure for the OER to be developed in the current sprint should be sketched, representing the connections between all components/elements needed for the learning context. The learning structure for the OER is designed iteratively in small increments (Iterative Modelling/Design) (AMBLER, 2001). Learning Design practices from OULDI (CONOLE, 
2013) are used together to describe and show how those components/elements should be linked with each other to achieve an effective pathway.

Figure 28 - Development: main steps.

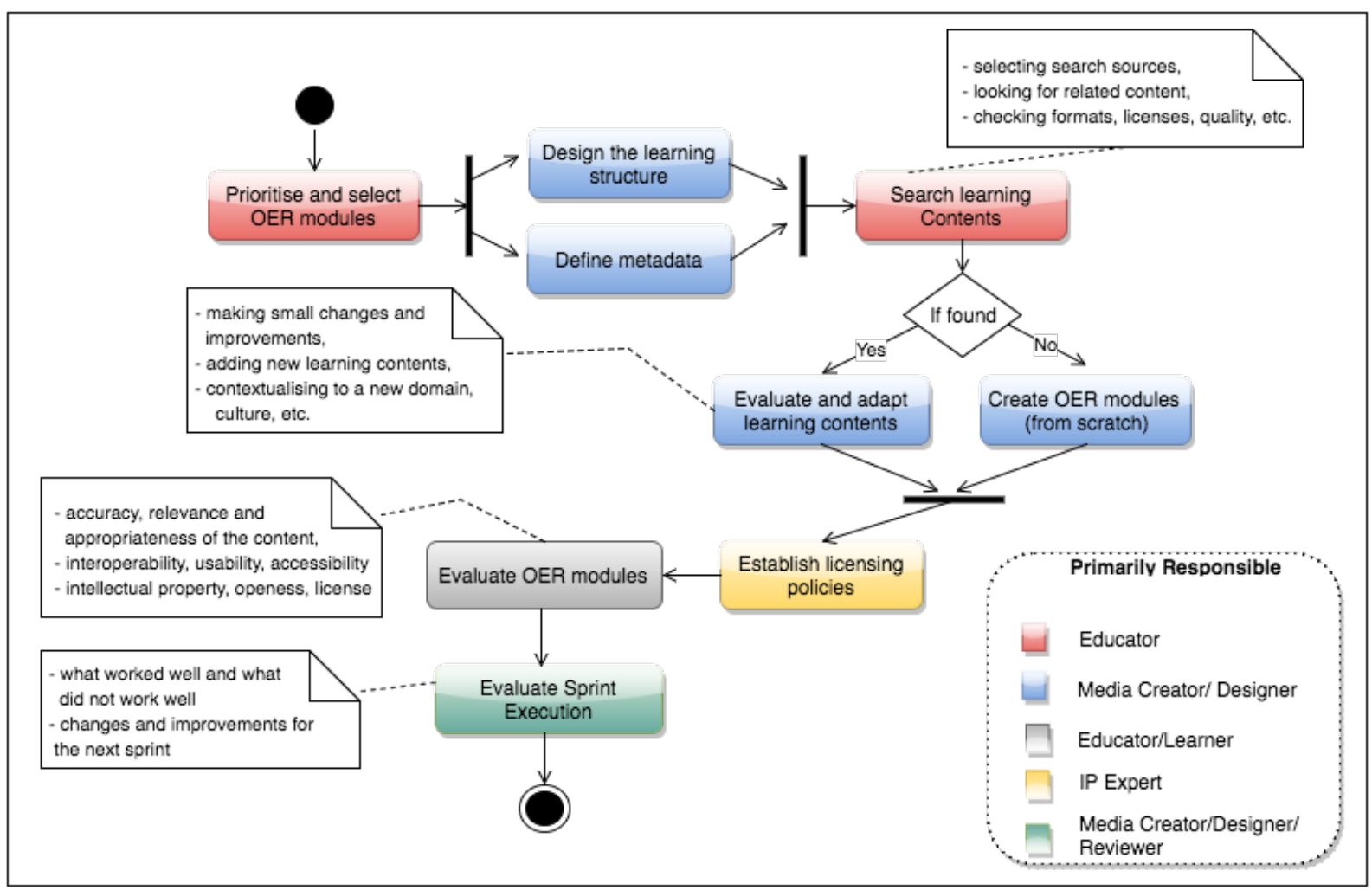

Source: Elaborated by the author.

Educators along with designers and media creators come together by a brainstorming session to discuss the design of the OER to obtain a structured process for the learning context. Based on the needs analysis (general goals, learning objectives, and domain or context of usage) and on the initial architecture of the OER (Initial Architecture View), the activities that learners will have to perform (learning activities) to achieve the desired learning outputs are established. This helps them to reflect on the flow of the activities of the OER and the strategies for its development.

The learning activities are mapped with the intended learning outcomes, contents, tools and assessment activities of learners. The result produces the Learning Structure View for the current sprint, based on the Learning Outcomes View (BRASHER et al., 2012). The Learning Outcomes View is a mandatory artefact used, updated and integrated throughout the development.

In Figure 29 we illustrate an example of the artefact Learning Outcomes View in the context of a introductory course of software testing. It is composed by the following items: (1) what is to be learnt (i.e., the learning objectives), represented by the blob on the left (such as demonstrate conceptual knowledge on software testing techniques); (2) learner activities, represented by the blob on the middle (such as study the fundamentals of testing techniques), (3) content/media and tools, accompanying and supporting the 
learner activities (such as lessons and moodle); and (4) learner output, represented by the blob on the right (such as oral presentation (work in group)). In this case, a learner enrolled in the activity demonstrate conceptual knowledge on software testing techniques would have acquired conceptual knowledge and critical understanding on the subject according to evaluations conducted throughout the course (i.e., oral presentation).

Figure 29 - Learning Outcomes View: Mapping learning activities with learning outcomes, content, tools and assessment activities.

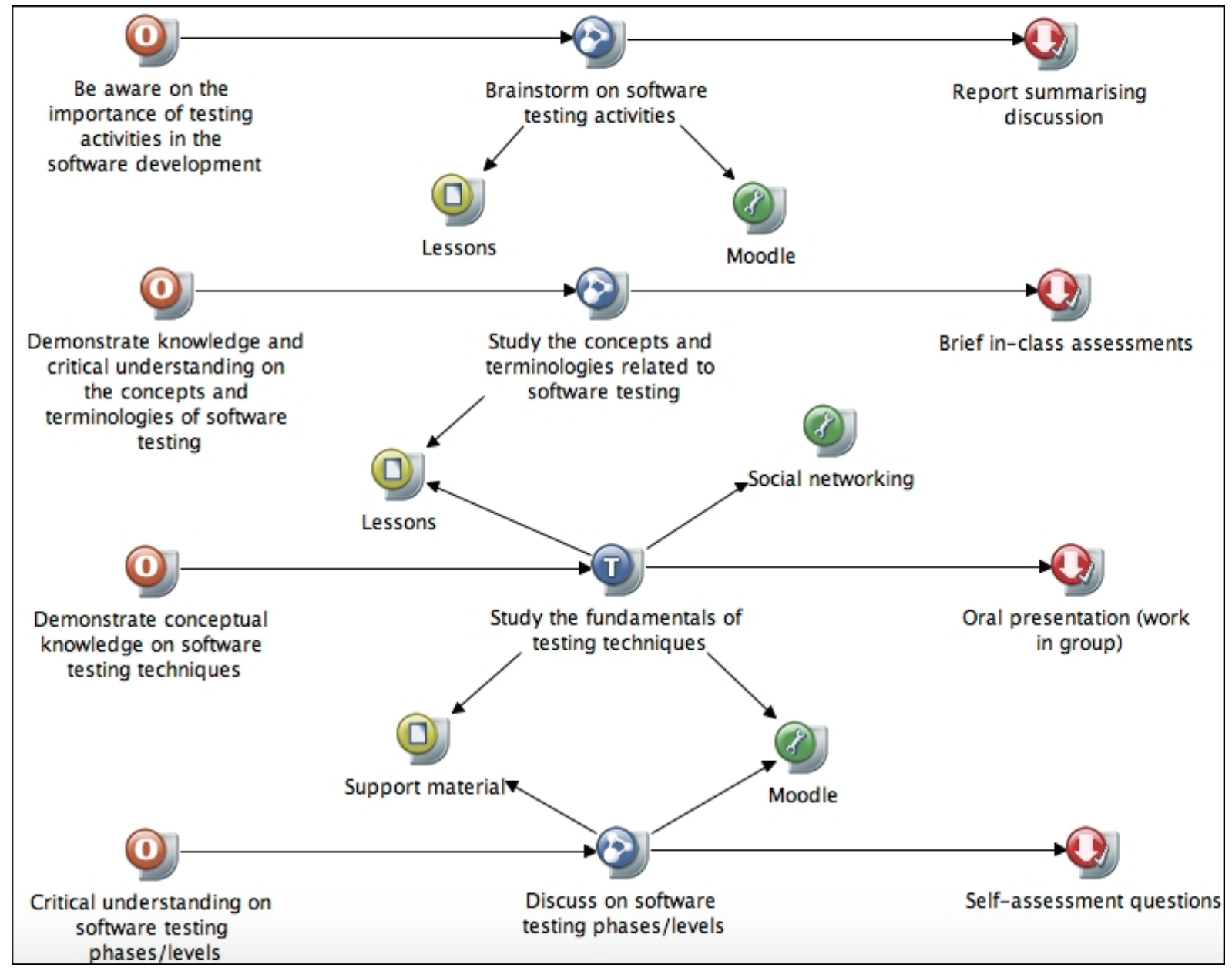

Source: Elaborated by the author.

\subsubsection{Define Metadata}

Educators and the development team should start identifying and gathering the primary metadata for the OER. Metadata describes relevant characteristics of the OER, facilitating its reuse and recovery by search engines. When an OER has integrated metadata, any user can easily find it (MADDEN, 2010).

The metadata specification must be standardised in order to facilitate the reuse and discoverability of OER. The standardisation of metadata also allows the (re)use of OER in different environments and learning systems, platforms and repositories. Examples of metadata standards include Dublin Core (National Information Standards Organization, 2007), Learning 
Object Metadata (LOM) (IEEE Learning Technology Standards Committee, 2002), IMS Metadata (IMS Global Learning Consortium, 2012) and Learning Resource Metadata Initiative (LRMI) (Learning Resource Metadata Initiative, 2015).

Based on the metadata standards aforementioned we identified and gathered 13 elements/attributes that are useful to describe relevant characteristics of any OER:

1. Author's name: indicating the primarily responsible for the development of the OER, which can be a person, an educational institution or organisation;

2. Publisher: indicating the entity responsible for making the OER available for other users, which can be a person, an educational institution or organisation;

3. Contributor: indicating the entity responsible for making contributions for the development of the OER, which can be a person, an educational institution or organisation;

4. Identifier: indicating an unambiguous reference to the OER within a specific context or domain of knowledge;

5. Title: concerning to the formal and objective name assigned to the OER;

6. Data: indicating the data/period of time related to the development or availability of the OER;

7. Rights: indicating clear authorship and intellectual property rights (IPR) and conditions of use on the OER. This includes IPR of third-party learning contents used to compose the OER;

8. Language: indicating the language of the learning contents associated to the OER;

9. Type: indicating the nature or genre of the learning contents associated to the OER;

10. Format: indicating the file format, physical medium, or dimension of the learning contents associated to the OER;

11. Grade level: indicating who is the target audience, such as primary or secondary school, undergraduate or graduate;

12. Subject: showing the topics related to the context of use of OER, which can be represented by keywords or key phrases; and,

13. Description: summarising the central idea of the OER and its objectives.

Throughout the development process, the OER metadata specification can be updated by adding new terms and/or modifying existing ones. 
Depending on the kind of OER, metadata may be added directly to the OER and/or included when the OER is shared through an environment and learning system, platform or repository (MADDEN, 2010).

\subsubsection{Search for Learning Contents}

This step essentially comprises seeking learning contents to be repurposed. Before starting the search, educators and the development team need to identify "where" to search. There are many places where learning contents can be searched. Materials previously used by the educators or colleagues should be used as starting point, including open textbooks, research papers, lessons plans, lectures notes, presentations, projects, exercises, assessments, among others.

On the other hand, the Internet provides facilities for seeking online contents through different mechanisms including specialised search engine (e.g., Open Courseware Consortium: <ocwconsortium.org>), institutional repositories (e.g., OpenLearn: <openlearn.open.ac.uk>), digital libraries (e.g., OER Commons: <oercommons.org>), general search engine (e.g., Google Search), and many others. Useful mechanisms to support the search for online contents through the Internet are gathered in Section 5.5.3 - Search Mechanisms.

Whilst searching for learning contents, specific issues need to be taken into consideration. An essential issue refers to the learning contents accessibility. Materials should be accessible and available in file formats that do not difficult their modification and conversion to other formats. Therefore, the file formats should provide facilities about their reuse, modification and remix as needed, without many restrictions. In this case, proprietary materials must be avoided, prioritising the usage of free and open materials. Therefore, when searching for and selecting related contents some issues should be taken into consideration:

- Consider different search engines, databases and repositories. Some search engines incorporate a large number of databases and repositories. Others are dedicated to seeking specific content/media (open textbooks, presentations, images, audio or video). Both should be considered during the search process;

- Be aware on the use of relevant keywords related to the learning material subject. This should avoid that potentially relevant contents be not located by the search engines;

- Prioritise learning contents provided with little or no restriction regarding their (re)use and adaptation. Verify if the file formats used can be modified and tailored to the desired needs;

- Be aware on the licensing types used on the available learning contents. Some licenses do not allow modification or remix on the contents, restricting their reuse. Others require that reused learning contents be shared under the same license used by their owners; and, 
- Make sure that the learning contents found are from reliable sources, including institutions/organisations engaged with education, renowned authors, among others. Verify if the learning contents are associated with ranking system, and if they are recommended by users. This is a means of ensuring the quality of the contents.

\subsubsection{Evaluate and Adapt Learning Contents}

After obtaining the learning contents, educators and reviewers need to evaluate whether they are appropriate for the OER purpose, before the development team modify, re-contextualise or adapt them. Basically, the evaluation should consider the following issues:

- Analysis whether the learning contents found fit the didactic and pedagogical objectives of the OER;

- Identify and establish what are the "weakness" and "shortcomings" of the learning contents or whatever needs to be revised, changed and/or improved; and,

- Define what has to be added or mixed with the learning contents, and what has to be created from "scratch" to compose the new OER.

An OER can be created by the development team from "scratch" or by reusing existing ones to compose a new OER. Composing a new OER from third-part learning materials involves different ways of adaptations in such materials to meet the particular educational needs. Adjustments may include the following:

- Make small fixes and modifications in the learning contents;

- Add some improvements and/or new functionalities to increase the quality;

- Add new learning activities, contents and pathways to improve the learning experience of learners;

- Provide different ways of learning to satisfy individual styles or preferences of learning. This includes the use of different type of contents and media;

- Recreate learning contents that are incomplete or have shortcomings;

- Repurpose learning contents to meet specific context or particular requirements; and,

- Contextualise the learning contents to adapt them to a new context or domain. This includes language and cultural issues, i.e., essential aspects of localisation and globalisation of OERs. 


\subsubsection{Create OER Modules from Scratch}

In many cases, it is necessary to develop an OER from "scratch". A major difficulty is related to the reuse of third-part learning materials to produce something new. There are different reasons for this. Several educators and practitioners do not often reuse third-part materials due to the difficulty to find "what they want". This problem lies in the discovery capability of OERs, commonly influenced by the lack of appropriate metadata (WENK, 2010; WILEY; BLISS; MCEWEN, 2014).

Problems related to the relevance and quality of available OERs also difficult their reuse (DIMITRIADIS et al., 2009; LOCKYER et al., 2008; OMOLLO; RAHMAN; YEBUAH, 2012). Furthermore, the mistrust that OERs are necessarily of inferior quality because they are free still remains (WILEY; BLISS; MCEWEN, 2014).

Another reason to develop an OER from scratch is the lack of contextually appropriate OERs (KANWAR; KODHANDARAMAN; UMAR, 2010; OMOLLO; RAHMAN; YEBUAH, 2012). Many OERs may be suitable for certain learning contexts, but may inappropriate to others. Oftentimes, it is hard to adapt and re-contextualise an OER for a particular learning situation or need.

Regardless of reuse third-party learning material or not, an OER is designed and created by the development team through several and repetitive sprints, culminating with the delivery of Small Releases at the end of a sprint or small set of sprints. Before starting to develop the OER itself, the development team comes together for a quick brainstorming session to discuss about the design, with the Active Participation of Users (mainly educators, and eventually learners). They practice a "just in time" design (Model/Design Storming) (AMBLER, 2001), discussing and identifying specific issues that need to be considered to develop the OER.

Practices of Learning Design from OULDI (CONOLE, 2013) are used in combination with the Design Storming, particularly to map the flow of OER activities within the intended learning structure. In other words, Learning Design practices are used to describe and map individual learning activities to the components that need to be addressed by such activities, such as: (1) contents or resources/tools involved in the activities; (2) types of tasks to be performed by learners; (3) type of assessment activities; and (4) roles of everyone involved in the learning intervention.

Therefore, designers and media creators refine and decompose the OER activities in simpler activities and atomic tasks, helping them to reflect upon one aspect of the design solution and how they can transform it for a more effective OER with embedded pedagogical design practices. The result culminates with the Learning Task View artefact, a refinement of the Learning Structure View artefact produced in the previous phase. The Learning Task View is based on the Task Swimlane View of OULDI (BRASHER et al., 2012).

In Figure 30 we illustrate an example of the Learning Task View artefact. It represents a simple learning activity Demonstrate conceptual knowledge on software testing techniques from the Learning Structure View, broken down into simple learning 
tasks. The contents or resources are linked to the relevant task node. In the figure, the learner determine the fundamentals of black-box testing (supported by lessons), determine the fundamentals of white-box testing, then, he/she is evaluated through an oral presentation on the subject (mediated by the educator). After that, he/she synthesise the strategies/criteria for both testing techniques, and produces a report on such strategies/criteria (having feedback from educators).

Figure 30 - Learning Tasks View: Mapping learning activity into individual and atomic tasks.

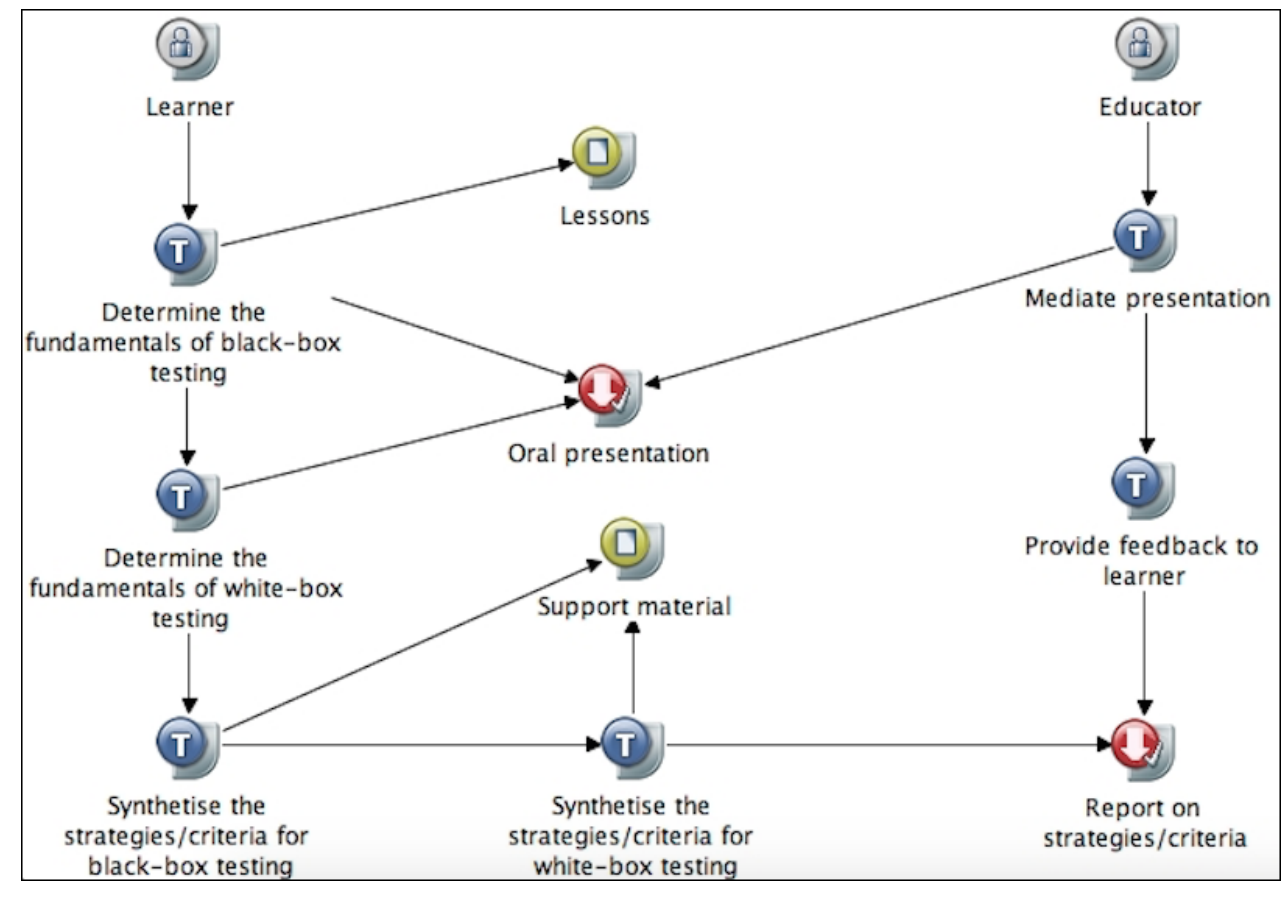

Source: Elaborated by the author.

Based on the Learning Task View, media creators and designers create the OER activities and contents, which will compose the OER. It involves the creation of any kind of content or media, and activities needed to the new OER. This may include the following: open textbooks, html pages, research papers, lecture notes/slide shows, streaming audios/videos, audios, videos, podcasts, images, animations, tests, among others.

The OER is reviewed and updated during its development. The team members work in constant collaboration throughout development. New solutions and improvements could be highlighted through feedback provided by interactions and cooperations with educators and learners. Media creators and designers constantly refactor their solution aiming to simplify and enhance it.

Similarly to the concept of Continuous Integration used in XP (BECK; FOWLER, 2000), during the development the team often integrates and links all components that compose the OER produced.

The learning structure of the OER, activities and contents are regularly reviewed throughout development to detect mistakes and other problems which may affect the quality of 
OER. Media creators and designers must update the OER to reflect the necessary corrections and changes.

\subsubsection{Establish Licensing Policies}

The licensing policies to share the OER with others are established by the IP Expert. OER implies the use of open licenses with little or no restriction. Open license enables sharing an OER without payment of a royalty or license fees. The usage of an open license is essential to provide reuse and benefit to others users.

When establishing the licensing policies of the OER we should take into consideration the following:

1. Verify the authorship and intellectual property rights of third-part learning contents (when used);

2. Decide how the OER will be available (for instance, if non-commercial use of work is allowed or not and if adaptations of work is allowed to be shared or not); and,

3. Choose the appropriate license taking into account items 1 and 2.

The most popular and widely used licenses to share learning materials such as OER are the Creative Commons Licenses (Creative Commons, 2013a).

Before choosing a license it is important to check its compatibility with other licenses, especially when different learning contents developed by third-party are used to develop a new OER. In Table 20 it is possible to verify the compatibility between Creative Commons Licenses. For instance, some types of license require that derived work from third-party be shared using the same license, as in the case of Attribution Non-Commercial Share Alike (CC BY-NC-SA) and Attribution Share Alike (CC BY-SA).

\subsubsection{Evaluate OER Modules}

The OER module produced and delivered at the end of the current sprint is evaluated and approved/disapproved during a workshop session involving the whole team. The Sprint Review is put into practice, supervised and mediated by the Coach. In summary, extensive evaluating activities and inspections on the OER is carried out by the educators/specialists/domain experts and learners. Eventually, external reviewers to the team may also participate.

Criteria to evaluate the OER produced in the current sprint should be identified. There are different characteristics which can be taken into consideration during an assessment program. In order to assist in the OERs evaluation we proposed a set of assessment criteria/aspects based on previous work (International Organization for Standardization, 2001; LEACOCK; NESBIT, 2007; JISC., 2010). Such criteria are divided into three categories summarised as follows: 
1. Didactic-pedagogical: this category encompasses (1) accuracy, e.g., the content is accurate and consistent for the learning objectives; (2) relevance, e.g., the content is relevant and fits for purpose; and (3) pedagogical design, e.g, the learning outcomes are presented and are in accordance with the needs of learners and the contents, activities and learning assessments are aligned with the learning outcomes.

2. Technical: this category encompasses (1) interoperability, e.g., easy to use in different browsers, platforms, repositories and/or educational environments; (2) accessibility, e.g., accessible to users with special needs, accessible by different means and open devices and available in accessible locations such as open platforms and repositories or stand-alone websites; (3) usability, e.g., easy to use and well-structured and organised contents, in compliance with usability standards; (4) discoverability, e.g., easy to find and metadata file included and well-defined, according to metadata standards; and (4) localisation/globalisation, e.g., easy to re-contextualise and modify, for a particular need, such as meet specific domain, or for cultural and language issues.

3. Legal: this category encompasses (1) intellectual property and rights, e.g., intellectual property and rights on original OER are set; and (2) licenses, e.g., licenses for the use of OER are well explained and documented according to open licensing policies.

Table 20 - Creative Commons licenses: Compatibility between licenses.

\begin{tabular}{|c|c|c|c|c|c|c|c|c|}
\hline & (C) PUBLIC & (0) $\begin{array}{c}\text { PuBLIC } \\
\text { Bowali }\end{array}$ & (c) $\left.(1) \Theta()_{\mathrm{BY}}\right)$ & (c) (1) (1) (2) & 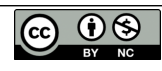 & 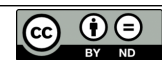 & (c) (1) () & (c) (1) \\
\hline (C) PUBLIC & $\checkmark$ & $\checkmark$ & $x$ & $\checkmark$ & $\checkmark$ & $\checkmark$ & $\checkmark$ & $x$ \\
\hline (0) Pubucic & $\checkmark$ & $\checkmark$ & $x$ & $\checkmark$ & $\checkmark$ & $x$ & $\checkmark$ & $x$ \\
\hline (c) $(1)(\Theta)$ & $x$ & $x$ & $x$ & $x$ & $x$ & $x$ & $x$ & $x$ \\
\hline (c) (1) (\$) (2) & $\checkmark$ & $\checkmark$ & $\checkmark$ & $x$ & $\checkmark$ & $x$ & $\checkmark$ & $x$ \\
\hline (c) $(1)(\Theta$ & $\checkmark$ & $\checkmark$ & $\checkmark$ & $x$ & $\checkmark$ & $x$ & $\checkmark$ & $x$ \\
\hline (c) $\underset{\mathrm{BY}}{(\mathrm{i})} \Theta_{\mathrm{ND}}$ & $x$ & $x$ & $x$ & $x$ & $x$ & $x$ & $x$ & $x$ \\
\hline (c) (1) (2) & $\checkmark$ & $\checkmark$ & $\checkmark$ & $\checkmark$ & $x$ & $x$ & $x$ & $x$ \\
\hline (c) (1) & $\checkmark$ & $\checkmark$ & $\checkmark$ & $\checkmark$ & $\checkmark$ & $x$ & $\checkmark$ & $x$ \\
\hline
\end{tabular}

Source: Elaborated by the author.

We highlight that the criteria mentioned above can be used together or separately, depending on the purpose of the evaluation. Other criteria should be also defined and adopted to support the evaluation. 
A set of activities should be conducted to evaluate and approve the work and artefacts produced in the current sprint. Different approaches should be taken into consideration as following:

- Users Assessment: evaluation conducted by educators/specialists/domain experts, learners and others users;

- Peers Review, evaluation conducted by peers of specialists - academic staff and educators/specialists/domain experts and others engaged with education;

- Individual Assessment: evaluation conducted by educators/specialists/domain experts within team or educational institution or organisation; and,

- External Assessment: evaluation conducted by educators/specialists/domain experts outside the team or external educational institution or organisation.

Regardless of the adopted approaches, educators and learners are involved in verifying whether the learning pathways associated with the contents contribute to the learning, taking into account the criteria previously discussed. Educators also analyse whether the type of contents and activities, learning assessments, and tools are appropriate to the purpose of the OER, e.g., if they are aligned with the intended learning outcomes. The results gathered from the evaluations conducted are used as the basis for proposing changes and adding improvements for the next release of the OER.

Early and continuous evaluation of the development process helps clarify problems and solutions and identify the needs for corrections and improvements. The modules of the OER, or part of them, can be reviewed by educators and learners throughout the process, and any change can be made at any stage of the development.

\subsubsection{Evaluate Sprint Execution}

This step consists of conducting the Sprint Retrospective under the Coach's responsibility. The team comes together through a brainstorming session to discuss the general execution of the current sprint to identify problems, mistakes and the need for improvements. Particularly, the team needs to think about the development strategy adopted in the sprint, mainly discussing how the team can improve the strategy for designing and creating the OER modules.

The team should identify the lessons learned ("what worked well" and "what did not work well") with the execution of the sprint. From this, they should discuss about "what needs to change and improve" in the next sprints.

Lessons learned and feedback from the evaluation should be analysed, gathered, and used for changing and improving the following sprints, contributing to the continuous improvement process. 


\subsubsection{Sharing}

The OER release should be provided to be delivered in a learning environment, and effective access to the release should be allowed according to its context. For this, the team needs to decide where and how the release will be published and delivered.

In Figure 31 we illustrate the main steps conducted in this phase: (1) deliver to a target audience; (2) make available in easily accessible locations, and (3) gather feedback and review. Such steps are summarised in Table 21, including the main participants, the input and/or support documents, and the outcomes and/or artefacts. The steps are described in detail next.

Table 21 - Sharing phase: summary of the steps.

\begin{tabular}{llll}
\hline Steps & Participants & $\begin{array}{l}\text { Input/Support } \\
\text { Documents }\end{array}$ & Outcomes \\
\hline $\begin{array}{l}\text { Deliver to a Target } \\
\text { Audience }\end{array}$ & Educators & OER release & Learner's experience \\
$\begin{array}{l}\text { Make Available in } \\
\text { Easily Accessible }\end{array}$ & Development Team & OER release & $\begin{array}{l}\text { Available on Platforms/ } \\
\text { Repositories or Stand-alone } \\
\text { Locations }\end{array}$ \\
$\begin{array}{l}\text { Wather Feedback and } \\
\text { Review }\end{array}$ & $\begin{array}{l}\text { Educators/ } \\
\text { Development Team }\end{array}$ & Released OER & $\begin{array}{l}\text { Learner's Experiences/User's } \\
\text { Feedback/Weaknesses and } \\
\text { Shortcomings }\end{array}$ \\
\hline
\end{tabular}

Source: Elaborated by the author.

Figure 31 - Sharing: main steps.

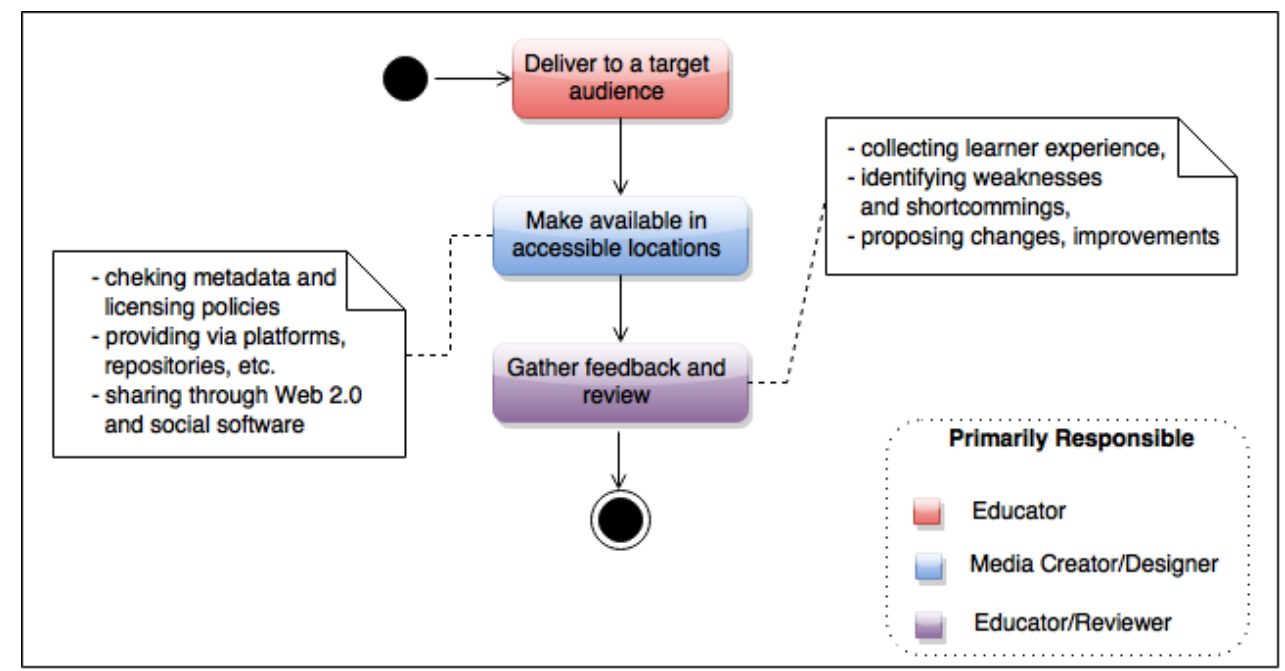

Source: Elaborated by the author.

\subsubsection{Deliver to a Target Audience}

The OER release is delivered for use in a learning environment with a group of learners. For instance, the OER release should be used to teach a subject (such as software testing, or 
more specifically, a small module within software testing, e.g., structural technique) of a course to undergraduate and graduate students in Computer Science, or any other subject or course.

The use of OER release by learners is critical to identify weaknesses and propose improvements. Educators provide the support needed to learners in their activities and monitor their progresses and achievements. Data about the learner's experience will be collected and analysed to improve the quality of the OER release.

\subsubsection{Make Available in Easily Accessible Locations}

The OER release can be provided through platforms or repositories and institutional or stand-alone websites. Primarily, it is necessary to certify that the OER release is made available together with the associated metadata, according to packaging standards such as the Dublin Core Metadata, LOM, IMS Metadata or LRMI. Also, it needs to be licensed openly, following open licenses such as Creative Commons licenses, providing few or no restriction on its (re)use.

To support the availability of the OER release, Web 2.0 technologies and social software should be used as support. For instance, microblogging (such as Twitter) and social networking (such as Facebook) are widely used by worldwide users, being considered important mechanisms for disseminating and sharing knowledge. Tools such as Slideshare, Flickr and YouTube are also widely used, and are accessible and easily mechanisms for sharing OER. Other tools such as RSS Feeds are also useful, particularly to link related learning contents, as well to disseminate and facilitate access to the OER.

The availability of OER release in CD/DVD formats also needs to be take into consideration when users have Internet problems. Furthermore, there are others open tools to be used to disseminate the OER. The widely availability of OER allows other users (such as external educators and researchers) to reuse and adapt it to their own context and needs.

\subsubsection{Gather Feedback and Review}

Educators should gather feedback from learner's experience on the usage of OER release in a learning environment, as well as the feedback provided by others users. Possible changes and improvements are analysed by the team and may be implemented in the further release.

Educators should gather feedback from users taking into account the following issues:

- The usefulness and easiness of learning, i.e., whether the learning structure of OER is well-structured and organised, guiding and facilitating the learning process; and,

- The effectiveness of learning, i.e., whether the learning structure (including the learning activities, related contents, tools and assessment activities) are appropriate, effectively contributing to the learning process; whether the users achieved the intended learning outcomes. 
Additionally, the team should review the OER release in order to identify mistakes, weaknesses and shortcomings. This includes the need to fix reported problems, perform small changes and adaptations, promote improvements or add new contents, activities, supporting materials or tools.

The OER development cycle should be restarted whenever changes and adjustments are required to keep the OER up-to-date and to improve its quality.

\subsection{Supporting Tools}

The supporting tools needed to develop an OER can be generically classified according to the roles they play within the development process of such OER. From this perspective, four basic categories of supporting tools may be identified:

1. Learning Objectives Statement Mechanisms: support the identification and specification of the learning objectives of an OER, helping in the learning assessment activities;

2. Search Mechanisms: support the search for learning materials that can be (re)used for creating and composing an OER;

3. Learning Design Tools: support the visualisation and graphical representation of the learning structure of an OER, making it more visible, understandable and reusable; and,

4. Content Editing Tools: support the creation, editing and repurposing of all contents and media needed to an OER, including text-based contents, images, audios/videos, and statistical data.

The main tools to support the whole OERs development process are summarised next.

\subsubsection{Learning Objectives Statement Mechanisms}

Benjamim Bloom (BLOOM et al., 1956) proposed in 1956 a taxonomy of the knowing or cognitive domain. The taxonomy aimed at assisting in the specification of learning objectives, and facilitating the planning of learning experiences and the preparation of assessment programs.

The Bloom's taxonomy provides a ready-made structure and set of verbs that has became widely used to support in writing measurable learning objectives/outcomes (KENNEDY; HYLAND; RYAN, 2007). Such taxonomy structures the cognitive domain hierarchically into levels, according to the increasing order of its complexity. There are six levels: (1) Knowledge; (2) Comprehension; (3) Application, (4) Analysis; (5) Synthesis; and (6) Evaluation.

In Table 22 we summarise the Bloom's taxonomy, including the six cognitive levels of learning together with a list of action verbs that can be used to specify the learning objectives suitable for that level of learning. In the Knowledge level, students are able to 
recall and remember information and facts without developing a deep understanding. An example of learning objective statement for demonstrating evidence of knowledge may be: students will be able to identify and consider the main implications when using structural testing technique in concurrent programs.

Table 22 - Bloom's taxonomy of the cognitive domain.

\begin{tabular}{ll}
\hline Cognitive Levels & Bloom's Taxonomy Verbs List \\
\hline Knowledge & $\begin{array}{l}\text { locate, match, name, offer, omit, pick, quote, repeat, say, sort, spell, recognise, } \\
\text { memorise, review, remember, relate, write, state, read, recall, catalogue, enumerate, } \\
\text { record, describe, tell, show, list, cite, restate, identify, arrange, find, choose, group, } \\
\text { label, select }\end{array}$ \\
Comprehension & $\begin{array}{l}\text { alter, vary, transform, qualify, infer, instruct, discern, discuss, change, retell, reword, } \\
\text { reorganise, construe, convert, expand, explain, interpret, outline, predict, distinguish, } \\
\text { translate, restate, figure, describe, clarify }\end{array}$ \\
Application & $\begin{array}{l}\text { construct, demonstrate, complete, relate, model, utilise, operate, handle, manipulate, } \\
\text { generalise, put into action, experiment, draw, solve, illustrate, examine, show, use, } \\
\text { calculate, apply, make, translate, record, teach }\end{array}$ \\
Analysis & $\begin{array}{l}\text { compare, classify, dissect, examine, take apart, test for, search, contrast, separate, } \\
\text { differentiate, dissect, distinguish, categorise, identify, explain, reduce, order, investigate, } \\
\text { abstract, summarise, break down, uncover, look into }\end{array}$ \\
Synthesis & $\begin{array}{l}\text { estimate, imagine, propose, create, combine, build compile, develop, produce, predict, } \\
\text { hypothesise, design, invent, improve, blend, construct, generate, formulate, add to, } \\
\text { compose, combine, plan, forecast, estimate, imagine, propose } \\
\text { discuss, editorialise, debate, consider, critique, criticise, select, assess, recommend, } \\
\text { verify, grade, argue, prioritise, judge, decide, rate, appraise, assay, rank, weight, accept, } \\
\text { reject, justify, determine }\end{array}$ \\
\hline Evaluation &
\end{tabular}

Source: Elaborated by the author.

In the Comprehension level, students are able to understand and interpret the acquired knowledge. An example of learning objective statement for demonstrating evidence of comprehension may be: students will distinguish between black-box (functional) and white-box (structural) testing.

In the Application level, students are able to apply the acquired knowledge in practical situations. An example of learning objective statement for demonstrating evidence of application may be: student will be able to apply mutation testing technique in concurrent programs.

In the Analysis level, students are able to analyse the relationship and organisational structure of learned information. An example of learning objective statement for demonstrating evidence of analysis may be: students will be able to compare and contrast the different software testing techniques.

In the Synthesis level, students are able to gather learned information together. An example of learning objective statement for demonstrating evidence of synthesis 
may be: student will be able to summarise the problems and peculiarities of testing in the context of concurrent programs.

In the Evaluation level, students are able to judge the value of material within a given context. An example of learning objective statement for demonstrating evidence of evaluation may be: students will be able to evaluate the different testing tools and to select the most appropriate for their purpose.

\subsubsection{Learning Design Tools}

One of the objectives of the Learning Design is to make the learning structure of learning materials more visible to facilitate understanding, and more shareable to be reused by educators and practitioners (CROSS; CONOLE, 2009). Therefore, tools supporting the graphical representation and visualisation of Learning Design activities and resulting artefacts are crucial.

CompendiumLD (BRASHER et al., 2008) is a Learning Design tool that fits in this context. It consists of a software tool for visually representing the learning activities of a course. It supports educators, practitioners and others engaged with education to help them articulate their ideas and outline the learning pathway. The process of visualising and representing design of learning materials can make such design more explicit and sharable to be reused by others. The tool helps to get a better understanding on the flow of learning activities, and to obtain an effective learning pathway.

CompendiumLD was developed as a part of the OULDI project (CROSS et al., 2012; CONOLE, 2013). It runs on Windows, Linux and Mac OS operating systems, being licensed under the GNU Lesser General Public (LGPL) ${ }^{3}$.

Additionally, Freemind ${ }^{4}$ is a mind-mapping tool that can be used as support to describe and map the components/elements of a learning material. Freemind allows to export the map as OpenDocument, HTML, SVG PNG format. The tool is cross-platform, being available through the GNU General Public License (GPL) ${ }^{5}$.

\subsubsection{Search Mechanisms}

There are several initiatives that help finding and promoting learning materials as OERs globally. We gather some useful sources of search to start getting a variety of different kinds of OERs, as summarised next:

- Institutional-based repositories and platforms: provide free online course materials usually used in regular courses within the universities. Typical examples of such initiatives include: (1) MIT Open Courseware (<ocw.mit.edu>); (2) OpenLearn (<openlearn.open. ac.uk>); (3) Open Learning Initiative (<oli.cmu.edu>); (4) Connexions (<cnx.org >); (5) 
Open Yale courses (<oyc.yale.edu>); (6) Utah State OpenCourseWare (<ocw.usu.edu>); and (7) Open.Michigan (<open.umich.edu>).

- Projects sites/wikis and digital libraries: provide a single point of access for searching learning contents through content/OER partners and digital libraries. Examples of such initiatives include: (1) OER Commons (<oercommons.org>); (2) Commonwealth of Learning (<col.org>); (3) OER Africa (<oerafrica.org>); (4) Wikiversity (<wikiversity. org $>$ ); (5) Wikieducators (<wikieducator.org >); (6) Saylor (<saylor.org >); and (7) Khan Academy ( $<$ khanacademy.org $>$ ).

- Specialised search: specifically for seeking open contents, particularly OERs. By using a specialised search engine it is possible to access and reuse a larger variety of OERs from renowned universities around the world. Typical examples of specialised search include: (1) OpenCourseWare/Open Education Consortium (<oeconsortium.org>); (2) Creative Commons Search (<search.creativecommons.org $>$ ); and (3) DiscoverED (<wiki. creativecommons.org/wiki/DiscoverEd $>$ ).

- Integrated and Meta-search: enable the search for a variety of OERs in different repositories and libraries from one place. They embed search engine using Google Custom Search. Examples of integrated and meta-search engine include: (1) OER Dynamic Search Engine (<edtechpost.wikispaces.com/OER+Dynamic+Search+Engine>); and (2) University Learning $=\mathrm{OCW}+\mathrm{OER}=$ Free .

- General search: usually used as starting point to seek for online contents. Typical examples of general search engines are Google, Yahoo and Bing. Through general search engines it is possible to restrict the search to only return contents openly licensed for reuse (for instance, using the option advanced search).

- Open textbook search: allows the specific search for open textbooks published as OER. Examples of open textbooks search include: (1) College Open Textbooks (<collegeopentextbooks.org>); (2) Open Stax College (<openstaxcollege.org>); (3) Siyavula (<siyavula.com>); and (4) ChemWiki (<chemwiki.ucdavis.edu>).

- Specific media search: allows the search for specific media/contents such as presentations, images, animations and videos. Examples of specific media search include: (1) SlideShare (<slideshare.net>); (2) Flickr (<flickr.com>); (3) Vimeo (<curriki.org>); (4) Wikimedia Commons $<(>$ commons.wikimedia.org); and (5) Free Clip Art (<clker.com $>$ ).

We also highlight other sources of search for OERs such as: (1) MERLOT (Multimedia Educational Resources for Learning and Online Teaching) (<merlot.org $>$ ); (2) OWL Institute Open Educational Resources (<owli.org/oer>); (3) OE Portal Resource Centre (<owli.org>); 
(4) SOFIA (Sharing of Free Intellectual Assets) OpenCourseWare (<sofia.fhda.edu>); and (5) Universia OCW (<ocw.universia.net>).

\subsubsection{Content Editing Tools}

Content editing tools are directly responsible for supporting the construction of contents/media associated with the OER. They may be used to support since the construction of text-based learning materials until images and multimedia files.

Besides the legal issues inherent to the use of open licenses, OERs should be accessible and available in formats that do not hamper further reuse and repurpose. Thus, the adoption of FLOSS is a prerequisite for the construction and delivery of OERs, increasing their potential and capability for reuse and adaptation.

We gathered some useful FLOSS editing tools for OERs and classified them according to the kind of the learning material supported: (1) text-based contents, (2) images, (3) audios and videos and (4) statistical data.

\subsubsection{Text-based Contents}

There are several FLOSS tools and applications for creating and editing learning materials based on text contents (including slides presentations). In Table 23 we summarise examples of these tools. Generic and classical WYSIWYG (What You See Is What You Get), such as LibreOffice Writer/LibreOffice Impress from LibreOffice suite, can be used to create and edit text contents and multimedia presentations. Online/web-based WYSIWYG editors, such as Firepad, Etherpad and CKeditor, can be used to provide a collaborative way for producing such materials.

More sophisticated tools, such as LaTeX, are alternatives for WYSIWIG editors. LaTeX is a high quality typesetting system useful to produce professional technical and scientific documents and presentations. Additionally, eXeLearning is useful for authoring and publishing learning materials as web contents without having much experience in HMTL/XML markup. This application allows to export learning materials in IMS Content Package/IMS Common Cartridge formats, SCORM 1.2, or as self-contained web pages. Other examples of text-based contents tools include OpenOffice Writer/Impress and PDFedit.

\subsubsection{Images}

FLOSS tools for creating and editing images mainly differ from each other by the number of formats supported. In Table 24 we summarise examples of such tools. For instance, GNU Image Manipulation Program (GIMP) is a comprehensive editor widely used for high-quality drawing and retouching images. It also allows processing tasks such as cropping photos, combining multiple images, and converting between different images formats (ISHAN, 2012). GIMP also supports the creation of animations, and the conversion of PDF files to raster 
images $^{6}$. GIMP supports different formats including BMP, GIF, JPEG, PDF, PNG, PS, PSD, TGA, XPM, among others.

Table 23 - Text-based contents supporting tools.

\begin{tabular}{|c|c|c|c|c|}
\hline Tool & Description & Platform & License & Available at \\
\hline $\begin{array}{l}\text { LibreOffice/ } \\
\text { OpenOffice } \\
\text { Writer }\end{array}$ & $\begin{array}{l}\text { Full-featured word processing and } \\
\text { editor for creating text documents }\end{array}$ & Cross-platform & $\begin{array}{lr}\text { GNU } & \text { Lesser } \\
\text { General } & \text { Public } \\
\text { Licence } & (\text { LGPL) }\end{array}$ & $\begin{array}{l}\text { libreoffice.org } \\
\text { /openoffice.org }\end{array}$ \\
\hline $\begin{array}{l}\text { LibreOffice } \\
\text { /OpenOffice } \\
\text { Impress }\end{array}$ & $\begin{array}{l}\text { Editors for creating and editing } \\
\text { lecture notes and multimedia } \\
\text { presentations }\end{array}$ & Cross-platform & GNU LGPL & $\begin{array}{l}\text { libreoffice.org } \\
\text { /openoffice.org }\end{array}$ \\
\hline Firepad & $\begin{array}{l}\text { Web-based word processing and } \\
\text { editing applications }\end{array}$ & & MIT license & firepad.io \\
\hline Etherpad & $\begin{array}{l}\text { Web-based word processing and } \\
\text { editing applications }\end{array}$ & & Apache license & etherpad.org \\
\hline CKeditor & $\begin{array}{l}\text { Web-based editor for web } \\
\text { contents } / \mathrm{html} \text { pages }\end{array}$ & & $\begin{array}{l}\text { GNU GPL, GNU } \\
\text { LGPL and Mozilla } \\
\text { License (MPL) }\end{array}$ & ckeditor.org \\
\hline LaTeX & $\begin{array}{l}\text { Typesetting system for producing } \\
\text { technical and scientific documents } \\
\text { and presentations }\end{array}$ & Cross-platform & $\begin{array}{lr}\text { LaTeX } & \text { Project } \\
\text { Public } & \text { License } \\
\text { (LPPL) } & \end{array}$ & latex-project.org \\
\hline eXeLearning & $\begin{array}{l}\text { Application that supports the } \\
\text { authoring and publishing of } \\
\text { learning materials as web contents }\end{array}$ & $\begin{array}{l}\text { Linux, Mac } \\
\text { OS X, and } \\
\text { Windows }\end{array}$ & GNU GPL & elearning.net \\
\hline PDFedit & $\begin{array}{l}\text { Editor and library for manipulating } \\
\text { and editing PDF files }\end{array}$ & Cross-platform & GNU GPL & pdfedit.cz \\
\hline
\end{tabular}

Source: Elaborated by the author.

Inkscape is another powerful editor focused on high-quality Scalable Vector Graphics (SVG). It allows object creation, object manipulation, text support, rendering, among others. It also supports other formats such as PNG, OpenDocument Drawing, DXF, sk1, PDF, EPS, and PostScript export formats. Alternatively, LibreOffice Draw (LibreOffice suite) or OpenOffice Draw (OpenOffice suite) can be used for creating and editing graphics and diagrams in all common formats such as BMP, GIF, JPEG, PNG, TIFF, and WMF. Other FLOSS tools that support the images creation and editing include GIMPshop, Blender, Kripta and Pain.NET.

\subsubsection{Audios and Videos}

A variety of FLOSS tools can be used for creating and editing of different formats of audio and video files. In Table 25 we summarise some examples of such tools. Audacity is an option for digital audio editing allowing to: (1) manage multiple recording and playback devices; (2) monitor volume levels, before, during and after recording; (3) record from microphone, line input USB device, etc; (4) remove undesirable sound parts; (5) edit large number of tracks, 
among others. It supports different formats such as WAV, AIFF, FLAC, MP2, MP3 or Ogg Vorbis sound files, AC3, M4A/M4R (AAC), and WMA. Ardour is another option for digital audio editing. Ardour allows to record, editing (cut, move, stretch, copy, paste, delete, align, drag, drop, etc.), and mix with an arbitrary number of tracks. It supports standard file formats, such as BWF, WAV, WAV64, AIFF and CAF.

Table 24 - Image supporting tools.

\begin{tabular}{|c|c|c|c|c|}
\hline Tool & Description & Platform & License & Available at \\
\hline GIMP & $\begin{array}{l}\text { Comprehensive editor for drawing } \\
\text { and retouching a variety of images }\end{array}$ & Cross-platform & GNU GPL & gimp.org \\
\hline Inkscape & $\begin{array}{l}\text { Powerful editor for creating and } \\
\text { manipulating vector graphics }\end{array}$ & Cross-platform & GNU GPL & inkscape.org \\
\hline $\begin{array}{l}\text { LibreOffice/ } \\
\text { OpenOffice } \\
\text { Draw }\end{array}$ & $\begin{array}{l}\text { Applications for creating and editing } \\
\text { graphics and diagrams }\end{array}$ & Cross-platform & GNU LGPL & $\begin{array}{l}\text { libreoffice.org } \\
\text { /openoffice.org }\end{array}$ \\
\hline GIMPshop & $\begin{array}{l}\text { GIMP's modification for drawing } \\
\text { and retouching images }\end{array}$ & Cross-platform & GNU GPL & gimpshop.com \\
\hline Blender & $\begin{array}{l}\text { Computer graphics software for } \\
\text { creating and editing animations, } \\
\text { visual effects, 3D printed models, } \\
\text { interactive 3D applications and } \\
\text { games }\end{array}$ & Cross-platform & GNU GPL & blender.org \\
\hline Krita & $\begin{array}{l}\text { Powerful tool for creating and } \\
\text { editing, images, illustration, concept } \\
\text { art and comics }\end{array}$ & Cross-platform & GNU GPL & krita.org \\
\hline Paint.NET & $\begin{array}{l}\text { Simple and powerful software tool } \\
\text { for editing images and photos }\end{array}$ & Windows & $\begin{array}{l}\text { Attribution } \\
\text { Non-Commercial } \\
\text { license (BY-NC) }\end{array}$ & getpaint.net \\
\hline
\end{tabular}

Source: Elaborated by the author.

Regarding video editor, we highlight the KDE Non-Linear Video Editor (Kdenlive) that allows to: (1) edit an arbitrary number of video and audio tracks; (2) create, move, trim and delete tracks of video, audio, text and images; (3) add different effects on sound (such as normalisation, volume adjustment, reverb and EQ filters, and others) and audio (such as masking, distortion, rotation, and others); (4) customise transitions between video clips, and other features. Kdenlive supports a wide range of formats such as MKV, MOV, MP3, WAV, AVI, among others. An alternative for web-based editor is the Yotube Video Editor that allows to: (1) trim video clips; (2) combine multiple video clips to create new ones; (3) customise clips lengths and transitions; (4) and share videos files openly for reuse and repurpose. Other examples of audio and video tools include Jokosher, LMMS (previously Linux MultiMedia Studio), Avidemux and Cinelerra. 


\subsubsection{Statistical Data}

Statistical data tools are essential to provide automated support to collect, handle, and assist in the analysis of sampled data. Generic tools such as LibreOffice Cal or OpenOffice Cal can be used for general purpose. They offer spreadsheet applications for supporting data analysis and presentations. Both are included into the LibreOffice and OpenOffice suites.

More sophisticated and comprehensive tools specific for statistical data may be useful. An example is the R Software (R Project, 1993), a powerful software environment for statistical computing and graphics. It supports the implementation of a wide range of statistical and graphical techniques and methods such as classical statistical tests and linear and non-linear modelling. R Software is cross-platform and is licensed under the GNU GPL ${ }^{7}$.

Table 25 - Audio/video supporting tools.

\begin{tabular}{|c|c|c|c|c|}
\hline Tool & Description & Platform & License & Available at \\
\hline Audacity & $\begin{array}{l}\text { Multi-track editor for recording, } \\
\text { editing and sharing digital audio }\end{array}$ & Cross-platform & GNU GPL & audacityteam.org \\
\hline Ardour & $\begin{array}{l}\text { Powerful full-featured workstation } \\
\text { for digital audio editing }\end{array}$ & $\begin{array}{l}\text { Linux and Mac } \\
\text { OS }\end{array}$ & GNU GPL & ardour.org \\
\hline Jokosher & $\begin{array}{l}\text { Simple non-linear multi-track } \\
\text { digital audio editor (create and } \\
\text { record music, podcasts, among } \\
\text { others), }\end{array}$ & $\begin{array}{l}\text { Linux, Solaris } \\
\text { and Windows }\end{array}$ & GNU GPL & launchpad.net \\
\hline LMMS & $\begin{array}{l}\text { Digital audio workstation for } \\
\text { creating and editing musics/sounds }\end{array}$ & $\begin{array}{l}\text { Linux, } \\
\text { FreeBSD } \\
\text { and Windows }\end{array}$ & GNU GPL & lmms.io \\
\hline Kdelive & $\begin{array}{l}\text { Multi-track video editor for } \\
\text { creating, editing and mixing } \\
\text { different kinds of media, including } \\
\text { video, audio and images }\end{array}$ & $\begin{array}{l}\text { Linux, } \\
\text { FreeBSD } \\
\text { and Mac OS }\end{array}$ & GNU GPL & kdenlive.org \\
\hline VirtualDub & $\begin{array}{l}\text { Tool for capturing and processing } \\
\text { video files that focuses on AVI } \\
\text { formats }\end{array}$ & Windows & GNU GPL & virtualdub.org \\
\hline $\begin{array}{l}\text { Youtube } \\
\text { Video Editor }\end{array}$ & $\begin{array}{l}\text { Web-based editor for editing } \\
\text { existing video }\end{array}$ & Cross-platform & $\begin{array}{l}\text { Attribution } \\
\text { License (BY) }\end{array}$ & youtube.com \\
\hline Avidemux & $\begin{array}{l}\text { Simple video editor for cutting, } \\
\text { filtering and encoding tasks. }\end{array}$ & $\begin{array}{l}\text { Linux } \\
\text { FreeBSD, } \\
\text { Mac OS and } \\
\text { Windows }\end{array}$ & GNU GPL & fixounet.free.fr \\
\hline Cinelerra & $\begin{array}{l}\text { Non-linear professional video } \\
\text { for editing and compositing } \\
\text { environment }\end{array}$ & Linux & GNU GPL & cinelerra-cv.org \\
\hline
\end{tabular}

Source: Elaborated by the author.

Another alternative for statistical manipulation and analysis of sampled data is the GNU PSPP (GNU PSPP, 2013). GNU PSPP has inter-operability with other FLOSS software including 
LibreOffice and OpenOffice suites. GNU PSPP is cross-platform and is licensed under the GNU GPL.

\subsection{Concluding Remarks}

In this chapter we investigated the OERs development process from the perspective of agile development. In this context, we proposed and agile method named AM-OER (Agile Method for the development of Open Educational Resources).

The AM-OER differs from other general approaches for the development of learning materials, particularly regarding the adaptation of agile practices from Software Engineering to the context of OERs, in combination with Learning Design practices from OULDI. The aim was to make the OERs development process more flexible, and to improve the quality of OERs by embedding pedagogical design practices throughout the development.

Mechanisms and tools to support the whole development process of OERs were also characterised and summarised. We focused on FLOSS tools, since they are aligned with the development of open contents, and are crucial to increase the adoption, and the potential for reuse and adaptation of OERs. Indeed, such characterisation is important to the selection of appropriate mechanisms and tools for the development of OERs.

In the next chapter we present two preliminary empirical assessment studies to validate the AM-OER. The method was applied in the development of OERs through a case study and an experiment, focusing on OER courses in Computer Science area, within the Software Engineering domain. 

CHAPTER

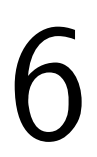

\section{APPLYING AM-OER IN THE SOFTWARE ENGINEERING DOMAIN}

\section{$\mathrm{T}$}

his chapter describes two empirical assessment studies involving the application of AM-OER. Both studies were conducted in the academic environment, focusing on the Source Software (FLOSS) and on software testing. The general goal was to investigate the feasibility/applicability and effectiveness of applying the AM-OER method in the design and creation of OERs.

In the first assessment study, we conducted an exploratory investigation based on observation, specifically a case study. In the second assessment study, we conducted an explanatory investigation based on experimentation. Data from these studies were collected and analysed using both qualitative and quantitative methods.

In Section 6.1 we describe a case study to assess the applicability and usefulness of the AM-OER method by applying it in the development of an introductory course on FLOSS. In Section 6.2 we describe an experiment involving the development of a testing course to assess the effectiveness of the AM-OER method. The assessment is based on three point of views: (1) effectiveness, (2) efficiency, and (3) quality of the results. Additionally, the applicability of the method is assessed in terms of: (1) appropriateness/usefulness, (2) ease of use, and (3) satisfaction. Concluding remarks are given in Section 6.3.

\subsection{An OER on FLOSS: A Case Study}

In this assessment study we chose a case study research method. A case study has several meanings and may be used to describe a unit of analysis, or as a case study of a particular organisation, or also to describe a research method (MYERS, 2002). It is "well suited for many kinds of software engineering research, as the objects of study are contemporary phenomena, which are hard to study in isolation" (RUNESON; HÖST, 2009). 
Yin (2013) argues that a case study research is typically used when:

- The purpose of the study is to answer "how" and "why" research questions;

- It is not possible or is hard to manipulate the behaviour of individuals involved in the study;

- It is desirable to cover contextual conditions that can be relevant to the phenomenon under study; or,

- The boundaries between phenomenon and context of the study are unclear.

The case study described in this section has an exploratory characteristic since we intend to investigate the applicability and usefulness of the AM-OER method to effectively support the development of OERs. An exploratory case study is indicated as preliminary investigation of a phenomenon, helping to derive new hypotheses (EASTERBROOK et al., 2007). The case study is characterised as a holistic case study where the case under study is investigated as a whole (YIN, 2013). The "case" is the same as the unit of analysis, i.e., the AM-OER method.

\subsubsection{Planning}

The objective of this study was to provide an initial assessment of the applicability of the AM-OER method in the OERs context, by applying it in the development of a course in the Software Engineering domain. The global research question that motivated and guided this P.h.D. thesis is: How can agile methods in combination with Learning Design practices support the development process of Open Educational Resources?

This research question is vague, making assumptions about the phenomenon we intend to investigate. In order to understand the nature of the phenomenon we are interested in, we asked and investigated a set of exploration questions (EASTERBROOK et al., 2007) in the early stage and throughout this P.h.D. research such as: (1) How OERs have been developed? (2) Is there an agile approach to develop OERs? (3) How agile are current approaches to develop OERs? (4) Do we need any different approach, from what is current practice, for the development of OERs? (5) How do agile approaches differ from AD-HOC or plan-driven approaches?

In the scope of this study we intended to investigate whether the AM-OER method is feasible/applicable for the development of OERs. We start from the proposition that the development of OERs can benefit from the usage of a process based on agile methods and that incorporates Learning Design practices.

The study was applied in an academic environment in the Institute of Mathematics and Computer Sciences (ICMC) at University of São Paulo (USP). This study addressed a real problem within a context of Software Engineering. It consisted of the development of an introductory course on FLOSS. 
The study was carried out by two participants and the researcher responsible for the study. The participants included a graduate student (P.h.D.) and an educator (P.h.D. student who also acts as educator) from the University of São Paulo (USP). They have basic background on the development of learning materials and on the subject and topics related to development of this course.

The data were collected through documentation, annotation and artefacts generated during the study, followed by a brief interview with participants.

\subsubsection{General Overview of the OER on FLOSS}

The introductory course on FLOSS was designed and created based on the book chapter: Software Livre e Propriedade Intelectual: Aspectos Jurídicos, Licenças e Modelos de Negócio (KON et al., 2011). Following we present the main phases and activities for designing and creating the FLOSS course.

\section{Kickoff - Defining Objectives and Overall Structure for the Course}

At the beginning of the project, the first activity was to identify and establish the general goals and specific objectives (intended learning objectives/outcomes) of the course, followed by the the definition of the overall structure of the desired course. In the context of AM-OER method, these activities are the user's responsibility (educators and learners). In the case study, the researcher with the educator played this role within the development process.

The general goal of the OER on FLOSS course is to introduce the FLOSS movement and clarify how specific characteristics of FLOSS may affect their use by individuals, companies, and governments (KON et al., 2011). At the end of the course, it is expected that the following intended learning objectives/outcomes will be achieved:

- Students will understand the motivation behind the emergence of FLOSS movement.

- Students will have essential background on the concepts and definitions of FLOSS.

- Students will have the ability to select an appropriate license that fits their purpose, and to understand the implications and consequences of using it in a product.

- Students will be aware of the benefits related to FLOSS.

- Students will have background on the characteristics and development culture of FLOSS.

- Students will be able to select appropriate methodologies, frameworks and tools for FLOSS development.

The overall structure for the FLOSS course is summarised in Figure 32, represented by the Initial Architecture View conceptual map. It maps the main components/elements 
of the course including the learning contents covered by the course, assessment criteria to assess learners throughout the course, and the dialogic and collaboration activities during the learning intervention. We highlight that the Initial Architecture View is a specific outcome of the application of the AM-OER method.

Figure 32 - OER on FLOSS: Overall structure.

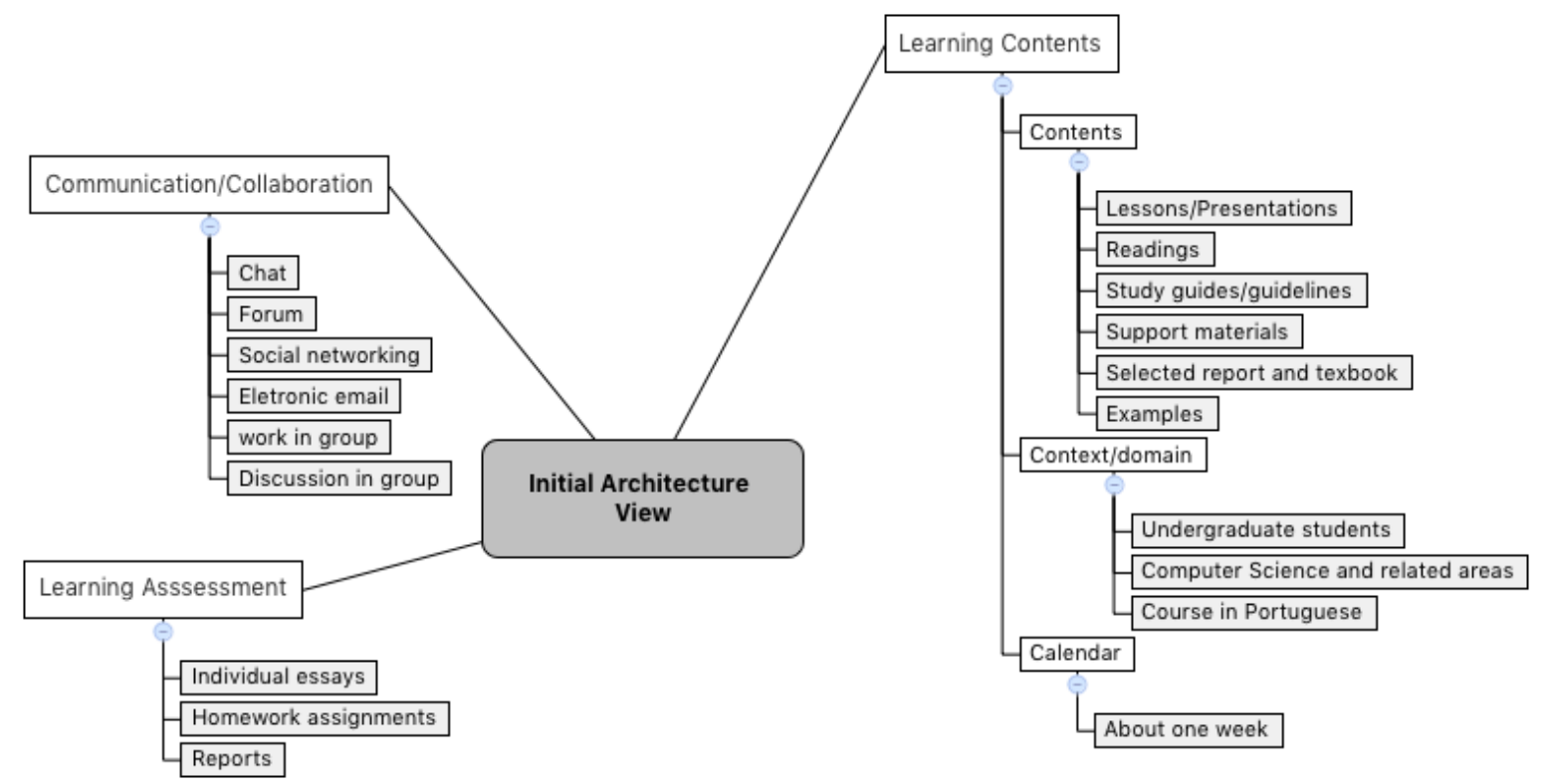

Source: Research data.

The FLOSS course was in Portuguese and the target audience was undergraduate students in Computer Science or other related areas, including Information Systems and Computer Engineering. The course lasts approximately one week. The students participate in activities to reinforce the theoretical concepts on FLOSS. No prerequisite is required.

The main contents of the FLOSS course include: presentations/lessons, readings, study guides/guidelines, supporting materials, selected report and textbook, and examples of methodologies, frameworks and supporting tools.

Students are evaluated throughout the course by individual essays, homework assignments and reports. They essentially communicate and collaborate with colleagues and educator/tutor through chat, forum, social networking, electronic email, work and discussion in group.

\section{Development - designing, creating and evaluating the learning structure and related contents and activities}

The FLOSS course was divided into three modules: (1) Module I: FLOSS Movement; (2) Module II: FLOSS licenses; and (3) Module III: Development and Business Model. We decided to develop the Module I first, and so on. Such justification is due to the fact that the Module I 
covers fundamental issues to understanding the FLOSS history and why we should adopt it. This knowledge is essential before moving on to other modules of the course.

Both the educator and the student who participated in the study played the role of: (1) designer, who was directly responsible for the creation and refinement of the overall structure for the course; and (2) media creator, who was responsible for the creation of contents/media, and activities related to the course.

In Figure 33 we synthesise the general overview of the learning structure for the course, represented by the Learning Structure View artefact, which is a specific outcome of the application of the AM-OER method. This artefact describes and maps, within the learning context, how learning activities are linked with the intended learning outcomes, learning contents, tools, and assessment activities. For instance, a student enrolled in the FLOSS course can take as activity sumarizar características de desenvolvimento de software livre (summarise the FLOSS characteristics). At the end of the course, a learning outcome could be that the learner has acquired critical understanding on the subject (background sobre desenvolvimento de software livre) (background on FLOSS development) according to the assessment activity conducted (relatório sobre desenvolvimento de software livre) (report on FLOSS development).

Figure 33 - OER on FLOSS: Learning structure overview (in portuguese).

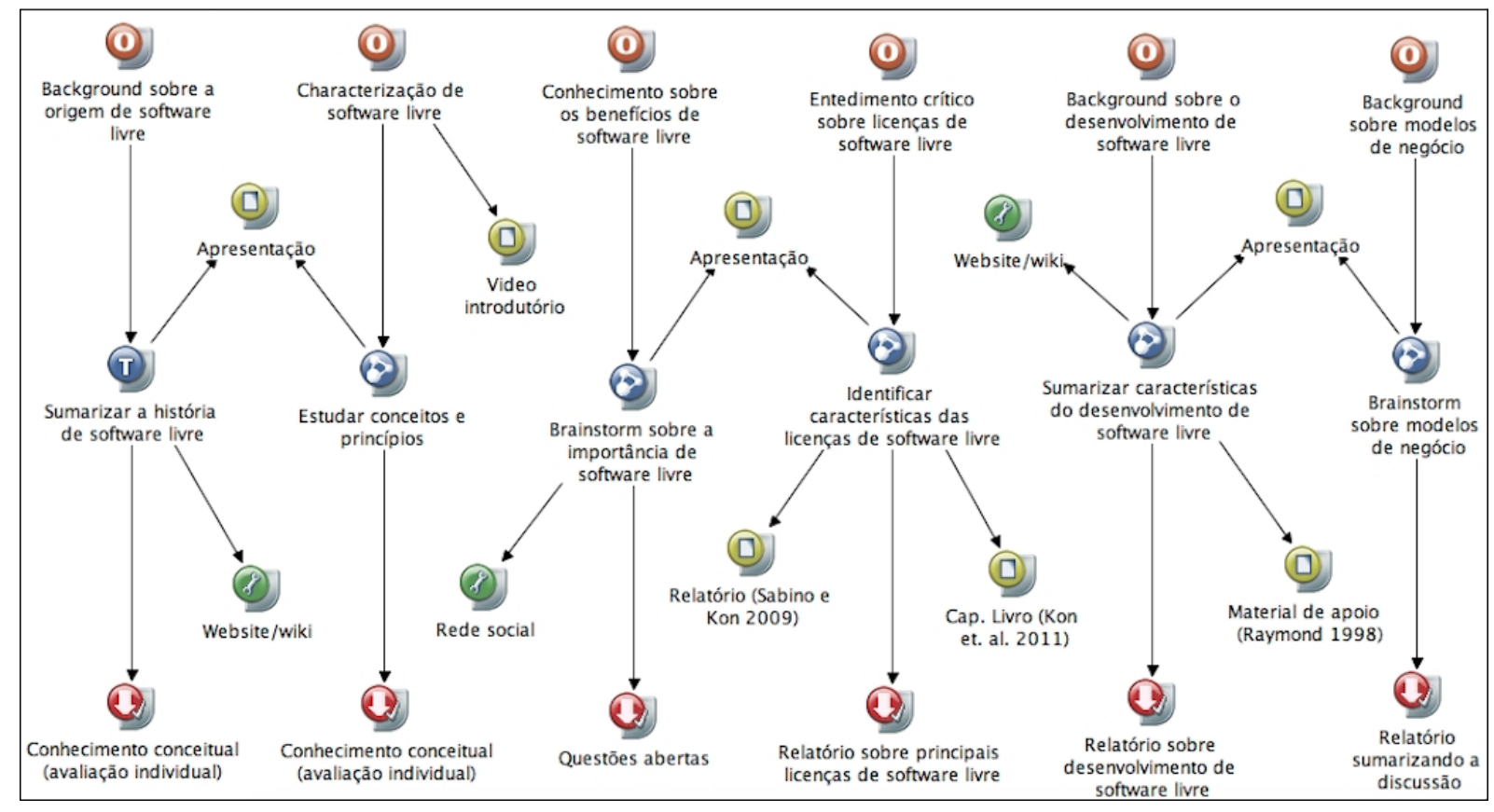

Source: Research data.

During the course development, the learning structure was refined to visualise the flow of course activities and to determine the tasks that students need to perform to achieve the learning outcomes. In Figure 34 we demonstrate an sketch of the Learning Tasks View artefact, representing a simple learning activity (sumarizar as características de desenvolvimento de software livre) from the overall Learning Structure View, broken down into simple and atomic tasks together with related contents, tools and assessment activity. For instance, a student 
enrolled in the activity sumarizar as características de desenvolvimento de software livre (summarise the FLOSS characteristics) needs to perform a set of tasks (e.g., investigar $o$ desenvolvimento de software livre (investigate the FLOSS development), identificar cultura de desenvolvimento (identify the development culture), sumarizar metodologias e ferramentas (summarise methodologies and tools) to identify and summarise the main characteristics related to the FLOSS development. The Learning Tasks View is a specific outcome of the application of the AM-OER method.

Figure 34 - OER on FLOSS: Learning structure refinement (in portuguese).

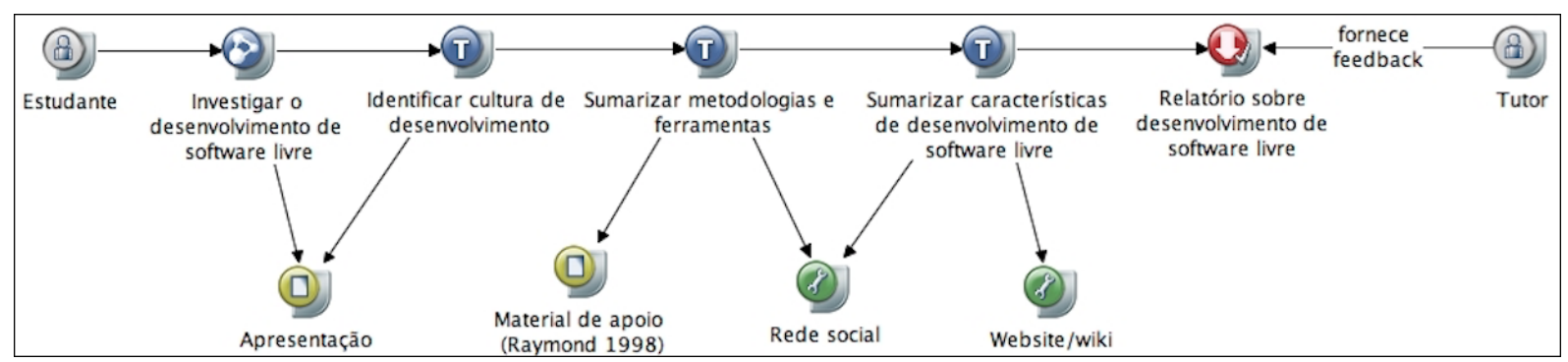

Source: Research data.

Associated learning contents were created/adapted and integrated into the FLOSS course activities. They essentially include html pages, lecture notes, readings, text documents, open textbooks, images and videos.

Module I addresses general aspects about the problems and issues related to closed or proprietary software, and how FLOSS may become an alternative. It briefly discusses the emergence of the FLOSS movement, perspectives, motivations, implications and consequences of adopting FLOSS. The module covers the following topics/units: (1) commitment solutions - copyrights and patents; (2) history of the FLOSS movement; (3) understanding on what is FLOSS; and (4) problems and risks related to FLOSS. In Figure 35 we exemplify a topic of this module, briefly explaining essential concepts and definitions associated to FLOSS.

Module II addresses general aspects of licensing options for FLOSS. It emphasises the characteristics and types of FLOSS licenses. It also describes the main licenses for FLOSS. The module covers the following topics: (1) context and origin of the licenses for FLOSS; (2) classification of the licenses according to their characteristics; (3) description about the main FLOSS licensing as BSD, MIT, Apache, GNU GPL (and similar) and Mozilla; and (4) main implications and consequences related to the use of such licenses in a product. In Figure 36 we exemplify a html page covering the topic about the classification of licenses, which describes the permissive or academic licenses.

Module III addresses general aspects and peculiarities associated to the development and to the business models for FLOSS. The module covers the following topics: (1) an essay of software engineering methods - Cathedral and the Bazaar, (2) FLOSS community, highlighting the opportunities and difficulties in the interaction with the FLOSS community; (3) framework and supporting tools for FLOSS; (4) main business model for the development of FLOSS; and 
(5) some examples of successful approaches for FLOSS. In Figure 37 we exemplify a html page providing an overview of business model for FLOSS development.

Figure 35 - OER on FLOSS: what is FLOSS? (in portuguese)

\begin{tabular}{|c|c|}
\hline Menu & Seguinte $»$ \\
\hline Visão Geral sobre Software Livre & O que é Software Livre? \\
\hline HоME & \multirow{10}{*}{$\begin{array}{l}\text { As duas principais organizações internacionais responsáveis pela proteção e promoção do software livre, a Free Software } \\
\text { Foundation (FSF) e a Open Source Initiative (OSI), atuam também para garantir que os conceitos de Free Software e Open } \\
\text { Source sejam utilizados de forma correta. O objetivo é evitar que empresas ou grupos usem esses conceitos de forma } \\
\text { indevida como ferramenta de marketing, atestando que um software é livre quando na realidade não é. } \\
\text { Em contraste com o software restrito, o software livre estabelece um novo mecanismo de licenciamento, no qual o software } \\
\text { pode ser utilizado, copiado, estudado, redistribuído e modificado com pouca ou nenhuma restrição. } \\
\text { Segundo a FSF, um software pode ser considerado livre quando ele satisfaz } 4 \text { liberdades fundamentais: } \\
\text { घ } 0 \text {. a liberdade de executar o programa para qualquer propósito. } \\
\text { a } 1 \text { a liberdade de estudar o funcionamento do programa, podendo adaptá-lo às necessidades particulares. } \\
\text { a 2. a liberdade de redistribuir cópias, a fim de ajudar o próximo. } \\
\text { a 3. a liberdade de aperfeiçoar o programa e publicar as melhorias, para que toda comunidade seja beneficiada. } \\
\text { Nota: Para que essas liberdades sejam satisfeitas, o acesso ao código-fonte do programa é pré-requisito. Dessa forma, o } \\
\text { programa "deve" ser distribuido juntamente com o seu código-fonte, sem restrições que impossibilitem o usuário alterar e } \\
\text { redistribuir esse código. }\end{array}$} \\
\hline Movimento de Software Livre & \\
\hline Direitos Autorais & \\
\hline Histórico & \\
\hline O que é Software Livre? & \\
\hline Por que Software Livre & \\
\hline Problemas com Software Livre & \\
\hline Licenças de Software Livre & \\
\hline $\begin{array}{l}\text { Desenvolvimento e Modelos de } \\
\text { Negócio }\end{array}$ & \\
\hline & \\
\hline & Sob licença Licença Creative Commons Atribuição Não Comercial Compartilha Igual 4.0 \\
\hline & Seguinte ” \\
\hline
\end{tabular}

Source: Research data.

Figure 36 - OER on FLOSS: Licensing options (in portuguese).

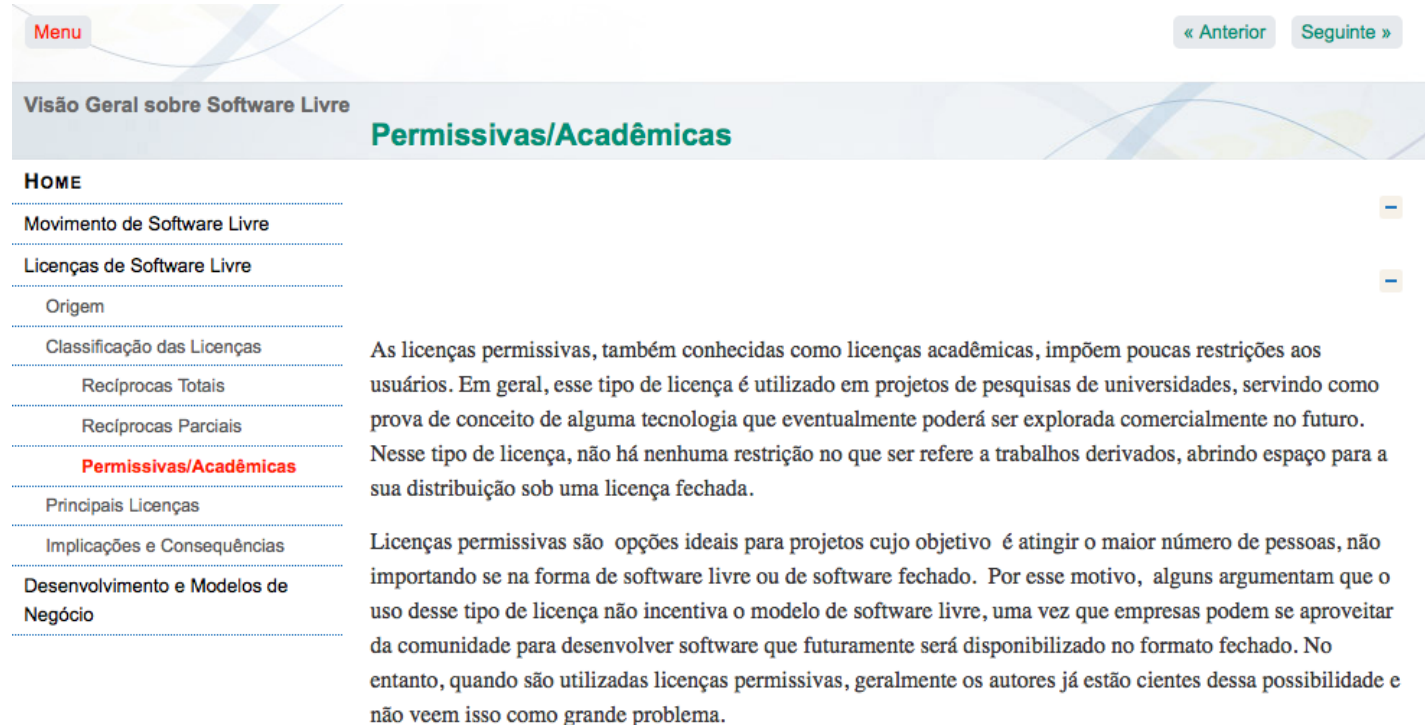

Neste curso, serão discutidas as licenças permissivas BSD, MIT e Apache.

Source: Research data. 
Throughout the course development, the educator played the role of reviewer, being responsible for a preliminary evaluation of the FLOSS course. He/she takes into consideration the criteria/aspects adopted by the AM-OER method such as: (1) accuracy and relevance of the contents; (2) adequacy and alignment of learning objectives to the contents/media, tools, and assessment activities; (3) usability and readability of contents and activities, among others. All suggestions for corrections, modifications and improvements were gathered and considered to improve the course.

Figure 37 - OER on FLOSS: Business model.

\begin{tabular}{|c|c|}
\hline Menu & «Anterior \\
\hline Visão Geral sobre Software Livre & Modelos de Negócio \\
\hline HOME & \multirow{6}{*}{$\begin{array}{l}\text { Diversas empresas têm obtido sucesso comercial explorando o software livre de várias maneiras diferentes. As vezes, } \\
\text { essa exploração envolve não somente software livre, mas também sistemas híbridos, em que o software restrito é } \\
\text { agregado ao software livre. } \\
\text { - Algumas abordagens são especificas para um tipo de produto ou situação especificos, como ocorre com a } \\
\text { propaganda no navegador Firefox; } \\
\text { - Outras são restritas a um nicho de mercado muito limitado, como ocorre com fornecedores de software em mídias } \\
\text { físicas (CD/DVD); } \\
\text { - Outras são adequadas para empresas de grande porte, enquanto ainda outras se prestam melhor a empresas } \\
\text { pequenas e médias. }\end{array}$} \\
\hline $\begin{array}{l}\text { Movimento de Software Livre } \\
\text { Licenças de Software Livre }\end{array}$ & \\
\hline $\begin{array}{l}\text { Desenvolvimento e Modelos de } \\
\text { Negócio }\end{array}$ & \\
\hline $\begin{array}{l}\text { Desenvolvimento de Software Livre } \\
\text { Ferramentas }\end{array}$ & \\
\hline Modelos de Negócio & \\
\hline \multirow[t]{6}{*}{ Casos de Sucesso } & \\
\hline & $\begin{array}{l}\text { No entanto, provavelmente o aspecto mais importante que diferencia os vários modelos de negócio que envolvem } \\
\text { software livre consiste na participaçăo no desenvolvimento. }\end{array}$ \\
\hline & $\begin{array}{l}\text { - Alguns modelos estão diretamente vinculadas à atividade de desenvolvimento, financiando o envolvimento de } \\
\text { programadores profissionais na evolução do software com a consequente melhoria em sua qualidade e } \\
\text { funcionalidades; }\end{array}$ \\
\hline & $\begin{array}{l}\text { - Outros não envolvem o financiamento de desenvolvimento em sim, mas promovem a adoção do software no } \\
\text { mercado, como treinamento e consultoria. Porém, todos eles fazem parte do ambiente econômico e tecnológico } \\
\text { que viabiliza o software livre no mercado. }\end{array}$ \\
\hline & $\begin{array}{l}\text { A seguir, discutiremos alguns modelos de negócio existentes, incluindo: redistribuição (CDs e DVDs com software livre), } \\
\text { extensőes não livres, produtos e serviços privilegiados, licenciamento dual, serviços baseados em software livre, serviços } \\
\text { diretos e padronizados e propagandas e franquias. }\end{array}$ \\
\hline & Sob licença Licença Creative Commons Atribuiçăo Não Comercial Compartilha Igual 4.0 \\
\hline
\end{tabular}

Source: Research data.

To create, edit and update the contents associated to the FLOSS course, the following resource and open source tools were adopted: (1) Bloom's taxonomy, for supporting the learning objectives statement; (2) Xmind, for creating and mapping the overall structure for the course (Initial Structure View); (3) LibreOffice, for creating the set of slides and text documents; (4) LaTeX, for creating text documents; (5) CompendiumLD, for creating and refining the learning structure for the course (Learning Structure View and Learning Tasks View); (6) Youtube Movie Maker, for editing video; and (7) eXelearning, for structuring html pages and delivering the course.

Asynchronous (electronic mail) and synchronous communications tools, such as instant messaging system and videoconference, were used to support the communication among participants throughout the course development. 
The educator was responsible for licensing the course contents. The FLOSS course is under the Creative Commons License (Creative Commons, 2013a) - Attribution Non-Commercial Share Alike 4.0 International ${ }^{1}$. It follows the same lines of the license used in the reused material that served as the basis for the development of this course.

\subsubsection{Summary of the Results}

The main goal of this case study was to assess whether the AM-OER method is feasible and applicable to the development of OERs.

In general, we found that the AM-OER method was useful to plan, design and build the course. According to the participants, the "method helped to shape the course as a whole and to determine the contents and activities that should be part of the course". They pointed out that the activities of the method allow a focus on the learning process; besides thinking in the learning content itself, the educator also thinks about the activities that the students must perform to achieve the intended learning outcomes at the end of the course, helping the systematic structuring of learning.

Participants reported shortcomings and weaknesses of the AM-OER method. According to them, some activities of the method were described superficially or were disconnected from each other. The main problems and difficulties faced by the participants were related to:

- Identify and describe relevant metadata associated to the course contents;

- Search for related learning contents that could be reused to compose the OER;

- Properly evaluate and select the learning contents found; and,

- Understand and establish the proper licensing policies for the course contents.

The results provided significant feedback for the development and enhancement of the AM-OER method for OERs development and delivery. All suggestions and changes identified in the case study were considered and incorporated into a new version of the method that was described in the previous chapter. For instance, participants had difficulty to seek for related contents to be reused to compose the course. We provided some guidelines on issues to be considered when searching for related contents and gathered useful search supporting mechanism.

The main limitations associated to this case study are the following:

- The number of participants in the study was small. Case studies involving a larger number of participants should be considered further;

- The study was applied in an academic environment and in a specific domain of knowledge;

$\overline{1 \text { creativecommons.org/licenses/by-nc-sa/4.0 }}$ 
- The study involved a single case study, then it can not be replicated by another researcher; and,

- The results of the case study do not allow generalisation.

The limitations aforementioned will be considered in the development of new assessment studies, which are being planned to be carried out further.

Although preliminary, the results show that the proposed agile method with embedded learning design practices is feasible and provides support to the design and creation of OERs.

Next, we describe a second assessment study to complement the validation of the AM-OER method.

\subsection{An OER on Software Testing: An Experiment}

In this study we chose a research method based on experimentation, in particular to collect, manipulate and analyse the empirical data. We adopted an experiment to allow a more rigid control on the environment, and a more rigorous manipulation of the phenomenon in study. It can generate more concise results based on quantitative analysis, providing evidence of the validity of AM-OER method to develop OERs. It can also allow the generalisation of the results within a population, and the replication of the experiment.

An experiment is used to identify casual relations and processes. The identification of casual relations provides an explanation of "why" a phenomenon occurred; whilst the identification of casual processes identify "how" the phenomenon occurred (YIN, 2013). In other words, an experiment represents an action to discover something unknown or testing a hypothesis involving the collection and analysis of data to provide "meaning" to the obtained data (BASILI; FOREST, 1999). In Software Engineering, the aim of an experiment is to characterise, evaluate, predict, control and improve methods, processes, models or products (TRAVASSOS; GUROV; AMARAL, 2002).

\subsubsection{Objectives}

The overall goal of this experimental study is to evaluate the effectiveness, efficiency and appropriateness of AM-OER in the development of OERs. For this, we compare the development of an OER using AM-OER in contrast to the development of the same OER using an AD-HOC method. In the context of AD-HOC method, the development is informal with no defined process, and without any guidelines or instructions to guide the development of OERs.

The objective of this experimental study is summarised in Table 26. We adopted the Goal/Question/Metric (GQM) template proposed by Basili (1996) to help designing the goal of the study:

- Entity of study: the object of study is the AM-OER method. 
- Purpose: the purpose is to evaluate AM-OER in the development of OERs, in particular comparing it with an AD-HOC method.

- Focus: the focus is the effectiveness, efficiency, quality of the results, appropriateness and satisfaction related to the AM-OER to create OERs.

- Perspective: the perspective is from the points of view of educators and non-experts/non-specialists in the development of OERs.

- Context: the experiment was run within an academic environment with graduate students, educators and researchers of software engineering, using the AM-OER and an AD-HOC method in the development of a short course in this domain. The experiment is characterised as multi-test within object of study, i.e., a single entity is examined across a set of subjects.

Table 26 - Experimental study: Summary of objectives.

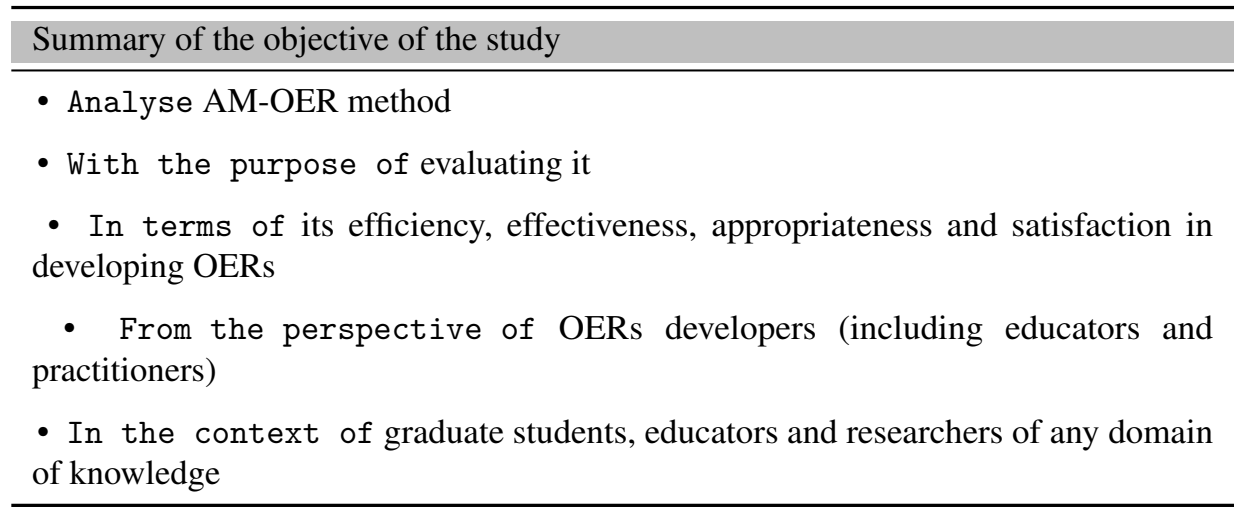

Source: Elaborated by the author.

In this study we broke down our global research question (How can agile methods in combination with Learning Design practices support the development process of Open Educational Resources?) into more specific research questions for the purpose of driving the experiment. Specific research questions are:

- RQ1. How effective is the AM-OER in the development of OERs compared to an AD-HOC method?

- RQ2. How efficient is the AM-OER in the development of OERs compared to an AD-HOC method?

- RQ3. How much better are the results obtained by AM-OER compared to an AD-HOC method? 
Effectiveness is an indirect measure which refers to the level in which a method achieves the objective of developing the OER that meets the specified needs, by contrasting "what was delivered" with "what was planned to be developed".

Efficiency is an indirect measure which refers to the time required for developing the by the usage of a method, taking into account the measures of "what was delivered" (OER delivered) and the time spent to develop them. The time is a direct measure that can be derived from the duration in hours, days or weeks. It can be considered the number of sprints/iterations as a measure of time. In this study we adopted the duration in hours as measure of time.

Quality results is a indirect measure which refers to the level in which a method achieves the percentage of compliance to quality attributes and desirable characteristics of an OER.

\subsubsection{Hypotheses and Variables}

Hypotheses are prerequisites to perform and guide the experiment, consisting of testable propositions made about a phenomenon to be tested. They are formulated in null and alternative hypotheses. Null hypotheses are the hypotheses we intend to reject whilst alternative hypotheses are hypotheses we expect to assume as true.

The null hypotheses $\left(H_{0}\right)$ established for the experiment are:

1. The efficiency of AM-OER is similar to the efficiency of AD-HOC method $\rightarrow H_{0}$ : $\pi \mathrm{AM}-\mathrm{OER} \mathrm{Effi}=\pi \mathrm{AD}-\mathrm{HOC}_{E f f i}$.

2. The effectiveness of AM-OER is similar to the effectiveness of AD-HOC method $\rightarrow H_{0}$ : $\pi{\mathrm{AM}-O \mathrm{ER}_{\text {Effe }}=\pi \mathrm{AD}-\mathrm{HOC}}_{E f f e}$.

3. The quality of the results of AM-OER is similar to the quality of the results of AD-HOC method $\rightarrow H_{0}: \pi \mathrm{AM}-\mathrm{OER}_{\text {Qual }}=\pi \mathrm{AD}-\mathrm{HOC}_{\text {Qual }}$.

In relation to the alternative hypotheses $\left(H_{1}\right)$ we established the following:

1. The efficiency of AM-OER is higher than the efficiency of AD-HOC method $\rightarrow H_{1}$ : $\pi{\mathrm{AM}-O \mathrm{ER}_{E f f i}}^{\neq} \pi \mathrm{AD}-\mathrm{HOC}_{E f f i}$ or $H_{1}: \pi \mathrm{AM}-\mathrm{OER} \mathrm{E} f f i>\pi \mathrm{AD}-\mathrm{HOC}_{E f f i}$.

2. The effectiveness of AM-OER is higher than the effectiveness of AD-HOC method $\rightarrow H_{1}$ : $\pi{\mathrm{AM}-O \mathrm{ER}_{E f f e}}^{\prime} \neq \pi \mathrm{AD}-\mathrm{HOC}_{E f f e}$ or $H_{1}: \pi \mathrm{AM}-\mathrm{OER} \mathrm{E} f f e_{2}>\pi \mathrm{AD}-\mathrm{HOC}_{E f f e}$.

3. The quality of the results of AM-OER is higher than the quality of the results of AD-HOC method $\rightarrow H_{1}: \pi \mathrm{AM}-\mathrm{OER} R_{Q u a l} \neq \pi \mathrm{AD}-\mathrm{HOC}_{\text {Qual }}$ or $H_{1}: \pi \mathrm{AM}-\mathrm{OER} \mathrm{R}_{\text {Qual }}>\pi \mathrm{AD}-\mathrm{HOC}_{\text {Qual }}$.

In Figure 38 we illustrate the configuration of the experimental study. To assess which of the defined hypotheses are true we consider the independent and dependent variables. The independent variables or factors are the input data under control, and can be modified within the 
experiment. Independent variables include the methods used in the experiment, and can take two treatments or values, i.e., the AM-OER and the AD-HOC method.

Figure 38 - Experimental study configuration.

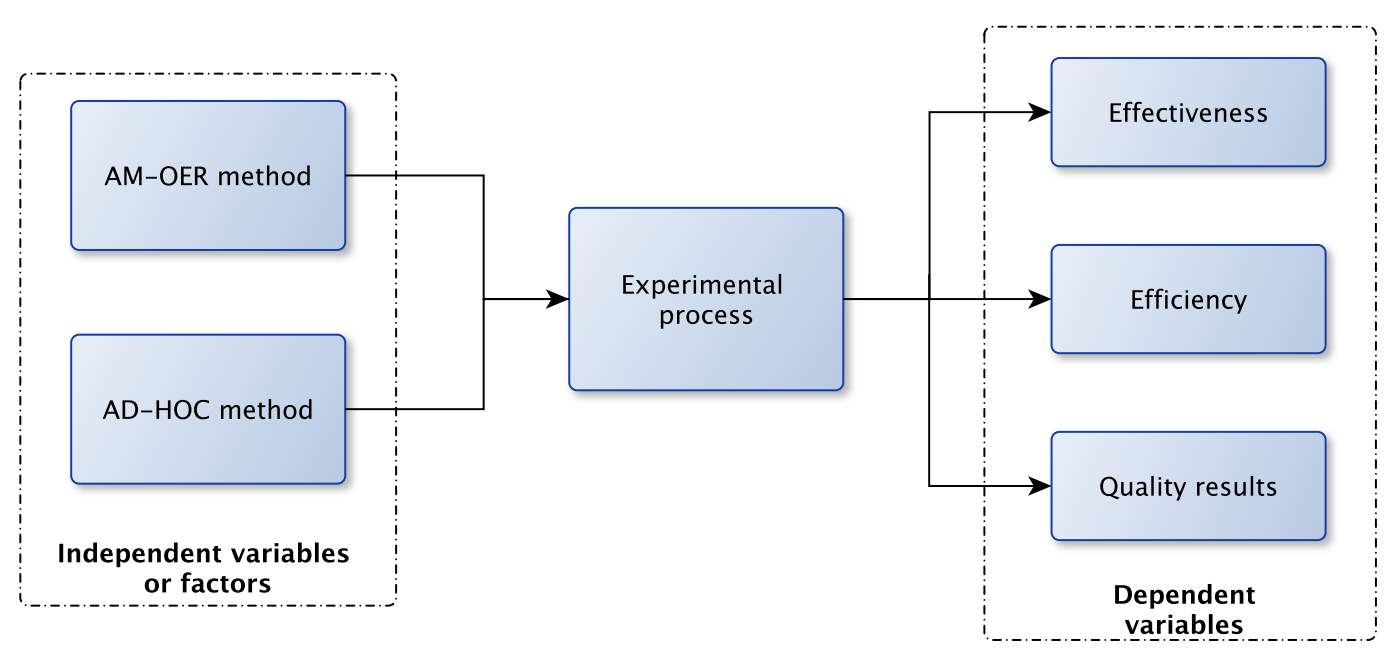

Source: Elaborated by the author.

Dependent variables are related to the expected results of the experiment, i.e., the results to be analysed and interpreted after the execution of the experiment. They are directly influenced by the independent variables. We defined three dependent variables:

1. Effectiveness: the relationship between the OER module developed and delivered compared to the OER module planned to be developed. It refers to the level in which the method achieves the objective of developing the specified OER.

2. Efficiency: the relationship between the OER module developed and delivered and the necessary time (in hours) spent to develop it. It refers to the time taken by using the method to develop and deliver the specified OER.

3. Quality results: the relationship between the the results obtained (OER developed) by the method compared to quality attributes and desirable characteristics of an OER.

\subsubsection{Subjects}

We used a non-probability sampling by convenience to select eight participants for the experiment. The participants were graduate students (MSc and $\mathrm{PhD}$ ), educators and researchers from the Software Engineering and the Computer applied to Education groups of the Institute of Mathematics and Computer Sciences (ICMC) at University of São Paulo (USP).

The participants filled out a short questionnaire identifying their level of knowledge/experience in the topics related to the experiment (i.e, learning materials development, 
pedagogical design/learning design, agile development and software testing). They provided the answers according to the scale below:

- 1 - None: never heard about the topic;

- 2 - Low: "know" the theory related to the topic - factual knowledge;

- 3 - Moderate: "know how to" apply the theory;

- 4 - High: able to "demonstrate" the theory in practice, considering pedagogically controlled situations; and,

- 5 - Very High: “do” in practice, considering a real application context - professional level.

In Figure 39 we summarise the level of experience of the participants regarding to the design and creation of learning materials. None of the participants has high experience in design/plan (Figure 34a) and creating learning materials (Figure 34b); only two of them have moderate experience whilst the others have little or no experience in these topics.

Figure 39 - Participants: Experience on pedagogical design and creation of OERs

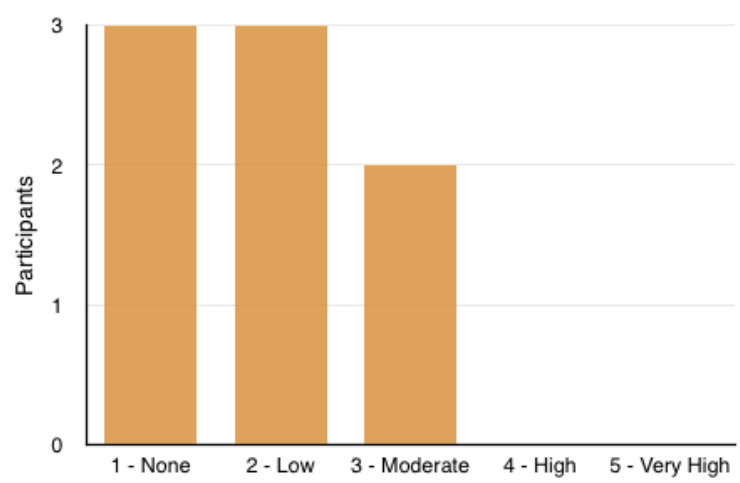

(a) Learning design of learning materials

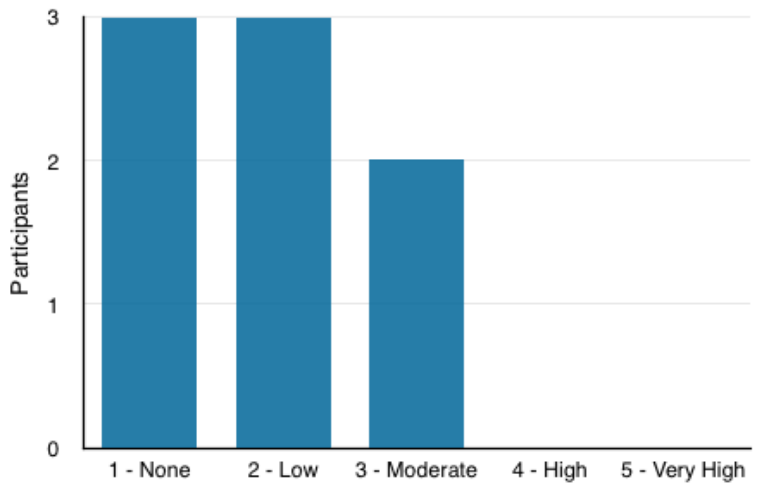

(b) Creation of learning materials

Source: Research data.

In Figure 40 we summarise the level of experience of participants in the topics related to agile development and software testing. Most of the participants have some experience in agile development (Figure 35a). In relation to the topic of software testing (Figure 35b), all of them have some experience. These factors were taken into consideration to obtain the homogeneity of the groups. Particularly, the factor "experience in agile development" was also used to compose the groups in order to not affect the results. In this case, participants who had more experience in agile development did not use the AM-OER method. 
Figure 40 - Participants: Experience on agile development and software testing.

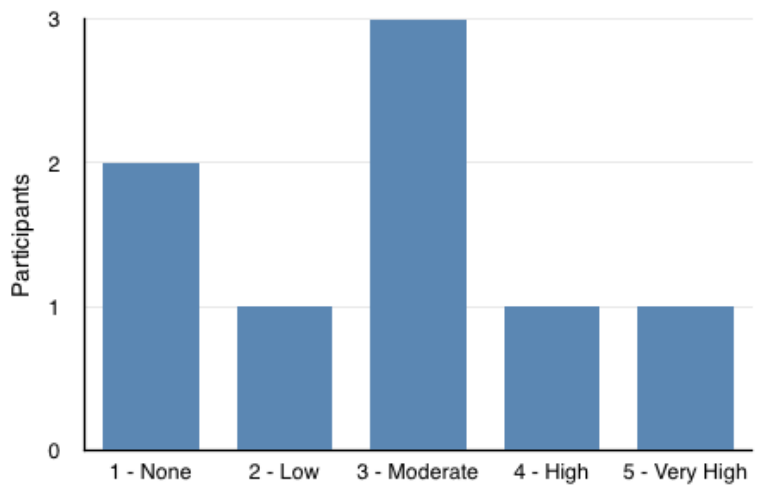

(a) Agile development

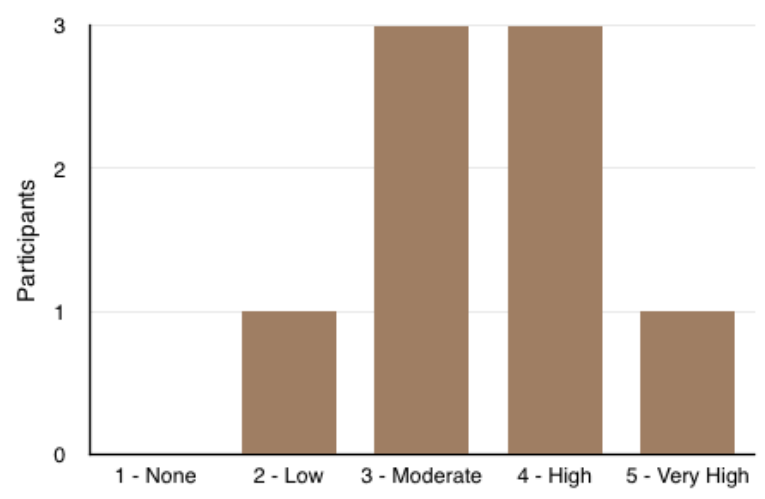

(b) Software testing

Source: Research data.

\subsubsection{Experiment Design}

In this experiment we use a combination of "blocking" and "balancing" principles of design (WOHLIN et al., 2000). Blocking is used to minimise undesired effects of the experiment whilst balancing is used to facilitate and strengthen the data analysis.

To minimise the effect of "experience" of the participants, we grounded them into two blocks, trying to create homogeneous groups according to the level of knowledge of each participant, especially in the context of OERs development and software testing. The two groups were balanced in terms of the number of participants, i.e., they have the same number of participants.

The experiment was characterised as one factor and two treatments. It compares two treatments (AM-OER and AD-HOC methods) against each other in the development of an OER. Both groups develop the same OER related to the software testing course, but each one uses a different treatment.

\subsubsection{Statistical Methods}

Initially, the sampled data was tabulated and graphically displayed, facilitating their visualisation and understanding. Descriptive statistics, including quartiles measures, were obtained to give an overview of how the set of data was distributed. The sampled data was displayed graphically by box-plot in order to show the discrepancy between the data.

The next step was to test the set of hypotheses established for the experiment. By testing the hypotheses two types of errors can occur:

1. First, when the alternative hypothesis $H_{0}$ is rejected, but it is true. This type of error is characterised as Error I. The probability of this type of error can be evaluated as: $\alpha=\mathrm{P}$ (Error $\mathrm{I})=\mathrm{P}\left(H_{0}\right.$ is rejected $\mid H_{0}$ is true $)$ 
2. Second, when $H_{0}$ is accepted, but it is false. This type of error is characterised as Error II. The probability of this type error can be evaluated as: $\beta=\mathrm{P}$ (Error II) $=\mathrm{P}\left(H_{0}\right.$ is not reject $\mid H_{0}$ is false)

From the aforementioned, we need to establish the levels of significance of the errors. In this experiment we adopted the usual practice of admitting a low value or level of significance for both errors: $\alpha=0,5$, and $\beta=0,5$.

To verify if the sampled data followed a normal distribution we used the Shapiro-Wilk Normality Test (SHAPIRO; WILK, 1965), which is a method for normality test suitable for small set of data.

To test the hypotheses established for the experiment, we adopted the Chi-squared test (PLACKETT, 1983), a non-parametric method useful to compare proportions, i.e., the possible differences between the observed and expected frequencies for a certain event.

\subsubsection{Instruments}

The main instruments that provided the essential information and background needed to the development and gathering of data on the experimental study included:

- Training addressing the entity of study (AM-OER method) used in the experiment.

- Guidelines describing how to use the entity of study (AM-OER method).

- Guidelines to guide and support the subjects during the development of the experimental study.

- Information about the OER on software testing to be created, including different kinds of media/contents that could be incorporated to the OER.

- Introductory materials about OERs, describing main concepts, definitions and characteristics of these materials.

- Recruitment and characterisation form of participants, identifying the level of experience of each one on the domain and topics involved in the experimental study.

- Application form including the statement of participation, procedures for developing the experiment, statement of confidentiality of information about participants and awareness that there will be no reward for participating in the experimental study.

- Data collection form for gathering data from the execution of the experiment. 


\subsubsection{Analysis and Results of the Experiment}

In Figure 41 we show the results obtained by each group using their respective method. The results are displayed by box-plots representing the sample data in three quartiles. The First Quartile or Lower Quartile (Q1) corresponds to the value related to a quarter of data. The Second Quartile or Median Quartile (Q2) corresponds to the value representing the median of the sample data. Whilst the Third Quartile or Upper Quartile (Q3) corresponds to the value representing three quarters of the sample data. The box-plots also show the minimum and maximum values of the sample. As can be observed, the minimum and maximum values of box-plots range from 50 to $100 \%$. In the sample of AM-OER, most of the percentage of results achieved is between 80 and $100 \%$.

Figure 41 - Results obtained by each method.

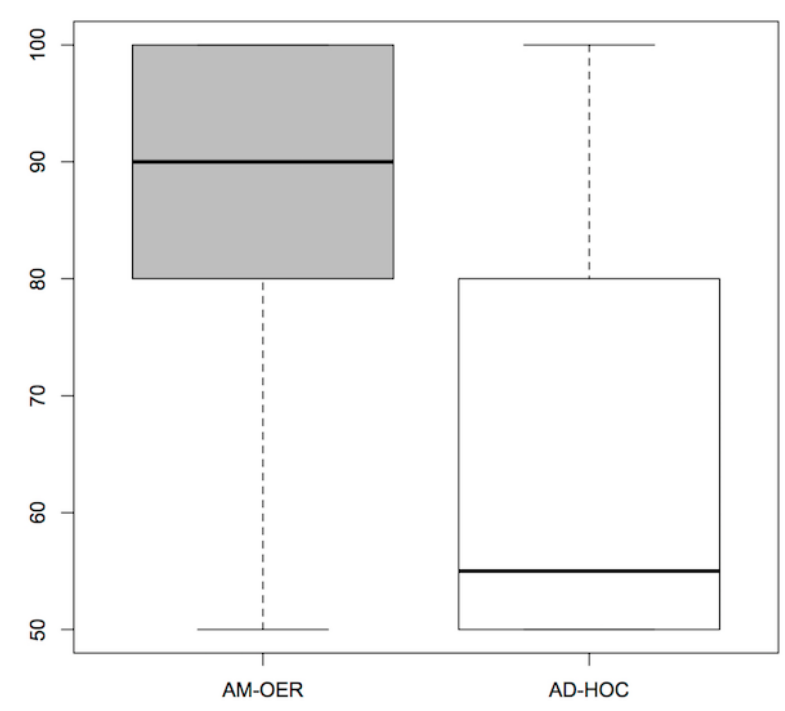

Source: Research data.

\section{RQ1. How effective is the AM-OER in the development of OERs compared to AD-HOC method?}

RQ1 aimed at assessing the effectiveness of AM-OER method in comparison to the AD-HOC method. Effectiveness measures the capacity of each method in the development of the planned OER. It is related to the OER module "planned" to be developed and to the OER module "developed" and "delivered" at the end of the experiment.

The metric to calculate effectiveness is given by:

- $\sum(x i / y i) * 100, i=1 . . n$, where $x i$ represents the average percentage of requirements fulfilled by each method whilst $y$ represents the requirements planned to be fulfilled.

The results for effectiveness show that AM-OER obtained $86.2 \%$ against $65 \%$ of the AD-HOC method (Table 27). We intended to statically infer that effectiveness of the group of 
participants using AM-OER is different and therefore greater than the effectiveness of the group of participants using AD-HOC method. Then, we need to:

1. Reject the null hypothesis given by $H_{0}: \pi \mathrm{AM}-\mathrm{OER} \mathrm{Effe}_{2}=\pi \mathrm{AD}-\mathrm{HOC}_{E f f e}$; or,

2. Accept the alternative hypothesis represented by $H_{1}: \pi \mathrm{AM}-O \mathrm{ER}_{E f f e} \neq \pi \mathrm{AD}-\mathrm{HOC}_{E f f e}$ or $H_{1}: \pi \mathrm{AM}-O \mathrm{ER}_{E f f e}>\pi \mathrm{AD}-\mathrm{HOC}_{E f f e}$.

Table 27 - Results obtained by each method.

\begin{tabular}{l|l|l}
\hline Method & Effectiveness & Efficiency \\
\hline AM-OER & $86,2 \%$ & 0.86 \\
AD-HOC & $65 \%$ & 0.73 \\
\hline
\end{tabular}

Source: Research data.

As we are working with proportional sampling (both samples are presented as percentage), test for proportion $(\pi p)$ is indicated. To test both samples for equality proportions we used the $\mathbf{R}$ Software (R Project, 1993) through the function prop.test(). The R software is a free software environment supporting statistical computing and graphics.

By admitting a low value or level of significance as $\alpha=0.5$ at a $95 \%$ percentage confidence interval, the obtained results was $p$-value $=0.000882$. There is a statistical significance when the $p$-value is lower than the level of significance $(\alpha)$ established for the study. Thus, we can reject the null hypothesis $\left(H_{0}: \pi \mathrm{AM}-0 \mathrm{ER} \mathrm{E} f f e=\pi \mathrm{AD}-\mathrm{HOC}_{E f f e}\right)$ and accept the alternative hypothesis $\left(H_{1}: \pi \mathrm{AM}-0 \mathrm{ER}_{E f f e} \neq \pi \mathrm{AD}-\mathrm{HOC}_{E f f e}\right.$ or $H_{1}: \pi \mathrm{AM}-0 \mathrm{ER} E f f e>$ $\pi \mathrm{AD}-\mathrm{HOC}_{E f f e}$ ).

\section{RQ2. How efficient is the AM-OER in the development of OERs compared to AD-HOC method?}

RQ2 aimed at assessing the efficiency of AM-OER in comparison to the AD-HOC method. Efficiency measures the effort needed by each group of participants to develop and delivery the intended OER. It is related to the OER "developed" and "delivered" and the time spent to do the work. Actually, the results of RQ1 and RQ2 are dependent on each other. To obtain RQ2 we used the results from RQ1 plus the time.

The metric to calculate the efficiency is given by:

- $\sum(x i / y i), i=1 . . n$, where $x i$ represents the average percentage of requirements fulfilled by groups on each method whilst $y$ represents the time (in hours) spent by them.

The results for efficiency shows that AM-OER obtained 0.86 against 0.73 of AD-HOC method (Table 27). It is noteworthy that the higher value obtained, the greater the efficiency. We intended to statically infer that efficiency of the group of participants using AM-OER is different 
and therefore greater than the efficiency of the group of participants using AD-HOC method. Then, we need to:

1. Reject the null hypothesis given by $H_{0}: \pi \mathrm{AM}-\mathrm{OER} \mathrm{E} f f i=\pi \mathrm{AD}-\mathrm{HOC}_{E f f i}$; or,

2. Accept the alternative hypothesis represented by $H_{1}: \pi \mathrm{AM}-\mathrm{OER} \mathrm{R}_{E f i} \neq \pi \mathrm{AD}-\mathrm{HOC}_{E f f i}$ or $H_{1}: \pi \mathrm{AM}-\mathrm{OER}_{E f f i}>\pi \mathrm{AD}-\mathrm{HOC}_{E f f i}$.

With a level of significance of $\alpha=0.5$ at a $95 \%$ percentage confidence interval, we obtained $p-$ value $=0.03556$. In this case, we can reject the null hypothesis $\left(H_{0}: \pi \mathrm{AM}-\mathrm{OER} E f f i\right.$ $\left.=\pi \mathrm{AD}-\mathrm{HOC}_{E f f i}\right)$ and accept the alternative hypothesis $\left(H_{1}: \pi \mathrm{AM}-0 \mathrm{ER}_{E f f i} \neq \pi \mathrm{AD}-\mathrm{HOC}_{E f f i}\right.$ or $\left.H_{1}: \pi \mathrm{AM}-O \mathrm{ER}_{E f f i}>\pi \mathrm{AD}-\mathrm{HOC}_{E f f i}\right)$.

\section{RQ3. How much better are the results obtained by AM-OER compared to AD-HOC method?}

RQ3 aimed at assessing the quality of the results obtained by the groups on each method. This was carried out by an specialist from the University of São Paulo (USP), taking into account the percentage of compliance to quality attributes and desirable characteristics of OERs. These were derived from the main characteristics of an OER such as: (1) contents fitness for purpose; (2) contents accurate and readable; (3) adherence to open technical standards; (4) metadata description; (5) accessible and modifiable formats; (6) facility for repurpose and reuse; (7) well-defined open licensing policies, among others.

In Figure 42 we show the percentage obtained by each method through box-plots regarding the quality of the results. The box-plot of AM-OER shows the results are closer to $80 \%$ and $100 \%$, ranging from $50 \%$ (minimum value) to $100 \%$. On the other hand, the box-plot of AD-HOC shows a higher variation, ranging from $0 \%$ to $100 \%$. Faraway values (discrepant values) within of set of values are considered outliers.

We intended to statically infer that quality of the results obtained by AM-OER is different and therefore greater than the quality of the results obtained by AD-HOC method. Then, we need to:

1. Reject the null hypothesis given by $H_{0}: \pi \mathrm{AM}-0 \mathrm{ER}_{\text {Qual }}=\pi \mathrm{AD}-\mathrm{HOC} \mathrm{C}_{\text {Qual }}$; or,

2. Accept the alternative hypothesis represented by $H_{1}: \pi \mathrm{AM}-\mathrm{OER} \mathrm{Rual}_{\text {Q }} \neq \pi \mathrm{AD}-\mathrm{HOC} \mathrm{Cual}_{\text {or }}$ $H_{1}: \pi \mathrm{AM}-\mathrm{OER}_{\text {Qual }}>\pi \mathrm{AD}-\mathrm{HOC}_{\text {Qual }}$.

The obtained result was $p-$ value $=0.0006052$ considering $\alpha=0.5$ at a $95 \%$ percentage confidence interval. In this case, there is an evidence to reject the null hypothesis $\left(H_{0}\right.$ : $\left.\pi \mathrm{AM}-\mathrm{OER}_{\text {Qual }}=\pi \mathrm{AD}-\mathrm{HOC}_{Q u a l}\right)$ and accept the alternative hypothesis $\left(H_{1}: \pi \mathrm{AM}-\mathrm{OER} \mathrm{R}_{Q u a l} \neq\right.$ $\pi \mathrm{AD}-\mathrm{HOC}_{\text {Qual }}$ or $\left.H_{1}: \pi \mathrm{AM}-\mathrm{OER} \mathrm{R}_{\text {Qual }}>\pi \mathrm{AD}-\mathrm{HOC}_{\text {Qual }}\right)$. 
Figure 42 - Quality of the results of each method.

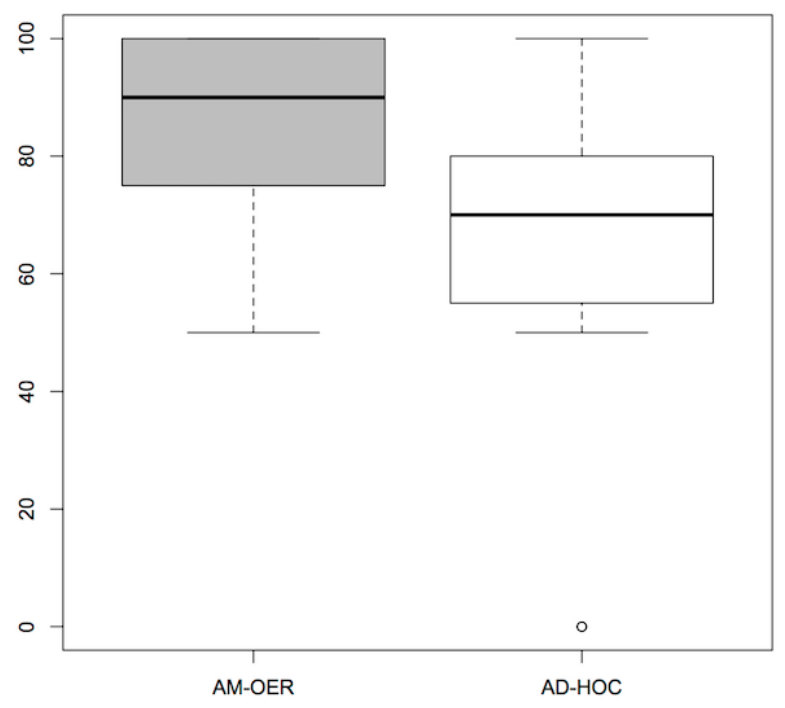

Source: Research data.

\section{Qualitative Analysis}

One of the goals of this work is to adequately support the development of OERs to increase the production, sharing and adoption of these resources in teaching and training of different areas of knowledge. To explore the applicability of AM-OER in the development of OERs we also investigate a set of research questions covering three perspectives:

1. Appropriateness/usefulness: refers to the level in which the method offers adequate support and guide the development of OERs.

2. Ease of use: refers to the level in which the method is easy to be used, especially by non-experts/non-specialists in the development of OERs.

3. Satisfaction: the level in which the participants wish to use the method in future projects and would recommend it to other interested parties.

The answers for the research questions were provided according to the following scale: (a) 1 - Strongly disagree; (b) 2 - Partially disagree; (c) 3 - Indifferent; (d) 4 - Partially agree; and (e) 5 - Strongly agree.

In Figure 43 we summarise the results of all questions covering appropriateness/usefulness, ease of use and satisfaction by box-plots. According to the results, the majority of answers were in the range between " 4 - Partially agree" and " 5 - Strongly agree". The results show a tendency of the acceptance of AM-OER in the development of OERs. However, other assessments must be conducted in order to provide more consistent results.

The participants also provided suggestions for changes and enhancements to the AM-OER. Such suggestions were mainly related to the identification of the learning needs 
for the course. This step was not clear enough in the method, requiring a more objective and detailed explanation on how to perform it.

Figure 43 - Qualitative analysis.

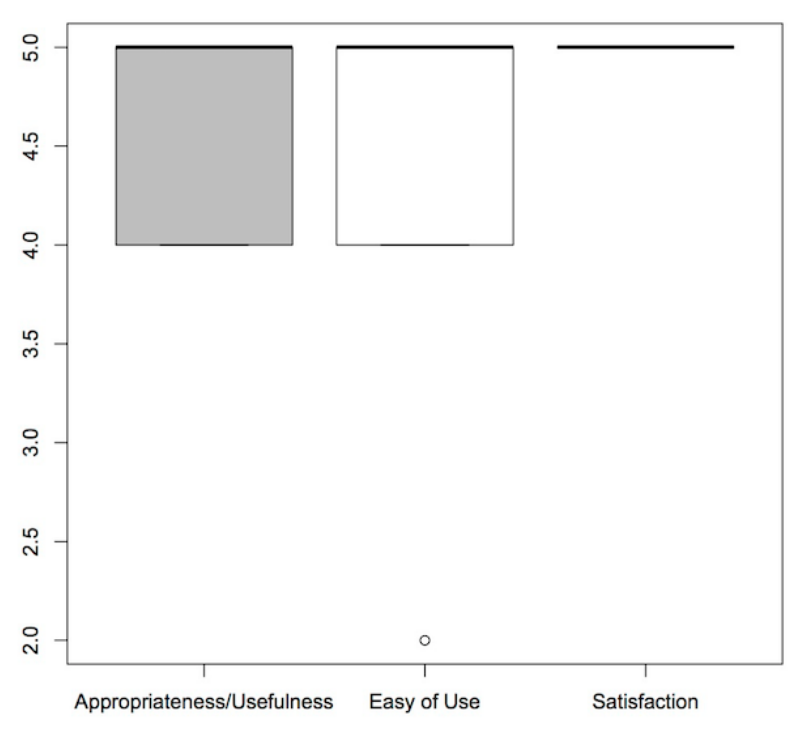

Source: Research data.

The participants also reported the difficulty and effort needed to find related contents with compatible licenses, which may hinder the reuse third-part learning materials during the development process.

The data collected and feedback obtained from participants were used to refine and improve the latest version of AM-OER (described in the Chapter 5).

Despite the lack of experience of some participants, it did not considerably affect the result of the experiment. Actually, the results can indicate that AM-OER can be used by non-experts in the development of an OER.

\subsubsection{General Overview of the OER on Software Testing}

The OER created in the experiment was a full class within a software testing course. It covers a brief overview of functional testing (black-box) and its criteria, particularly equivalence partitioning testing and boundary values analysis (MYERS, 2004; DELAMARO; MALDONADO; JINO, 2007). Each group had 5 (five) hours to produce such OER.

Following we present the main phases and activities for designing and creating the OER on software testing by the group following the AM-OER method.

\section{Kickoff - Defining Objectives and Overall Structure for the Course}

Before starting the course project, the main roles within the AM-OER method were distributed and shared with the participants, according to the experience and skills of each one in the function to be performed. 
The project started with the educator/domain expert defining the general goals and specific objectives to be achieved by students that will be enrolled in the course. The general goals of the course were to provide students an overview of the functional testing technique, and show how such technique can be applied in the software construction. In order to achieve the general goals, the following key learning objectives were defined to the course:

- Students will be able to discuss and describe the fundamentals of functional testing.

- Students will be able to explain and distinguish the two major functional testing criteria: partitioning functional testing and boundary values analysis.

- Students will be able to apply the partitioning functional testing and boundary values analysis, and to argue and defend both criteria.

In Figure 44 we present the Initial Architecture View conceptual map, summarising the overall structure including the main components/elements needed to the testing course. It includes the learning contents covered by the course, the assessments criteria to evaluate learning, and the mechanisms supporting communication and collaboration during the learning intervention. This structure is specific to the AM-OER method, and it was not produced by using an AD-HOC method.

The course module is inserted in the context of Software Engineering, specifically software testing domain. The target audience includes undergraduate students in Computer Science or other related areas such as Computer Engineering. It can also include any students interested in getting an overview on functional testing. The module consists of a full class within a software testing course with an expected duration of three hours and a half. Students can be supported both physically and online. As prerequisites and experience, the students must have basic skills on fundamentals of programming and software testing.

The learning contents that compose the course include lessons, guidelines, examples, supporting materials and specification and implementation of a program named $\mathrm{Cal}^{2}$.

Throughout the course, students will be evaluated through essays, self-assessment questions and project reports. They will communicate and collaborate with colleagues and educator in person (face-to-face), or through chat, forum, peer-to-peer work and discussion in group.

\section{Development - Designing, creating and evaluating the learning structure and related contents and activities}

The testing course on functional testing technique covers the following topics and issues:

- Contextualisation, including a brief remind of concepts related to software testing;

2 This program is about a Calendar, wherein the user can obtain a calendar for a particular month and/or year 
- Fundamentals of functional testing, including concepts and definitions;

- Fundamentals of equivalence partitioning testing, including definition and application; and,

- Theoretical and practical activities for students, including test and assessments activities.

Figure 44 - OER on software testing: Overall structure.

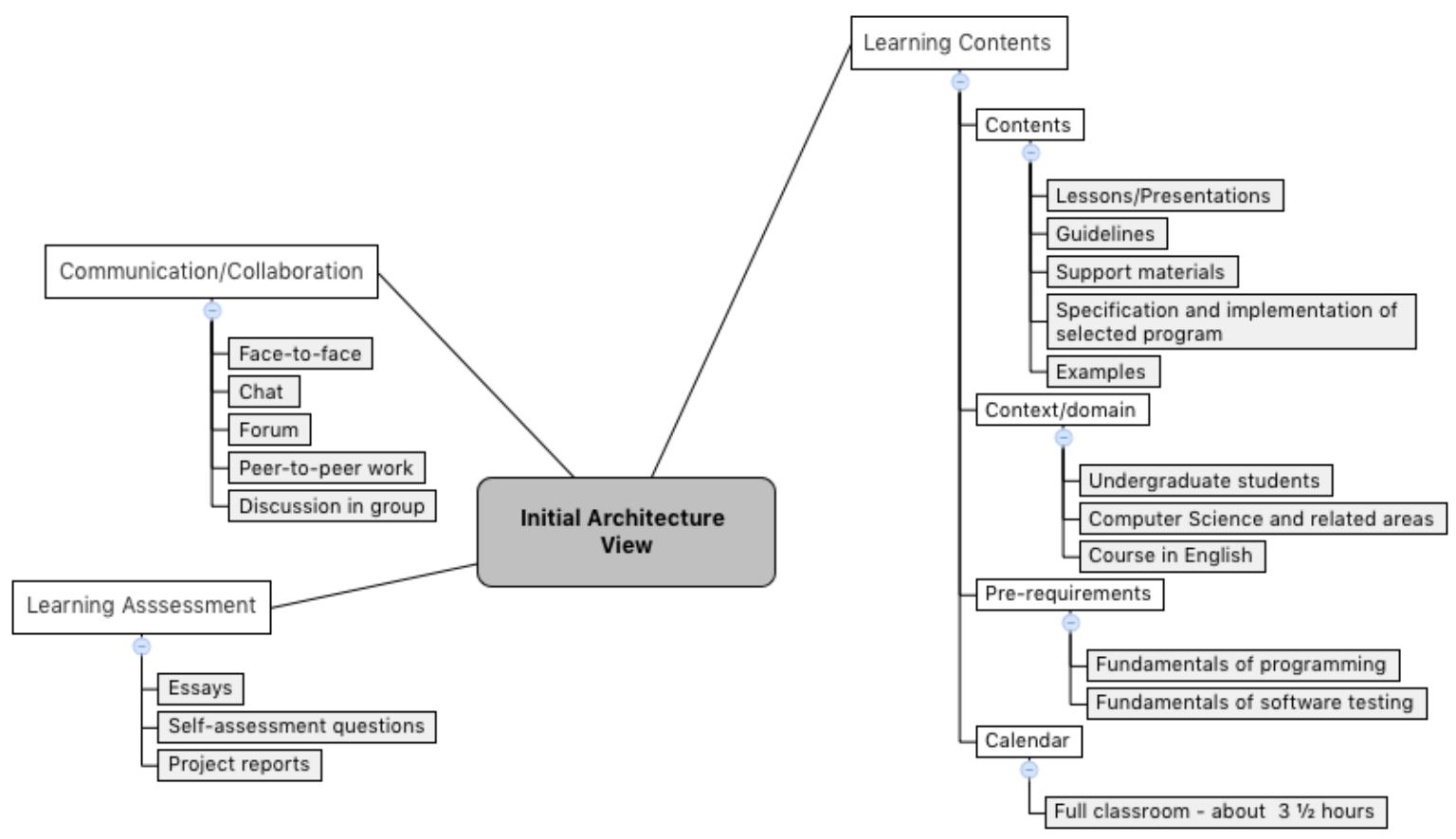

Source: Research data.

The participants get together to discuss and think about the overall learning structure of the course within a learning scenario. They sketched an Initial Architecture View (Figure 45), mapping the learning activities that students take part (such as brainstorm the functional testing criteria) with intended learning outcomes (such as demonstrate knowledge and critical understanding on fundamentals of functional testing), contents (such as Cal program specification/Cal program implementation), tools (such as framework xUnit), and assessment activities (such as essay summarising discussion). For instance, a student enrolled in the course should design and execute test cases using functional testing criteria (learning activity). In this case, it is expected that the student has demonstrated ability to apply functional testing criteria (intended learning outcomes) according to the assessment activity performed for it (report on design and execution of test cases). 
Figure 45 - OER on software testing: Learning structure overview.

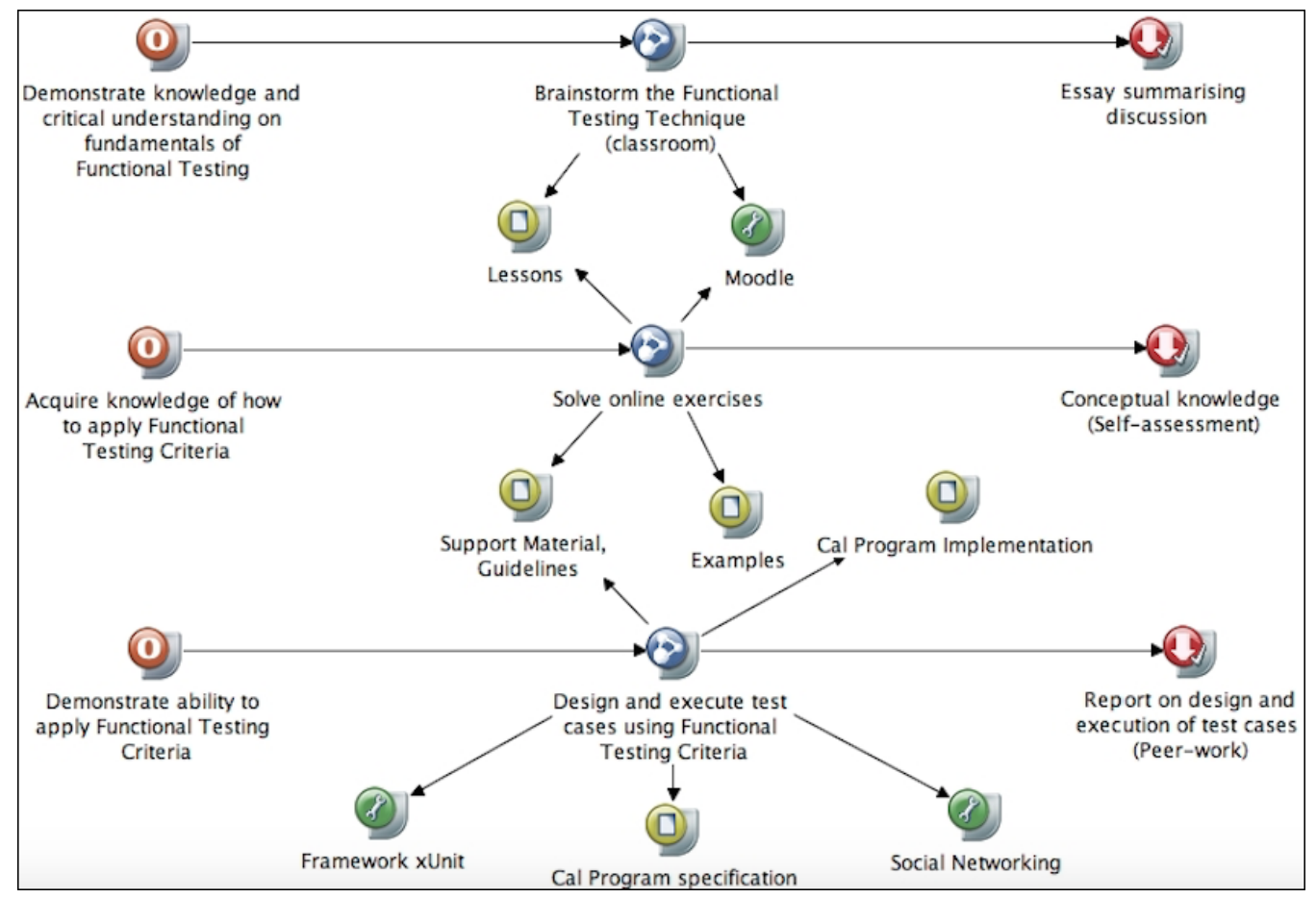

Source: Research data.

The overall learning structure aforementioned was refined in order to map the flow of individual activities and to determine the tasks that students need to perform to achieve the intended learning outcomes. A sketch of this refinement is shown in Figure 46, represented by a Learning Tasks View artefact. Simple learning activities from Learning Structure View were decomposed into simple and atomic tasks with related contents, tools, and assessments. For instance, a student enrolled in the activity design and execute test cases using functional testing criteria needs to perform a set of related tasks (such as design test cases using boundary values analysis and execute test cases), using or supported by contents ( $\mathrm{Cal}$ program specification, and $\mathrm{Cal}$ program implementation), and tool (framework xUnit). Then, he/she will elaborate a testing report on the work done (assessment activity).

In comparison to the AD-HOC method, the definition and mapping of the learning structure and activities of the course through the Learning Structure View and Learning Tasks View are activities specifically related to the AM-OER method.

Based on the learning structure of the course, the contents were created by the participants who integrated the development team. The contents were reviewed and integrated to other components of the course. Contents essentially included html pages/text documents, lessons/lecture notes, images and video. To exemplify, in Figure 47 we show one of the learning assessment activities proposed for the students. It consists of a practical activity involving the design and implementation of partitioning functional testing and boundary values analysis criteria. 
Figure 46 - OER on software testing: Learning structure refinement.

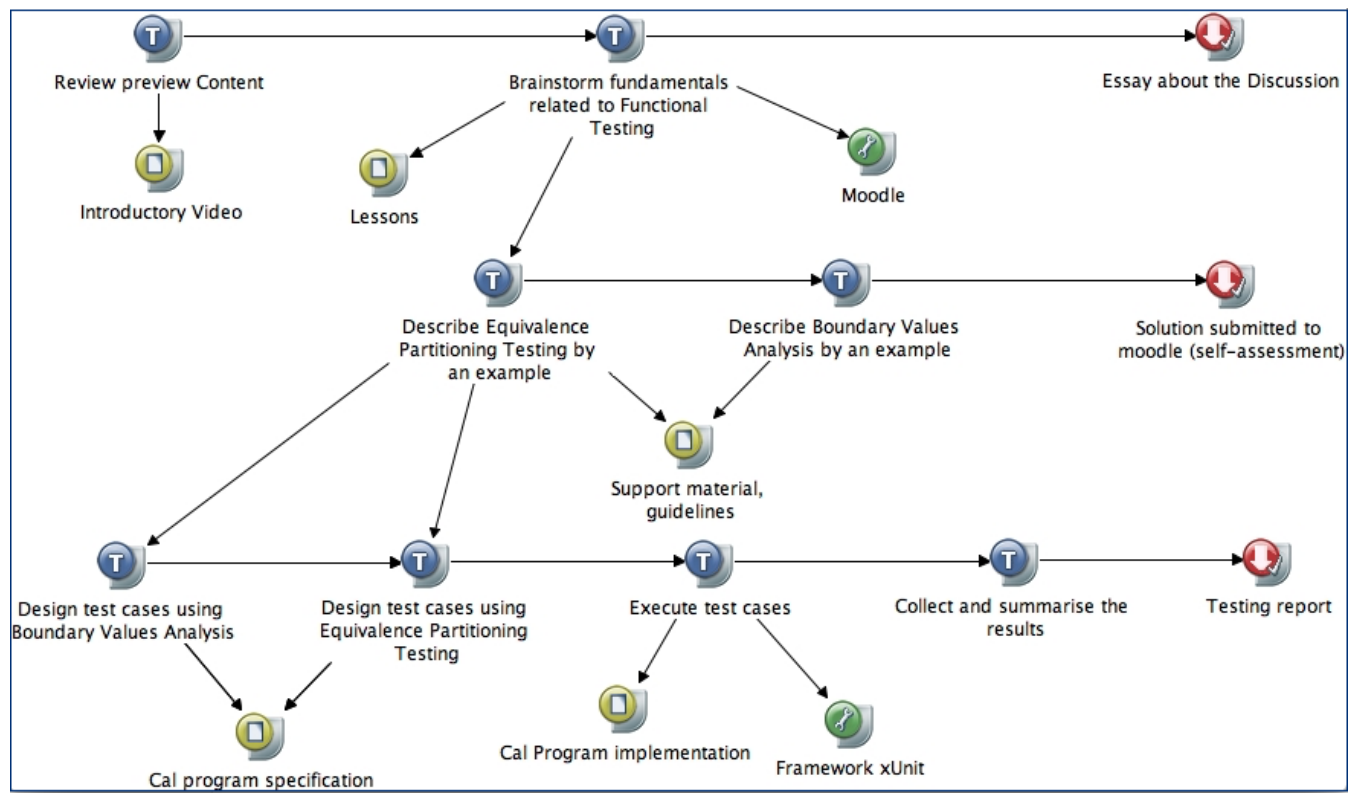

Source: Research data.

Figure 47 - OER on software testing: Assessment activity.

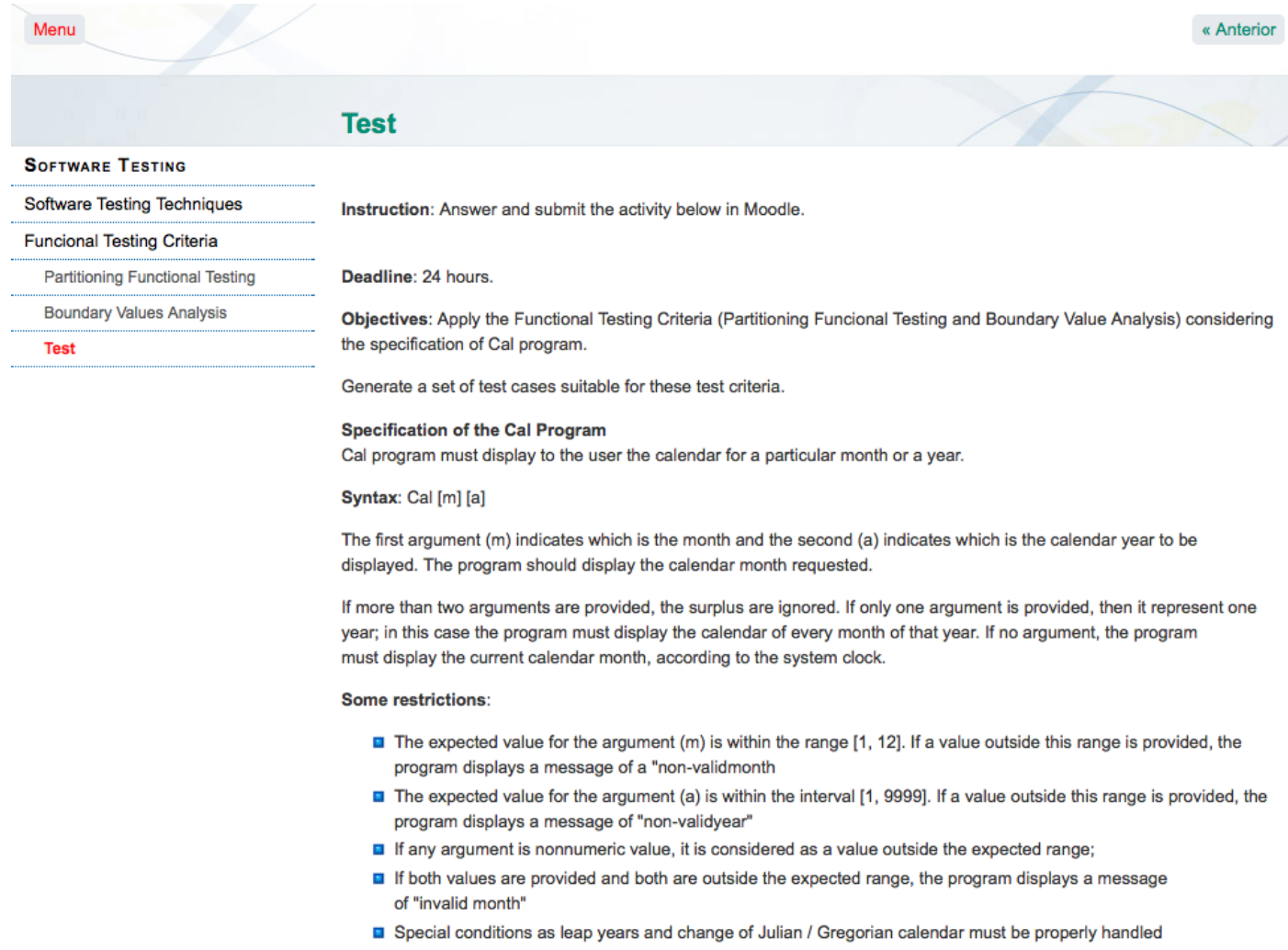

Source: Research data.

To create, edit and update the content associated to course, the following mechanisms and tools were adopted: (1) Bloom's taxonomy, for supporting the learning objectives statement; (2) Xmind, for creating and mapping the overall structure for the course (Initial Structure View); (3) 
LibreOffice, for creating the set of slides and text documents; (4) CompendiumLD, for creating and refining the learning structure for the course (Learning Structure View and Learning Tasks View); and (5) eXelearning, for structuring html pages and delivering the course.

After the development activities, all components of the course were evaluated by the role of educator and potential learner within the group of participants. The evaluation activities were performed according to the criteria/aspects considered in the AM-OER method. Feedback from the evaluation was gathered and used to improve the whole course.

The OER on testing course is provided under the Creative Commons License (Creative Commons, 2013a) - Attribution Non-Commercial Share Alike 4.0 International ${ }^{3}$.

\subsubsection{Threats to Validity}

We consider some factors that may affect and impact the analysis and interpretation of the results from the experiment. The main threats to validity of the experiment are presented into three categories:

1. Internal validity: including three threats to validity (1) Learning: the AM-OER method can not provide well-defined steps and guidelines to guide the development of OERs. We have tried to minimise this effect by conducting an appropriate training covering all subjects involved in the experiment before executing it. All training materials were shared with the participants. Besides that, they received all instructions needed to develop their tasks; (2) Conformance to the original study - there may be a discrepancy between the training step and the original study. We have carefully planned the time of the training development tasks in accordance with the time needed for the development tasks of the experiment; and (3) Language - all material available for the development of experiment (such as lecture notes, development tasks, artefacts) were written in English. The lack of proficiency in English may affect the results of the study. However, we believe everyone involved in the experiment have already been acquainted with the English language.

2. External validity: including four threats to validity (1) Environment of the experiment - the environment must be suitable for the experiment. We conducted the experiment in a laboratory with no external interference and adequately furnished with computer and Internet access; (2) Experience of participants - the level of experience of participants could influence in the validation. Before the experiment, participants were asked to answer a questionnaire about their level of familiarly and experience, covering the subjects involved in the experiment. From this, we have tried to create homogeneous groups with similar level of experience on the subjects; (3) Time for the experiment - the time allocated to the experiment was short due to the unavailability of participants, usually involved with other activities. In this case, we established a simple and short module

\footnotetext{
3 creativecommons.org/licenses/by-nc-sa/4.0
} 
suitable to be developed in the experiment. Only one five hours sprint could seem as the application of waterfall (ROYCE, 1970) instead of an agile method. However, in the sprint of our experiment, all phases were performed together, with the active participation and collaboration between the participants. The module was defined, designed, created and evaluated during the sprint and, then, delivered to a target audience. (4) Number of participants - the number of participants of the experiment is relatively small and may not adequately reveal the applicability and effectiveness of the proposed method to support the development of OERs. Currently, we are working to replicate and plan new experiments with a large number of participants.

\subsection{Concluding Remarks}

This chapter presented the empirical assessment studies conducted to validate the agile method for OERs - AM-OER. The approaches used for validation and the main results were gathered and summarised.

The main contributions are twofold. The first contribution refers to the exploratory research consisting of a holistic case study for feasibility and applicability analysis of the AM-OER method in the development of OERs. The second contribution is an explanatory research consisting of an experiment to validate the effectiveness, efficiency and quality of the results achieved by the AM-OER in the development of OERs. Issues related to the applicability of the method were also considered in the experiment.

We recognised the threats and limitations of the two studies and general conclusions cannot be drawn from the results discussed in this chapter. However, these studies bring preliminary empirical evidence of the applicability and effectiveness of the method in the development of OER.

In the next chapter we summarise the main contributions and general limitations of the work conducted in this P.h.D. research, and showing perspectives for continuing this work. 

CHAPTER

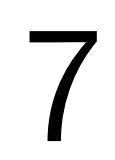

\section{CONCLUSIONS AND FURTHER WORK}

$\mathrm{T}$ he production activities are the most costly in most initiatives involving the development and delivering of OERs (SCHUWER et al., 2010). Similarly to the software development,

the design and creation of OERs require the use of appropriate mechanisms to ensure the productivity of the development process and the quality of the resultant materials.

This P.h.D. research offers contributions to the development of OERs and advances in the area, by investigating theoretical (concepts, definitions, characteristics, open licensing options, pedagogical design) and practical (mechanisms/approaches to support the development, challenges, barriers and gaps) issues of OERs, and proposing and applying an agile method (AM-OER) to effectively support the design and creation of OERs.

The establishment of AM-OER fills the gap regarding the need of systematic and flexible approaches, specifically designed for the development and delivery of OERs, as highlighted in previous works (PETRIDES et al., 2008; SCLATER, 2009; CONOLE et al., 2009; Open Educational Quality Initiative, 2011; ARIMOTO; BARBOSA, 2012b) and also identified in the studies described in Chapter 4.

This chapter is organised as follows. In Section 7.1 we revisit the main contributions of this P.h.D. research. In Section 7.2 we summarise the limitations of the work undertaken and provide future directions for research. In Section 7.3 we present the main publications resulting from this P.h.D. research.

\subsection{Contributions}

This P.h.D. research aimed at investigating the development of OERs and providing effective mechanisms for the production and sustainable sharing of OERs. In this context, we described and discussed a set of studies to investigate and answer a set of exploration questions, providing the subsidies for the understanding and development of the P.h.D. research. As main result, we highlight the establishment of an agile method for the design and creation of OERs 
that stands on practices of Software Engineering (agile methods) and Learning Design. Although preliminary, the results from the empirical validation studies have provided positive feedback regarding the applicability and effectiveness of the method in the development of OERs.

The main contributions of this P.h.D. research are the following:

- Characterisation of OERs through the identification of related concepts, definitions, types and essential characteristics and principles behind OERs that remains unclear, helping to obtain a better understanding on the subject. We identified essential characteristics that need to be considered during the development and sharing of OERs in order to increase their adoption and impact on education. Based on the literature, we defined OERs as educational/learning materials for teaching and learning which are freely and openly available through an open license, allowing their (re)use, modification, adaptation, and distribution in a flexible way with little or no restriction. We categorised OERs in four main types: (1) complete modules: representing more complete and standardised structure of learning materials; (2) components representing small blocks of educational contents and activities; (3) interactive media: representing digital and interactive components within a module; and (4) supporting mechanisms: representing mechanisms that support the teaching and learning process, and the construction and delivery of learning materials.

- Characterisation of agile methods by identifying values and principles that underpin the agile development philosophy, and investigating the well-known and widely used agile methods nowadays, i.e., Scrum and XP. We have identified characteristics and practices related to those agile methods that could be useful and bring benefits to the development of software and learning materials, especially OERs. The study provided subsidies for the proposition and establishment of the agile method for OERs presented in this P.h.D. research. It can also help other researchers and enthusiasts to adopt and disseminate agile in academic environment.

- An evidence-based research, consisting of a systematic mapping on the mechanisms/approaches for the development and sharing of learning materials, especially OERs. It provided an overview (a map) of the approaches that have been used and proposed for the development process of OERs. The results can aid to understand the principal needs regarding the development and sharing of OERs, by identifying issues that still require investigation or particular needs on the OERs development process that have not been addressed yet. We highlighted the gaps and trends for research and development in the area and also provided a guide to help other researchers in planning and developing future research.

- Quantitative survey-based research on the development of OERs in the Brazilian context. It provided a big picture about how OERs have been developed in Brazil. We could identify the main problems, difficulties, barriers and challenges faced by educators, developers and 
practitioners of OERs. It also highlighted the key factors that may effectively promote the production, adoption and sharing of OER in Brazil. The results can aid to foster the collective work (government, educational institutions, researchers, educators and learners) in order to provide the foundation and appropriate mechanisms to the production, use and sharing of OERs, helping to promote the idea of broader access and participation of all citizens in education. Our idea was to contribute to deepening the discussions and improvement of the process of development and sharing of OERs, and therefore contributing to the wide dissemination and adoption of OERs in Brazilian education.

- An agile method to support the design and creation of OERs - AM-OER, based on a combination of agile practices from Software Engineering and Learning Design practices from OULDI project. The AM-OER method allows designs to be created, modified, repurposed and evolved according to the needs of users emerging during the OERs development process. Pedagogical design practices are embedded in the development of OERs improving quality and facilitating reuse and adaptation. The AM-OER method provides a flexible approach for accommodating changes and improvements throughout the development, minimising their cost and impact. The method prioritises the cooperation and collaboration of those involved in the process. The active participation of users is encouraged throughout the process. These factors help reduce the development time and effort, promoting an effective production process for a sustainable supply of OERs.

- Empirical assessment studies to validate AM-OER method. We conducted two different empirical assessment studies: (1) an exploratory research, consisting of a holistic case study research for feasible and applicability analysis of AM-OER in the development of an OER on FLOSS introductory course; and (2) an explanatory research, consisting of an experimental study to validate AM-OER through the development of an OER on software testing course. The experiment taken into consideration measures of effectiveness, efficiency and quality of the results achieved by the method. Issues related to the applicability of the method were also analysed in the experiment. In terms of qualitative analysis, the preliminary results indicate that the method is useful and easy to use, especially for non-experts in the development of OERs. Regarding quantitative analysis, the results obtained so far have shown that the method is effective and efficient to the development of OERs.

\subsection{Limitations and Further Work}

The main limitations related to the work undertaken in this P.h.D. research are summarised as follows: 
- Study on the agile development: the study conducted only focus on agile methods Scrum and XP. Although the study has covered the overview of agile development, specific characteristics and practices of others agile methods (e.g., Lean Development (POPPENDIECK; POPPENDIECK, 2006; POPPENDIECK; POPPENDIECK, 2009) that could be useful and suited to the context of OERs development was not explored.

- Study on the development of OERs: the studies conducted on the development of OERs, both in the international and Brazilian context, have in common a relatively small sampled data. In the first study, which consisted of a systematic mapping, the quantity of selected primary studies may be not be representative of the population. In the survey-based research, it was not possible to exactly determine the number of participants who received the questionnaire, may also affect the representativeness of sample.

- Study and establishment of an agile method for OERs: the AM-OER was proposed focusing on the development of OER by a team. It should be considered the construction of a team bringing together the necessary knowledge and skills for the effective development of OERs, including technical and pedagogical issues. Therefore, one constraint or limitation on the usage and applicability of the AM-OER refers to the development of OERs individually, without a team involved. If there is no specific knowledge and skills within the team, training may be necessary. Furthermore, the AM-OER was only applied in the development of OERs in academic environment and within a specific domain of knowledge.

- Empirical assessment studies: The first assessment study conducted consisted of a single case study research with a small number of participants. This case study cannot be replicated, and the obtained results do not allow generalisation. The second assessment study, which consisted of an experiment, also involved a small number of participants, what may affect the representativeness of the sample of population. Besides that, both assessment studies were conducted within an academic environment.

We can identify several possibilities of continuity of the work undertaken in this P.h.D. thesis and future directions for research. Following we briefly summarise some of them:

- Planning and conduction of new empirical studies: we are planning and developing new experiments to validate AM-OER method, considering the involvement of a large number of participants. We are also concerned to the need of planning and conducting experiments covering the development of OERs in other areas and knowledge domains.

- Evolution of the proposed method: the idea is to evolve and improve AM-OER method according to the results from the conduction of the empirical assessment studies and the feedback obtained from the participants of the experiments. 
- Make available OERs for different areas and knowledge domains: the idea is to develop and provide OERs in a variety of areas and knowledge domains, such as Software Engineering, Computing Engineering, Information Systems, and Mathematics and Statistics. In addition to the Higher Education, the idea is to provide OERs for other teaching context that includes Elementary School, Middle School and Vocational Training.

- Definition of a theoretical assessment framework: we intend to define a theoretical framework to support the assessment of OERs. The idea is to use the preliminary set of criteria defined in Chapter 5 to evaluate OERs as a foundation, by refining and expanding it, and proposing other criteria and perspectives of assessments to OERs.

- Planning and assessment of OERs: we intend to assess different kinds of OERs following the theoretical framework to be proposed. The idea is to conduct empirical assessment studies for assessing OERs developed with the application of AM-OER method. The theoretical framework should also be used to support the assessment of other OERs available on the Web.

\subsection{Publications}

The main publications resulting from the activities conducted during the P.h.D. research are summarised as follows:

- Arimoto, M. M.; Barroca, L. and Barbosa, E. F. AM-OER - An Agile Method for the Development of OERs. Informatics in Education Journal, v.15, n.2, pages 1-25, 2016.

- Arimoto, M. M.; Barroca, L. and Barbosa, E. F. A Learning Design Method for Open Educational Resources. In IEEE Frontiers in Education Conference (FIE), 21-24 October 2015, El Paso, Texas/USA, pages 1897-1905, 2015.

- Arimoto, M. M.; Barroca, L. and Barbosa, E. F. Recursos Educacionais Abertos: Aspectos de desenvolvimento no cenário brasileiro. Revista Novas Tecnologias na Educação (RENOTE), v.12, n.2, pages 1-10, 2014.

- Arimoto, M. M. and Barbosa, E. F. Towards the establishment of an Agile Method for OERs Development and Delivery. In IEEE Frontiers in Education Conference (FIE), 23-26 October 2013, Oklahoma City, Oklahoma/USA, pages 541-547, 2013.

- Arimoto, M. M. and Barbosa, E. F. A. Systematic Review of Methods for Developing Open Educational Resources. In 20th International Conference on Computers in Education (ICCE’2012), 26-30 November 2012, pages 262-269, Singapore, 2012. 
- Arimoto, M. M. and Barbosa, E. F. Um Conjunto Preliminar de Práticas para o Desenvolvimento Ágil de Recursos Educacionais Abertos. In Congresso Brasileiro de Informática na Educação (CBIE), II International Symposium on OER: Issues for globalization and localization, 26-30 November 2012, Rio de Janeiro, RJ/Brazil, pages $1-8,2012$.

Furthermore, the following papers have been produced and submitted to to conference and international journal:

- Arimoto, M. M.; Barroca, L. and Barbosa, E. F. Developing Open Educational Resources through Learning Design and Agile Practices. In Congresso Brasileiro de Informática na Educação (CIBE), XXVII Simpósio Brasileiro de Informática na Educação (SBIE), pages 1-10, 2016.

- Arimoto, M. M.; Barroca, L. and Barbosa, E. F. Development of Open Educational Resources: A systematic mapping. International Journal of Distance Education Technologies (IJDET), pages 1- 19, 2016. 
ABRAHAMSSON, P.; SALO, O. Empirical evaluation of agile software development. In: 5th International Conference on Product Focused Software Process Improvement (PROFES 2004). Kyoto-Nara, Japan: Springer, 2004. v. 39, p. 408-423. Cited on page 60.

ABRAHAMSSON, P.; SALO, O.; RONKAINEN, J.; WARSTA, J. Agile software development methods: Review and analysis. [S.1.], 2002. Cited 3 times on pages 60, 68, and 76.

Agile Manifesto. Manifesto for agile software development. 2001. <www.agilemanifesto.org> [02/2016]. Cited 2 times on pages 60 and 69.

AKHTAR, M.; AHSAN, A.; SADIQ, W. Scrum adoption, acceptance and implementation (a case study of barriers in Pakistan's IT industry and mandatory improvements). In: IEEE 17Th International Conference on Industrial Engineering and Engineering Management (IE EM'2010). Xiamen, China, October 20-31: IEEE, 2010. p. 458-461. Cited 2 times on pages 68 and 69.

AMARAL, L. L.; GOMES, T. A.; SOUZA, M. F. C.; FILHO, J. A. d. C.; PEQUENO, M. C. Um aprimoramento do modelo de processo de criação de objetos de aprendizagem do projeto RIVED. In: XXVI Congresso da SBC - XII Workshop de Informática na Escola. Campo Grande, MS, Brazil: SBC, 2006. p. 373-376. Cited 2 times on pages 86 and 98.

AMBLER, S. W. Agile design practices. 2001. <agilemodeling.com/essays/agileDesign.htm>. [02/2016]. Cited 8 times on pages 30, 109, 112, 113, 117, 122, 124, and 130.

Agile modelling: Effective practices for eXtreme programming and the unified process. [S.1.]: New York: John Wiley \& Sons, 2002. Cited 2 times on pages 30 and 75.

AMIEL, T.; OREY, M.; WEST, R. Recursos educacionais abertos (REA): Modelos para localização e adaptação. Campinas: Educação Temática Digital (ETD), São Paulo - SP, v. 12, n. 1, p. 112-125, 2011. Cited 3 times on pages 28, 42, and 120.

AMIEL, T.; SANTOS, K. Uma análise dos termos de uso de repositórios de recursos educacionais digitais no Brasil. Revista Trilha Digital, São Paulo - SP, v. 1, n. 1, p. 118-133, 2013. Cited 2 times on pages 28 and 120.

ARIMOTO, M. M. Um processo ágil de software baseado no OpenUP aderente ao nível G do modelo de referência MR-MPS. Dissertação (Mestrado) - Centro Universitário Eurípides de Marília (UNIVEM) - Fundação de Ensino Eurípides Soares da Rocha (FEESR), Marília, SP, 2009. Cited on page 29.

ARIMOTO, M. M.; BARBOSA, E. F. A systematic review of methods for developing open educational resources. In: 20th International Conference on Computers in Education (ICCE'2012). Singapore, November 26-30: National Institute of Education, Nanyang Technological University/Singapore, 2012. p. 262-269. Cited 8 times on pages 25, 28, 29, 30, 32, 103, 107, and 108 . 
Um conjunto preliminar de práticas para o desenvolvimento ágil de recursos rducacionais abertos. In: Congresso Brasileiro de Informática na Educação (CBIE), II International Symposium on OER: Issues for globalization and localization. Rio de Janeiro, RJ: CBIE, 2012. p. 1-8. Cited 8 times on pages 25, 29, 32, 81, 82, 103, 107, and 175.

Towards the establishment of an agile method for OERs development and delivery. In: IEEE Frontiers in Education Conference (FIE). Oklahoma City, Oklahoma, USA, October 23-26: IEEE Computer Sociecty, 2013. p. 541-547. ISSN 0190-5848. Cited 7 times on pages $32,43,86,91,93,107$, and 108 .

ARIMOTO, M. M.; BARROCA, L.; BARBOSA, E. F. Recursos educacionais abertos: Aspectos de desenvolvimento no cenário brasileiro. Revista Novas Tecnologias na Educação (RENOTE), v. 12, n. 2, p. 1-10, 2014. Cited 6 times on pages 28, 29, 33, 103, 104, and 107.

A learning design method for open educational resources. In: IEEE Frontiers in Education Conference (FIE). El Paso, Texas, USA, Octboer 21-24: IEEE Computer Society, 2015. p. 1-9. Cited 5 times on pages 26, 29, 33, 81, and 108.

AM-OER: An Agile Method for the development of Open Educational Resources. Informatics in Education Journal, v. 15, n. 2, p. 1-25, 2016. Cited 3 times on pages 28, 29 , and 33.

ARIMOTO, M. M.; CAMARGO, V. V.; CAGNIN, M. I. Uma ferramenta de controle de versões de Frameworks. In: XXXIII Latin-American Conference of Informatics (CLEI'07). San José, Costa Rica: Centro Latinoamericano de Estudios en Informática, 2007. Cited on page 88.

Version control on the crosscutting framework based-development. In: XXIII ACM Annual Symposium on Applied Computing (SAC'08). Fortaleza, CE, Brazil: ACM, 2008. p. 753-758. Cited on page 88.

ARIMOTO, M. M.; MURAKAMI, E.; CAMARGO, V. V.; CAGNIN, M. I. Adherence analysis of agile methods according to the MR-MPS reference model. In: VIII Simpósio Brasileiro de Qualidade de Software (SBQS'09). Ouro Preto, MG, Brazil: SBC, 2009. p. 249-263. Cited on page 29 .

AUSUBEL, D. P. Aquisição e retenção de conhecimentos: uma perspectiva cognitiva. 1. ed. Lisboa, Portugal: Platano, 2003. 219 p. ISBN 972-707-364-6. Cited on page 91.

AVRAAMIDOU, A.; ECONOMOU, A. Visualized learning design: The challenges of transferring an innovation in the cyprus educational system. Teaching English with Technology, Special Edition on LAMS and Learning Design, C. Alexander, J. Dalziel, J. Krajka E. Dobozy (Eds.), v. 12, n. 3, p. 3-17, 2012. Cited on page 55.

BAHETI, P.; GEEHRTNGER, E.; STOTTS, D. Exploring the efficacy of distributed pair programming. In: Extreme Programming and Agile Methods - XP/Agile Universe. Chicago, USA: Springer, 2002. Cited on page 63.

BAHL, R. S. Adaptive-ADDIE: Scrum framework for instructional systems design. Ranvir Singh Bahl, University of British Columbia: [s.n.], 2012. ETEC 511 - Section 64D. Cited on page 56 .

BARANIUK, R. G.; BURRUS, C. S. Viewpoint: Global warming toward open educational resources. v. 51, p. 30-32, 2008. Cited on page 42. 
BARBOSA, E.; MALDONADO, J. Establishing a mutation testing educational module based on IMA-CID. In: Second Workshop on Mutation Analysis. Raleigh, North Carolina, USA, November 7-10: [s.n.], 2006. p. 14. Cited on page 86.

BARBOSA, E. F.; ARIMOTO, M. M. Recursos educacionais abertos, In Educação e Ciência Aberta: O impacto das novas tecnologias no apoio e distribuição de conhecimento. Computação Brasil, Revista da Sociedade Brasileira de Computação (SBC), Porto Alegre, RS, v. 2, n. 22, p. 17-21, 2013. Cited on page 43.

BARBOSA, E. F.; MALDONADO, J. C. Towards the establishment of a standard process for developing educational modules. In: 36th Annual Frontiers in Education Conference (FIE'06). San Diego, CA, USA: IEEE Computer Society, 2006. p. 1-6. Cited on page 86.

Specialization and instantiation aspects of a standard process for developing educational modules. In: ISOLA'08: 3rd International Symposium on Leveraging Applications of Formal Methods, Verification and Validation. Kassandra, Chalkidiki, Greece: [s.n.], 2008. p. 1-16. Cited on page 86.

Collaborative development of educational modules: A need for lifelong learning. E-Infrastructures and Technologies for Lifelong Learning: Next Generation Environments-G. D. Magoulas. (Org.), p. 37, 2011. Cited 2 times on pages 29 and 39.

BARBOSA, E. F.; SOUZA, S. R. S.; MALDONADO, J. C. An experience on applying learning mechanisms for teaching inspection and software testing. In: 21st Conference on Software Engineering Education and Training (CSEE'08). Charleston, SC: IEEE Computer Society, 2008. p. 189-196. Cited on page 86.

BARESI, L.; NITTO, E. D.; GHEZZI, C. Towards Open-world Software: issue and challenges. In: IEEE Computer Society (Ed.). Proceedings of the 30th Annual IEEE/NASA Software Engineering Workshop. Columbia, MD, USA: [s.n.], 2006. p. 249-252. Cited on page 59.

BASILI, V. R. Applying the goal/question/metric paradigm in the experience factory. In: Software Quality Assurance and Measurement: A worldwide perspective, In Norman Fenton, Robin Whittty, and Yoshinori Lizuka (Eds). London, UK: International Thomson Publishing, 1996. Cited on page 156.

BASILI, V. R.; FOREST, S. F. L. Building knowledge through families of experiments. IEEE Transactions on Software Engineering, v. 25, n. 4, p. 456-473, 1999. Cited on page 156.

BECK, K. Test-driven development: by example. [S.1.]: Addison-Wesley Professional, 2003. Cited on page 71 .

BECK, K.; ANDRES, M. Extreme programming explained: embrace change. 2. ed. [S.1.]: Addison-Wesley, 2004. Cited 9 times on pages 29, 30, 60, 61, 69, 71, 75, 108, and 109.

BECK, K.; FOWLER, M. Planning extreme programming. 1. ed. [S.1.]: Addison-Wesley, 2000. Cited 11 times on pages 29, 30, 61, 69, 70, 71, 75, 108, 110, 114, and 131.

BEETHAM, H.; SHARPE, R. Rethinking pedagogy for a digital Age: Designing and delivering e-learning. Oxford: London: Routledge, 2007. Cited 3 times on pages 28, 54, and 62.

BIGGS, J. Teaching for quality learning at university. Buckinghtam: Open University Press, 1999. Cited on page 55. 
BLACKALL, L.; JELLEY, R. Open education practices: A user guide for organisations. 2013. <http://en.wikibooks.org/wiki/Open_Education_Practices:_A_User_Guide_for_ Organisations $>$. [02/2016]. Cited 2 times on pages 29 and 103.

BLOOM, B.; ENGLEHART, M.; FURST, E.; HILL, W.; KRATHWOHL, D. Taxonomy of educational objectives: The classification of educational goals. Toronto: Longmans, Green, 1956. Handbook I: Cognitive domain. Cited 2 times on pages 120 and 137.

BLOOM, B. S.; HASTINGS, J. T.; MADAUS, G. F. Manual de avaliação formativa e somativa do aprendizado escolar. São Paulo: Pioneira, 1983. Cited on page 121.

BOEHM, B. Get ready for agile methods with care. IEEE Computer, v. 35, p. 64-69, 2002. Cited on page 63.

BOEHM, B. W. A spiral model of software development and enhancement. IEEE Computer, n. 5 , p. 61-72, 1988. Cited on page 60 .

BOLAND, A.; FITZGERALD, M. Transitioning from a co-Located to a globally-distributed software development team: A Case study and analog devices Inc. In: 3rd International Workshop on Global Software Development. Edinburgh, UK: IEEE, 2004. p. 4-7. Cited on page 78 .

BORGES, V. A.; MALDONADO, J. C.; BARBOSA, E. F. Towards the establishment of supporting mechanisms for modeling and generating educational content. In: Proceedings of the 2011 ACM Symposium on Applied Computing (ACM SAC'11). TaiChung, Taiwan: ACM, 2011. p. 1202-1207. Cited on page 86.

BOYLE, T. Layered learning design: towards an integration of learning design and learning object perspectives. Computers \& Education, v. 54, n. 2010, p. 661-668, 2010. Cited on page 86.

BOYLE, T.; COOK, J.; WINDLE, R.; WHARRAD, H.; JEEDER, D.; ALTON, R. An agile method for developing learning Objects. In: 23rd Annual Ascilite Conference: Who's Learning? Whose Technology? Sydney, Australian, December 3-6: Ascilite, 2006. p. 189-196. Cited 4 times on pages 86, 91, 95, and 118 .

BRAGA, J. C.; PIMENTEL, E.; DOTTA, S. Metodologia INTERA para o desenvolvimento de objetos de aprendizagem. In: XXIV Simpósio Brasileiro De Informática na Educação (SBIE). Campinas, São Paulo, Brazil,November 25-29: CBIE, 2013. p. 306-315. Cited on page 86.

BRASHER, A.; CONOLE, G.; CROSS, S.; WELlER, M.; CLARK, P.; WHITE, J. CompendiumLD - A tool for effective, efficient and creative learning design. In: Proceedings of the 2008 European LAMS Conference: Practical Benefits of Learning Design. Cadiz, Spain: LAMS Foundation, 2008. p. 25-27. Cited on page 139.

BRASHER, R.; CROSS, A.; GALLEY, S.; WELLER, M. Technical report, Final project report of the OULDI-JISC project: Challenge and change in curriculum design process. 2012. Cited 8 times on pages 54, 55, 112, 113, 117, 122, 125, and 130.

BUDGEN, D.; TURNER, M.; BRERETON, P.; KITCHENHAM, B. Using mapping studies in software engineering. In: Proceedings of Psychology of Programming Interest Group (PPIG'2008). Lancaster University, UK: University of Lancaster, 2008. p. 195-204. Cited on page 82 . 
BURRUS, C. S. Open educational resources (OER) and Connexions. 2010. 9 p. ConneXions Project, Rice University, Houston, Texas-USA. Cited on page 51.

BURRUS, C. S.; BARANIUK, R. G.; FRANTZ, J. P.; HOLMES, C. Connexions: sharing knowledge and building communities for global education. In: ASEE International Colloquium on Engineering Education. Beijing, China: American Society for Engineering Education, 2004. Cited on page 51.

BUTCHER, N. A basic guide to open educational resources (OER). 2015. A. Kanwar \& S. Uvalic-Trumbic (Eds.). Vancouver and Paris: COL and UNESCO. Cited 4 times on pages 28, 29,37 , and 103.

Cape Town Open Education Declaration. The Cape Town open education declaration: Unlocking the promise of open educational resources. 2007. <capetowndeclaration.org/ read-the-declaration>. 02/2016. Cited 2 times on pages 29 and 103.

CARSON, S.; FORWARD, M. L. Development of the OCW consortium. In: IEEE EDUCON Education Engineering 2010 - The Future of Global Engineering Education. Madrid, Spain: IEEE Engineering Education, 2010. p. 1657-1660. Cited on page 48.

CASWELL, T.; HENSON, S.; JENSEN, M.; WILEY, D. Open educational resources: enabling universal education. International Review of Research in Open an Distance Learning, v. 9, n. 1, p. 1-12, 2008. ISSN 142-3831. Cited on page 48.

COCKBURN, A. Crystal Clear: a human-powered methodology for small teams (Agile Development Series). 1. ed. Boston, MA: Addison-Wesley Professional, 2004. Cited 3 times on pages 29,62 , and 77 .

Agile software development: the cooperative game. 2. ed. Boston, MA: Addison-Wesley Professional, 2006. Cited on page 62.

COHEN, D.; LINDVALL, M.; COSTA, P. An introduction to agile methods. Advances in Computers, v. 62, p. 1-66, 2004. Elsevier Inc. Cited on page 60.

COHN, M. User stories applied: for agile software development. 1. ed. Boston, MA: Addison-Wesley Professional, 2004. Cited on page 71.

Succeeding with agile: software development using Scrum. 1. ed. Boston, MA: Addison-Wesley Professional, 2009. 504 p. Cited on page 63.

CONOLE, G. New schemas for mapping pedagogies and technologies. 2008. <ariadne.ac.uk> [last accessed on 02-2016]. Ariadne Article. Cited on page 55.

Learning design: Making practice explicit. In: Con-nectED Conference. Sydney: [s.n.], 2010. Cited 5 times on pages 26, 28, 53, 54, and 108 .

Designing for learning in an open world (Explanation in the Learning Sciences, Instructional Systems and Performance Technologies Series). New York: Springer-Verlag, 2013. Cited 10 times on pages 27, 28, 30, 53, 54, 108, 112, 125, 130, and 139.

CONOLE, G.; WILSON, T.; MCANDREW, P.; CULVER, J.; BRASHER, A.; CROSS, S. New Methods and approaches to the design and evaluation of open educational resources. In: EDEN Annual Conference 2009. Gdansk, Poland, June 10-13: ERASMUS, 2009. Cited 4 times on pages $28,55,103$, and 175 . 
Creative Commons. About the Creative Commons licenses. 2013. <http://creativecommons. org/licenses/about> [02/2016]. Cited 6 times on pages 44, 46, 48, 132, 155, and 172.

Keep the Internet creative, free and open. 2013. <http://creativecommons.org/> [02/2016]. Cited on page 46.

CRISTAL, M.; WILDT, D.; PRIKLADNICKI, R. Usage of Scrum practices within a global company. In: IEEE International Conference on Global Software Engineering (ICGSE'2008). Bangalore, India: IEEE Computer Society, 2008. p. 222-226. Cited 2 times on pages 68 and 69 .

CROSS, S.; CONOLE, G. Learning about learning design. 2009. Institute of Educational Technology, the Open University: Milton Keynes, United Kingdom. Cited 2 times on pages 54 and 139.

CROSS, S.; GALLEY, R.; BRASHER, A.; WELLER, M. Final project report of the OULDI-JISC project: Challenge and change in curriculum design process, communities, visualisation and practice. 2012. Institute of Educational Technology, The Open University: Milton Keynes, United Kingdom. Cited 4 times on pages 30, 54, 108, and 139.

DAGIENE, V.; GUDONIENE, D.; BURBAITE, R. Semantic web technologies for e-learning: Models and implementation. Informatic International Journal, v. 26, n. 2, p. 125-133, 2015. Cited on page 86.

DALZIEL, J. Prospects for learning design research and LAMS. Teaching English with Technology -- Special Issue on LAM and Learning Design, v. 1, n. 9, p. 1-4, 2009. Cited on page 55 .

Visualising learning design in LAMS: A historical view. Teaching English with Technology -- Special Issue on LAM and Learning Design, v. 11, n. 1, p. 19-34, 2011. Cited on page 55.

DELAMARO, M. E.; MALDONADO, J. C.; JINO, M. Introdução ao teste de software. São Paulo: Campus Elseiver, 2007. Cited on page 167.

DEVRIES, I. Evaluating open educational resources: lessons learned. In: 2nd World Conference on Educational Technology Research. [S.1.]: Procedia - Social and Behavioral Sciences, 2013. v. 83, p. 56-60. Cited on page 119.

DIMITRIADIS, Y.; MCANDREW, P.; CONOLE, G.; MAKRIYANNIS, E. New design approaches to repurposing open educational resources for collaborative learning using mediating artefacts. In: In Ascilite 2009: Same places, different spaces. Auckland, New Zealand, December 6-9: Ascilite, 2009. Cited 7 times on pages 26, 28, 53, 86, 92, 108, and 130.

DOWNES, S. Models for sustainable open educational resources. Interdisciplinary Journal of Knowledge and Learning Objects, v. 3, p. 29-44, 2007. Cited 2 times on pages 29 and 103.

DYBÅ, T.; JØRGENSEN, M. Empirical studies of agile software development: A systematic review. Information and Software Technology, v. 50, p. 833-859, 2008. Cited 2 times on pages 60 and 63 . 
EASTERBROOK, S.; SINGER, J.; STOREY, M.; DAMIAN, D. Selecting empirical methods for software engineering research. In: Guide to Advanced Empirical Software Engineering, Springer-Verlag. London, United Kingdom: Springer, 2007. p. 285-311. Cited 2 times on pages 96 and 148 .

EHLERS, U.; CONOLE, G. Open educational practice: Unleashing the power of OER. In: UNESCO workshop on OER. Windhoek, Namibia: UNESCO, 2010. Cited on page 27.

EVERTSE, J. Open educational resources: Access to high-quality educational for all. 2011. Surf Foundation. Cited on page 26.

FELLER, J.; FITZGERALD, B.; HISSAM, S. A.; LAKAHANI, K. R. Perspectives on free and open source software. Cambridge, MA: MIT Press, 2005. Cited 2 times on pages 25 and 36.

Free Software Foundation. What is copyleft? 2012. <http://www.gnu.org>. [02/2016]. Cited on page 45 .

FREIRE, A.; GATTO, F.; KON, F. Cigarra - A peer-to-peer cultural grid. In: In Anais do VI Workshop sobre Software Livre (WSL'2005). Porto Alegre, RS, Brazil, June 1-4: SBC, 2005. Cited on page 76 .

FREIRE, A.; KON, F.; GOLDMAN, A. The "bootstrap", "split personality", and "abandon complex" antipractices - eXPeriences teaching XP in academic and business environments. In: Workshop de Desenvolvimento Rápido de Aplicações (WDRA'2007). Porto de Galinhas, PE, Brazil: SBC, 2007. Cited on page 76.

FUENTES, L. M.; ARTEAGA, J. M.; RODRIGUEZ, I. F. A methodology for design collaborative learning objects. In: 8th IEEE International Conference on Advanced Learning Technologies. Satander, Cantabria, Spain: IEEE Computer Society, 2008. p. 87-91. Cited on page 86 .

GAMMA, E.; HELM, R.; JOHNSON, R.; VLISSIDES, J. Design patterns: Elements of reusable object-oriented software. [S.1.]: Addison-Wesley Professional, 1994. Cited on page 74.

GESER, G. Open educational practices and resources. 2012. OLCOS Roadmap 2012, Open eLearning Content Observatory Services - OLCOS. Cited 2 times on pages 38 and 40.

GIMENES, I. M. S.; BARROCA, L.; FELTRIM, V. D. Tendências na educação a distância e educação aberta na Computação. In: Porto Alegre: SBC, 2012. (In: Souza, A. F. and Galante, R. and Cesar Junior, M. F. and Pozo, A. T. R. (Org.). XXXI Jornada de Atualização em Informática (JAI'2012), XXXII Congresso da Sociedade Brasileira de Computação), p. 5-45. Cited 3 times on pages 26, 49, and 51.

GNU PSPP. PSPP - GNU Project. 2013. <https://www.gnu.org/software/pspp/> [ 01/2016]. Free Software Foundation. Cited on page 144.

GOLDMAN, A.; KON, F.; SILVA, P. J. S.; YODER, J. W. Being extreme in the classroom: Experiences teaching XP. Journal of the Brazilian Computer Society (SBC), v. 10, n. 2, p. 1-17, 2004. Cited on page 76. 
GOODYEAR, P.; YANG, D. F. Patterns and pattern languages: Supporting understanding and performance in educational design. In L. Lockyer, S. Bennett, S. Agostinho, \& B. Harper (Eds.), Handbook of Research on Learning Design and Learning Objects: Issues, applications and technologies, Hersey: IGI Global, 2008. Cited on page 54.

GURELL, S.; WILEY, D. OER handbook for educators, version 1.0. 2008. <http:// wikieducator.org/OER_Handbook/educator_version_one>. [02/2016]. Cited on page 123.

HARDY, M.; BRYMAN, A. The handbook of data analysis. [S.1.]: London: Sage Publications, 2009. Cited on page 31 .

HARTEL, R. W.; FOEGEDING, E. A. Learning: Objectives, competencies or outcomes? Journal of Food Science Education, v. 3, n. 4, p. 69-70, 2004. Cited on page 119.

HERRINGTON, J.; REEVES, T.; OLIVER, R. Online learning as information delivery: Digital myopia. Journal of Interactive Learning Research, v. 16, n. 4, p. 353-367, 2005. Cited on page 28.

HIGHSMITH, J. Agile software development ecosystems. 1. ed. [S.1.]: Addison-Wesley, 2002. Cited 2 times on pages 60 and 61.

Agile project management: Creating innovative products. 2. ed. [S.1.]: Addison-Wesley Professional, 2009. Cited on page 67.

HIGHSMITH, J.; COCKBURN, A. Agile software development: the Business of innovation. IEEE Computer Society, v. 34, n. 9, p. 120-127, set. 2001. Cited 3 times on pages 29, 59, and 60 .

HILTON, J. I.; WILEY, D. Examining the reuse of open textbooks. International Review of Research in Open and Distance Learning, v. 13, n. 2, p. 45-58, 2012. Cited on page 42.

HOFMAN, J.; WEST, P. A draft of Chapter 6 "open licences" of copyright for authors, educators and librarians (Version: 12 April, 2008). 2008. Cited 2 times on pages 45 and 46.

HUITT, W. Bloom's taxonomy of the cognitive domain. 2011. Educational Psychology Interactive. Valdosta, GA: Valdosta State University. Cited on page 120.

HYLÉN, J. Open educational resources: Opportunities and challenges. In: Open Education 2006: Community, Culture, and Content. Utah State University, Logan UT: Centre for Educational Research and Innovation, 2006. p. 49-63. Cited 3 times on pages 39, 41, and 57.

HYLÉN, J.; DAMME, D. V.; MULDER, F.; D’ANTONI, S. Open educational resources: Analysis of responses to the OECD country questionnaire. France: OECD Education Working Papers, OECD Publishing, 2012. Cited 2 times on pages 42 and 43.

IEEE Learning Technology Standards Committee. Learning object metadata (LOM). [S.1.], 2002. Cited on page 127.

IMS Global Learning Consortium. Learning resource meta-data specification. 2012. < http: //www.imsglobal.org/metadata/>. [02/2016]. Cited on page 127.

International Organization for Standardization. Standard, Software engineering - Product quality — Part 1: Quality model. 2001. Cited on page 132. 
Systems and software engineering - software life cycle Processes. [S.1.], 2008. Cited on page 91.

ISHAN, S. A. The Re-use and adaptation of open educational resources (OER): An exploration of technologies avalilable. 2012. Commonwealth Learning. Cited on page 141.

JISC. Open educational resources (OERs). 2010. <https://jisc.ac.uk/guides/ open-educational-resources>. [01/2016]. Cited on page 132.

JOYCE, A. OECD study of OER: Forum report. 2006. Paris: International Institute for Educational Planning. Cited on page 42.

KANWAR, A.; KODHANDARAMAN, B.; UMAR, A. Toward sustainable open education resources: A perspective from the global south. v. 24, n. 32, p. 65-80, 2010. Cited on page 130.

KATSAMANI, M.; RETALIS, S. Orchestrating learning activities using CADMOS learning design tool. v. 21, 2013. Cited on page 55.

KEMCZINSKI, A.; COSTA, I. A.; WEHRMEISTER, M. A.; HOUNSELL, M. S.; VAHLDICK, A. Metodologia para construção de objetos de aprendizagem interativos. In: XXIII Simpósio Brasileiro De Informática na Educação (SBIE). Rio de Janeiro, RJ, Brazil, November 26-30: CIBE, 2012. p. 1-10. Cited on page 86.

KENNEDY, D.; HYLAND, A.; RYAN, N. Writing and using learning outcomes: A practical guide. In: __ Germain: Berlin: Raabe Verlag, 2007. (In: Froment, E. and Kohler, J. and PUrser, L. and Wilson, L. (eds.): EUA Bologna Handbook - Making Bologna Work, article C3.4-1). Cited 2 times on pages 119 and 137.

KITCHENHAM, B. Procedures for performing systematic reviews. [S.1.], 2004. Cited on page 82 .

Guidelines for performing systematic literature reviews in software engineering. [S.1.], 2007. Cited on page 82.

KNIBERG, H. Scrum and XP from the trenches. 1. ed. [S.1.]: InfoQ Enterprise Software Development Series, 2008. Cited on page 63.

KON, F.; LAGO, N.; MEIRELLES, P.; SABINO, V. Software livre e propriedade intelectual: Aspectos jurídicos, licenças e modelos de negócio. In: Rio de Janeiro: Editora PUC-Rio, 2011. (In: Jr. Meira, W. and Souza, A. F. (Org.). XXX Jornada de Atualização em Informática (JAI'2011), XXXI Congresso da Sociedade Brasileira de Computação), p. 59-107. Cited 2 times on pages 44 and 149.

KON, F.; SABINO, V. Licenças de software livre: História e classificação. In: . Brasília: SERPRO, 2009. (CONSEGI'2009), p. 13-60. Cited on page 44.

KOPER, R. Current lesearch in Learning design. Educational Technology \& Society, v. 9, n. 1, p. 13-22, 2006. Cited 3 times on pages 28, 53, and 109.

LABIB, A. E.; PENADÉS, M. C.; CANÓS, J. H.; GÓMEZ, A. Enforcing reuse and customization in the development of learning objects: A product line approach. In: Proceedings of the 30th Annual ACM Symposium on Applied Computing. New York, NY, USA: ACM, 2015. (SAC '15), p. 261-263. ISBN 978-1-4503-3196-8. Cited on page 86. 
LAPOLLI, F.; MOTTA, C. L. R.; CRUZ, C. M.; OLIVEIRA, C. E. T. Modelo de desenvolvimento de objetos de aprendizagem baseado em metodologias ágeis e scaffoldings. Revista Brasileira de Informática na Educação, v. 18, n. 2, p. 41-53, 2010. Cited 3 times on pages 86, 91, and 95 .

LARMAN, C. Agile and iterative development: A manager's guide. 1. ed. Boston: Addison-Wesley, 2003. 368 p. Cited 2 times on pages 60 and 69.

LARMAN, C.; VODDE, B. Practices for scaling Lean \& Agile Development: Large, multisite, and offshore product development with large-scale Scrum. 1. ed. [S.1.]: Addison-Wesley Professional, 2010. 624 p. Cited on page 62.

LAURILLARD, D. P.; CHARLTON, B.; CRAFT, D.; DIMAKOPOULOS, D.; LJUBOJEVIC, G.; MAGOULAS, E.; MASTERMAN R.; PUJADAS, E. A.; WHITLEY; WHITTLESTONE, K. A Constructionist learning design. Journal of Computer Assisted Learning, Dec. 15 2011. Cited on page 55 .

LAVAZZA, L.; MORASCA, S.; TAIBI, D.; TOSI, D. Applying Scrum in an OSS development process: Empirical evaluation. In: International conference on Agile Software Development (XP). Trondheim, Norway, June 1-4: Springer, 2010. p. 147-159. Springer LNBI. Cited 2 times on pages 68 and 69.

LAYMAN, L.; WILLIAMS, L.; CUNNINGHAM, L. Exploring extreme programming in context: An industrial case study. In: Agile Development Conference. Salt Lake City, Utah, USA, June 25-28: Agile Alliance, 2004. p. 32-41. Cited on page 76.

LEACOCK, T. L.; NESBIT, J. C. A framework for evaluating the quality of multimedia learning resources. v. 10, n. 2, p. 44-59, 2007. Cited on page 132.

Learning Resource Metadata Initiative. LRMI Metadata Specification. 2015. < http://www. lrmi.net/about>. [02/2016]. Cited on page 127.

LEE, G.; XIA, W. Toward agile: An integrated analysis of quantitative and qualitative field data on software Development Agility. MIS Quarterly, v. 34, n. 1, 2010. Cited on page 63.

LESSIG, L. Free culture: How big media uses technology and the law to lock dwon culture and control creativity. New York: Penguin Group, 2005. Cited on page 47.

LETHBRIDGE, T.; SIM, S.; SINGER, J. Studying software engineers: Data collection techniques for software field studies. Empirical Software Engineering, v. 3, n. 10, p. 311-341, 2005. Cited on page 31 .

LEVERY, L. Finding relevant OER in Higher Education: A personal account. Glennie, J., Harley, K., Butcher, N. and Wyk, T. van (Eds), Open Educational Resources and Change in Higher Education: Reflections from practice, Commonwealth of Learning, Vancouver, 2012. Cited on page 123.

LIANG, L. Guide to open content licences. Roterdam: Piet Zwart Institute, 2004. Version 1.2. Cited 3 times on pages 44, 45, and 46.

LINDSTROM, L.; JEFFRIES, R. Extreme Programming and agile software development methodologies. Information Systems Management, v. 21, n. 13, p. 41-53, 2005. Cited 2 times on pages 69 and 75 . 
LINDVALL, M.; BASILI, V. R.; BOEHM, B. W.; COSTA, P.; DANGLE, K.; SHULL, F.; TESORIERO, R.; WILLIAMS, L. A.; ZELKOWITZ, M. V. Empirical findings in agile methods. In: 2nd XP Universe and First Agile Universe Conference on eXtreme Programming and Agile Methods - XP/Agile Universe. Chicago, IL, USA, August 04-07: Springer, 2002. p. 197-207. Cited on page 59.

LINDVALL, M.; MUTHIG, D.; DAGNINO A. WALLIN, C. S. M. Agile software development in large organisations. IEEE Computer, v. 37, p. 27-34, 2004. Cited on page 78.

LOCKYER, L.; BENNETT, S.; AGOSTINHO, S.; HARPER, B. E. Handbook of research on learning design and learning objects: Issues, applications and technologies. [S.1.]: Hersey PA: IGI Global, 2008. Cited 3 times on pages 28, 53, and 130.

LYCETT, M.; MACREDIE, R.; PATEL, C.; PAUL, R. Migrating agile methods to standardized Development Practice. IEEE Computer, v. 36, n. 06, p. 79-85, 2003. Cited on page 59.

MADDEN, T. Turning a resource into an open educational resource (OER). 2010. UK Physical Sciences Centre - Briefing Paper. Cited 2 times on pages 126 and 128.

MANGALARAJ, G.; MAHAPATRA, R.; NERUR, S. Acceptance of software process innovations - the case of extreme programming. European Journal of Information Systems, v. 18, p. 344-354, 2009. Cited on page 63.

Massachusetts Institute Technology. MIT OpenCourseWare — OWC. 2002. <http://ocw.mit. edu/index.htm>. [02/2016]. Cited 3 times on pages 37, 48, and 49.

MASTERMAN, L.; WILD, J. JISC Open Educational Resources Programme: Phase 2. 2011. OER impact study: Research Report, version 1.0. Cited on page 42.

MCANDREW, P.; SANTOS, A. I.; LANE, A.; GODWIN, S.; OKADA, A.; WILSON, T.; CONNOLlY, T.; FERREIRA, G.; SHUM, S. B.; BRETTS, J.; WEBB, R. OpenLearn: Research report 2006-2008. [S.1.], 2008. Cited on page 49.

MCKERLICH, R.; IVES, C.; MCGREAL, R. Measuring use and creation of open educational resources in Higher Education. The International Review of Research on Open and Distance Learning, v. 14, n. 4, 2013. Cited on page 101.

MELO, C. O.; SANTOS, V. A.; CORBUCCI, H.; KATAYAMA, E.; GOLDMAN, A.; KON, F. Métodos ágeis no Brasil: Estado da prática em times e organizações. [S.1.], 2012. RT-MAC-2012-03. Cited on page 62.

MOE, N. B.; DINGSØYR, T.; DYBÅ, T. Overcoming barriers to self-management in software teams. IEEE Software, v. 26, n. 6, p. 20-26, 2009. Cited on page 63.

MOHAN, P.; BUCAREY, S.; DANIEL, B. Employing object-oriented design principles in the design of learning objects in a software engineering course. In: IEEE International Conference on Advanced Learning Technologies. Kerkrade, Netherlands, July 5-7: IEEE Computer Society, 2006. p. 56-60. Cited on page 86.

MOLENDA, M. In Search of the Elusive ADDIE model. Performance Improvement, v. 45, n. 5, p. 34-36, 2003. Cited 2 times on pages 28 and 54. 
MORAES, M.; RAYMUNDO, V.; BOCCHESE, J.; LIMA, V. Elaboração de objetos de aprendizagem para o LAPREN: Processo de desenvolvimento e sistema de produção. In: XXII Simpósio Brasileiro De Informática na Educação (SBIE). [S.1.]: CBIE, 2011. p. 224-233. Cited on page 86.

MOREIRA, M. A. Aprendizagem significativa. Brasília: Editora da Universidade de Brasília (UnB), 1999. Cited on page 120.

MORRISON, G. R.; ROSS, S. M.; KEMP, J. E.; KALMAN, H. Designing effective instruction. 6th. ed. [S.1.]: John Wiley \& Sons, 2010. Cited on page 56.

Mountain Goat Software. Scrum overview for agile software development. 2005. < https: //www.mountaingoatsoftware.com/agile/scrum/overview>. [02/2016]. Cited on page 68.

MYERS, G. J. The art of software testing. 2. ed. New York: John Wiley \& Sons, 2004. Cited on page 167.

MYERS, M. D. Qualitative research in information systems. MIS Quarterly, n. 2, p. 241-242, 2002. Cited on page 147.

National Information Standards Organization. The Dublin Core Metadata Element Set. NISO Press, n. ANSI/NISO Z39.85-2007, 2007. ISSN 1041-5635. Cited on page 126.

NERUR, S.; MAHAPATRA, R.; MANGALARAJ, G. Challenges of migrating to agile methodologies. Communications of the ACM, v. 48, p. 73-78, 2005. Cited on page 63.

OCHOA, X.; DUVAL, E. Quantitative analysis of learning object repositories. IEEE Transactions on Learning Technologies, v. 2, n. 3, p. 226-238, 2009. Cited on page 27.

OLIVEIRA, E. R.; NELSON, M. A. V.; ISHITANI, L. Ciclo de vida de objetos de aprendizagem baseado no padrão SCORM. In: XVIII Simpósio Brasileiro de Informática na Educação (SBIE'07). São Paulo, SP, Brazil: CBIE, 2007. p. 217-226. Cited on page 86.

OLIVEIRA, K. A.; AMARAL, M. A.; BARTHOLO, V. F. Uma experiência para definição de storyboard em metodologia de desenvolvimento colaborativo de objetos de aprendizagem. Ciência \& Cognição, v. 15, n. 1, p. 19-32, 2010. Cited on page 86.

OLIVEIRA, L. H. Exemplo de cálculo de ranking médio para Likert. 2005. Notas de Aula. Metodologia Científica e Técnicas de Pesquisa em Administração. Mestrado em Administração e Desenvolvimento Organizacional. PPGA CNE/FACECA: Varginha. Cited on page 101.

OMOLLO, K. L.; RAHMAN, A.; YEBUAH, C. Producing open educational resources from scratch: The case of Health Sciences at University of Ghana and Kwame Nkrumah University of Science and Technology. Vancouver, British Columbia, Commonwealth of Learning: [s.n.], 2012. Open Educational Resources and Change in Higher Education: Reflections from Practice. Cited on page 130.

Open Educational Quality Initiative. Beyond OER: Shifting focus to open educational practices. 2011. OPAL Report 2011. Essen, Germany: Open Education Quality Initiative. Cited 5 times on pages $28,42,101,103$, and 175 .

OpenCourseWare Consortium. The Open Education Consortium: The global network for open education. 2012. <http://www.oeconsortium.org/>. [01/2016]. Cited on page 48. 
Organisation for Economic Co-operation and Development. Giving knowledge for Free. The emergence of open educational resources. [S.1.]: Centre for Educational Research and Innovation (CERI), 2007. Cited 6 times on pages 25, 28, 37, 38, 57, and 107.

PAASIVAARA, M.; DURASIEWICZ, S.; LASSENIUS, C. In: Fourth IEEE International Conference on Global Software Engineering (ICGSE'2009). [S.1.: s.n.]. Cited 2 times on pages 68 and 69 .

PALMER, S. R.; FELSING, J. M. A practical guide to Feature-Driven Development. Englewood Cliffs. 1. ed. New Jersey: Prentice Hall, 2002. Cited on page 61.

PATRICIA, C. C. S.; ROCIO, R. M. G. d.; ELIZABETH, R. P. A. OER's production cycle with social authorship and semantic tools. In: IEEE Engineering Education Conference 2010 The Future of Global Learning in Engineering Education. Madrid, Spain, April 14-16: IEEE Education Society, 2010. p. 121-128. Cited 2 times on pages 86 and 92.

PAULK, M. C. Agile methodologies and process discipline. CrossTalk - The Journal of Defense Software Engineering, p. 15-18, 2002. Cited on page 60.

PAWLOWSKI, J. M. Emotional ownership as the key to OER adoption: From sharing products and resources to sharing ideas and commitment across borders. 2011. EFQUEL Innovation Forum. Cited 2 times on pages 29 and 103.

PERUCIA, A.; BERTHÊM, A.; BERTSCHINGER, G.; CASTRO, R. R. Desenvolvimento de jogos eletrônicos: teoria e prática. 2. ed. São Paulo, SP: Novatec, 2007. Cited on page 98.

PESSOA, M. C.; BENITTI, F. B. V. Proposta de um processo para produção de objetos de aprendizagem. Hífen, v. 32, n. 6, 2008. Cited 4 times on pages 86, 98, 103, and 107.

PETERSEN, K.; FELDT, R.; MUJTABA, S.; MATTSSON, M. Systematic mapping studies in software engineering. In: 12th International Conference on Evaluation and Assessment in Software Engineering. Bari, Italy, June 26-27: University of Bari/Italy, 2008. p. 71-80. Cited 2 times on pages 82 and 88 .

PETRIDES, L.; NGUYEN, L.; KARGLIANI, A.; JIMES, C. Open educational resources: Inquiring into author reuse behaviours. In: Berlin: Springer, 2008. (In P. Dillenbourg \& M. Specht (Eds.), Times of convergence. Technologies across learning contexts, v. 5192), p. 344-353. Cited 4 times on pages 28, 81, 103, and 175.

PFLEEGER, S. L.; KITCHENHAM, B. Principles of survey research: part 1: Turning lemons into lemonade. ACM SIGSOFT Software Engineering Notes, v. 26, n. 6, p. 16-18, 2001. Cited on page 96.

Principles of survey research. 2003. Software Engineering Notes, (6 parts). Cited on page 95 .

PIKKARAINEN, M.; HAIKARA, J.; SALO, O.; ABRAHAMSSON, P.; STILL, J. The impact of agile practices on communication in software development. Empirical Software Engineering, v. 13, n. 3, p. 303-337, 2008. Cited on page 63.

PINSONNEAULT, A.; KRAEMER, K. Survey research methodology in management information systems: An assessment. Journal of Management Information Systems - Special section: Strategies and competitive information systems, v. 10, n. 2, p. 75-105, 1993. Cited on page 96. 
PLACKETT, R. L. Karl Pearson and the Chi-Squared Test. International Statistical Review, v. 51, n. 1, p. 59-72, 1983. Cited on page 162.

POPPENDIECK, M.; POPPENDIECK, T. Lean Software Development: An agile toolkit. 1. ed. [S.1.]: Addison-Wesley Professional, 2003. Cited on page 62.

Implementing Lean Software Development: From concept to cash. 1. ed. [S.1.]: Addison-Wesley Professional, 2006. Cited 2 times on pages 62 and 178.

Leading Lean Software Development: Results are not the point. 1. ed. [S.1.]: Addison-Wesley Professional, 2009. Cited 2 times on pages 62 and 178.

PRESSMAN, R. S. Engenharia de Software: uma abordagem profisional. 7. ed. [S.1.]: Porto Alegre: AMGH, 2011. Cited on page 60.

R Project. The R project for statistical computing. 1993. <https://www.r-project.org/>. [02/2016]. Cited 2 times on pages 144 and 164.

RAMESH, B.; CAO, L. A. N.; MOHAN, K.; PENG, X. Can distributed software development be agile? Communications of the ACM, v. 49, p. 41-46, 2006. Cited on page 63.

REIGELUTH, C. M. Instructional-design theories and models: An overview of their current status. [S.1.]: New York: Routledge, 1983. Cited 2 times on pages 28 and 53.

REIGELUTH, C. M.; CARR-CHELLMAN, A. A. Instructional-design theories and models. [S.1.]: London: Routledge, 2009. Cited 2 times on pages 28 and 54.

Rhaptos Software. Enterprise Rhaptos. 2013. <http://enterpriserhaptos.org/>. [12/2015]. Cited on page 51 .

RICHTER, T.; EHLERS, U. D. Barriers and motivators for using open educational resources in schools. In: Open Education Conference 2010. Barcelona, Spain, November 2-4: OpenEd, 2010. Cited 2 times on pages 28 and 101.

ROBSON, C. Real world research. 3. ed. [S.1.]: John Wiley \& Sons, 2011. Cited on page 31.

ROLFE, V. Open educational resources: Staff attitudes and awareness. Research in Learning Technology, v. 20, n. 1, p. 7-19, 2012. Cited on page 42.

ROSSINI, C. Green-paper: The state and challenges of OER in Brazil: From readers to writers ? The Berkman Center for Internet \& Society at Harvard University, Research Publication, p. 75, 2010. Cited 2 times on pages 29 and 57.

ROYCE, W. W. Managing the development of large software systems; concepts and techniques. In: Proceedings of Wescon. [S.1.: s.n.], 1970. Cited 2 times on pages 60 and 173.

RUNESON, P.; HÖST, M. Guidelines for conducting and reporting case study research in software engineering. Empirical Software Engineering, v. 14, n. 2, p. 131-164, April 2009. Cited on page 147.

SALO, O.; ABRAHAMSSON, P. Agile methods in European embedded software development organisations: A survey on the actual use and usefulness of Extreme Programming and Scrum. IET Software, v. 2, n. 1, p. 58-64, February 2008. ISSN 1751-8806. Cited 3 times on pages 68, 69, and 76. 
SAMPSON, D.; PAPANIKOU, C. A framework for learning objects reusability within learning activities. In: Ninth IEEE International Conference on Advanced Learning Technologies (ICALT). Riga, Latvia, July 15-17: IEEE Computer Society, 2009. p. 32-36. Cited on page 86.

SANTOS, A. I. d. Recursos educacionais abertos no Brasil: $O$ estado da arte, desafios e perspectivas para o desenvolvimento e inovação. [S.1.]: São Paulo: Comitê Gestor da Internet no Brasil, 2013. Cited 5 times on pages 29, 51, 52, 57, and 81.

SCHMIDT, C. T.; VENKATESHA, S. G.; HEYMANN, J. Empirical insights into the perceived benefits of agile software engineering practices: a case study from SAP. In: 36th International Conference on Software Engineering. Hyderabad, India, May 31/June 07: ACM/IEEE Computer Society, 2014. p. 1-9. Cited 4 times on pages 62, 68, 69, and 76.

SCHNEIDER, J.; JOHNSTON, L. eXtreme Programming at universities: An educational perspective. In: Proceedings of the 25th International Conference on Software Engineering. Portland, Oregon: IEEE Computer Society, 2003. (ICSE '03), p. 594-599. Cited on page 76.

SCHUWER, R.; WILSON, T.; VALKENBERG, W. V.; LANE, A. Production of OER: A quest for efficiency. In: 7th Annual Open Education Conference. Barcelona, Spain, July 6-8: EDULEARN, 2010. p. 2-4. Cited 5 times on pages 28, 56, 57, 107, and 175.

SCHWABER, K. The Scrum development process. In: Proceedings of the 10th Annual ACM Conference on Object Oriented Programming Systems, Languages, and Applications (OOPSLA'95). Austin, Texas, USA, October 15-19: ACM, 1995. p. 117-134. Cited 4 times on pages $63,109,114$, and 115 .

Agile project management with Scrum. [S.1.]: Microsoft Press, 2004. 192 p. Developer Best Practices Series. Cited on page 63.

SCHWABER, K.; BEEDLE, M. Agile software development with Scrum. 1. ed. [S.1.]: Prentice Hall, 2002. Cited 6 times on pages 29, 30, 61, 63, 68, and 108.

The enterprise and Scrum. [S.1.]: Microsoft Press, 2007. Developer Best Practices Series. Cited on page 63.

SCHWABER, K.; SUTHERLAND, J. Scrum guide. [S.1.], 2010. Cited 3 times on pages 61, 64, and 108.

Scrum guide. The definitive guide to Scrum: the rules of the game. [S.1.], 2011. Cited 3 times on pages 64, 66, and 67.

SCLATER, N. The organizational impact of open educational resources. In U. -D. Ehlers \& D. Schneckenberg (Eds.), Changing cultures in higher education: Moving ahead to future learning, Springer, Berlin, p. 1-14, 2009. Cited 4 times on pages 28, 81, 103, and 175.

SEPULVEDA, B. E. S.; ZAZUETA, F. S.; BUCKLIN, R.; HOLZAPFEL, H.; EDUARDO, A. Rapid prototyping of learning objects for agricultural and biological engineering education. Applied Engineering in Agriculture, v. 22, n. 3, p. 461 - 475, 2006. ISSN 08838542. Cited on page 86.

SHAPIRO, S. S.; WILK, M. B. An analysis of variance test for normality (complete samples). Biometrika, v. 52, n. 3/4, p. 591-611, 1965. Cited on page 162. 
SILVA, M.; BARBOSA, E.; MALDONADO, J. Model-driven development of learning objects. In: SOCIETY, I. C. (Ed.). IEEE Frontiers in Education Conference (FIE). Rapid City, SD, USA, October 12-15: [s.n.], 2011. p. 1-6. ISSN 0190-5848. Cited on page 86.

SJØBERG, D. I. K.; DYBÅ, T.; JØRGENSEN, M. The future of empirical methods in software engineering research. Future of Software Engineering (FOSE' 07), IEEE Computer Society, Washington, DC, USA, p. 358-378, 2007. Cited on page 96.

Standish Group. CHAOS manifesto. 2011. 56 p. The Standish Group International, Inc. Cited on page 62 .

STRADER, R.; THILLE, C. The Open Learning initiative: enacting instruction online. In Oblinger, D.G. (Ed.) Game Changers: Education and Information Technologies, p. 201-213, 2012. Cited on page 50.

STRICKLAND, A. W. ADDIE - Analysis, Design, Development, Implementation and Evaluation model. 2006. Idaho State University College of Education, Science. Math \& Technology Education (Retrieved 2006-06-29). Cited 3 times on pages 56, 91, and 98.

SUTHERLAND, J. Future of Scrum: parallel pipelining of sprints in complex projects. In: Proceedings of the Agile 2005 Conference. Orlando, FL, USA, July 24-29: IEEE Computer Society, 2005. Cited on page 63.

SUTHERLAND, J.; VIKTOROV, A.; BLOUNT, J.; PUNTIKOV, N. Distributed Scrum: Agile project management with outsourced development teams. In: 40th Annual Hawaii International Conference on System Sciences (HICSS'2007). Hawaii, USA, January, 3-6: IEEE Computer Society, 2007. p. 274-284. Cited 6 times on pages 29, 63, 64, 66, 68, and 69.

TELES, V. M. Extreme Programming: aprenda como encantar seus usuários desenvolvendo software com agilidade e alta qualidade. 1. ed. São Paulo: Novatec, 2004. Cited 2 times on pages 60 and 70 .

THILLE, C. Education technology as a transformational innovation. In: White House Summit on Community Colleges: conference papers. Washington, DC, USA, October 5: U.S Department of Education, 2010. p. 73-78. Cited on page 50.

TRAVASSOS, G.; GUROV, D.; AMARAL, E. Introdução à engenharia de software experimental. [S.1.], 2002. ES-590/02-Abril. Cited on page 156.

UNESCO. UNESCO promotes new initiatives for Free educational resources on the Internet. 2002. <http://www.unesco.org/education/news_en/080702_free_edu_ress.shtml>. [12/2015]. Cited 2 times on pages 25 and 38.

VAKHTINA, E.; PALKOVÁ, Z. Didatic designing of learning objects. In: International Scientific Conference on Engineering for Rural development. Jelgava, Latvia, May 20-22: Latvia University, 2015. p. 661-668. Cited on page 86.

VERSIONONE. 9th Annual state of agile survey. 2015. 16 p. <http://info.versionone.com/ state-of-agile-development-survey-ninth.html>. [01/2016]. Cited 2 times on pages 63 and 78.

VLǍDOIU, M. State-of-the-Art in Open Courseware initiatives worldwide. Informatics in Education, v. 10, n. 2, p. 271-194, 2011. Cited on page 50. 
WATSON, J. A case study: Developing learning objects with an explicit learning design. Electronic Journal of e-Learning, v. 8, n. 1, p. 41-50, 2010. Cited on page 86.

WENK, B. Open educational resources (OER) inspire teaching and learning. In: IEEE Education Engineering Conference 2010. Madrid, Spain, April 14-16: IEEE Education Engineering, 2010. p. 435-442. Cited on page 130.

WHEELER, D. A. Why open source software/free software (OSS/FS, FLOSS, or FOSS)? Look at the numbers! 2003. Revised in April 16, 2007. Cited 2 times on pages 25 and 36.

WIERINGA, R.; MAIDEN, N. A. M.; MEAD, N. R.; ROLLAND, C. Requirements engineering paper classification and evaluation criteria: A proposal and a discussion. Requirement Engineering, v. 11, n. 1, p. 102-107, 2006. Cited on page 88.

WILEY, D.; BLISS, T. J.; MCEWEN, M. Open educational resources: A review of the literature. 2014. 787-794 p. Handbook of Research on Educational Communications and Technology. Cited on page 130.

WILEY, D. A. Open content. 1998. <http://opencontent.org> [01/2016]. Cited 2 times on pages 37 and 44 .

Connecting learning objects to instructional design theory: A definition, a metaphor, and a taxonomy. Bloomington: Association for Educational Communications and Technology, 2002. In: D. Wiley (ED.). Cited on page 40.

Expert meeting on open educational resources. 2006. Centre for Educational Research and Innovation (CERI). <http://www.oecd.org/edu/ceri/36224377.pdf> [01/2016]. Cited 2 times on pages 26 and 36.

On the sustainability of open educational resources initiatives in Higher Education. 2007. Organisation for Economic Co-operation and Development (OECD). Cited on page 42.

Openness as catalyst for an educational reformation. EDUCAUSE, v. 45, n. 4, p. 14-20, 2010. July/August 2010. Cited on page 41.

WILLEKE, M. H. H. Agile in academics: Applying agile to instructional design. In: Proceedings of the Agile 2011 Conference. Salt Lake City, Utah, USA, August 7-13: IEEE Computer Society, 2011. p. 246-251. Cited on page 56.

William and Flora Hewlett Foundation. Education program: Strategic plan. 2010. <http: //www.hewlett.org/uploads/documents/Education_Strategic_Plan_2010.pdf>. 02/2016. Cited 2 times on pages 26 and 37.

White paper: Open educational resources - Breaking the lockbox on education. 2013. $<$ http://www.hewlett.org/>. 02/2016. Cited on page 27.

WILLIAMS, L.; COCKBURN, A. Agile software development: It's about feedback and change. IEEE Computer, v. 36, n. 6, p. 39-43, 2003. Cited on page 60.

WILLIAMS, L.; KESSLER, R. R.; CUNNINGHAM, W.; JEFFRIES, R. Strengthening the case for pair programming. IEEE Software, v. 17, p. 19-25, 2000. Cited on page 63.

WOHLIN, C.; RUNESON, P.; HÖST, M.; OHLSSON, M. C.; REGNELL, B.; WESSLEN, A. Experimentation in software engineering: An introduction. Massachusetts, USA: Kluwer Academic Publishers, 2000. ISBN 0-7923-8682-5. Cited on page 161. 
WU, Z.; DOULAI, P. Modelling process for the development of learning content for tertiary education. In: 4th International Conference on Distance Learning and Education (ICDLE). San Juan, PR, USA, October 12-13: [s.n.], 2010. p. 119-124. Cited on page 86.

YIN, R. K. Case study research: Design and methods (Applied Social Research Methods). 5. ed. USA: SAGE Publications, Inc, 2013. Cited 2 times on pages 148 and 156.

YUAN, L.; NEILL, S. M.; KRAAN, W. Open educational resources - Opportunities and challenges for Higher Education. JISC CETIS, 2008. Cited on page 36. 
APPENDIX

\section{A}

\section{SURVEY ON THE DEVELOPMENT OF OERS \\ IN BRAZIL}

This questionnaire is a mechanism for gathering information to investigate "how" OERs have been developed in the Brazilian context. It also intends to highlight the key issues, difficulties and barriers associated with the development of these materials. The ultimate aim is to characterise the Brazilian current setting regarding the development of OERs.

We hope that the questionnaire does not take more than 15 minutes to be answered. It is only focused on individuals who develop and/or have already developed any OER, either by individual initiative or linked to any institution. The results will be disseminated through online and/or printed publication. We emphasise that the data will be used only for research purposes. No personal information is requested.

Thank you for participating in this online survey on the development of OERs in Brazil. It may contribute to deepening the discussions and improvement of the development process, and therefore contributing to the wide dissemination and adoption of OERs in Brazil.

\section{(*) Required}

\section{A.1 Survey Questionnaire}

\section{What is your familiarity with the development of Open Educational Resources ?*}

$\bigcirc$ Very high (more than 4 years)

High (3-4)

$\bigcirc$ Median (2-3)

$\bigcirc$ Low (1-2)

$\bigcirc$ Very low (Less than 1 year)

$\bigcirc$ Others: 
2. Do you follow any process to develop Open Educational Resources ?*

$\bigcirc$ Yes

$\bigcirc$ Partially

$\bigcirc$ No

Unable to answer

3. Which approaches or methods do you use to develop Open Educational Resources ?*

Traditional methods for software development (e.g., plan-driven/cascade)

Agile Methods/practices (e.g., Scrum, XP)

$\bigcirc$ Learning Design approach/practices

Specific to learning materials

Others:

4. How do you develop Open Educational Resources ?*

$\square$ Reuse and adaptation of (non-OERs) existing materials

$\square$ Reuse and adaptation of (OERs) existing materials

$\square$ From scratch

$\square$ Others:

5. Which types of Open Educational Resources do you have developed over the years ?*
Textbooks
Research papers
$\square$ Lessons/lecture notes
$\square$ Tests and assessments
$\square$ Audios/Video
$\square$ Games
$\square$ Images
$\square$ Others:

6. What is the purpose of Open Educational Resources developed ?*

Main material to the course

Supporting material (eg., additional material to a course)

$\bigcirc$ Only to share

$\bigcirc$ Others: 
7. In which area/domain of knowledge do you have developed Open Educational Resources ?*
Computer Science
$\square$ Mathematics and Statistics
Chemistry
$\square$ Physics
$\square$ Biology
$\square$ Education
Language
$\square$ Geography
$\square$ History
$\square$ Others:

8. In which context of teaching/learning Open Educational Resources developed have been applied ?*
Pre-school
$\bigcirc$ Elementary school
$\bigcirc$ Middle school
Vocational training
$\bigcirc$ High education
Others:

9. Is the development of Open Educational Resources an individual tasks or it involves an development team linked to an institution ?*
Individual
$\bigcirc$ Team
Unable to answer
$\bigcirc$ Others:

10. Is there any involvement of users during the development of Open Educational Resources ?*

Throughout the development

$\bigcirc$ Partial

$\bigcirc$ Unable to answer

$\bigcirc$ Others: 
10.1 What is the role of users during the development of Open Educational Resources?
Active participation
$\bigcirc$ Only as collaboration
$\bigcirc$ Unable to answer
Others:

11. How do you evaluate Open Educational Resources ?*
$\square$ Peer review
$\square$ Individual assessment
$\square$ External assessment
$\square$ Unable to answer
$\square$ Others:

12. How important is the involvement and participation of users during the development of Open Educational Resources ?*
$\bigcirc$ Very important
$\bigcirc$ Important
Slightly important
Irrelevant
$\bigcirc$ Unable to answer
Others:

13. Which are the issues considered during the evaluation of Open Educational Resources ?*

Didactic-pedagogical issues (e.g., accuracy and relevance of the content and pedagogical design of contents and activities)

$\square$ Technical issues (e.g., accessibility, usability, discoverability and localisation capabilities)

$\square$ Legal issues (e.g., intellectual property and rights, licensing)

$\square$ Unable to answer

$\square$ Others: 
14. Who are the responsible for the evaluation of Open Educational Resources ?*
Educators
Learners
Both
Unable to answer
Others:

15. What are the problems and difficulties for the development of Open Educational Resources ?*

\begin{tabular}{|c|c|c|c|c|}
\hline Items & $\begin{array}{l}\text { Very } \\
\text { Important }\end{array}$ & Important & $\begin{array}{l}\text { Slightly } \\
\text { Important }\end{array}$ & Irrelevant \\
\hline Lack of recognition and incentive & $\square$ & $\square$ & $\square$ & $\square$ \\
\hline Lack of time & $\square$ & $\square$ & $\square$ & $\square$ \\
\hline Lack of acquaintance & $\square$ & $\square$ & $\square$ & $\square$ \\
\hline $\begin{array}{l}\text { Lack of method and approaches to support the } \\
\text { development }\end{array}$ & $\square$ & $\square$ & $\square$ & $\square$ \\
\hline Lack of public and institutional policies & $\square$ & $\square$ & $\square$ & $\square$ \\
\hline $\begin{array}{l}\text { Lack of quality and relevance of available } \\
\text { materials }\end{array}$ & $\square$ & $\square$ & $\square$ & $\square$ \\
\hline $\begin{array}{l}\text { Cultural and languages } \\
\text { (reuse/adaptation) }\end{array}$ & $\square$ & $\square$ & $\square$ & $\square$ \\
\hline
\end{tabular}

16. What are the factors that can contribute to the increase and the improvement in the development and distribution of Open Educational Resources in Brazil ?* 